\title{
WestVirginiaUniversity
}

THE RESEARCH REPOSITORY @ WVU

Graduate Theses, Dissertations, and Problem Reports

2020

\section{Review of Modern Nondestructive Testing Techniques for Civil Infrastructure}

Shabnam Khanal

West Virginia University, sk0142@mix.wvu.edu

Follow this and additional works at: https://researchrepository.wvu.edu/etd

Part of the Civil Engineering Commons

\section{Recommended Citation}

Khanal, Shabnam, "Review of Modern Nondestructive Testing Techniques for Civil Infrastructure" (2020). Graduate Theses, Dissertations, and Problem Reports. 7747.

https://researchrepository.wvu.edu/etd/7747

This Problem/Project Report is protected by copyright and/or related rights. It has been brought to you by the The Research Repository @WVU with permission from the rights-holder(s). You are free to use this Problem/Project Report in any way that is permitted by the copyright and related rights legislation that applies to your use. For other uses you must obtain permission from the rights-holder(s) directly, unless additional rights are indicated by a Creative Commons license in the record and/ or on the work itself. This Problem/Project Report has been accepted for inclusion in WVU Graduate Theses, Dissertations, and Problem Reports collection by an authorized administrator of The Research Repository @ WVU. For more information, please contact researchrepository@mail.wvu.edu. 


\title{
REVIEW OF MODERN NONDESTRUCTIVE TESTING TECHNIQUES FOR CIVIL INFRASTRUCTURE
}

\author{
Shabnam Khanal \\ Problem Report submitted to the \\ Benjamin M. Statler College of Engineering and Mineral Resources \\ at West Virginia University \\ in partial fulfillment of the requirements \\ for the degree of \\ Master of Science \\ in \\ Civil Engineering
}

Udaya B. Halabe, Ph.D., P.E., Chair

Hema J. Siriwardane, Ph.D., P.E.

Bhaskaran Gopalakrishnan, Ph.D., P.E.

Wadsworth Department of Civil and Environmental Engineering

Morgantown, West Virginia

2020

Keywords: Nondestructive Testing; NDT; Impact Echo; Digital Tap Hammer; Infrared Thermography; Ultrasonic; Unmanned Aerial System; UAV; Concrete; Timber

Copyright 2020 Shabnam Khanal 


\section{ABSTRACT \\ Review of Modern Nondestructive Testing Techniques for Civil Infrastructure}

Shabnam Khanal

The repair and maintenance of aging infrastructures, in the United States alone, are estimated to have backlogs of trillions of dollars. This has posed widespread concerns about the existing and proposed infrastructures to adequately sustain the quality of life in the near future. Efficient and cost-effective approaches, such as nondestructive testing (NDT), are therefore required to better shape our future. Various NDT techniques have been developed over the past two decades with cutting-edge advances towards investigation and condition assessment of civil infrastructures. While the performance of NDT techniques has reached unparalleled heights, limitations remain. On one side, are the instrument limitations such as penetration depth, resolution, data analysis, accessibility, etc., that are being addressed by the constantly evolving field of NDT. On the other side, there are gaps in the validation and strategic standardization of the techniques for their application in the field. These gaps are further broadened by the lack of experience and understanding of the techniques by the officials with the authority of repairing and maintaining infrastructures, such as the federal and state Department of Transportation (DOT) personnel.

This report aims to be a comprehensive review of state-of-the-art nondestructive testing techniques such as Impact-echo, Ultrasonic Testing, Infrared Thermography, and Digital Tap Hammer. Research and innovation integrated into contemporary features and possible future trends of such techniques for rapid and inclusive condition assessment of concrete and timber structural members are presented in the report. As the future of NDT, this report reviews the alignment of NDT techniques with novel automated technologies, including Unmanned Aerial System (UAS). Such practices have shown promising results in the effective and proactive condition assessment of structures with greater ease and at significantly lower cost, without the need for extensive knowledge about the techniques. Hence, it is recommended that the responsible bodies such as federal and state DOTs utilize nondestructive testing techniques to improve the resiliency and service life of our infrastructures effectively. 


\section{ACKNOWLEDGEMENTS}

I would like to express my deepest gratitude to my academic and research advisor, Dr. Udaya B. Halabe for his consistent support and assistance during my Master of Science in Civil Engineering (MSCE) degree program. I am extremely grateful to Dr. Halabe for his invaluable guidance that was monumental towards the completion of this study. I feel privileged to have worked under Dr. Halabe, who is vastly knowledgeable and experienced in the field of nondestructive testing and evaluation.

I would like to thank Dr. Hema J. Siriwardane and Dr. Bhaskaran Gopalakrishnan, for serving as members of my Advisory and Examining Committee and for providing insightful suggestions.

I also wish to acknowledge the Wadsworth Department of Civil and Environmental Engineering at West Virginia University for the educational experience, resources and financial support that I received in the form of graduate teaching assistantships and tuition waivers during my MSCE degree program.

Finally, I would like to take this opportunity to thank my family (Mr. Arun Khanal, Ms. Sunita Khanal and Ms. Anupama Khanal Dhungana) for their continuous support and encouragement throughout my study. 


\section{TABLE OF CONTENTS}

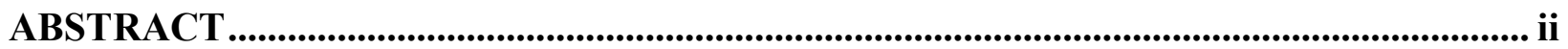

ACKNOWLEDGEMENTS ….................................................................................................

LIST OF FIGURES .......................................................................................................... vii

LIST OF TABLES .............................................................................................................................. xiv

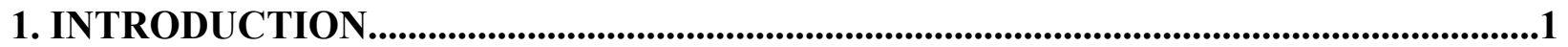

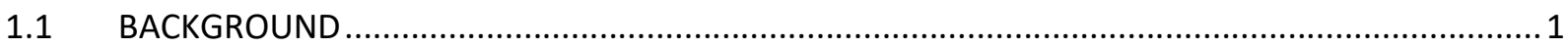

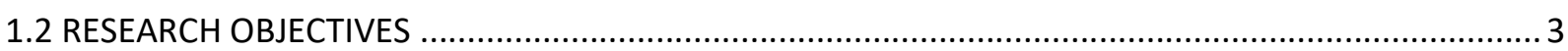

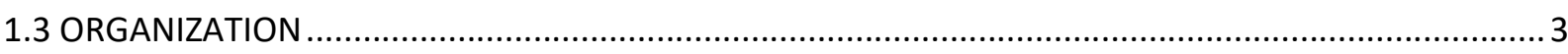

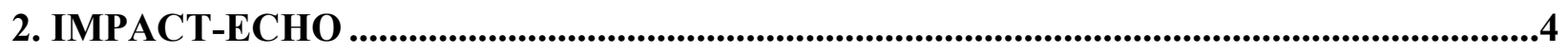

2.1 INTRODUCTION ...........................................................................................................

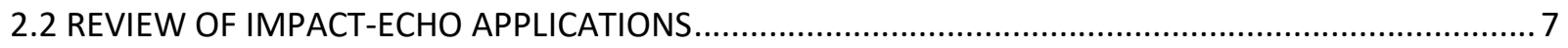

2.2.1 USE OF IMPACT-ECHO IN CONCRETE PLATES WITH SMALL THICKNESSES AND DIFFERENT KIND

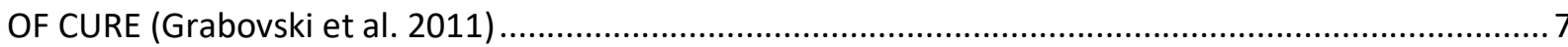

2.2.2 RAPID BRIDGE DECK CONDITION ASSESSMENT USING THREE-DIMENSIONAL VISUALIZATION OF

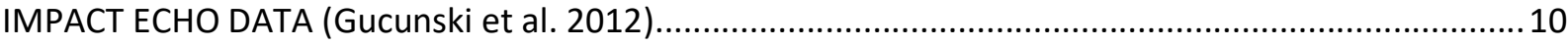

2.2.3 EFFECTIVENESS OF IMPACT ECHO TESTING IN DETECTING FLAWS IN PRESTRESSED CONCRETE SLABS (Chaudhary 2013)

2.2.4 POST-FIRE ASSESSMENT OF MECHANICAL PROPERTIES OF CONCRETE WITH THE USE OF THE IMPACT-ECHO METHOD (Krzemień and Hager 2015)

2.2.5 PRACTICAL CONSIDERATIONS IN DETERMINING TIMBER PILE DEPTH USING THE SONIC ECHO METHOD (Jwary 2017)

2.2.6 GROUTING DEFECT DETECTION OF LAPPED BAR CONNECTIONS BASED ON IMPACT-ECHO METHOD (Liu et al. 2019).

2.2.7 AUTOMATED AIR-COUPLED IMPACT-ECHO TESTING OF A CONCRETE BRIDGE DECK FROM A

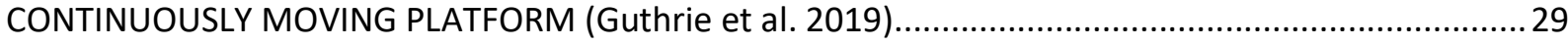

2.3 CONCLUSION .32

3. ULTRASONIC TESTING TECHNIQUES .................................................................................34

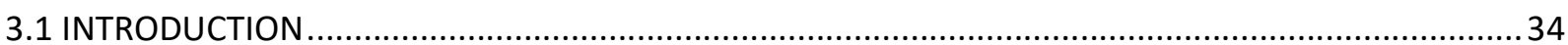

3.2 REVIEW OF APPLICATIONS OF ULTRASONIC TECHNIQUES............................................................. 42

3.2.1 ASSESSMENT OF CONCRETE STRUCTURES USING THE MIRA AND EYECON ULTRASONIC SHEAR WAVE DEVICES AND THE SAFT-C IMAGE RECONSTRUCTION TECHNIQUE (Haza et al. 2013)

3.2.2 DAMAGE DETECTION OF ASPHALT CONCRETE USING PIEZO-ULTRASONIC WAVE TECHNOLOGY (Pan et al. 2019) 
3.2.3 IN SITU ASSESSMENT OF STRUCTURAL TIMBER USING STRESS-WAVE MEASUREMENTS

(Dackermann et al. 2014).

3.2.4 A NOVEL METHODOLOGY FOR CONDITION ASSESSMENT OF WOOD POLES USING ULTRASONIC TESTING (Tallavo et al. 2012)

3.2.5 CORROSION DETECTION OF REINFORCEMENT OF BUILDING MATERIALS WITH PIEZOELECTRIC SENSORS (Peng 2017)

3.2.6 THE LAUS : FIRST APPLICATIONS OF A NEW SYSTEM FOR ULTRASONIC IMAGING OF VERY CONCRETE STRUCTURES. (Niederleithinger and Wiggenhauser 2018)

3.2.7 IN SITU NONLINEAR ULTRASONIC TECHNIQUE FOR MONITORING MICROCRACKING IN CONCRETE SUBJECTED TO CREEP AND CYCLIC LOADING (Kim et al. 2018).

3.2.8 IMAGING WOOD DEFECTS USING AIR COUPLED FERROELECTRET ULTRASONIC TRANSDUCERS IN REFLECTION MODE (Vossing et al. 2020). .70

3.2.9 IN SITU INSPECTION OF CONCRETE STRUCTURES USING A ROLLING ULTRASOUND SCANNER

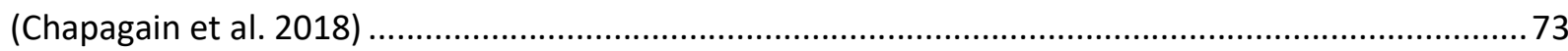

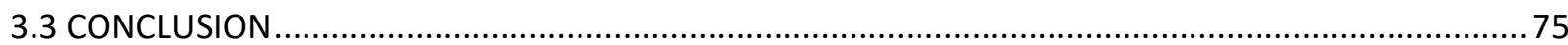

4. INFRARED THERMOGRAPHY AND DIGITAL TAP TESTING ..............................76

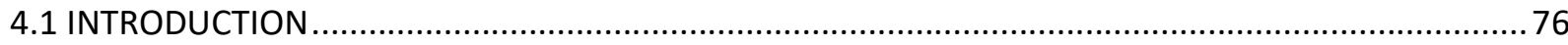

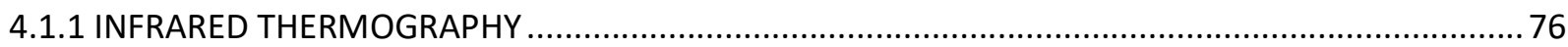

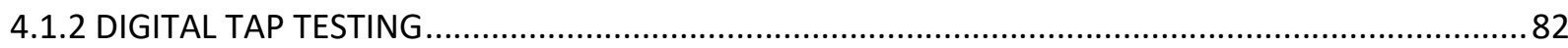

4.2 REVIEW OF APPLICATIONS OF INFRARED THERMOGRAPHY AND DIGITAL TAP TESTING ................86

4.2.1 IR THERMOGRAPHY IN MOISTURE AND EARTHQUAKE DAMAGE DETECTION PERFORMED IN THE

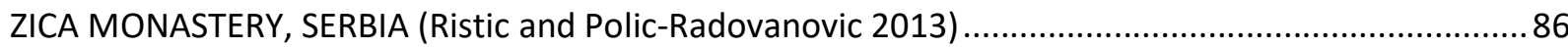

4.2.2 EVALUATING THE DAMAGE DEGREE OF CRACKING IN FACADES USING INFRARED THERMOGRAPHY (Bauer et al. 2018).....

4.2.3 EVALUATING THE QUALITY OF REINFORCED CONCRETE ELECTRIC RAILWAY POLES BY THERMAL

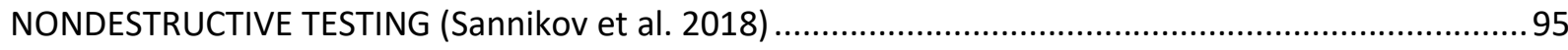

4.2.4 THERMOGRAPHY-BASED DETERIORATION DETECTION IN CONCRETE BRIDGE GIRDERS STRENGTHENED WITH CARBON FIBER-REINFORCED POLYMER (Mac et al. 2020) 99

4.2.5 INFRARED THERMOGRAPHY MODEL FOR AUTOMATED DETECTION OF DELAMINATION IN RC

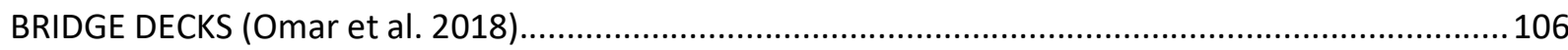

4.2.6 USING VARIOUS INFRARED TECHNIQUES FOR ASSESSING TIMBER STRUCTURES (Sandak and Sandak 2017).....

4.2.7 TAP TESTING OF COMPOSITES BENCHMARKED WITH DIGITAL SHEAROGRAPHY (Gryzagoridis and Findeis 2013)

4.2.8 NONDESTRUCTIVE TESTING OF FRP COMPOSITE STRUCTURAL COMPONENTS AND FRP REHABILITATED BRIDGE USING DIGITAL TAP TESTING (Halabe et al. 2020) 
4.3 CONCLUSION

5. NDT TECHNIQUES INTEGRATED WITH UNMANNED AERIAL SYSTEM ..........120

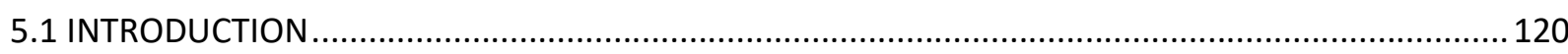

5.2 REVIEW OF APPLICATIONS OF NDT TECHNIQUES INTEGRATED WITH UNMANNED AERIAL SYSTEM

5.2.1 DEVELOPMENT OF CRACK DETECTION SYSTEM WITH UNMANNED AERIAL VEHICLES AND DIGITAL IMAGE PROCESSING (Kim et al. 2015)

5.2.2 THERMAL DETECTION OF SUBSURFACE DELAMINATIONS IN REINFORCED CONCRETE BRIDGE DECKS USING UNMANNED AERIAL VEHICLE (Omar and Nehdi 2019).... 127

5.2.3 AERIAL VS. VEHICLE-BASED INFRARED THERMOGRAPHY FOR BRIDGE DECK DELAMINATION DETECTION (Guarino et al. 2018).

5.2.4 REMOTE RAILROAD BRIDGE STRUCTURAL TAP TESTING USING AERIAL ROBOTS (Moreu et al. 2018) 132

5.2.5 DEVELOPMENT OF A WALL-STICKING DRONE FOR NON-DESTRUCTIVE ULTRASONIC AND CORROSION TESTING (Mattar and Kalai 2018). 136

5.3 CONCLUSION. 139

6. CONCLUSIONS AND RECOMMENDATIONS......................................................140

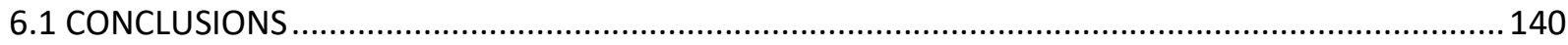

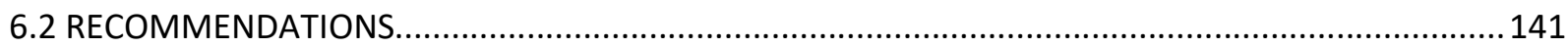

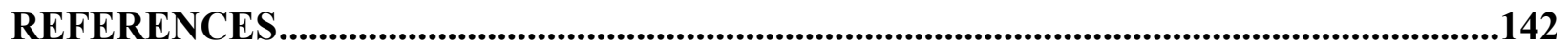




\section{LIST OF FIGURES}

Figure 2.1: Schematic diagram of IE method (Carino 2015) ............................................... 5

Figure 2.2: Detectable range of horizontal void using IE method (Carino 2001, Liu et al. 2019). 7

Figure 2.3: (a) Transducer with manual impactor; (b) Mechanical impact device (Grabovski et al. 2011).

Figure 2.4: Waveforms and frequency spectra for $43 \mathrm{~mm}$ dry cured slab with (a) manual; (b) mechanical impact (Grabovski et al. 2011). 9

Figure 2.5: (a, b) PSPA with impactor and receiver; (c, d) Stepper with impactor (Gucunski et al. 2012). 10

Figure 2.6: Condition map of Van Buren Bridge from PSPA (Gucunski et al. 2012). 11

Figure 2.7: Condition map of Route 18, Iowa Bridge with extracted cores (Gucunski et al. 2012).

Figure 2.8: 3-D visualization of (a) Carter Creek Bridge deck; (b) Van Buren Bridge (Gucunski et al. 2012). 13

Figure 2.9: 3 -D visualization of the bridge on Interstate 287 over Route 1 in Woodbridge, NJ (dimensions in meter) (Gucunski et al. 2012). 13

Figure 2.10: (a) IE test area; (b) crooked tendons in the PT system (Chaudhary 2013). 14

Figure 2.11: Time and frequency domain plots for upper slab and beam (Chaudhary 2013).... 15

Figure 2.12: Comparison of thickness range measured by IE method and allowed by the code (Chaudhary 2013). 16

Figure 2.13: (a) Vu-Con IE equipment set; (b) IE test arrangement on a specimen (Krzemień and Hager 2015). 17

Figure 2.14: 4 sample points on concrete slab for IE test after exposing to heat (Krzemień and Hager 2015). 19

Figure 2.15: IE time domain and frequency domain signals for concrete slab (Krzemień and Hager 2015). 
Figure 2.16: Equipment for SE test (Jwary 2017).................................................... 21

Figure 2.17: Wooden column test setup in Biology Annex Building (Jwary 2017)................. 22

Figure 2.18: Velocity trace obtained using accelerometer \#2 for the Wooden Column (Jwary

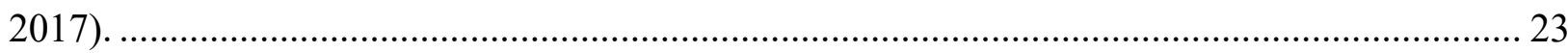

Figure 2.19: Springer Bridge test site(Jwary 2017)........................................................ 24

Figure 2.20: (a) Test specimen; (b, c) details of test surface 1 and 2; (d) section 1-1 (Liu et al. 2019). 26

Figure 2.21: The waveform and frequency for (a) section with hole A; (b) solid concrete (Liu et al. 2019). 27

Figure 2.22: Relationships between (a) frequency and hole depth (b) amplitude and hole depth (Liu et al. 2019). 28

Figure 2.23: Air-coupled IE device (Guthrie et al. 2019) 30

Figure 2.24: Bridge deck condition map using (a) air-coupled IE device; (b) chain dragging; (c) coring (Guthrie et al. 2019). 31

Figure 3.1: Schematic diagram of the ultrasonic wave velocity testing method (Bilgehan and Turgut 2010). 34

Figure 3.2: (a) Direct transmission, (b) Semi-direct transmission, (c) Indirect transmission, (d) Ultrasonic pulse-echo, (e) Angled beam assembly, (f) Ultrasonic array. 38

Figure 3.3: (a) MIRA equipment ( $1^{\text {st }}$ Generation); (b) MIRA equipment $\left(2^{\text {nd }}\right.$ Generation); (c) Eyecon System (Haza et al. 2013)....

Figure 3.4: (a) Four-step concrete plate specimen with empty ducts; (b) Prestressed, precast box beam; (c) Eyecon test in progress on marble panel (Haza et al. 2013) 43

Figure 3.5: Mira results (B, C, and D scans) for the four-step concrete plate (Haza et al. 2013). 44

Figure 3.6: Mira (top) vs. Eyecon (bottom) results for $1.25 \mathrm{~m}$ deep concrete foundation mat (Haza et al. 2013). 45 
Figure 3.7: 3D isosurface view of Mira test results (Haza et al. 2013). ................................ 45

Figure 3.8: Mira results showing (a) delaminated area; (b) solid area (Haza et al. 2013).......... 46 Figure 3.9: Eyecon A-scan showing delaminated depth (left); full panel thickness (right) (Haza et al. 2013). 46

Figure 3.10: Mira delaminated area image (left); Eyecon A-scan showing delaminated depth (right) (Haza et al. 2013) 47

Figure 3.11: Comparison of ultrasonic velocities of Marshall specimens with different (a) voidage; (b) environmental conditions (Pan et al. 2019).... 49

Figure 3.12: Ultrasonic velocity in a defected sample with different environmental conditions (Pan et al. 2019). 50

Figure 3.13: Ultrasonic velocity in five types of grooves in the samples (Pan et al. 2019)....... 50

Figure 3.14: Ultrasonic velocity change trend during the entire process of damage (Pan et al. 2019) 51

Figure 3.15: (a) Timber test member in site; (b) relative velocity decrease in test locations (Dackermann et al. 2014). 54

Figure 3.16: (a) Sensor setup in the timber post; (b) 2D-tomogram of the timber post (Dackermann et al. 2014). 55

Figure 3.17: (a) Tomographic image segmentation of area with a velocity less than $600 \mathrm{~m} / \mathrm{s}$; (b) less than $900 \mathrm{~m} / \mathrm{s}$ (Dackermann et al. 2014). 55

Figure 3.18: (a) B-scan of the sample obtained from the ultrasonic echo method (units in $\mathrm{mm}$ ); (b) Timber sample with defects (Dackermann et al. 2014). 56

Figure 3.19: (a) Ultrasonic transducer setup with raypaths; (b) test setup in aged specimen (Tallavo et al. 2012). 59

Figure 3.20: (a) Measured wave velocity for different receiver positions in new pole; (b) aged pole (Tallavo et al. 2012) 59

Figure 3.21: (a) Transmission factors for receiver located at $135^{\circ}$ in new pole; (b) aged pole (right) (Tallavo et al. 2012) 60 
Figure 3.22: Dissimilarity indices in 14 raypaths (left); estimated condition of the aged pole using DIs (top, right); actual condition of the aged pole (bottom, right) (Tallavo et al. 2012)............ 60

Figure 3.23: (a) Time of corrosion vs. the number of ultrasonic signals; (b) Received ultrasonic signals under different loadings (Peng 2017). 62

Figure 3.24: Mass loss of steel vs. the amplitude growth rate of ultrasonic signals (Peng 2017).

Figure 3.25: (a) The LAUS unit; (b) Foundation slab under test with LAUS data acquisition; (c) SAFT-reconstructed B-scan of the slab (Niederleithinger and Wiggenhauser 2018). 64

Figure 3.26: (a) SAFT-reconstructed B-scan of the girder at $1.8 \mathrm{~m}$ depth; (b) C-scan of the girder at $1.8 \mathrm{~m}$ depth: rectangle - measurement area, hatched line - the level of concrete at the start of rainstorm and ellipse - anomalous area (Niederleithinger and Wiggenhauser 2018). .... 65

Figure 3.27: (a) The LAUS system data acquisition in the retaining wall in former coal mine plant; (b) Saft-reconstructed B-scan of the retaining wall (Niederleithinger and Wiggenhauser 2018). 66 Figure 3.28: (a) Schematic diagram of SHG setup for concrete cylinders; (b) SHG setup (Kim et al. 2018). 68

Figure 3.29: SHG measurement results under creep: (a) Time domain signal for concrete specimens; (b) $\beta$ as a slope of the plot (Kim et al. 2018).

Figure 3.30: (a) Strain vs. $\beta$ curve with time after loading under creep load of $22 \mathrm{MPa}$; (b) change in $\beta$ with cycles of $26 \mathrm{MPa}$ loading (Kim et al. 2018). 69

Figure 3.31: (a) Through transmission; (b) reflection techniques setup (Vossing et al. 2020)... 71

Figure 3.32: (a) Multiplex sample with top three millings and bottom delamination; (b) C-scan of the sample in reflection mode; (c) C-scan of the sample in transmission mode (Vossing et al. 2020).

Figure 3.33: (a) Concrete test sample with rolling scanner prototype; (b) D-scan and 3D image of the concrete sample (Chapagain et al. 2018). .74

Figure 4.1: Schematic diagram of Infrared Thermography (Jo et al. 2013)......................... 77

Figure 4.2: DTT devices: a) Woodpecker; b) RD3; c) CATT (Poveromo 2015)...................... 82 
Figure 4.3: Different levels of force vs. time curves for (a) good area; (b) bad area (Hsu et al. 2009). 84

Figure 4.4: Linear regression curve for stiffness computed from the Static Load Test vs. the Tap Test (Hsu et al. 2009). 84

Figure 4.5: (a) Monastery complex entrance; (b) the entrance ceiling; (c) thermogram corresponding to the entrance (Ristic and Polic-Radovanovic 2013). 87

Figure 4.6: (a) St. Savior Tower wall with corresponding thermogram (Ristic and PolicRadovanovic 2013). 88

Figure 4.7: Eastern façade with corresponding thermogram (Ristic and Polic-Radovanovic 2013).

Figure 4.8: (a) IRT target building façade with visible cracks in regions 1, 2, and 3; (b) Data acquisition position of the IR camera (Bauer et al. 2018). 91

Figure 4.9: Temperature profile over time obtained from the hygrothermal simulation and comparison with IRT data in region 1 (Bauer et al. 2018). 92

Figure 4.10: Thermograms showing different patterns at (a) 0; (b) 20; (c) 40; and (d) 150 minutes (Bauer et al. 2018). 93

Figure 4.11: Temperature profiles of the pixels along the line perpendicular to the crack obtained (a) as an example; (b) from thermograms of crack 1 (Bauer et al. 2018) ................................ 93

Figure 4.12: Delta-T plots for cracks 1, 2, and 3 (Bauer et al. 2018). 94

Figure 4.13: Test setup with a target length of $1 \mathrm{~m}$ marked by the aluminum strip (Sannikov et al. 2018). 96

Figure 4.14: Maxigrams of the pole section above the ground level from (a) a defect-free area; (b) damaged area (Sannikov et al. 2018). 97

Figure 4.15: (a) Assessment of the pole section below the ground level; (b) Maxigram of the section (Sannikov et al. 2018). 97

Figure 4.16: Maximum $\Delta \mathrm{T}$ rate for pole sections (1) $50 \mathrm{~cm}$ above the ground level; (2) at the ground level; (3) $30 \mathrm{~cm}$ below the ground level (Sannikov et al. 2018). 98 
Figure 4.17: Concrete specimen with artificial delaminations arrangement with and without CFRP sheets installed (Mac et al. 2020). 100

Figure 4.18: (a,c) Delaminations from the back face with the corresponding thermogram after 15 min heating and 10 min cooling $(b, d)$ delaminations from the front face with the corresponding thermogram after $25 \mathrm{~min}$ heating and $40 \mathrm{~min}$ cooling (Mac et al. 2020). ............................. 102

Figure 4.19: Absolute temperature contrast $(\Delta \mathrm{T})$ vs. time (Mac et al. 2020)......................... 102

Figure 4.20: Maximum absolute contrasts for delaminations from the back face in CSC (BD3-CF)

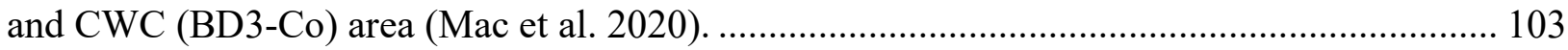

Figure 4.21: Thermograms for delaminations from the back face after $15 \mathrm{~min}$ heating and $20 \mathrm{~min}$ cooling in the CSC area (top); CWC area (bottom) (Mac et al. 2020). 103

Figure 4.22: Comparison of thermograms (10 min heating for delaminations from the back face) processed using different algorithms (Mac et al. 2020) .................................................... 105

Figure 4.23: IR camera setup (Omar et al. 2018)............................................................ 107

Figure 4.24: Condition maps of Montreal Bridge using thermograms collected during (a) day; (b)

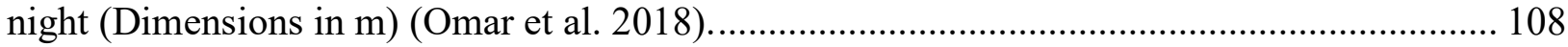

Figure 4.25: Condition maps of Bridge A determined using (a) novel automated system (dimensions in m); (b) IRT by Wisconsin DOT (dimensions in ft.) (Omar et al. 2018). 109

Figure 4.26: (a) FLIR ONE with the recording smartphone; (b) IRT setup for wooden block under compression testing machine; (c) IRT setup for wooden beam (Sandak and Sandak 2017)...... 113

Figure 4.27: Wooden beam specimen with recorded thermograms from active IRT (Sandak and Sandak 2017). 113

Figure 4.28: Wooden block specimen with recorded thermograms from passive IRT (Sandak and Sandak 2017). 114

Figure 4.29: a) Woodpecker WP-632AM; b) Specimens used in the experiments (Gryzagoridis and Findeis 2013) 116

Figure 4.30: Woodpecker colour tile map for (a) Specimen\#1; (b) Specimen\#2 (Gryzagoridis and Findeis 2013). 116 
Figure 4.31: Woodpecker colour tile map for (a) Specimen\#3; (b) Specimen\#4 (Gryzagoridis and Findeis 2013). 117

Figure 5.1: Traditional vs. UAS assisted inspection savings (Wells and Lovelace 2018)....... 122

Figure 5.2: Field inspection site for the proposed device (Kim et al. 2015). ...................... 125

Figure 5.3: Crack analysis and quantification steps (Kim et al. 2015).............................. 126

Figure 5.4: Inspire 1 Pro and FLIR Vue Pro thermal camera (Omar and Nehdi 2019). .......... 127

Figure 5.5: Bridge \#2 testing site (Omar and Nehdi 2019). ........................................... 128

Figure 5.6: UAV-borne system condition map of (a) Bridge\#1; (b) Bridge \#2 (Omar and Nehdi 2019). 129

Figure 5.7: Bridge\#4 vehicle-based raw image (top); condition map (bottom) (Guarino et al. 2018) 132

Figure 5.8: Bridge\#4 aerial raw image (top); condition map (bottom) (Guarino et al. 2018)... 132 Figure 5.9: Tap hammer mechanism with a closed-loop and planar four-bar linkage (Moreu et al. 2018) 134

Figure 5.10: Concrete specimens (a) good; (b) bad (Moreu et al. 2018).............................. 135

Figure 5.11: Tri-copter model used in the experiments (Mattar and Kalai 2018).................. 137

Figure 5.12: The proposed device taking measurements from the oil storage tank wall (Mattar and Kalai 2018) 138

Figure 5.13: Comparison of thicknesses obtained from the drone and manual ultrasonic testing (Mattar and Kalai 2018) 138 


\section{LIST OF TABLES}

Table 2.1: Resonant frequencies obtained for various conditions on the slabs using IE test

(Grabovski et al. 2011)...... 9

Table 2.2: Comparison of $f_{c}$ calculated from wave period and destructive tests (Krzemień and

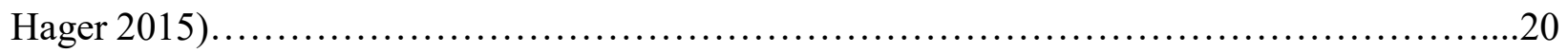

Table 2.3: Results of SE field test for wooden column (Jwary 2017).....................23

Table 2.4: Pile depths calculated using SE test for Springer Bridge (Jwary 2017)..............24

Table 2.5: Comparison of finite element analysis and IE test results (Liu et al. 2019)...........28

Table 3.1: Different Ultrasonic Methods and their principles, applications, advantages, and

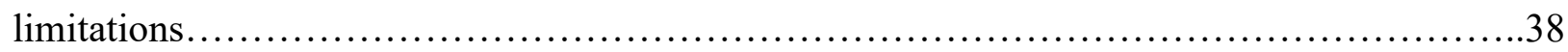

Table 3.2: Adjustment factors for MC and temperature (Dackermann et al. 2014)..............52

Table 3.3: Percentage decayed area corresponding to the relative velocity decrease (Dackermann

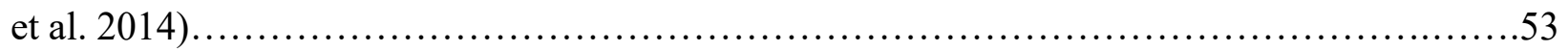

Table 3.4: Details of wood panel samples (Vossing et al. 2020)..........................71

Table 4.1: Damage width of the crack (Bauer et al. 2018) ...............................94

Table 4.2: IR camera specification used in the tests (Omar et al. 2018)......................... 107

Table 4.3: Environmental conditions during the IRT tests in all four bridges (Omar et al. 2018).107

Table 4.4: Comparison of results for four bridges obtained from different NDT (Omar et al.

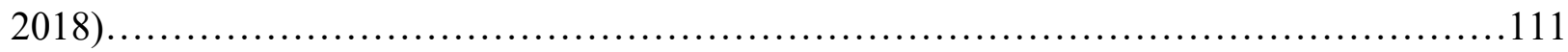




\section{INTRODUCTION}

\subsection{BACKGROUND}

Infrastructure is the mainstay of any country's economic development and prosperity. Maintaining infrastructures is as critical as constructing the new ones. In 2017, the American Society of Civil Engineers (ASCE) identified the cumulative infrastructure grade of the United States as D+. To earn a grade B, repair and maintenance of these infrastructures require an estimated investment of $\$ 2$ trillion (www.infrastructurereportcard.org). The current investment gap, however, poses widespread concerns about the existing and proposed infrastructures to adequately sustain the quality of life in the near future. Efficient and cost-effective approaches are therefore necessary to improve the resiliency and service life of our infrastructures.

In the realm of civil infrastructure, nondestructive testing (NDT) comprises methods to inspect any material or structural component without affecting its intended performance and integrity. NDT techniques can provide quantitative information regarding the in-situ properties of structural components, unlike traditional visual inspection, coring or standard tests on specimen cast simultaneously. Also, methods such as coring give properties at specific points only, whereas NDT techniques can generate continuous maps of material properties and sub-surface defects for the entire structure. These maps can be used to characterize the conditions and flaws of the components, which is very important for timely maintenance/repair of a structure to ensure longevity. NDT can thus be very useful for condition evaluation and rehabilitation of existing structures, and quality control and assurance of new construction works (ACI 228.2R-13).

Many different types of NDT techniques have been developed over the years. More commonly used methods include Acoustic Emission Testing, Electromagnetic Testing, Liquid Penetrant Testing, Magnetic Particle Testing, Radiographic Testing, Thermal/Infrared Testing, Ultrasonic Testing, Leak Testing, Magnetic Flux Testing and Visual Testing. These terms mostly imply the type of penetrating material or wave, or the equipment used in the particular test. (https://www.asnt.org/MajorSiteSections/Learn/Introduction to_Nondestructive_Testing.aspx).

As there is a multitude of options, understanding the applications and limitations of each technique is the key to selecting the right method for evaluation. One must comprehend different variables 
while selecting the techniques such as the type of material, location, the extent of the test as well as application (e.g., desired property or defect map), accuracy, speed of coverage, and cost of equipment and data collection using the technique. These techniques may be applied individually, or a combination of techniques can be used for more robust analysis and results.

This problem report focuses mainly on the nondestructive testing of concrete and timber structures. Concrete is one of the most durable and economical construction materials. Regardless of the ideality, concrete structures have some limitations. These structures are vulnerable to different environmental and loading conditions that may cause degradation in the strength or serviceability and lead ultimately to failure. NDT can be used to trace the vulnerability by determining the information regarding member dimensions; strength of concrete; steel reinforcement (cover, location, size and intensity of corrosion); location, size and orientation of defects (subsurface cracks, debonds, delamination); voids, honeycombing, and damage extent from freeze and thaw phenomena, fire or chemicals (ACI 228.2R-13). This report concentrates on reviewing the methodology of quantifying these variables using NDT techniques like impact-echo, digital tap hammer, infrared thermography, and ultrasonic testing.

Timber is one of the oldest and complex construction materials. Being an organic material, it is prone to weathering, decay and deterioration due to environmental factors, because of which its structural performance could be compromised. Nonetheless, if maintained well, timber structures are very durable as demonstrated by the numerous historic structures throughout the world. Therefore, timber should be assessed for their physical properties (size, age, moisture content, density) and mechanical properties (strength and elasticity) along with structural deterioration resulting from decay, weathering, insect attacks or mechanical damage (Deuse 2017). Approaches to finding some of these parameters using the ultrasonic technique, and infrared thermography are discussed in the following chapters.

Along with the advancement in technology, the field of NDT is also constantly evolving. Modern NDT equipment are becoming increasingly efficient, portable, and affordable. Moreover, integrating remote sensing into these methods has become a viable option for a rapid and comprehensive assessment of civil infrastructures. Unmanned Ariel System (UAS) is a prevalent example of this approach which is reviewed later in this report. These advances ultimately help to 
improve the performance and service life of our infrastructure, possibly helping to bridge the infrastructure investment gap.

\subsection{RESEARCH OBJECTIVES}

Nondestructive testing techniques have been researched vastly over the past years. In recent years, more efficient and cost-effective methods have been developed for in-situ condition assessment of structural components. The specific objectives of this research are:

$>$ To conduct a literature review focusing on recent advances in impact-echo, ultrasonic technique, digital tap hammer, and infrared thermography.

$>$ To conduct a literature review focusing on the integration of modern NDT technology with UAS which is going to be the future of NDT.

\subsection{ORGANIZATION}

This problem report is organized into six chapters. Chapter 1 presents the introduction to NDT and highlights its importance in the assessment of concrete and timber structural members, and lists the objectives of this report. Chapter 2 describes the background, advantages, limitations, and applications of Impact-Echo for condition assessment of structural members along with detailed reviews of case studies and experimental research. Chapter 3, Chapter 4, and Chapter 5 present similar reviews of Ultrasonic Testing, Infrared Thermography and Digital Tap Testing, and their integration with Unmanned Aerial System respectively. Chapter 6 presents the conclusions of the literature review and recommendations for future implementation. All the references cited in this report have been listed at the end. 


\section{IMPACT-ECHO}

\subsection{INTRODUCTION}

Impact-Echo (IE) is a transient stress-wave based nondestructive method that is primarily used for the assessment of concrete and masonry structures. This method was introduced in the mid-1980s (Sansalone and Carino 1986) and was developed into a field instrument for the first time in 1992 (Pratt and Sansalone 1992). The instrumentation has since undergone a series of changes and advances over the years and today comes with a lightweight, portable and wireless system with the ability for rapid in-situ analysis of results.

IE method comprises of three components: an impactor, a transducer, and data acquisition and analysis system. It is based on the impact generated stress waves that propagate through the member and is reflected by any discontinuities, such as internal defects and external surfaces, due to differences in acoustic impedances. An impactor, such as a hammer or steel sphere, generates high-energy stress waves with low frequency (typically between 5 and $40 \mathrm{kHz}$ ) that can penetrate deep into the test structural member (Schubert and Kohler 2008). The size of an impactor influences contact duration, the frequency range of the wave and minimum depth of the discontinuity that can be determined (ASTM C1383-15). In the case of slender members, such as piles, hammers are used as impactors with longer contact duration (greater than $1 \mathrm{~ms}$ ) whereas for members less than 40 in. ( $1 \mathrm{~m})$ thick, steel spheres with shorter contact duration (20 to $80 \mu \mathrm{s})$ are used (ACI 228.2R-13). The diameter of steel balls is inversely proportional to the maximum frequency of the stress waves (Sansalone and Carino 1986).

The receiving transducer measures the mechanical surface displacement caused by the reflection of stress waves and converts it into a time-domain waveform. The reflection should be dominated by $\mathrm{P}$-wave, which is made possible by the placement of transducers close to the impact point (Sansalone and Carino 1986). The recommended spacing is less than $40 \%$ of the flaw depth (Sansalone and Streett 1997 and ASTM C1383-15). However, if placed too close, Rayleigh waves

will dominate affecting the test data. Geophones (velocity transducer) and accelerometers are commonly used for slender members. Accelerometers are accurate for high frequencies whereas 
geophones for lower frequencies. Similarly, for plate-like structures, conically tipped piezoelectric transducers are used (ACI 228.2R-13).

The data acquisition and analysis system is useful to capture, digitize, process and store the responses from the surface vibrations caused by impact. The responses are displayed in numerical and graphical form as the time domain waveform and frequency spectrum with various features including peaks highlights, multiple gain settings, test member depths and so on.

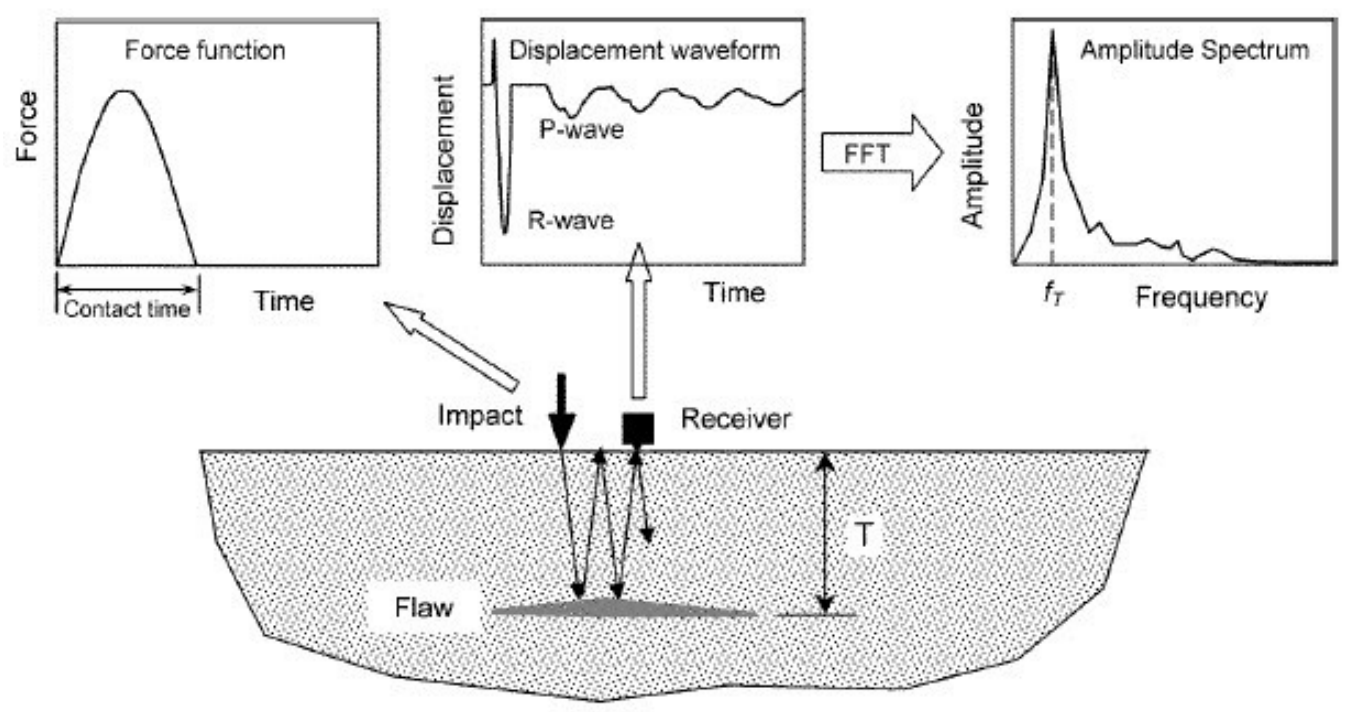

Figure 2.1: Schematic diagram of IE method (Carino 2015).

Testing a sound member using IE produces a distinctive waveform and spectra but the presence of discontinuity disrupts those plots. The difference in acoustic impedances of the two materials at an interface result in differences in reflected $\mathrm{P}$-wave which gives a distinction between the types of discontinuity (Sansalone and Carino 1990, Cheng and Sansalone 1993b). IE method can detect thickness of plate-like structures; depth of piles; early age strength of concrete (Pessiki and Carino 1988); location of internal flaws such as cracks, voids, honeycombing, debonds and delamination; porosity between two layers of the structure, etc. It has been successfully used for the assessment of various structural components, such as reinforced concrete beams and columns, concrete blocks, epoxy-concrete interface, prestressed concrete slabs, bridge decks, I-girders, tunnel linings, timber piles, cavities around concrete sewage pipelines, precast concrete structural members with grouted lap splice etc. (Liu et al. 2019). 
Fast Fourier Transform (FFT) converts the waveforms to the frequency spectrum, wherein the frequency of maximum amplitude represents the dominant frequency in the waveform. This frequency is also known as the thickness frequency (f) which is associated with the depth of back wall or discontinuities. The fundamental equation to compute the thickness of a tested member or depth of discontinuity $(\mathrm{d})$ is given by:

$$
\mathrm{d}=\frac{\beta \mathrm{KV}}{\mathrm{nf}}
$$

(Equation 2.1)

Here, $\mathrm{K}$ is a geometric correction factor depending on the ratio of thickness $(\mathrm{T})$ and lateral dimension (1) of the test object: $(\mathrm{T} / 1) \leq 0.2$ gives the value of $\mathrm{K}$ as $1 . \mathrm{n}$ is a constant factor $(2$ or 4$)$ that depends on the acoustic impedance $(Z=\rho V p)$ of the concrete member and scattering object. $\mathrm{n}=2$ if the $\mathrm{P}$ - wave is reflected by an interface with a transition from a high-impedance to a lowimpedance material (open back wall surrounded by air or the air-filled delamination or voids), whereas $n=4$ if the transition is from low to high acoustic impedance (e.g. steel layer) (Schubert and Kohler 2008). $\beta$ is an empirical Lamb Wave correction factor that has a value of 0.95 or 0.96 (Carino 2001, Sansalone and Streett 1997, Schubert et al. 2004 and Schubert and Kohler 2008). Pwave velocity $(\mathrm{Vp})$ for a 3D object is calculated using the following expression:

$$
\mathrm{V}_{\mathrm{p}}=\sqrt{\frac{\mathrm{E}(1-v)}{\rho(1+v)(1-2 v)}} \quad(\text { Equation 2.2) }
$$

Where, E, $\rho$, and $v$ are the elastic modulus, density, and Poisson's ratio of the target respectively (Liu et al. 2019).

Experiments have shown that a crack with a sufficient length and width as small as $25 \mu \mathrm{m}$ can be detected using the IE method (Cheng and Sansalone (1995a, 1995b) and Gucunski et al. 2012). However, the detection of the voids depends on the ratio of its lateral dimension (1) to depth (d) and the contact time. If $1>0.25 \mathrm{~d}$, the flaw can only be detected qualitatively; if $0.33<1<1.5 \mathrm{~d}$, the flaw depth can be measured; and if $1>1.5 \mathrm{~d}$, the flaw behaves like an infinite boundary (or a plate like structure). Within the range of $1 / 3$ and 1.5 (shaded region in Figure 2.2), the frequency spectrum generally has two peaks: a higher frequency peak corresponding to the flaw depth (obtained only if the impact contact time is short), and a lower frequency peak corresponds to the member thickness that is lower than the thickness frequency of the sound component (Carino 2001, 
Liu et al. 2019). Additionally, the embedded reinforcement can be detected only if its thickness ( $t$ ) is greater than half its wavelength $(\lambda / 2)$ (Schubert and Kohler 2008). This rule can be applied to the detection of any defect.

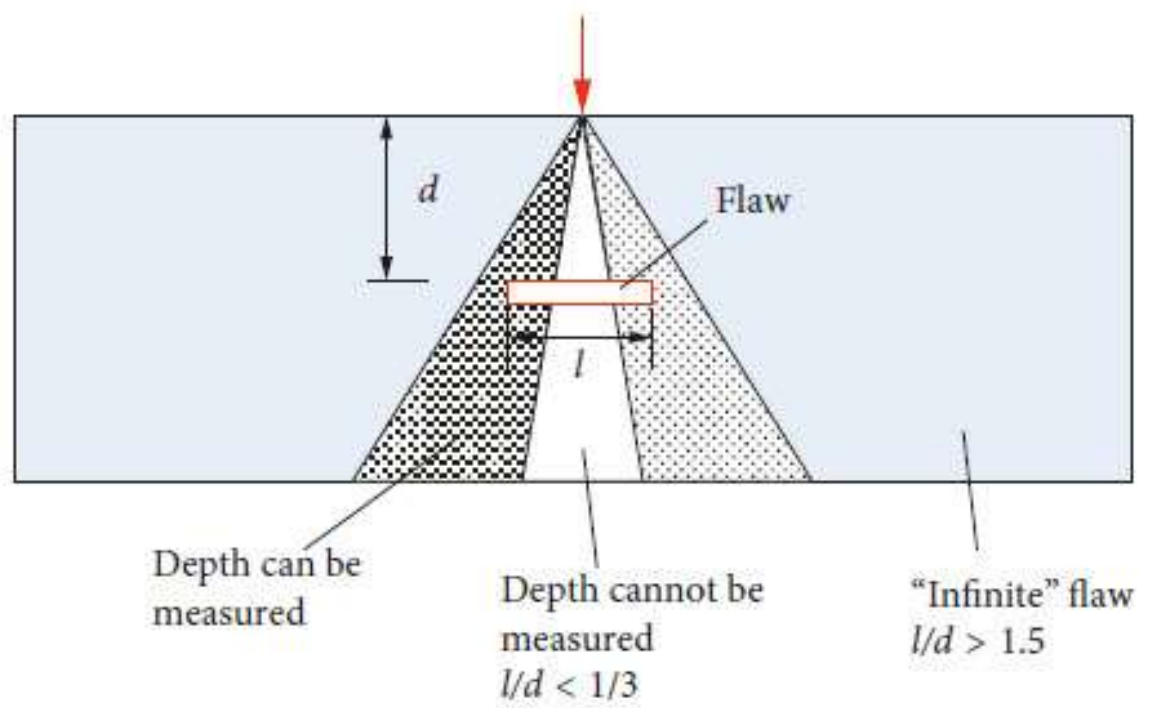

Figure 2.2: Detectable range of horizontal void using IE method (Carino 2001, Liu et al. 2019).

\subsection{REVIEW OF IMPACT-ECHO APPLICATIONS}

\subsubsection{USE OF IMPACT-ECHO IN CONCRETE PLATES WITH SMALL THICKNESSES AND DIFFERENT KIND OF CURE (Grabovski et al. 2011)}

\section{Introduction}

IE method has been successfully applied to estimate the thickness of bridge decks, pavements, slabs and walls since the 80s. Previous literature established the relevancy of the test for the computation of thickness ranging from $200 \mathrm{~mm}$ to $1000 \mathrm{~mm}$ only. This study primarily focused on the application of IE on concrete plate samples made with thicknesses smaller than the previously established range. Other aspects of the study covered the sensitivity of IE test on concrete with different curing processes and differences between manual and mechanical impact.

\section{$\underline{\text { Experimental Tests }}$}

Slab samples of thicknesses $60 \mathrm{~mm}, 40 \mathrm{~mm}$ and $30 \mathrm{~mm}$ were cast using self-compacting concrete and were cured for 28 days in dry condition and in wet condition. The IE tests were 
conducted on the samples, using the equipment manufactured by Impact-Echo Instruments (LLC), to evaluate the thicknesses of the concrete samples. To accommodate the small thicknesses of the samples, several parameters were adjusted: a steel sphere was used with the diameter of $3.2 \mathrm{~mm}$ that could reach frequency up to $91 \mathrm{kHz}$; the distance between the impactor and transducer was kept $10 \mathrm{~mm}$ (exceeding the maximum limit of 0.4 times the thickness); the wave velocities in the samples were acquired using direct ultrasonic method $(4450 \mathrm{~m} / \mathrm{s}$ for dry cured and $4531 \mathrm{~m} / \mathrm{s}$ for wet cured samples). The steel sphere was attached to a mechanical device developed to ensure consistent impact and accurate results as shown in Figure 2.3b. The impact was made at the center of the slabs with lateral dimensions of $600 \times 600 \mathrm{~mm}^{2}$. To reduce noisy signals, the results were filtered at $20 \mathrm{kHz}$. The tickness of the members were determined using Equation 2.1, with $\beta=$ $0.96, \mathrm{n}=2$, and $\mathrm{K}=1$ (for highest $\mathrm{T} / 1=60 / 600=0.1<0.2$ ).

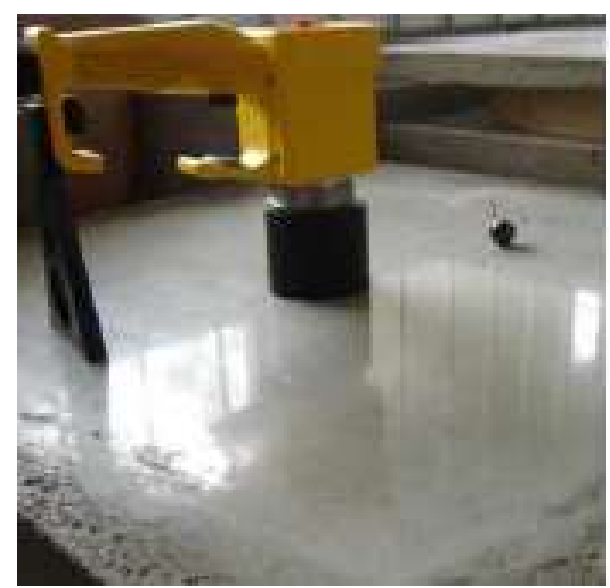

(a)

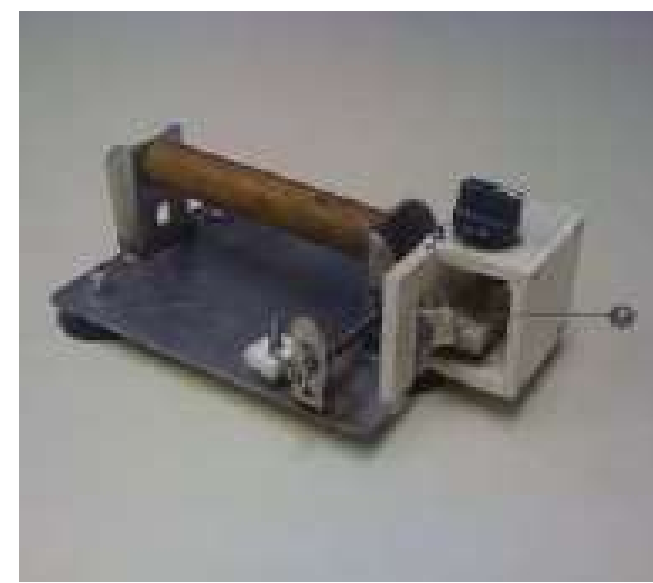

(b)

Figure 2.3: (a) Transducer with manual impactor; (b) Mechanical impact device (Grabovski et al. 2011).

\section{$\underline{\text { Results }}$}

The waveforms and frequency spectra obtained from IE tests on the concrete samples were analyzed to calculate the sample thicknesses. Figure 2.4 shows that the resonant frequency for a $40 \mathrm{~mm}$ (actual $43 \mathrm{~mm}$ ) dry-cured slab was $46.6 \mathrm{kHz}$ for both manual and mechanical impacts. Additionally, it can be noticed that the manual impact produced a lot of noise in the frequency spectra compared to mechanical impact. Table 2.1 shows the similarly acquired resonant frequency results addressing three aspects: the thickness of the plates, cure type (wet and dry) and impact type (manual and mechanical). It was observed that the errors for measuring the thickness of 
concrete plates with dry and wet cure respectively were $1.8 \%$ and $0.2 \%(60 \mathrm{~mm}), 3.9 \%$ and $0 \%$ $(40 \mathrm{~mm})$, and $3.9 \%$ and $1 \%(30 \mathrm{~mm})$. The frequencies, on average, for the saturated samples were about $1.7 \%$ higher than dry samples, compliant with the ultrasonic pulse velocity (higher by $2 \%$ in saturated concrete than in dry).

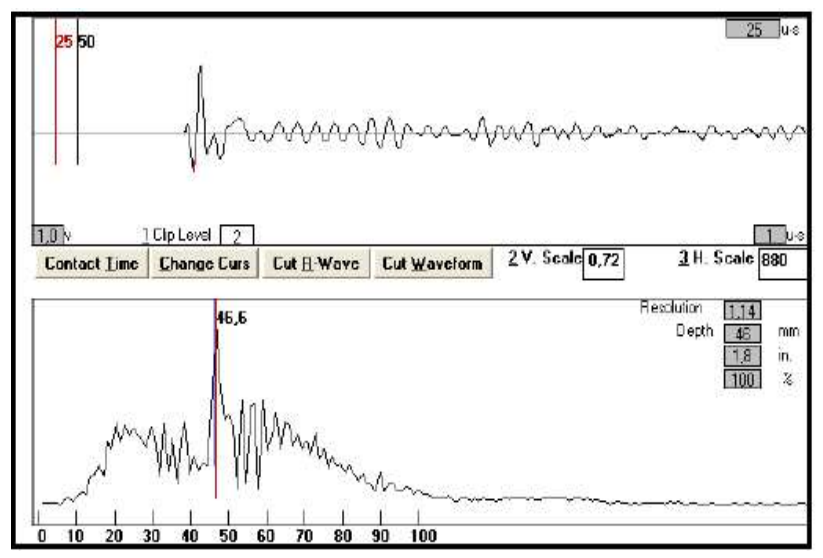

(a)

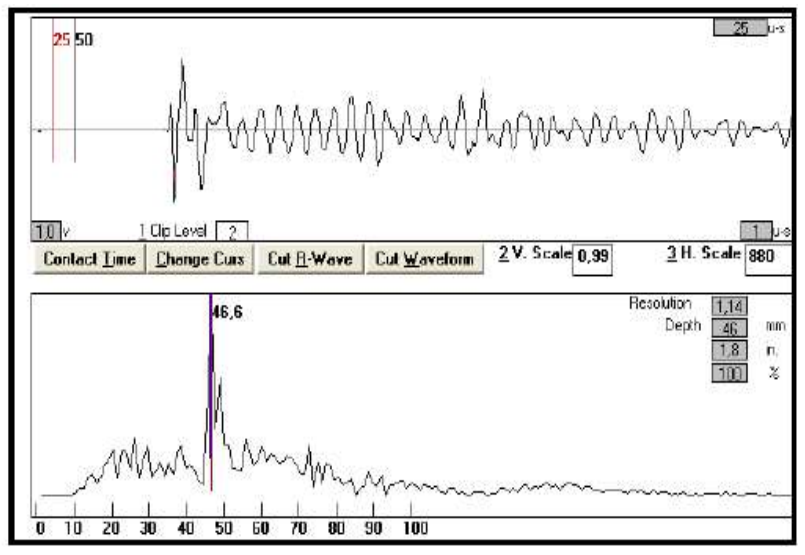

(b)

Figure 2.4: Waveforms and frequency spectra for $43 \mathrm{~mm}$ dry cured slab with (a) manual; (b) mechanical impact (Grabovski et al. 2011).

Table 2.1: Resonant frequencies obtained for various conditions on the slabs using IE test (Grabovski et al. 2011).

\begin{tabular}{|c|c|c|c|c|}
\hline \multirow{2}{*}{$\begin{array}{c}\text { Plate } \\
\text { thickness } \\
(\mathrm{mm})\end{array}$} & \multicolumn{2}{|c|}{ Air-curing condition } & \multicolumn{2}{c|}{ Wet cure condition } \\
\cline { 2 - 5 } & Manual Impacto & Mechanical Impact & Manual Impacto & Mechanical Impact \\
\cline { 2 - 5 } & Frequency $(\mathrm{kHz})$ & Frequency $(\mathrm{kHz})$ & Frequency $(\mathrm{kHz})$ & Frequency $(\mathrm{kHz})$ \\
\hline 60 & 35,6 & 35,6 & 36,2 & 36,2 \\
\hline 40 & 53,4 & 53,4 & 54,3 & 54,3 \\
\hline 30 & 71,3 & 71,1 & 72,6 & 72,4 \\
\hline
\end{tabular}

\section{Conclusion}

IE test was found effective for estimating the concrete plate thickness, as low as $30 \mathrm{~mm}$, with the lowest accuracy of $96.1 \%$ and the precision of $3 \%$. The cure type was also found to influence the test: the wet cured samples showed higher frequencies than the dry ones. The type of impact was independent of thickness or method of cure. Nevertheless, the consistent target point and force applied, with the use of mechanical impact, enhanced repeatability for more reliable data. 


\subsubsection{RAPID BRIDGE DECK CONDITION ASSESSMENT USING THREE- DIMENSIONAL VISUALIZATION OF IMPACT ECHO DATA (Gucunski et al. 2012)}

\section{$\underline{\text { Introduction }}$}

This study discussed the implementation of the traditional IE testing approach for the bridge deck assessment, based on single-point records and proposed a new approach based on three-dimensional data visualization. Features of advanced presentation as well as an automated interpretation of IE data has been shown. The data was presented in terms of 3D visualizations and the interpretation platform developed helped the overall assessment of the deck condition and identification of deteriorated zones for the appropriate repair or rehabilitation decisions.

\section{Experimental Tests}

The tests were conducted on two bridges (Van Buren and Iowa bridge) using two systems: Portable Seismic Property Analyzer (PSPA) and Stepper (developed at BAM). PSPA is primarily used for the evaluation of surface pavement layers and bridge decks. The device integrates IE, bulk wave and surface wave based ultrasonic techniques. Stepper is an automated system used for continuous data collection with a speed of 10 to 15 points per minute. It can use multiple probes to collect data reducing the errors through multiple impacts and signal averaging, or use different techniques simultaneously. Figure 2.5 shows the systems being used for a grid with $0.6 \mathrm{~m}$ testpoint spacing.

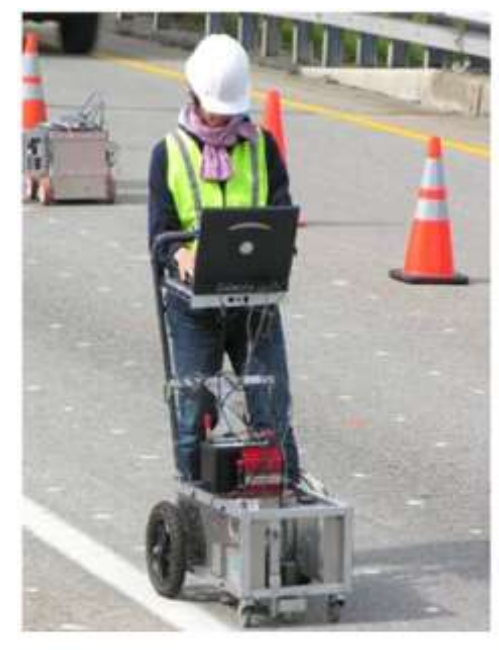

(a)

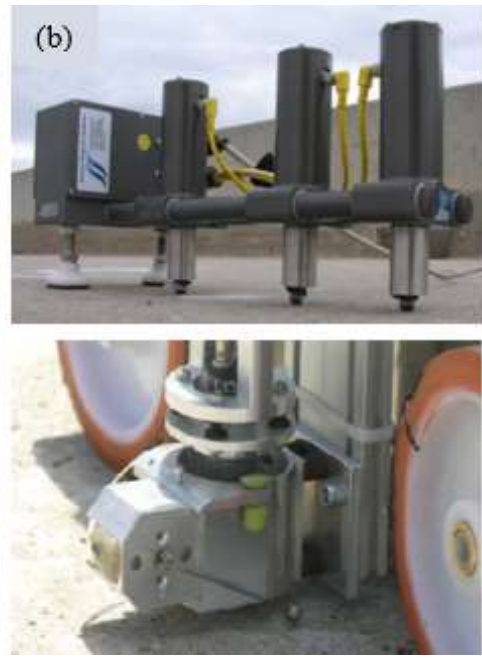

(c)

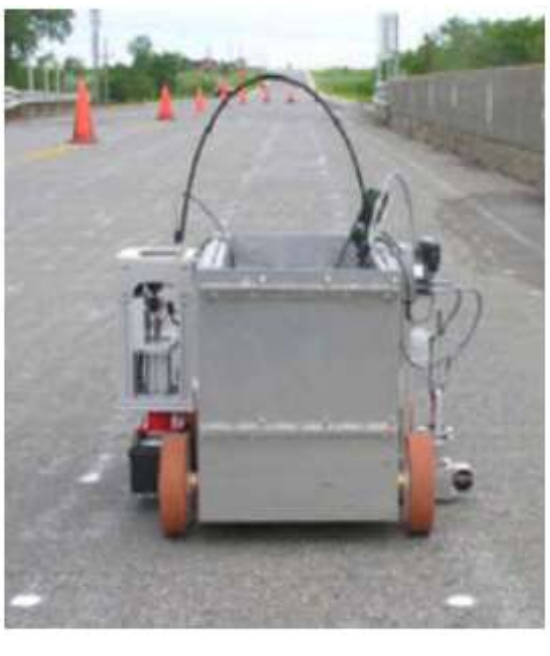

(d)

Figure 2.5: (a, b) PSPA with impactor and receiver; (c, d) Stepper with impactor (Gucunski et al. 2012). 


\section{$\underline{\text { Results }}$}

Figure 2.6 presents the condition map of the Van Buren Bridge in VA, acquired using PSPA, which clearly illustrated the deteriorated condition of the deck, ranging from good to serious (sound, initial and progressed delamination). Chain drag data, on the other hand, was able to estimate only the poor to the serious condition (progressed) of the deck (represented by area under yellow lines). The Stepper was used for the assessment of the bridge on Route 18 over the Cedar River in Iowa. Figure 2.7 shows the condition map of its deck, where the shaded white parts were the repaired sections after chain drag results. The delaminated and sound conditions shown in the map were found consistent with the observation from coring, as shown in the figure.

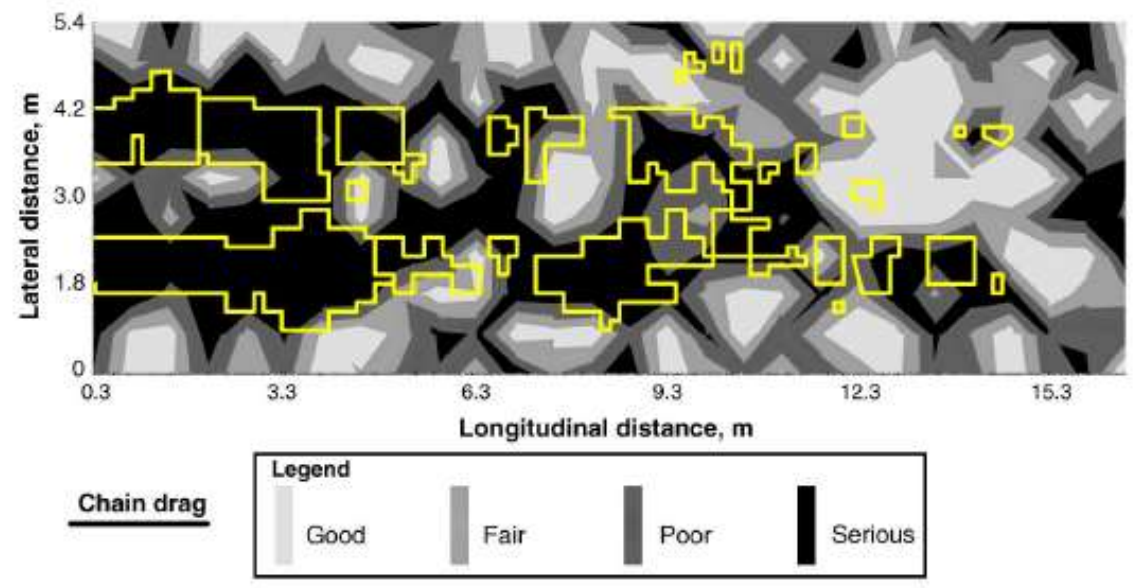

Figure 2.6: Condition map of Van Buren Bridge from PSPA (Gucunski et al. 2012).
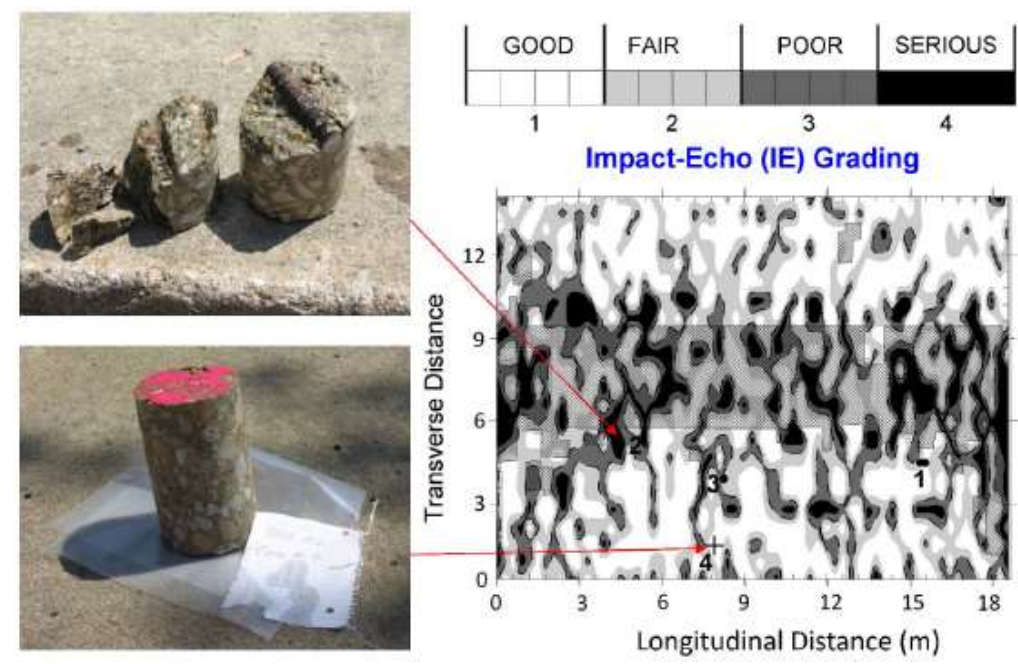

Figure 2.7: Condition map of Route 18, Iowa Bridge with extracted cores (Gucunski et al. 2012). 


\section{$\underline{\text { IE Data Visualization }}$}

Assuming a constant P-wave velocity, a unique thickness/depth was associated with each frequency spectrum component developing a depth spectrum through which the data interpretation was made easy for the detection of degree of delamination (position of the depth and the amplitude of dominant and secondary peaks determine the reflection energy). A 3-D visualization platform was formed for IE data from Carter Creek Bridge and Van Buren Bridge. Data from sets of single test points along different lines were combined to form 3-D spectral surfaces or volumes. Figure 2.8a represents the 3-D visualization of the Carter Creek Bridge deck. Two horizontal axes denoted the longitudinal and lateral distances of the deck whereas the vertical axis denoted the depth of the reflector detected. The set of shallow reflectors indicated at the depth of about $0.1 \mathrm{~m}$ represented initial to progressed delamination corresponding to fair to poor condition. At the depth of about $0.2 \mathrm{~m}$, the large group of reflectors indicated the reflections from the bottom of the deck. Some deep reflectors can be seen in the figure representing zones in serious condition. These depths were apparent as they were caused due to flexural oscillations of the upper deck section. The flexural oscillations were in a lower frequency range than the return frequency from the bottom of the deck, causing the apparent depth below the bottom reflection depth. Comparison of the images Figure 2.8a and 2.8b inferred that Van Buren Bridge was in far worse delaminated condition than Carter Creek Bridge. Furthermore, a procedure was developed that translated the deep reflectors into their actual positions for easier data interpretation. Figure 2.9 shows the model of the bridge on Interstate 287 over Route 1 in Woodbridge, NJ with two distinct layers. The green layer at about $0.2 \mathrm{~m}$ depth represented the reflections from deck bottom, while the red layer at $0.1 \mathrm{~m}$ depth represented reflections from delamination. The shallow reflections in the red layer represented fair to poor condition, estimating the initial stage of delamination. The deep reflections represented serious condition, estimating a progressed stage of delamination. The transparency degree of each colour was related to the strength of the reflections.

\section{Conclusion}

IE method reliably detected the zones of delamination at initial, progressed and developed stages, for overall condition assessment of bridge decks. Comparing the results with those from scanners, the accuracy of the delamination depth visualization was $94.5 \%$ that occurred due to boundary influence. However, exact position of delamination is not of high priority in a heavily 
damaged bridge decks like those surveyed. Nonetheless, scanners and advanced data visualization techniques using 3-D translucent imaging was shown to improve the speed and ease of data interpretation significantly for effective repair and rehabilitation judgments.

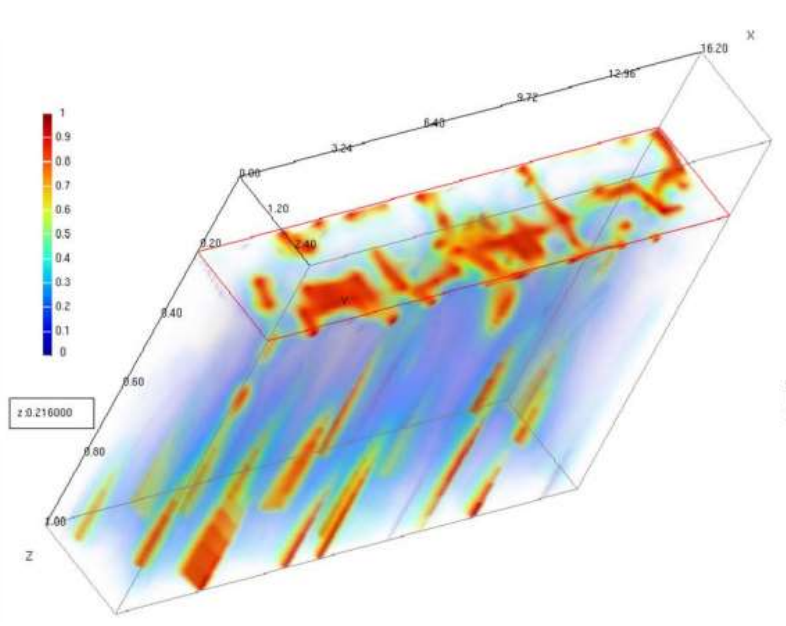

(a)

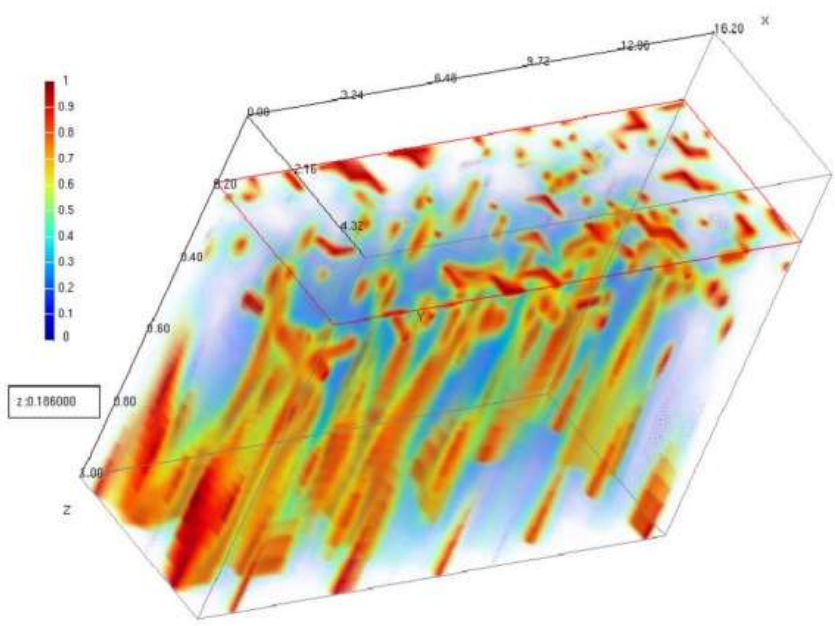

(b)

Figure 2.8: 3-D visualization of (a) Carter Creek Bridge deck; (b) Van Buren Bridge (Gucunski et al. 2012).

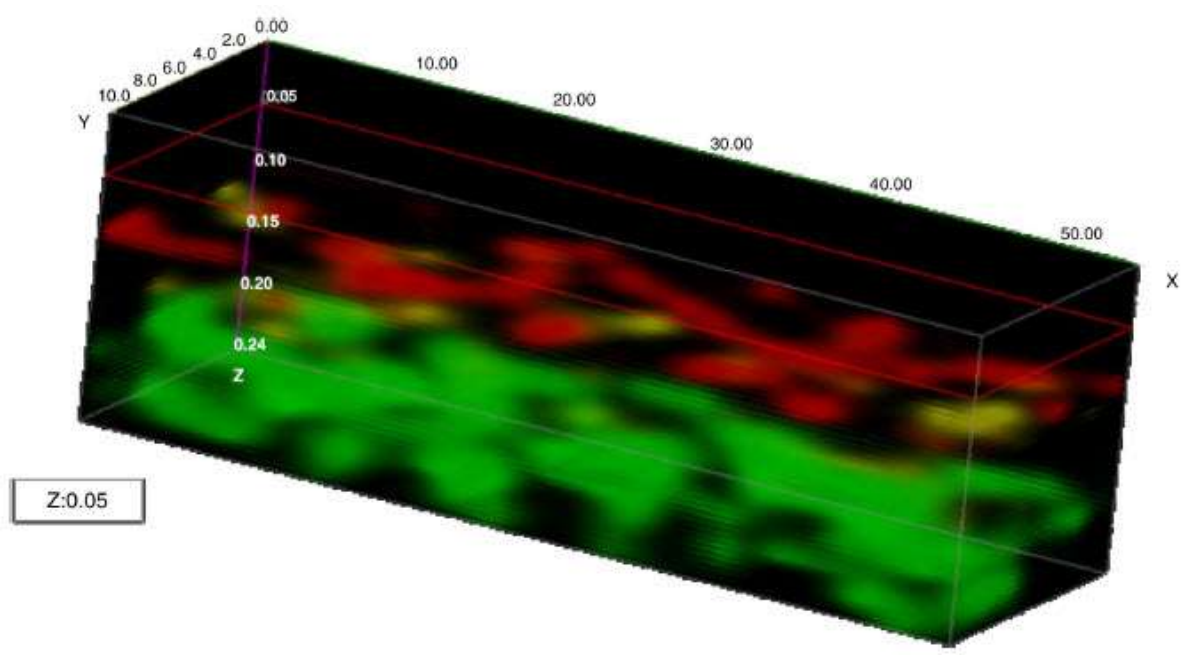

Figure 2.9: 3 -D visualization of the bridge on Interstate 287 over Route 1 in Woodbridge, NJ (dimensions in meter) (Gucunski et al. 2012). 


\subsubsection{EFFECTIVENESS OF IMPACT ECHO TESTING IN DETECTING FLAWS IN PRESTRESSED CONCRETE SLABS (Chaudhary 2013)}

\section{$\underline{\text { Introduction }}$}

This study evaluated the applicability of the IE technique for the assessment of concrete in the anchorage zones of a post-tensioned (PT) slab in a high-rise building. The test area consisted of an L-shaped interface of a PT concrete beam and a PT dropped floor slab. Over-elongation during the stressing operation and crookedness while anchoring of PT tendons was recorded in some areas as shown in Figure 2.10b. An investigation of the extent and severity of internal flaws (honeycombing/voids) around the anchorage zones were carried out. Repair schemes for the defected area were developed based on the results.

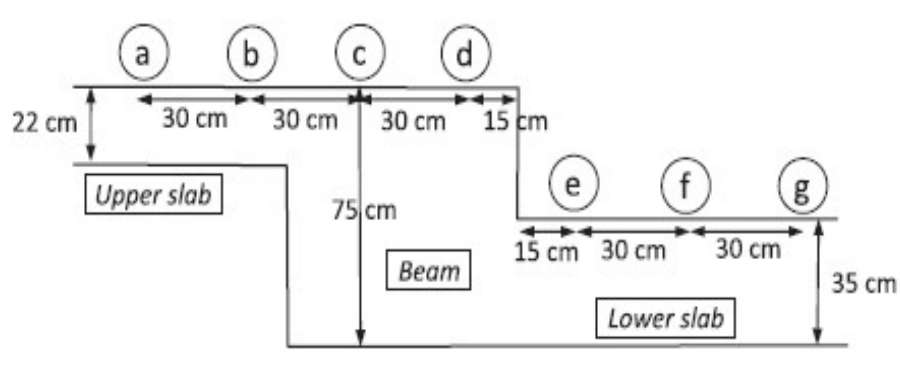

(a)

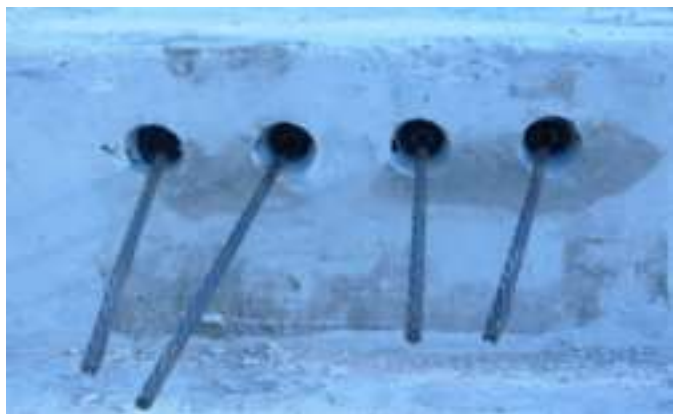

(b)

Figure 2.10: (a) IE test area; (b) crooked tendons in the PT system (Chaudhary 2013).

\section{Field Tests}

The unbonded post-tensioned members comprised of $12 \mathrm{~mm}$ diameter tendons and concrete with a cylinder strength of $35 \mathrm{MPa}$. The stepped interface consisted of a $75 \mathrm{~cm}$ deep beam, $35 \mathrm{~cm}$ thick dropped slab and $22 \mathrm{~cm}$ thick upper slab. This configuration coupled with a wrong practice (pouring of concrete starting from upper slab causing the concrete to flow to the bottom slab) instigated honeycombing in the concrete behind the anchorage zones in the beam and upper slab. IE test was conducted along two strips (18 $\mathrm{m}$ long line-4 and $12 \mathrm{~m}$ long line-E) of the floor plan in a seven-grid set up in each section (1.8 m wide) as shown in Figure 2.10a. A $120 \mathrm{gm}$ impactor was used in the tests and the thickness of the test object (d) was computed using Equation $2.1(\mathrm{~K}=1, \beta=0.96, \mathrm{n}=2)$. The actual thicknesses were measured using a total station and incorporating tolerances as per ACI 117-10. The average P-wave velocity calculated theoretically 
for beam, upper slab, and lower slab were $3582 \mathrm{~m} / \mathrm{s}, 3720 \mathrm{~m} / \mathrm{s}$ and $4116 \mathrm{~m} / \mathrm{s}$ respectively, whereas the resonant frequencies ranges were found to be $2.14-2.32 \mathrm{kHz}, 7.14-8.34 \mathrm{kHz}$, and $5.31-5.81$ $\mathrm{kHz}$ respectively.
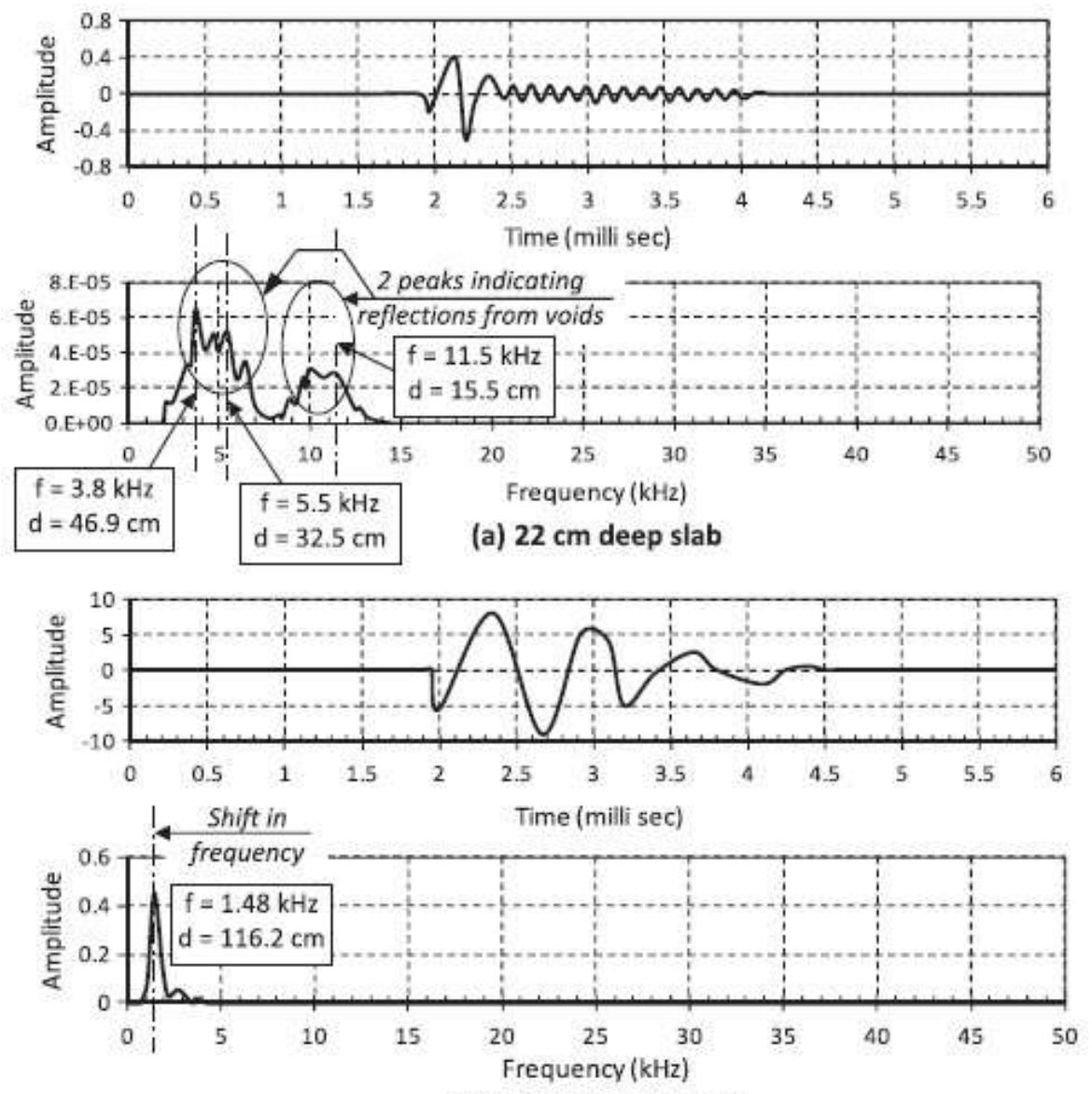

(b) $75 \mathrm{~cm}$ deep beam

Figure 2.11: Time and frequency domain plots for upper slab and beam (Chaudhary 2013).

\section{$\underline{\text { Results }}$}

The frequencies obtained, using IE tests on sound concrete, were found to be in the theoretical range. Defects in the members were recognized by the shift of the resonant frequency or by the presence of a second peak in the frequency spectrum. The resonant frequency for the beam was $1.48 \mathrm{kHz}$ as shown by Figure 2.11. In the case of the upper slab, three peaks were corresponding to frequencies of $3.8 \mathrm{kHz}, 5.5 \mathrm{kHz}$, and $11.5 \mathrm{kHz}$. The frequencies with a shift to lower values indicated the presence of defects and their severity level (good to poor) was estimated by the percent difference in the measured thicknesses. The condition of concrete was qualified 
based on the thickness tolerance ranges in ACI 117-10. Figure 2.12 presents the comparison between measured and allowable thickness range for lines 4 and E separately. Based on the categories, $84 \%$ of the tested locations were classified as Good or Fair (without internal flaws), $10 \%$ were estimated Questionable (have possible voids) and 6\% were considered Poor. The majority of the defected area was found in the upper slab and beam along line $\mathrm{E}$ as expected. These locations were further investigated by physical probing, which revealed that the accuracy of flaws prediction by the IE method was $60 \%$. Experimental research concluded that the inaccuracy was caused by incorrect prediction of the geometric correction factor $(\mathrm{K})$ in the equation to calculate thickness (Sangoju et al. 2009 and Schubert et al. 2004). It was found that K does not depend only on the member dimensions but is also influenced by the duration of the time-domain signals used in FFT and distance of point of measurement from the vertical boundaries. Adjusting the value of $\mathrm{K}$ in IE testing to 0.95 (suggested $\pm 5 \%$ ) improved the accuracy to $81 \%$.

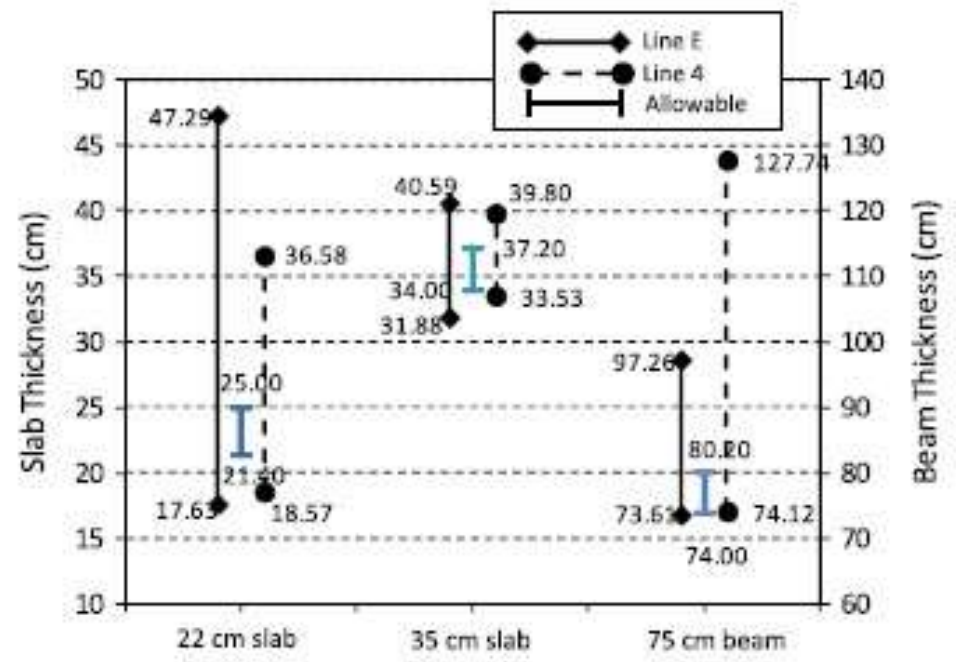

Figure 2.12: Comparison of thickness range measured by IE method and allowed by the code (Chaudhary 2013).

\section{$\underline{\text { Conclusion }}$}

The IE test results were more or less reliable and were capable of providing a detailed overview of the condition of PT concrete members. This made it easier to devise a proper repair scheme to improve the structural performance of the tested members. However, this study recommends adopting a revised geometric correction factor in IE testing of members under different field conditions for more accurate results. 


\subsubsection{POST-FIRE ASSESSMENT OF MECHANICAL PROPERTIES OF CONCRETE WITH THE USE OF THE IMPACT-ECHO METHOD (Krzemień and Hager 2015) \\ $\underline{\text { Introduction }}$}

The main objective of this paper was to establish a relation between the parameters measured using the IE test (signal characteristics in time and frequency domain, elastic wave velocity) and the mechanical properties (modulus of elasticity, compressive strength, and density) of concrete specimens subjected to high temperature.

\section{$\underline{\text { Experimental Tests }}$}

IE tests were carried out using Vu-Con equipment, produced by James Instruments, as shown in Figure 2.13a. An $8 \mathrm{~mm}$ diameter steel spherical impactor was used in the tests. The tests were conducted on 120 days old $(0.15 \mathrm{~m}$ x $0.15 \mathrm{~m}$ x $0.15 \mathrm{~m})$ cubic specimens.

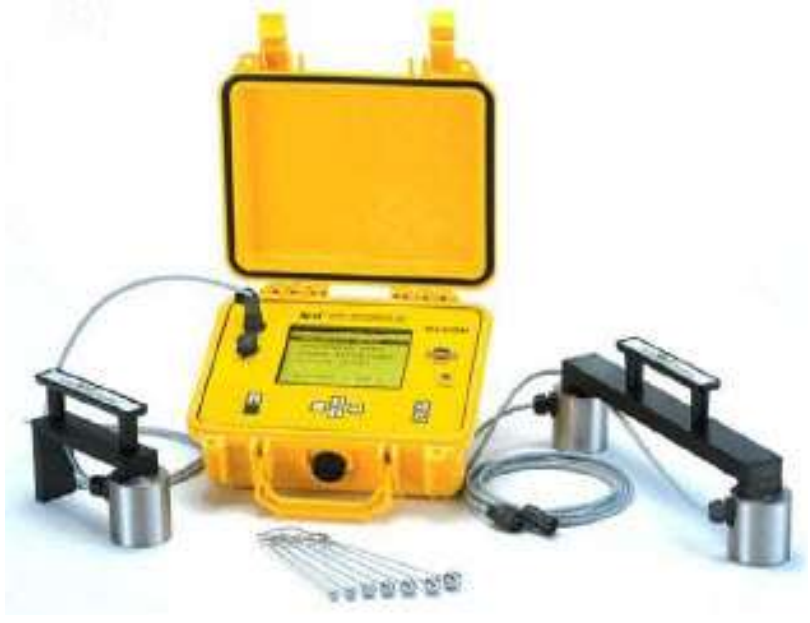

(a)

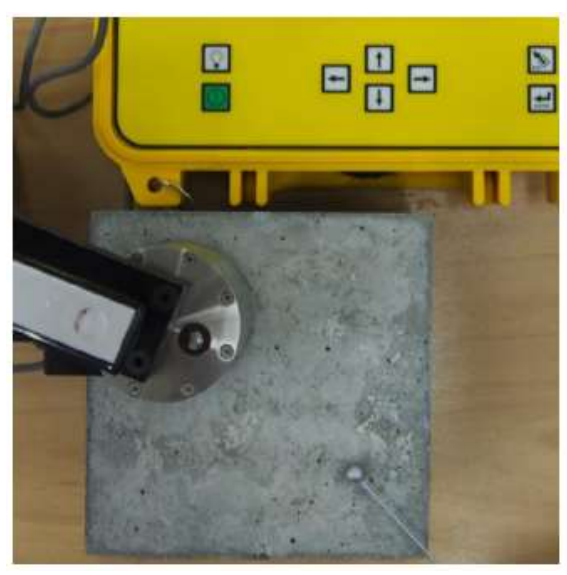

(b)

Figure 2.13: (a) Vu-Con IE equipment set; (b) IE test arrangement on a specimen (Krzemień and Hager 2015).

\section{Mechanical Parameters}

Two specimens were heated at the rate of $0.5{ }^{\circ} \mathrm{C} / \mathrm{min}$, for each target temperature $\left(200{ }^{\circ} \mathrm{C}\right.$, $400{ }^{\circ} \mathrm{C}, 600{ }^{\circ} \mathrm{C}, 800{ }^{\circ} \mathrm{C}$, and $1000{ }^{\circ} \mathrm{C}$ ) in a programmable furnace. After cooling, the mechanical properties (apparent density, elastic wave parameters using the IE test and residual compressive strength) were determined for all the specimens. The static modulus of elasticity was determined by subjecting the same heat to sound specimens. Mean concrete properties were found for all the 
specimens (heated and unheated) and compared to find that the mechanical properties of concrete decline with the increase in temperature.

\section{Signal Analysis}

IE tests were conducted on the heated cubic specimens after cooling. Figure $2.13 \mathrm{~b}$ shows the impactor and receiver set up at the surface of the cube, where the impact was made at about 6 $\mathrm{cm}$ from the edge of the receiver. It was found that the resonant frequency decreases with the increase in temperature. Thus, a connection was established between the resonant frequency magnitude and the level of damage in concrete due to higher temperatures. For a thickness (t) of $0.15 \mathrm{~m}$ and frequency $(\mathrm{f})$, elastic wave velocity $\left(\mathrm{V}_{\mathrm{p}}\right)$ was calculated using the relationship: $\mathrm{V}_{\mathrm{p}}=(2$ t f) / $\beta$; where ( $\beta$ ) was taken as the ratio of thickness to width of the specimen, i.e. 1 in this case. The dynamic modulus of elasticity $\left(\mathrm{E}_{\mathrm{d}}\right)$ was also computed using Equation 2.2. Both $\mathrm{V}_{\mathrm{p}}$ and $\mathrm{E}_{\mathrm{d}}$ were found to decrease with higher temperatures.

\section{Regression Curves}

To check the possibility of applying IE test parameters for the post-fire assessment of concrete, regression curves relating compressive strength $\left(f_{c}\right)$ and static modulus of elasticity $(E)$ with resonant frequency $(f)$ and elastic wave velocity $\left(V_{p}\right)$ were plotted. The correlations attained were very strong with $\mathrm{R}^{2}>99 \%$.

\section{Post Fire Assessment of Concrete}

A concrete slab shown in Figure 2.14 was assessed for degree of damage after exposing it to high-temperature condition (with the intensity of ISO 834 curve) for 2 hours, simulating a real fire. IE tests were conducted before $\left(20^{\circ} \mathrm{C}\right)$ and after heating $\left(218^{\circ} \mathrm{C}\right)$ on four points. For the collection of data, the receiver was placed on the four points and impacts were made by a hammer about $8 \mathrm{~cm}$ from the edge of the receiver. Figure 2.15 shows the time and frequency domain plots attained from the tests. The recorded data were validated by drilled samples. The mean compressive strengths for all the samples were also determined before and after heating. Table 2.2 shows the results, demonstrating higher resonant frequency for unheated specimens $(6.84 \mathrm{kHz})$ compared to the heated one $(4.03 \mathrm{kHz})$ confirming the earlier observation. The $5.85 \%$ and $27.5 \%$ errors in compressive strength were explained to have resulted because of defects like macro- 
cracks in the slab and the fact that IE test considered data of larger area for assessment compared to core drillings. The resonant frequency measured and the corresponding compressive strength obtained from the drillings were plotted and the previously developed regression plot was modified to $\mathrm{f}_{\mathrm{c}}=7.5525(\mathrm{f})+3.045$, with a shift of $\delta \mathrm{f}=43.07 \mathrm{MPa}$.

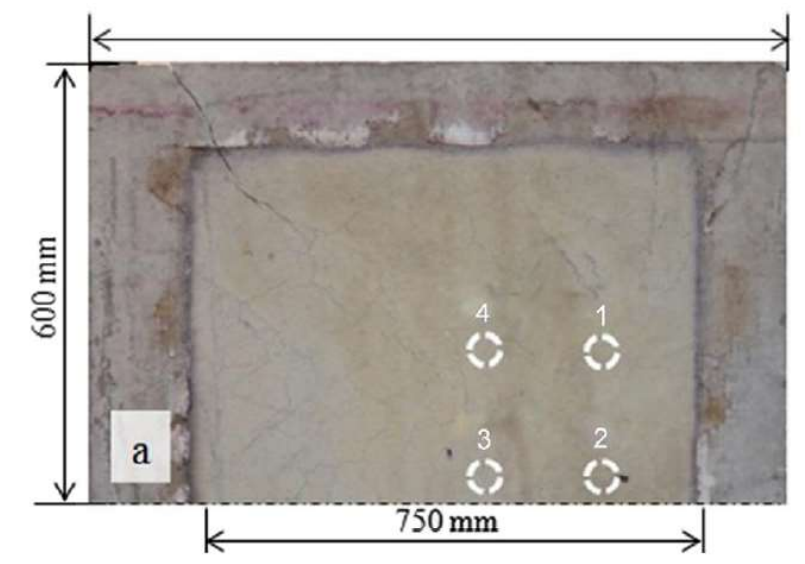

Figure 2.14: 4 sample points on concrete slab for IE test after exposing to heat (Krzemień and Hager 2015).
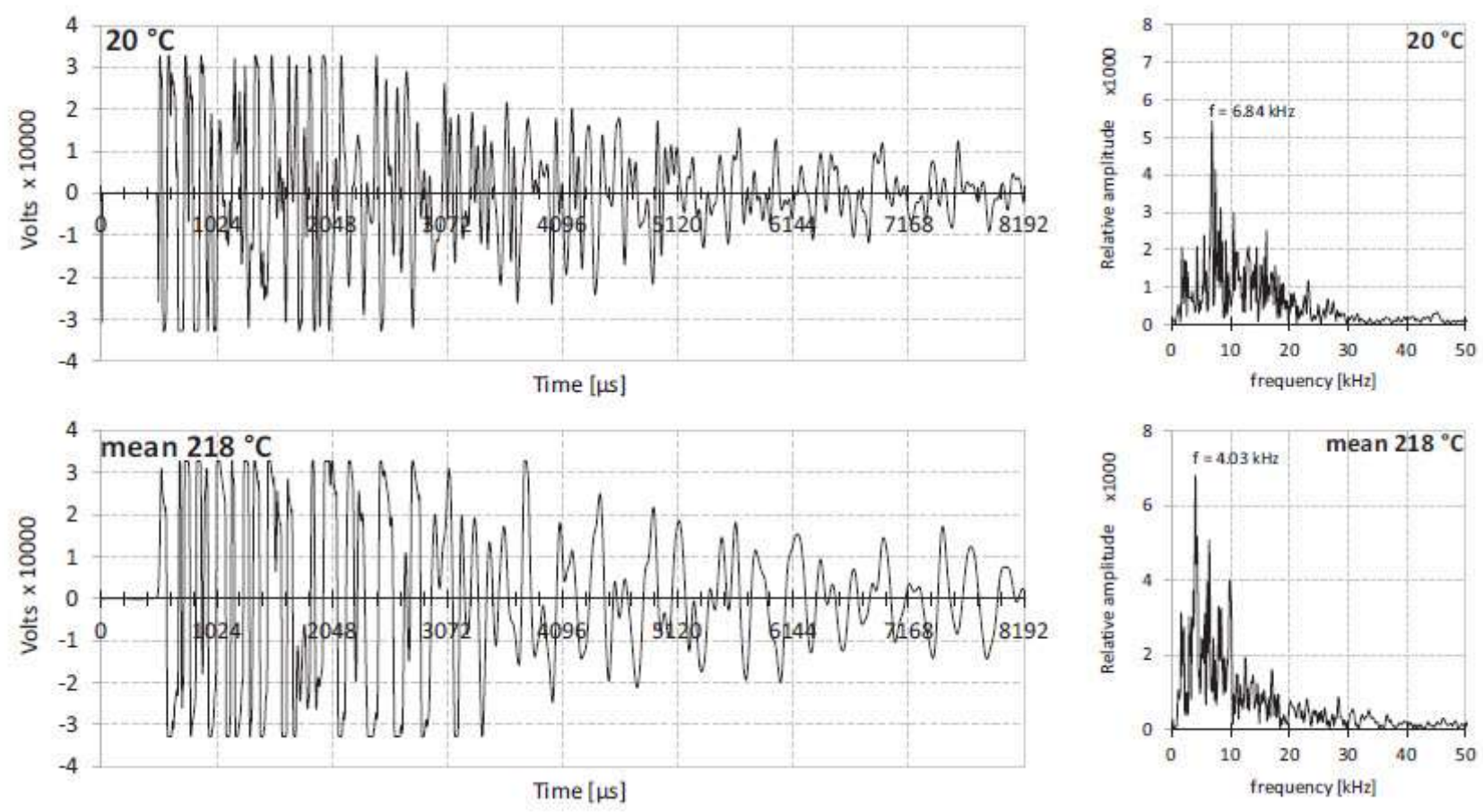

Figure 2.15: IE time domain and frequency domain signals for concrete slab (Krzemień and Hager 2015). 
Table 2.2: Comparison of $f_{c}$ calculated from wave period and destructive tests (Krzemień and Hager 2015).

\begin{tabular}{lllll}
\hline$T\left({ }^{\circ} \mathrm{C}\right)$ & $f(\mathrm{kHz})$ & $\begin{array}{l}f_{\text {cmean }} \text { (test) } \\
(\mathrm{MPa})\end{array}$ & $\begin{array}{l}f_{\text {c.mean }}(f) \\
(\mathrm{MPa})\end{array}$ & $\begin{array}{l}\text { Error mean } \\
(\%)\end{array}$ \\
\hline 20 & 6.84 & 58.1 & 54.7 & 5.85 \\
After ISO 834 & 4.03 & 46.2 & 33.5 & 27.5 \\
\hline
\end{tabular}

\section{$\underline{\text { Conclusions }}$}

IE test parameters were proved to be consistent with the mechanical properties of concrete (compressive strength, static modulus of elasticity and density). The time and frequency domain signals and elastic wave velocity obtained from the tests were found to be strongly dependent on the degree of damage in concrete subjected to high temperature. The regression curves developed were verified in the actual post-fire assessment of a concrete specimen and showed a good correlation of results for compressive strength. Hence, it was established that the IE test can be employed effectively in the non-destructive post-fire assessment of concrete.

\subsubsection{PRACTICAL CONSIDERATIONS IN DETERMINING TIMBER PILE DEPTH USING THE SONIC ECHO METHOD (Jwary 2017)}

\section{$\underline{\text { Introduction }}$}

The purpose of this paper was to explore the efficiency of the Sonic-Echo (SE) method to determine the unknown depths and types of bridge piles. The standardized test was mentioned to be found in ASTM D5882-00.

\section{$\underline{\text { Field Tests and results }}$}

SE tests were conducted on 18 timber piles (abutments and bents) of three different bridges located in New Mexico and a wooden column at the Biology annex building of University of New Mexico campus. The test setup comprised of three major components: rubber tipped hammer (between 0.6 to $11 \mathrm{lbs}$ ) as the impactor, an accelerometer as the signal receiver and Olson Freedom Data PC (with WinTFS software) as the data acquisition and analysis system as shown in Figure 2.16. Smaller hammers of different hardness levels (hard, medium hard, medium soft and soft) were used for timber piles to take an advantage of short and narrow pulses with higher frequency content. Small wooden and aluminum blocks (2" x 2" and 4" x 4") were used to attach the 
accelerometer to the side of the piles and for the hammer strike. When the accelerometer was placed on the top of the pile, the pile depth (D) was calculated as a function of the reflection time $(\mathrm{t})$ and the stress wave velocity $\left(\mathrm{V}_{\mathrm{p}}\right)$ as:

$$
\mathrm{D}=\frac{\mathrm{Vpt}}{2}
$$

When the accelerometer was placed on the side of the pile using a wooden block (coupled with epoxy, anchor bolts/another wooden block to attach accelerometer on top of it), the total pile depth $\left(\mathrm{L}_{\mathrm{t}}\right)$ and buried depth $\left(\mathrm{L}_{\mathrm{b}}\right)$ were calculated as functions of $\mathrm{t}, \mathrm{V}$, distance from the top of the pile to the accelerometer (d) and the distance from the bottom of the pile cap to the ground level (h) as:

$$
\begin{aligned}
& \mathrm{L}_{\mathrm{t}}=\frac{\mathrm{V} \Delta \mathrm{t}}{2}+\mathrm{d} \\
& \mathrm{L}_{\mathrm{b}}=\mathrm{L}_{\mathrm{t}}-\mathrm{h}
\end{aligned}
$$

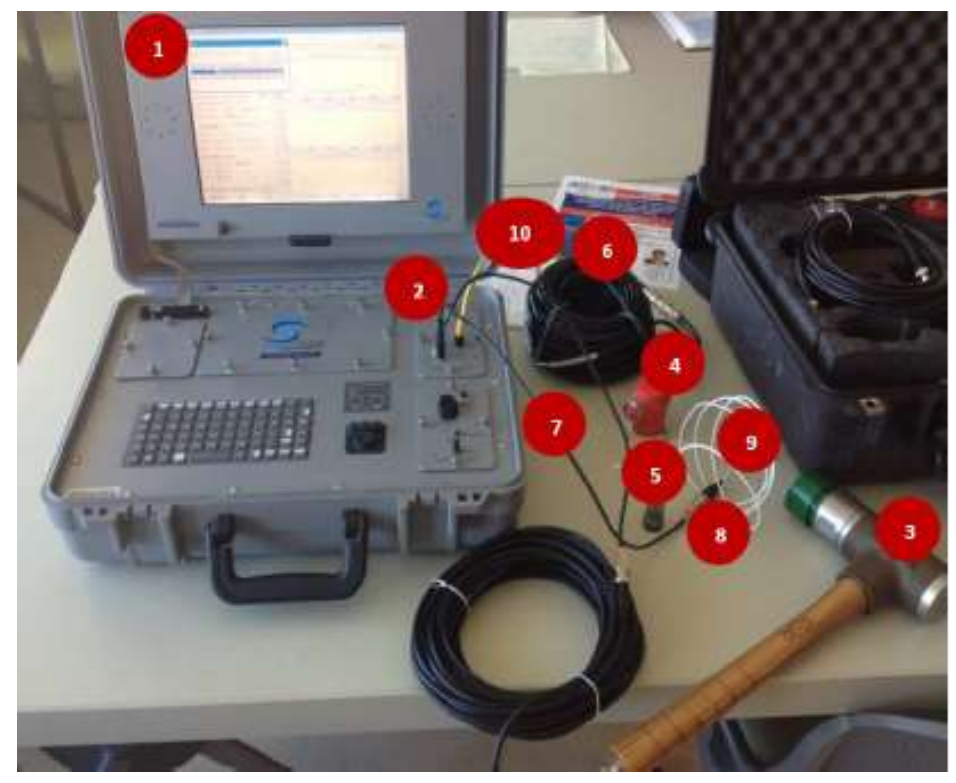

Figure 2.16: Equipment for SE test (Jwary 2017).

\section{1) Biology Annex Building Wooden Column at the University of New Mexico}

Located in Albuquerque, the site was used to calibrate the SE equipment. Sixteen tests were conducted with the impact at point A (downward strike) and at B (upward strike) as shown in Figure 2.17. Two accelerometers were mounted on wooden blocks that were glued to the column. 
The wave propagated to the column top and was reflected back. The travel distance of the wave is known in this case (column height). In the velocity versus time plot obtained (Figure 2.18), the time difference between the initial response and initial echo sensed by accelerometer \#2 was 1380 $\mu \mathrm{s}$. Hence, the wave velocity of the timber was found to be of $12600 \mathrm{ft} / \mathrm{s}$ using Eq. 2.3. Using the velocity, the column clear length ( $\mathrm{L}_{\mathrm{obs}}$ ) was obtained from accelerometer \#2 data (time difference from velocity trace as shown in Figure 2.18) and Equation 2.3 for calibration. Similarly, the total column length $\left(\mathrm{L}_{\mathrm{t}}\right)$ was found using accelerometer \#1 data and Equation 2.4. Table 2.3 shows the results obtained. The total length measured from accelerometer \#1 was close to the predicted length of 11.7 feet. Accelerometer \#2 results were reasonable for impact on point A; but were erroneous for impact at B because the accelerometer was too far from the impact point. Except soft tip hammer, all other types gave reliable results.
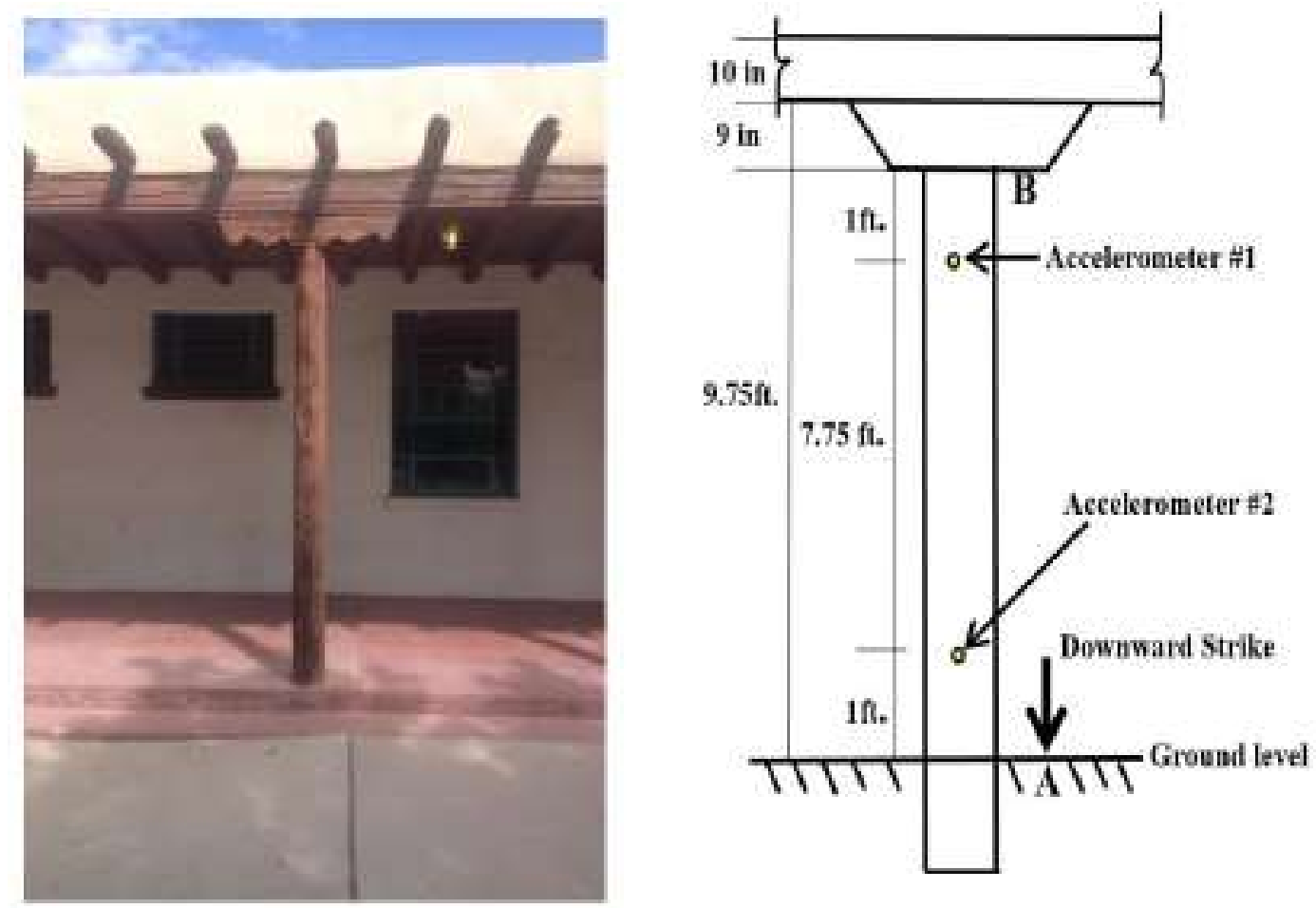

Figure 2.17: Wooden column test setup in Biology Annex Building (Jwary 2017). 
Table 2.3: Results of SE field test for wooden column (Jwary 2017).

\begin{tabular}{|c|c|c|c|c|c|c|c|c|}
\hline \multirow{2}{*}{ Test No } & \multirow{2}{*}{$\begin{array}{l}\text { Hammer } \\
\text { Tip's Type }\end{array}$} & \multirow{2}{*}{$\begin{array}{c}\text { Direction of } \\
\text { Strike }\end{array}$} & \multicolumn{3}{|c|}{ Accelerometer 1} & \multicolumn{3}{|c|}{ Accelerometer 2} \\
\hline & & & $\Delta t(\mu s)$ & $L_{t}(\mathrm{ft})$ & $D(f t)$ & $\Delta t(\mu s)$ & $\mathrm{L}_{\text {obce }}$ (ft.) & D (ft.) \\
\hline 1 & Hand & A-Downward & 1900 & 11.97 & 1 & 1380 & 9.7 & 1 \\
\hline 2 & Hard & A-Downward & 1880 & 11.8 & 1 & 1360 & 9.6 & 1 \\
\hline 3 & Med-hard & A-Downward & 1940 & 12.2 & 1 & 1440 & 10.1 & 1 \\
\hline 4 & Med-hard & A-Downward & 1960 & 12.35 & 1 & 1460 & 10.2 & 1 \\
\hline 5 & Med-soft & A-Downward & 2040 & 12.85 & 1 & 1460 & 10.2 & 1 \\
\hline 6 & Med-soft & A-Downward & 2020 & 12.7 & 1 & 1480 & 10.2 & 1 \\
\hline 7 & Soft & A-Downward & 2060 & 12.98 & 1 & 1420 & 9.85 & 1 \\
\hline 8 & Soft & A -Downward & 2040 & 12.85 & 1 & 1420 & 9.85 & 1 \\
\hline 9 & Hard & B -Upward & 1680 & 11.584 & 1 & 1980 & 12.5 & 1 \\
\hline 10 & Hard & B -Upward & 1760 & 12.1 & 1 & 1520 & 9.6 & 1 \\
\hline 11 & Med-hard & B -Upward & 1660 & 11.5 & 1 & 2600 & 16.4 & 1 \\
\hline 12 & Med-hard & B -Upward & 1680 & 11.6 & 1 & 2320 & 14.6 & 1 \\
\hline 13 & Med-soft & B -Upward & 1980 & 13.5 & 1 & 2620 & 16.5 & 1 \\
\hline 14 & Med-soft & B -Upward & NS & NS & 1 & NS & NS & 1 \\
\hline 15 & Soft & B - Upward & 2020 & 13.7 & 1 & NS & NS & 1 \\
\hline 16 & Soft & B -Upward & 2300 & 15.5 & 1 & NS & NS & 1 \\
\hline
\end{tabular}

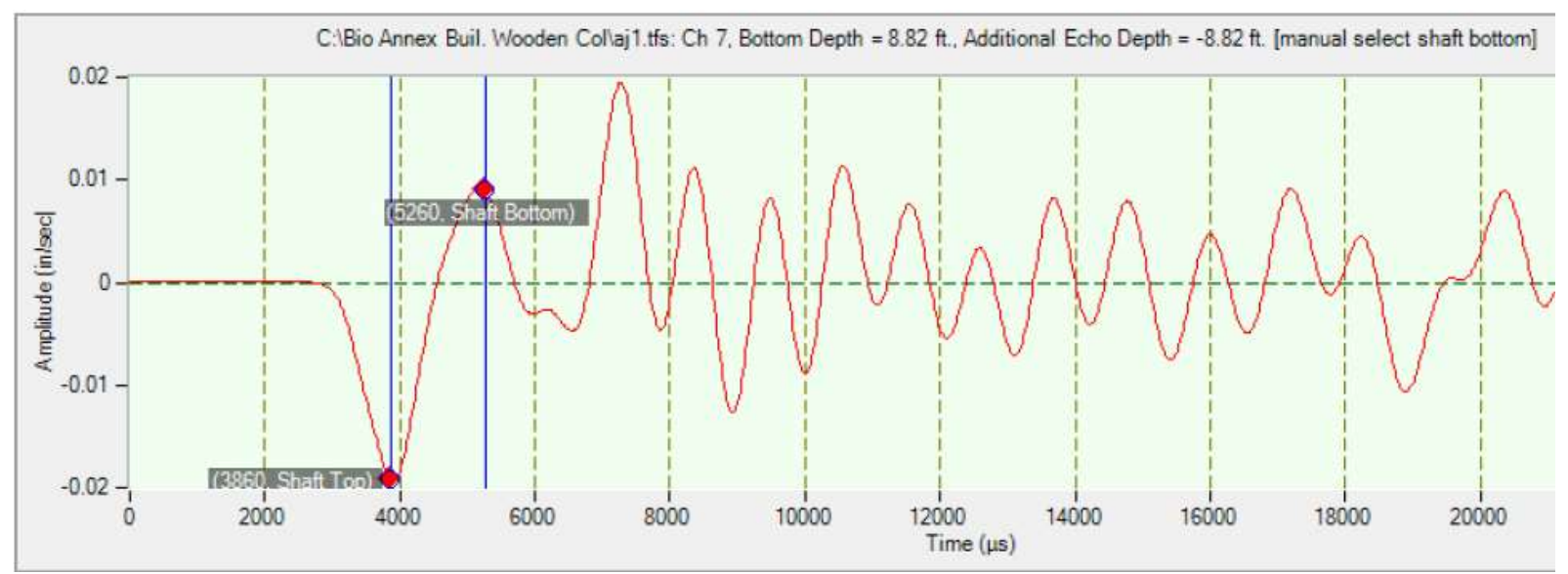

Figure 2.18: Velocity trace obtained using accelerometer $\# 2$ for the Wooden Column (Jwary 2017).

\section{2) Bridge Tests}

SE tests were conducted similarly on three sawn lumber beam bridges with pile abutments: four-span bridge in Albuquerque, one-span bridge in Las Vegas, and two-span bridge in Springer, New Mexico (Figure 2.19). The tests were conducted on 4, 6, and 8 piles with measured wave velocities of $14845 \mathrm{ft} / \mathrm{s}, 15000 \mathrm{ft} / \mathrm{s}$, and $15000 \mathrm{ft} / \mathrm{s}$ respectively for the above mentioned bridges. Table 2.4 shows the results obtained which were also validated with frequency spectrum and 
ABAQUS results. The SE tests were capable to determine the unknown depths with an accuracy of $\pm 15 \%$ and the success rate of $94 \%$. The range of the buried depth measured were between 16 to 38 feet. The results obtained were reliable except for pile 15 of Las Vegas Bridge. This was explained to be resulted because the pile was at the upstream end. Therefore, with the high pressure from water flow, there was a possibility of noise amplification influencing the results. Therefore, it is recommended to conduct the SE test on the pile where the water pressure is low. The use of hard and medium hard tip hammers provided best results for timber piles. Additionally, the study revealed that the impact could be made on a wooden block bolted (aluminum block was unreliable) on the pile side if the top surface is not accessible. An alternative approach of upward strike was found acceptable for an impact with an adjustment factor of 1.1 for the depth calculation. Moreover, recommended position of accelerometer was 1 foot from the top end of the pile attributing to the best results when the impact point was close to the accelerometers.

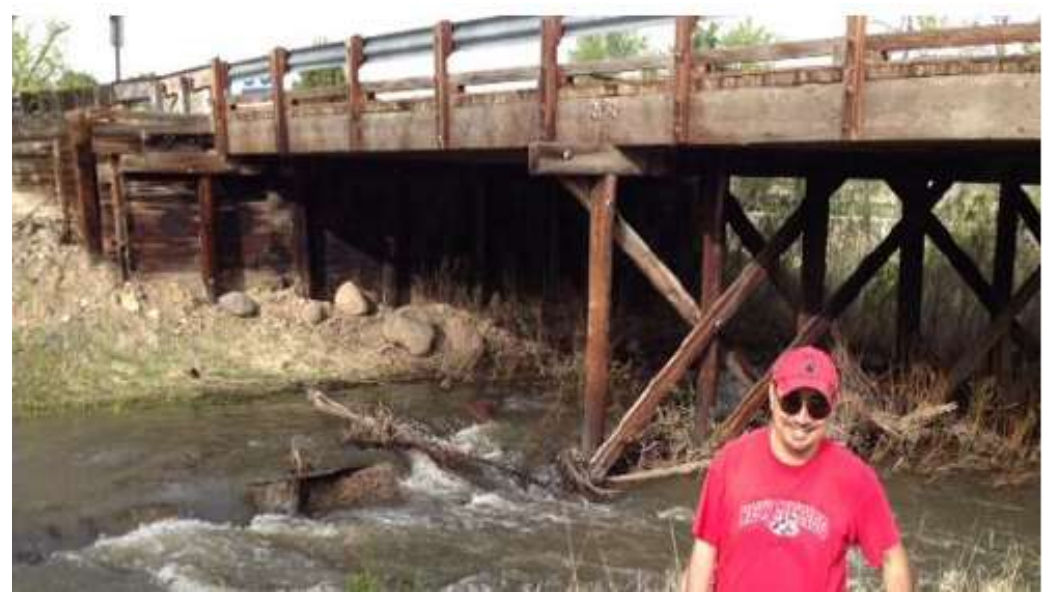

Figure 2.19: Springer Bridge test site(Jwary 2017).

Table 2.4: Pile depths calculated using SE test for Springer Bridge (Jwary 2017).

\begin{tabular}{|c|c|c|}
\hline Pile No. & $\begin{array}{c}\text { Assessed Total Pile } \\
\text { Depth (ft.) }\end{array}$ & $\begin{array}{c}\text { Assessed Buried Pile } \\
\text { Depth (ft) }\end{array}$ \\
\hline Pile 1 & 25.4 & 18 \\
\hline Pile 8 & 24 & 17 \\
\hline Pile 10 & 25 & 18 \\
\hline Pile 15 & NS & NS \\
\hline Pile 19 & 34 & 24 \\
\hline Pile 21 & 26 & 16 \\
\hline Pile A & 24 & 18 \\
\hline Pile B & 19 & 14 \\
\hline
\end{tabular}




\section{Conclusion}

SE method was established as a reliable technique to determine the unknown depths of timber piles for the abutments and bents of the bridges with an accuracy of $\pm 15 \%$, thereby making it easier to a certain degree to estimate the scour risk of the timber bridges.

\subsubsection{GROUTING DEFECT DETECTION OF LAPPED BAR CONNECTIONS BASED ON IMPACT-ECHO METHOD (Liu et al. 2019)}

\section{$\underline{\text { Introduction }}$}

The quality of the grout in a precast concrete construction directly affects the structural performance of the members. Defects like voids in the grout can cause corrosion and concentration of stress in the lapped bars. Hence, it is very important to be able to detect these defects to ensure overall structural safety. This study assessed the applicability of IE method to locate such defects on lap-splice connections of a precast shear wall filled with grout in the laboratory setting.

\section{$\underline{\text { Experimental Tests }}$}

IE tests were conducted on a precast shear wall $\left(2000 \times 1000 \times 200 \mathrm{~mm}^{3}\right)$ containing 18 grouting holes on two surfaces of the specimen. Each hole had a diameter of $35 \mathrm{~mm}$, length of 630 $\mathrm{mm}$, steel bar had diameter of $16 \mathrm{~mm}$ and anchorage length of $600 \mathrm{~mm}$, and grouting outlet hole had a diameter of $30 \mathrm{~mm}$. Each hole had different conditions on surface 1 and surface 2 as shown in Figure 2.20. The defects were formed using plastic foam and their holes had solid grout with steel bars. A test on solid concrete of the specimen was also conducted for reference. The frequency response of all the grouted holes were determined and compared using IE tests. The tests comprised of SPC-MATS equipment including a $6 \mathrm{~mm}$ steel sphere impactor (contact time of approximately $25 \mu \mathrm{s}$ ) and a piezoelectric accelerometer (frequency up to $15 \mathrm{kHz}$ ). The impact was made at a distance of $20 \mathrm{~mm}$ to $30 \mathrm{~mm}$ for each test point. The specimens were tested on a total of 20 points (1-15 over the hole and 16-20 in the solid part), at intervals of $40 \mathrm{~mm}$, along a line on both surfaces. For sound specimen, the frequency of $9.5 \mathrm{kHz}$ was computed using equations 2.1 , where, $\mathrm{K}, \beta, \mathrm{n}$, $\mathrm{V}_{\mathrm{p}}$ and $\mathrm{d}$ were taken as $1.0,0.96,2.0,3960 \mathrm{~m} / \mathrm{s}$, and $200 \mathrm{~mm}$ respectively. 
Test surface 2 (back side)

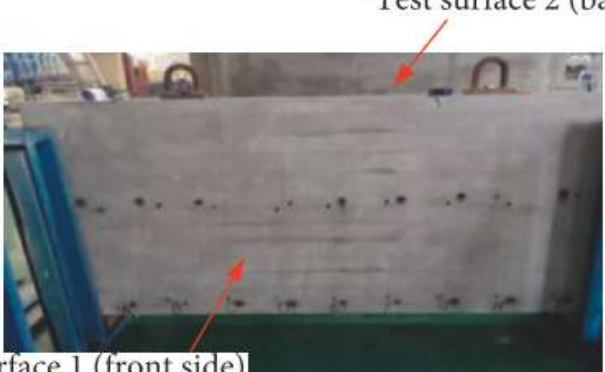

(a)

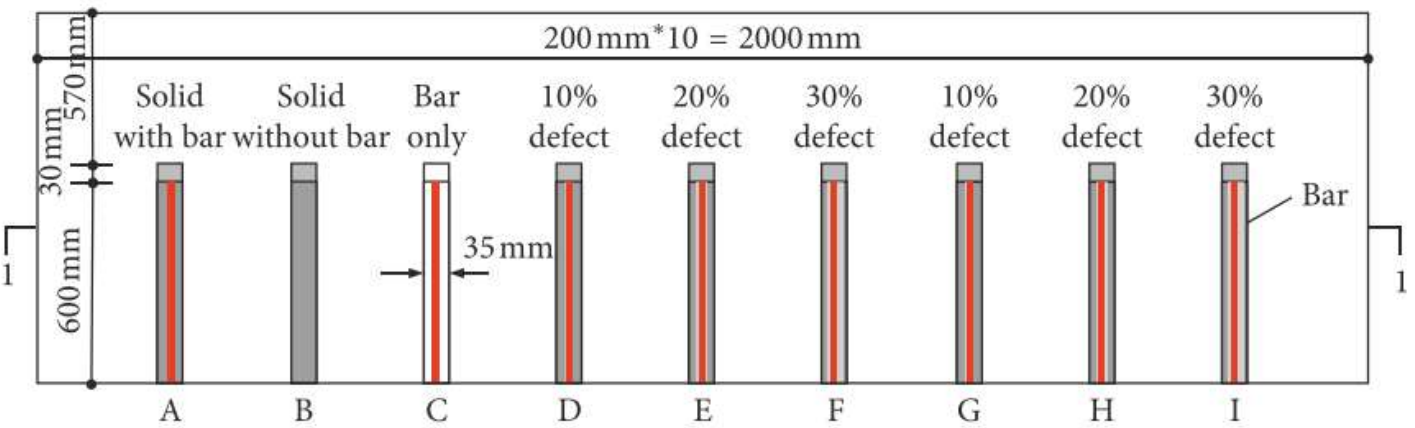

(b)

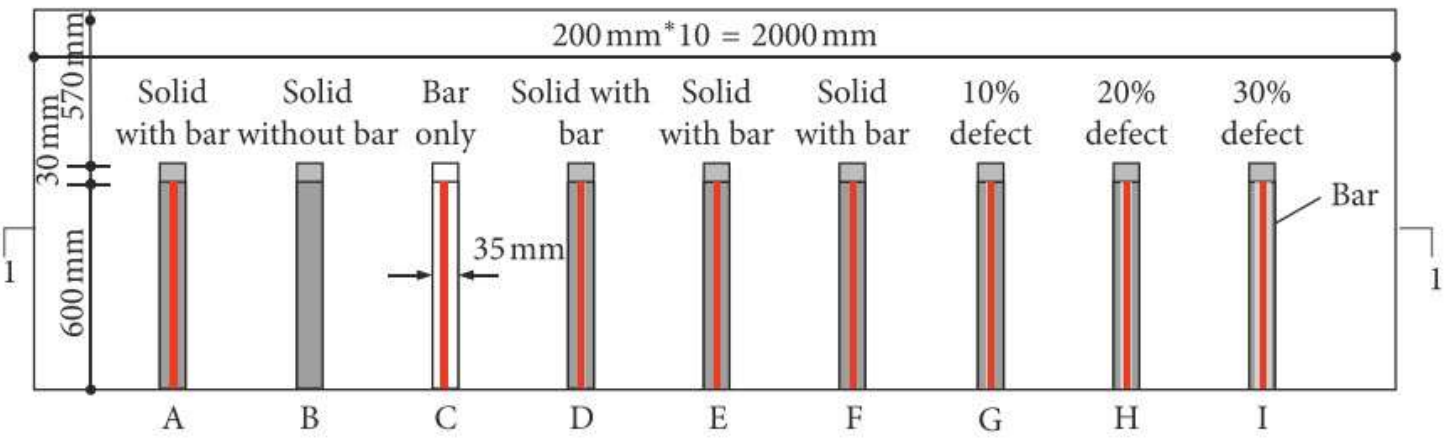

(c)

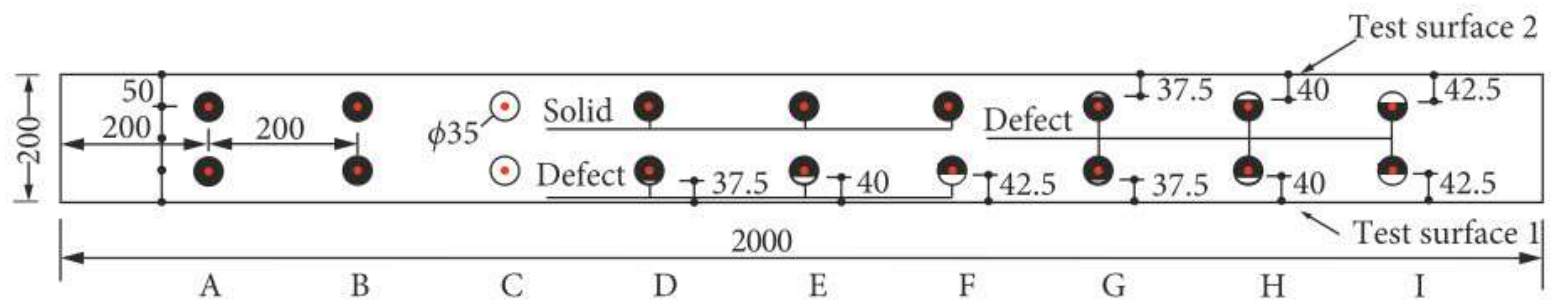

(d)

Figure 2.20: (a) Test specimen; (b, c) details of test surface 1 and 2; (d) section 1-1 (Liu et al. 2019). 


\section{$\underline{\text { Results }}$}

The results showed that the peak frequency of the solid wall $(9.644 \mathrm{kHz})$, acquired using IE test, was consistent with that calculated using equation $(9.5 \mathrm{kHz})$. Additionally, Figure 2.21 shows that the dominant frequency obtained for hole A was same as the solid concrete and hole B. This meant that fully grouted holes and holes with bar did not affect the frequency. For the defected holes, the peak frequency decreased for the ones with considerable defect. For hole G (10\% void), the frequency was only slightly lower than that for solid concrete; but for holes with $20 \%$ and $30 \%$ void, it was as low as $9.277 \mathrm{kHz}$. The empty hole $\mathrm{C}$ showed the lowest peak frequency as the travel time of the wave increases significantly to go around the hole. Also, for the holes in two surfaces along $\mathrm{C}$, the frequency spectrum showed only one peak amplitude instead of two because the frequency corresponding to the depth of nearest hole was beyond the instrument range. Moreover, for holes with small defect sizes, the frequencies obtained did not indicate actual condition. It was summarized that the dominant frequency decreased with the increase in void in the grout. The defect depth could not be calculated because the shift in the frequency were almost equal for both surfaces but the test was useful to indicate relative level of defects in grouted lap-splice connections.
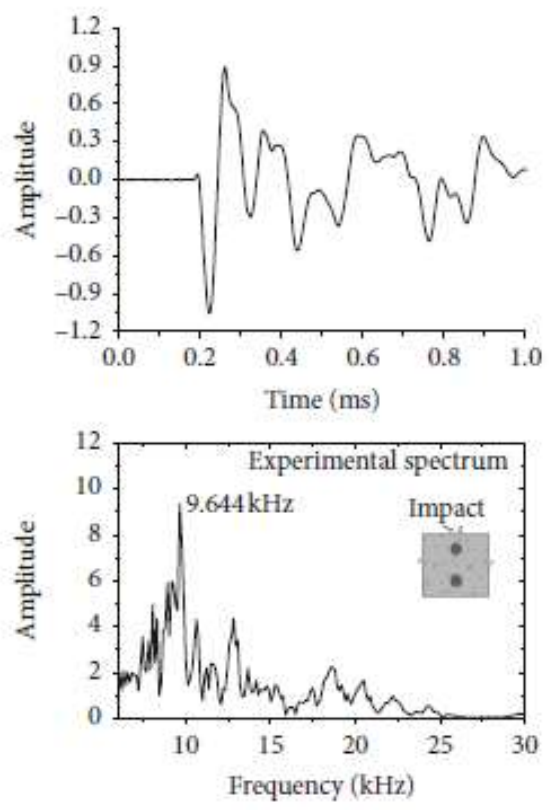

(a)
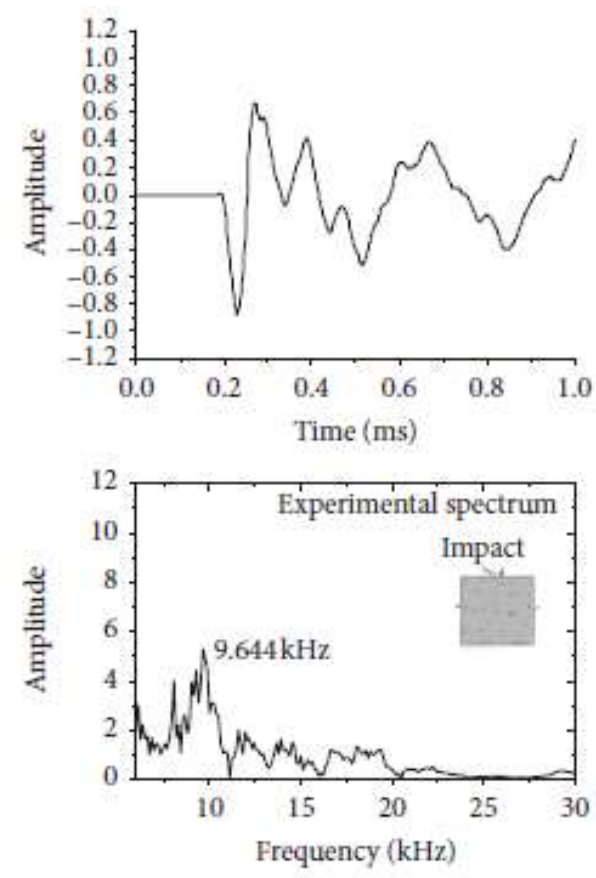

(b)

Figure 2.21: The waveform and frequency for (a) section with hole A; (b) solid concrete (Liu et al. 2019). 


\section{Finite Element Analysis}

Finite Element Analysis was performed using ABAQUS to simulate and validate the IE tests. The defect levels in the model were defined as shown in Figure 2.20 (d). The wave velocity was used as $3960 \mathrm{~m} / \mathrm{s}$ and the element size was set to $5 \mathrm{~mm}$. The results were obtained as shown in Table 2.5 with maximum error between the experimental and analytical frequencies of $2.83 \%$. In addition, simulations were run to investigate the effect of an empty hole depth on the frequency responses. In total, five depths $(50,75,100,125$ and $150 \mathrm{~mm})$ were used in the study. Figure 2.22 shows that the peak frequency based on the reflection holes initially decreased with increase in depth till mid-section of the specimen. Beyond that point, frequency increased with increasing depth, creating a symmetrical pattern. On the other hand, the amplitude of the peak frequency decreased continuously with increasing hole depth throughout the section. This observation made it easier to find the void location more accurately.

Table 2.5: Comparison of finite element analysis and IE test results (Liu et al. 2019).

\begin{tabular}{lcccc}
\hline Conditions & Defect ratio $(\%)$ & FE analysis frequency value $(\mathrm{kHz})$ & Experimental frequency value $(\mathrm{kHz})$ & Error $(\%)$ \\
\hline Hole A and B & 0 & 9.497 & 9.644 & 1.52 \\
Hole D & 10 & 9.497 & 9.644 & 1.52 \\
Hole E & 20 & 9.330 & 9.277 & 0.57 \\
Hole F & 30 & 9.330 & 9.277 & 0.57 \\
Hole G & 10 & 9.497 & 9.644 & 1.52 \\
Hole H & 20 & 9.330 & 9.277 & 0.57 \\
Hole I & 30 & 9.163 & 8.911 & 2.83 \\
Hole C & 100 & 8.997 & 8.911 & 0.97 \\
\hline
\end{tabular}

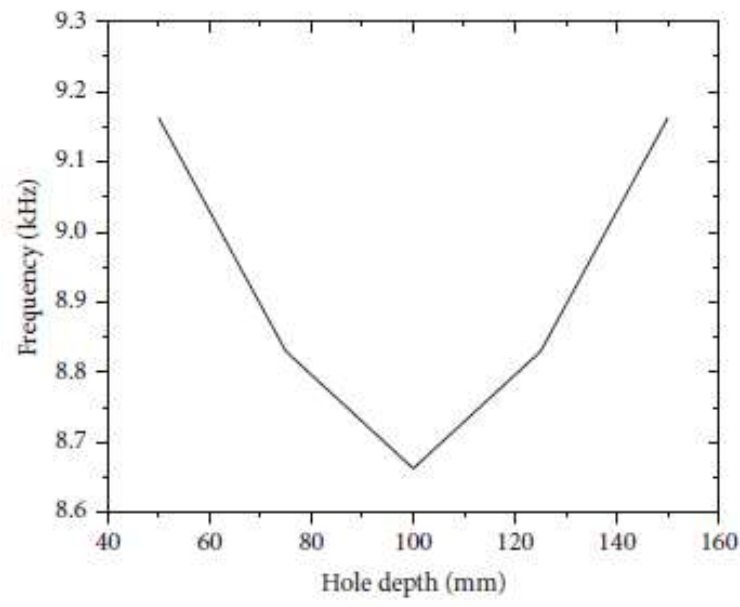

(a)

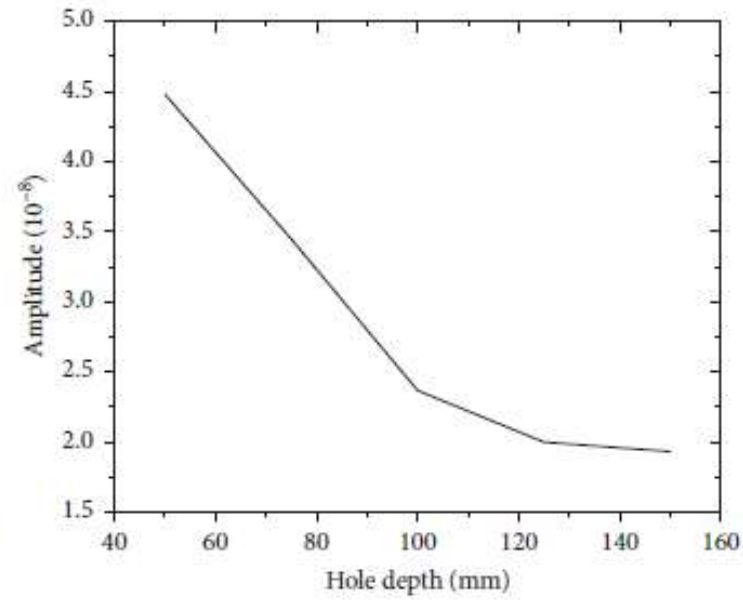

(b)

Figure 2.22: Relationships between (a) frequency and hole depth (b) amplitude and hole depth (Liu et al. 2019). 


\section{Conclusion}

The observations made in this study reasoned IE as a potential method for qualitative detecting defects in grouted lap-splice connections. The presence and degree of defects were found to be depicted by a shift in the peak frequency to a lower value compared to that of a sound concrete. However, the results showed that the frequency shift cannot be used to detect the fully grouted tendons and to determine the depth of the defect. A further study about the calibration on the obtained signal amplitude was recommended for more accurate results using the frequency spectrum. Alternatively, extending the method from frequency-domain to time-domain analysis using IE scanners to obtain echo hyperbola, in the time-domain B-scans or C-scans, to find the location of the grouted ducts was proven reliable. Also, SAFT images is capable to display exact locations of tendons with this approach. Hence, determining the grouting condition of a duct was found to be difficult and unreliable in the field (Schubert and Kohler 2008).

\subsubsection{AUTOMATED AIR-COUPLED IMPACT-ECHO TESTING OF A CONCRETE BRIDGE DECK FROM A CONTINUOUSLY MOVING PLATFORM (Guthrie et al. 2019) \\ Introduction}

The primary objective of this study was to develop an automated air-coupled IE testing device in order to map the delamination in a concrete bridge deck. Combining manual point wise IE data and generating an electronic delamination map can take a very long time. There have been various studies on automated impact system to enhance the data collection speed. Nonetheless, the results obtained were not very accurate due to the need for good mechanical coupling between the accelerometers and the surface of the test members that may not always be possible in the field. This study introduced a device comprising of a continuously moving cart with a fast and repeatable mechanism and algorithms for the collection and analysis of acoustic data.

\section{$\underline{\text { Experimental Tests }}$}

The device included an impactor, a moving cart, a microphone for air-coupled sensing, a distance measuring instrument (DMI) and a signal processing system, as shown in Figure 2.23. A percussion mallet actuated using a motor was used as an impactor in the test. The impactor was mounted within a moving cart and attached to the motor. The motor would rotate the cam shaft 
and generate consistent impacts repeatedly, independent of the speed of the cart. The system was able to achieve a high impact rate of four impacts per second. The cart was constructed with wooden panels and foam lining to insulate the impactor and avoid noise in the data processing. The other partitioned side of the cart consisted of a microelectrical-mechanical system Dodotronic ultrasonic microphone (Ultramic250k) with an effective frequency range of up to $125 \mathrm{kHz}$, used to record the acoustic response of the bridge deck after the impact. The microphone was suspended from the cart top, keeping the height of its diaphragm about $50 \mathrm{~mm}$ above the test surface. The cart was equipped with pneumatic tires to be pushed by an operator for a quiet, stable scan of a bridge deck surface to automatically generate impacts and record the acoustic responses. A buzzer was placed to signal the start and end of a given pass to interpret the microphone data easily. The cart also included a DMI recording the distance travelled automatically using the rotation encoder. The microphone measurements and signal processing were done using a laptop. The signal processing was automated using a series of algorithms in MATLAB. The acoustic responses were shown in the form of waveforms (amplitude ranging from -1 to 1) and spectrograms (computed using a Discrete Fourier Transform). The device was used to conduct a field demonstration on a $434 \mathrm{~m}$ long and $8.7 \mathrm{~m}$ wide concrete bridge deck with 11 spans in northern Utah. The deck was divided into 15 sections with a grid of $3 \mathrm{~m}$ and $1.2 \mathrm{~m}$ spacing in longitudinal and transverse direction respectively. The results obtained were compared with chain dragging and $100 \mathrm{~mm}$ diameter concrete coring.
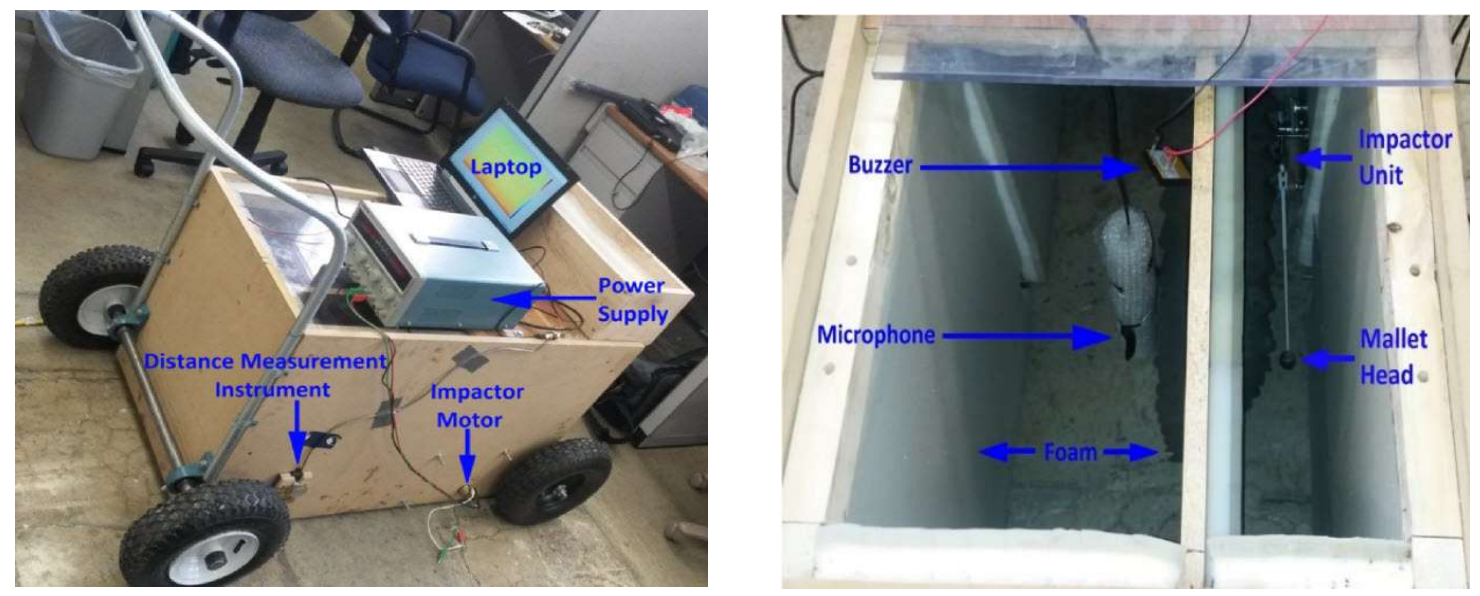

Figure 2.23: Air-coupled IE device (Guthrie et al. 2019). 


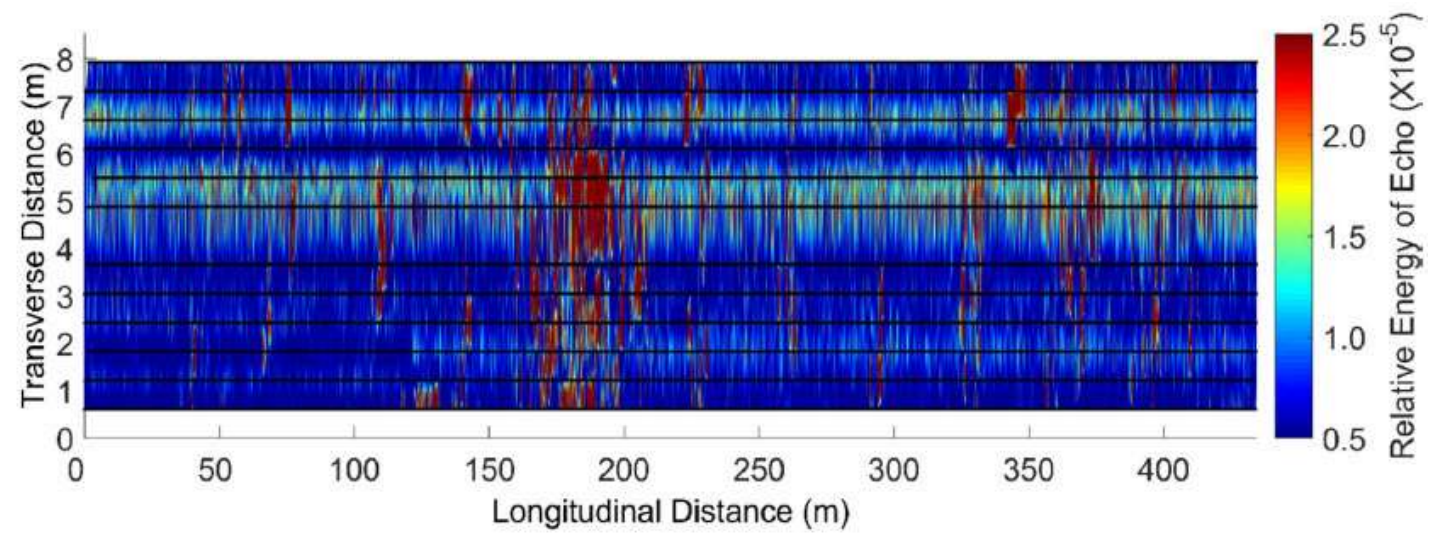

(a)

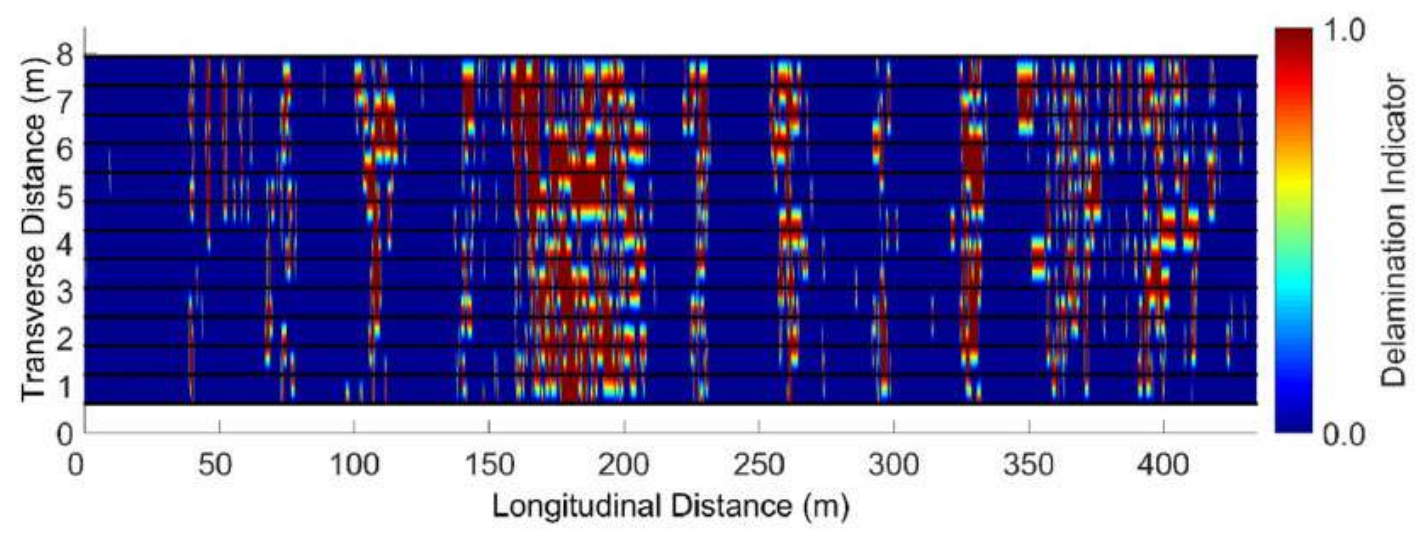

(b)

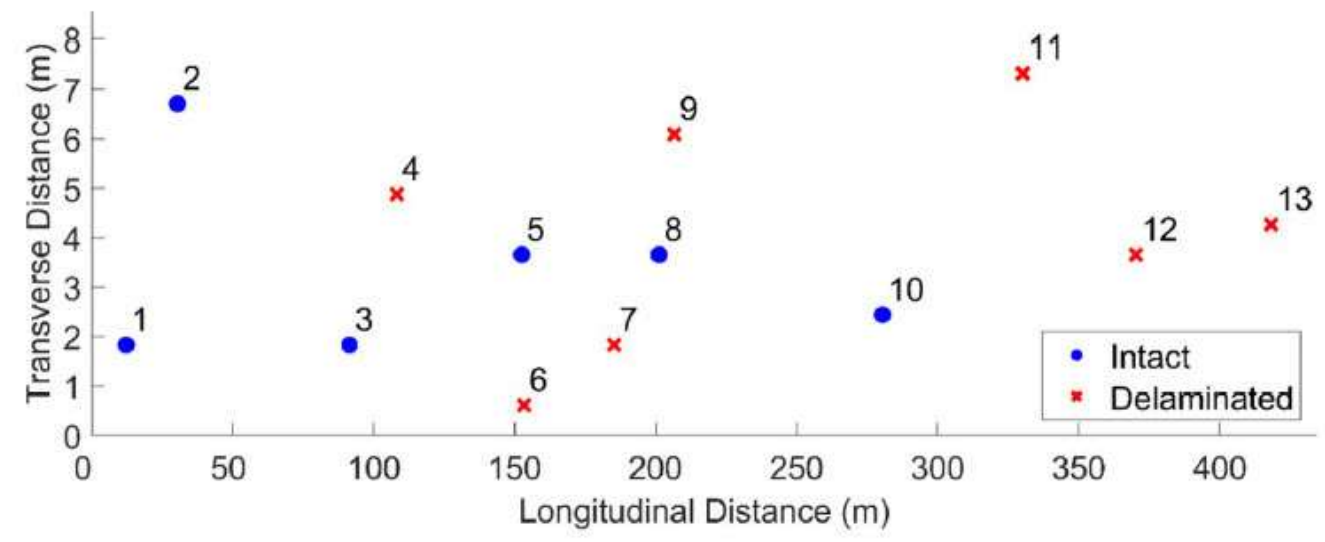

(c)

Figure 2.24: Bridge deck condition map using (a) air-coupled IE device; (b) chain dragging; (c) coring (Guthrie et al. 2019). 


\section{$\underline{\text { Results }}$}

The testing of the entire deck was finished in 4 man-hours using the new device, whereas it took more than 30 man-hours to complete chain dragging. Hence, it was deduced that the new device was more than seven times faster than chain dragging. The air-coupled IE test gave waveforms and spectrograms for intact and delaminated concrete, which were converted into a relative energy of echo vs. distance plot. The increasing value of the relative energy of echo, in Figure 2.24a, indicated the increasing possibility of delamination. Values of 0 to 1 , in Figure 2.24b, indicated the absence and presence of delamination respectively. The maps showed greater similarities for IE and chain dragging results, with a higher degree of delamination over 170 to $200 \mathrm{~m}$ of the deck. The results from both techniques were consistent for 10 out of 13 cored deck sections as shown in Figures 2.24b and 2.24c. The three inconsistencies at the depth of about 30 $\mathrm{mm}$ (two) and $110 \mathrm{~mm}$ below the deck surface were justified as the result of stress induced during coring and the depth being out of the theoretical detectable range of the new device. To differentiate intact and delaminated areas using the relative energy of echo values, a detection threshold of $1.415 \times 10^{-5}$ for the new device was established by comparing with the chain dragging results (within 3\%), giving the same average delamination of $15 \%$ for both techniques. The test sections showed the delamination ranging from 7 to $21 \%$ demonstrating the use of the new device for various amounts of delamination.

\section{$\underline{\text { Conclusion }}$}

The automated technique using an air-coupled IE testing device was inferred to give greater accuracy, speed, and coverage and provide the ability to generate bridge deck delamination maps for appropriate maintenance and rehabilitation strategies. Future work could be focused on development of a multi-channel system to enhance the speed and to test varieties of impactor units to improve the scope of this technique for deeper defect detection.

\subsection{CONCLUSION}

IE method has proved to be a cost-effective and reliable technique for the thickness measurement and qualitative as well as quantitative assessment of various types of defects in different structural members as discussed above. The major advantages of the technique are that it needs only one surface to be accessible for testing and it does not require coupling material. Recent 
advances like air-coupled sensors, automated systems, and volume visualization techniques have made IE testing more efficient. Nonetheless, there are some limitations to the application of the IE technique: the use is limited to the parallel surfaces and members with thickness up to $1 \mathrm{~m}$ (ASTM C1383-15) (with the exception from sonic-echo test); 5-15\% error in thickness measurement (Baggens and Ryden 2014); complications in the case of circular or irregular members and thick and rubbery coatings on test members; and requires specialized expertise. Most of the new and even some old facts have not been well established in the domain of IE technique, requiring revaluation of various associated parameters. Hence, there is still a need for further research to improve the performance of the available systems that can address the limitations of the technique and derive more accurate results in a shorter time. 


\section{ULTRASONIC TESTING TECHNIQUES}

\subsection{INTRODUCTION}

Ultrasonic Testing (UT) is a technique based on elastic-waves that are induced by the vibration in materials. Ultrasound for NDT in Civil Engineering was first introduced 81 years ago (Meyer and Bock 1939, Schickert and Krause 2010). There have been significant advances in the technical performance of the UT technique over the past two decades, from handheld to automated testing equipment. Today, it is one of the most widely used methods for the testing of concrete, metal, wood, ceramic, rocks, composite materials, and their structural members.

The basic principle of this method includes a high-frequency sound wave (greater than 20 $\mathrm{kHz}$ ) propagating through the member under observation, which is detected and analyzed for the information about the inner condition. Figure 3.1 represents a typical UT system that comprises two functional units: pulse generator-amplifier-data acquisition-display unit, and transducers. High voltage electric pulses from a pulse generator vibrate the crystals within the transmitting transducer generating short ultrasonic pulses. The pulses, when interacting with discontinuities (such as defects and voids) and boundaries of the member, may partly reflect and partly transmit depending on the acoustic impedance of the media. Receiving transducer detects and transforms the pulses into an electrical signal, which is amplified, digitized, and displayed in the data acquisition-display unit.

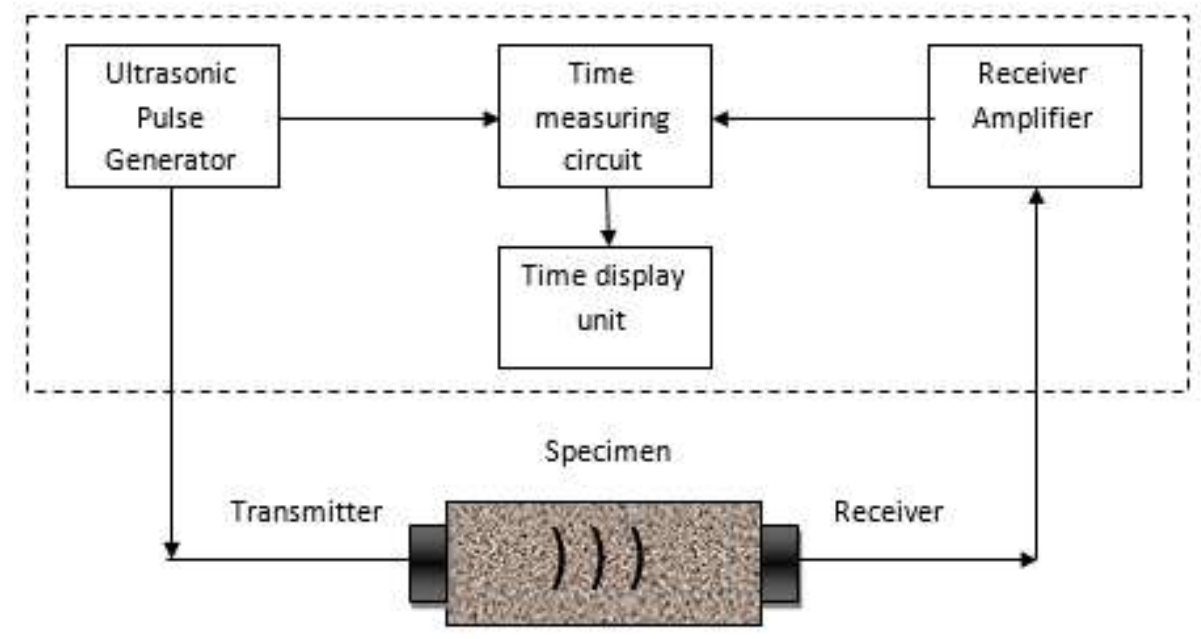

Figure 3.1: Schematic diagram of the ultrasonic wave velocity testing method (Bilgehan and Turgut 2010). 
The selection of frequency in the UT technique is mainly dependent on the material property and the goal of testing, aiming towards minimization of wave scattering and higher sensitivity and resolution. The ability to detect the smallest defect possible is called sensitivity whereas the ability to separate and locate individual flaws is called resolution. A general rule of thumb says the smallest detectable size is about one half the wavelength of the wave (Lipa et al. 2018). This implies that high-frequency waves, with its narrower beam, would be able to detect smaller defects. However, signal attenuation also increases with frequency. Hence, there must be a balance between the sensitivity and the level of signal energy or penetration depth (Senalik et al. 2014). The typical frequency range employed in steel is $500 \mathrm{kHz}$ to $50 \mathrm{MHz}$ (Halabe et al. 1995), whereas it is $20 \mathrm{kHz}$ to $500 \mathrm{kHz}$ in timber (Kasal et al. 2010). In concrete, because of high attenuation, frequency range from $20-150 \mathrm{kHz}$ is more suitable (Bungey et al. 2006). The possible choices of optimal frequency for concrete members depending on path length and minimum transverse dimension are tabulated in Ndagi et al. 2019.

Ultrasonic waves can propagate as longitudinal/pressure waves (P-waves), shear waves (Swaves), Rayleigh waves (R-waves), and plate waves (Lamb waves and Love waves). Among these, P-waves and S-waves, together referred to as bulk waves that travel through the material in the direction of propagation, are most widely used in UT and is considered ideal for anisotropic materials (Gao et al. 2014). Various research have shown advantages of S-waves over P-waves owing to the reduced wavelength (60\% of P-wave at a given frequency (Olympus 2020)), and the reduced amount of backscattering and signal attenuation due to the propagation direction of the wave (Haza et al. 2013). On the other hand, R-waves and plate waves are types of guided waves that travel along the surface of the test member within the depth of one wavelength approximately, or at the interface between two materials or a plate member parallel to its boundary surface. These waves are suitable to detect and characterize defects on or near the surface for plates and pipe structures. Guided waves do not disperse and therefore can travel for several meters in the test member providing a continuous line of inspection (Sadler and Maev 2007). Hence, guided waves yield remarkable potential for time and cost savings and can accurately detect small defects at very low frequencies. It is important to note that there are other types of guided waves such as Lamb waves and Stoneley waves whose wave velocities are dependent on the frequency. 
The analysis of the results from the UT technique is based on two parameters: time-domain velocity and frequency domain attenuation of amplitude/energy of the waveform acquired. These parameters are sensitive and attributed to the characteristics of the member material as well as defects along the propagation path. With the measured transit time, the velocity of the wave can be determined over a known path and compared with reference velocities. The higher the velocity better is the quality of the test member. Lower velocity indicates the presence of defects or nonuniformity. For sound concrete, the reference longitudinal and shear wave velocity ranges from 3500 to $4500 \mathrm{~m} / \mathrm{s}$ and 1800 to $2500 \mathrm{~m} / \mathrm{s}$ respectively (Lee and Oh 2016). For sound wood, the reference longitudinal and shear wave velocity ranges from 3,500 to $5,000 \mathrm{~m} / \mathrm{s}$, and 1,000 to 1,500 $\mathrm{m} / \mathrm{s}$ respectively (Dackermann et al. 2014). Attenuation of the sound waves is a factor describing the decrease in wave intensity or pressure, from the effects of scattering and absorption. It can be calculated using the equation: $\left(\mathrm{A}_{1} / \mathrm{A}_{2}\right)=\left(\mathrm{x}_{1} / \mathrm{x}_{2}\right)^{\beta} \mathrm{e}^{\alpha(\mathrm{x} 1-\mathrm{x} 2)}$, where, $\mathrm{A}_{1}$ and $\mathrm{A}_{2}$ are the amplitudes at distances $\mathrm{x}_{1}$ and $\mathrm{x}_{2}, \beta$ is the geometric attenuation constant and $\alpha$ is the spatial coefficient of attenuation (Roblero 2017). Amplitude attenuation is considered more sensitive than velocity measurement. For instance, the difference in velocity for a thin crack is not as significant as the amplitude attenuation due to a change in impedance (Berubé 2008). Measurement, on the other hand, is more difficult for attenuation than velocity, as the amplitude is affected by clamping force on transducers and the contact area between transducer and material. However, combining both provides more information than using each alone, increasing the sensitivity of the technique to defects (Halabe and Franklin 1999).

The most important aspect of UT is the generation and detection of ultrasonic pulses, which is achieved most commonly by using electromechanical transducers (piezoelectric/electrostrictive). Available in a wide variety of frequencies (up to $200 \mathrm{MHz}$ ), sizes and bandwidths, these transducers convert the electrical energy to ultrasonic pulses and vice-versa (Olympus 2020). The distance of $600 \mathrm{~mm}$ between the transmitting and receiving transducers was found to be the best in indirect measurements in timber (Teder et al. 2011), even though it is possible up to $5 \mathrm{~m}$ in concrete (Niederleithinger 2018). Conventionally, transducers were attached to the test surface using couplants to increase pulse transmission and receiving efficiency. Commonly used couplants were water, grease, petroleum jelly, glycerin gels, cellophane sheets, starch glucose, silicone rubber, etc. (Senalik et al. 2014). This practice is time-consuming and has 
a possibility of test surface corruption following a wrong choice. As a better alternative, springloaded dry point contact (DPC) transducer was developed by Acoustic Control Systems, capable of transmitting low frequency ( $30 \mathrm{kHz}$ to $150 \mathrm{kHz}$ ) elastic waves that can travel greater distance without the need of a couplant (Khazanovich and Hoegh 2016). Another subjective factor that needed accounting for was the pressure applied. The transmission power increases with the increase in pressure up to a certain point after which it starts diminishing (Senalik et al. 2014). To overcome this uncertainty, non-contact transducers such as air-coupled transducers were developed as a viable option that continue to be explored for various materials (Vossing et al. 2020, Rus et al. 2019). These transducers utilize only P-waves as it is the only wave that can travel through the air. Certain transducers can be embedded in concrete as well for permanent monitoring of the member (Wolf et al. 2014).

An important headway in the technique was the application of wedges (steel, plastic, ceramic, composites) between the transducers and the test surface. One major advantage of using such a setup is the ability to generate and detect all types of sound waves by simply changing the critical angle, without separate probes for each wave. For plastic wedge with carbon steel inspection, the critical angle of $27.2^{\circ}$ results in P-wave refracted on the surface. Angles below $27.2^{\circ}$ would transmit the P-way into the material. Wedge angles between $27.2^{\circ}$ to $55.8^{\circ}$ generates S-wave (USNRC 2020). At the critical angle of $55.8^{\circ}$ the S-wave gets refracted on the surface. Similarly, the angle of $66.95^{\circ}$ using the Lucite wedge would generate R-wave into the aluminum surface (Schmerr et al. 2016). These wedges can be made with single or multiple materials, the latter can be designed to accommodate sound dampening, durability, improving SNR, and wear resistance. Larger the element size, higher is the area coverage with lesser inspection time and vice-versa. However, the reflected echo amplitude from smaller discontinuities will decrease. Smaller the element size, there will be an increase in the reflection amplitude from small discontinuities but the inspection time will be longer as the coverage area is less (Olympus 2020). Contoured wedges have been used for the testing of small diameter curved surface elements. Similarly, point probes with the diameter as small as $1 \mathrm{~mm}$ have been used to test prefabricated element joints or irregular elements (Stawiski and Kania 2019). Recent developments for convenience include a single unit transducer and wedge assembly and manually rotatable dual element probe that is useful for pitch-catch inspection in a small area while detecting near-surface 
defects. In all cases, transducers should be calibrated for the specific material being tested to ensure precision.

Based on the position and some advanced features of transducers used, UT techniques can be categorized as shown in Figure 3.2 and Table 3.1.

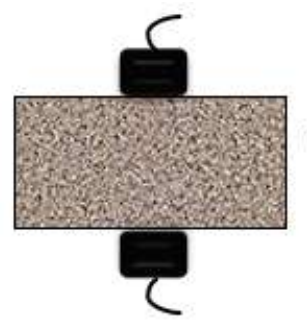

(a)

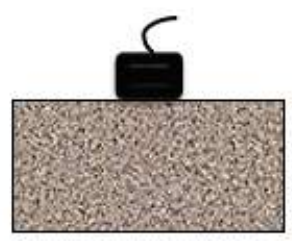

(d)

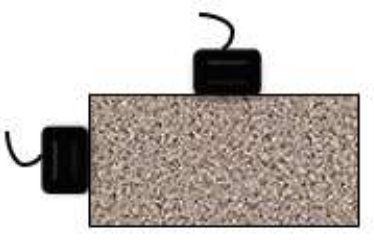

(b)

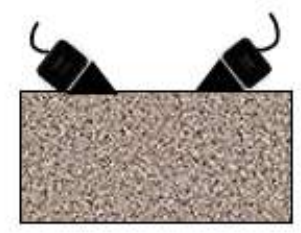

(e)

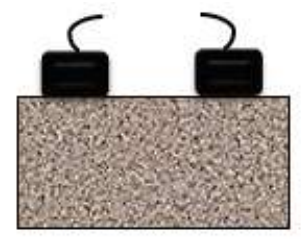

(c)

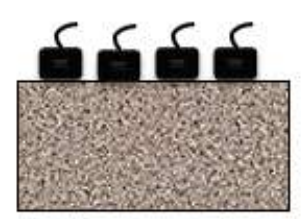

(f)

Figure 3.2: (a) Direct transmission, (b) Semi-direct transmission, (c) Indirect transmission, (d) Ultrasonic pulseecho, (e) Angled beam assembly, (f) Ultrasonic array.

Table 3.1: Different Ultrasonic Methods and their principles, applications, advantages, and limitations.

\begin{tabular}{|c|c|c|c|}
\hline Method & $\begin{array}{c}\text { Principle / } \\
\text { Configuration }\end{array}$ & Advantages / Applications & Limitations \\
\hline $\begin{array}{l}\text { Ultrasonic } \\
\text { Pulse } \\
\text { Velocity / } \\
\text { Through / } \\
\text { Direct } \\
\text { Transmission }\end{array}$ & $\begin{array}{l}\text { The time of travel } \\
\text { and/or attenuation of } \\
\text { ultrasonic pulses over } \\
\text { a known distance is } \\
\text { observed, with two } \\
\text { transducers placed on } \\
\text { the opposite sides of } \\
\text { the test member. }\end{array}$ & $\begin{array}{l}\text { - Fastest and accurate time readings } \\
\text { (with errors below 1\%) (Bucur } \\
2006 \text { ). } \\
\text { - Less attenuation of energy/ high } \\
\text { noise immunity (Bolotina et al. } \\
\text { 2019). } \\
\text { - No dead zone (Bolotina et al. 2019). } \\
\text { - Simple interpretation. } \\
\text { - Check the uniformity and relative } \\
\text { quality of the test material, indicate } \\
\text { the presence of defects (voids, } \\
\text { cracks), and the effectiveness of } \\
\text { defect repairs (ACI 228.2R-13). }\end{array}$ & $\begin{array}{l}\text { - Needs access to both sides of } \\
\text { the test members. } \\
\text { - The test surfaces must be } \\
\text { parallel. } \\
\text { - It does not provide information } \\
\text { related to the defect nature and } \\
\text { depth (ACI 228.2R-13). } \\
\text { - Not reliable to compute } \\
\text { strength or modulus of } \\
\text { elasticity (Kocab et al. 2019). } \\
\text { - Does not detect defects } \\
\text { parallel to the wave direction. }\end{array}$ \\
\hline
\end{tabular}




\begin{tabular}{|c|c|c|c|}
\hline $\begin{array}{l}\text { Semi-direct } \\
\text { Transmission }\end{array}$ & $\begin{array}{l}\text { The time of travel } \\
\text { and/or attenuation of } \\
\text { ultrasonic pulses over } \\
\text { a known distance is } \\
\text { observed, with the } \\
\text { transmitting and } \\
\text { receiving transducers } \\
\text { placed on the adjacent } \\
\text { edges. }\end{array}$ & $\begin{array}{l}\text { - More sensitive than indirect } \\
\text { transmission (Bungey et al. 2006). } \\
\text { - Doesn't need access to both sides of } \\
\text { the member. }\end{array}$ & $\begin{array}{l}\text { - Less sensitive than direct } \\
\text { transmission (Bungey et al. } \\
\text { 2006). } \\
\text { It could be used only if the } \\
\text { angle between transducers and } \\
\text { the path length are not too } \\
\text { large (Bungey et al. 2006). }\end{array}$ \\
\hline $\begin{array}{l}\text { Indirect } \\
\text { Transmission }\end{array}$ & $\begin{array}{l}\text { Time of travel and/or } \\
\text { attenuation of the } \\
\text { reflected wave (by } \\
\text { discontinuities or } \\
\text { member backwall) is } \\
\text { observed with the } \\
\text { transmitting and } \\
\text { receiving transducers } \\
\text { placed on the same } \\
\text { side of the test } \\
\text { member at a certain } \\
\text { distance. }\end{array}$ & $\begin{array}{l}\text { - Needs access to only one side of the } \\
\text { member. } \\
\text { - Simple interpretation. } \\
\text { - The localization of defects is } \\
\text { possible. }\end{array}$ & $\begin{array}{l}\text { - Signal amplitude is } 3 \% \text { less } \\
\text { than direct transmission } \\
\text { (Bungey et al. 2006). } \\
\text { - The path length is not certain } \\
\text { (Bungey et al. 2006). } \\
\text { - Risk of interference by surface } \\
\text { waves. } \\
\text { - Less sensitive than direct and } \\
\text { semi-direct transmissions } \\
\text { (Bungey et al. 2006). }\end{array}$ \\
\hline $\begin{array}{l}\text { Ultrasonic } \\
\text { Pulse Echo }\end{array}$ & $\begin{array}{l}\text { Wave signals are } \\
\text { measured from a } \\
\text { single transducer that } \\
\text { transmits and receives } \\
\text { the reflected ultrasonic } \\
\text { waves by } \\
\text { discontinuities or the } \\
\text { test member backwall. }\end{array}$ & $\begin{array}{l}\text { - Needs access to only one side of the } \\
\text { member. } \\
\text { - Simple setup. } \\
\text { - High sensitivity resulting from the } \\
\text { use of a high-frequency wave } \\
\text { (Bolotina et al. 2019). } \\
\text { - Member thickness can be measured. } \\
\text { - Lateral position, depth, size, and } \\
\text { shape of an internal defect, such as } \\
\text { cracks, voids, delamination, } \\
\text { honeycombing, knots, can be } \\
\text { measured (Bolotina et al. 2019). } \\
\text { - Construction of A-scan, B-scan, C- } \\
\text { scan, and 3-D tomographic images } \\
\text { using S-wave point transducers and } \\
\text { SAFT (Synthetic Aperture Focusing } \\
\text { Technique) (ACI 228.2R-13). }\end{array}$ & $\begin{array}{l}\text { - Applicable to limited member } \\
\text { thickness and is not very } \\
\text { reliable in highly attenuating } \\
\text { materials (ACI 228.2R-13). } \\
\text { - Information sometimes can be } \\
\text { complex due to the presence of } \\
\text { reinforcements in the wave } \\
\text { path. } \\
\text { - Dead zone for few centimeters } \\
\text { with lower frequency waves } \\
\text { (Sharma et al. 2011). } \\
\text { - Defects positioned other than } \\
\text { perpendicular to the direction } \\
\text { of wave propagation may be } \\
\text { difficult to detect. } \\
\text { - Transducer ringing (residual } \\
\text { oscillation) may affect the } \\
\text { signal received (Subodh et al. } \\
\text { 2015). } \\
\text { - Needs an experienced operator } \\
\text { (ACI 228.2R-13). }\end{array}$ \\
\hline $\begin{array}{l}\text { Angled Beam } \\
\text { Assembly }\end{array}$ & $\begin{array}{l}\text { Wave signals are } \\
\text { measured from the } \\
\text { setup of single or dual } \\
\text { transducers, where one } \\
\text { or both are slightly } \\
\text { inclined with a critical } \\
\text { angle offset from the }\end{array}$ & $\begin{array}{l}\text { - Locate defects perpendicular or in a } \\
\text { tilted position with respect to the } \\
\text { test surface. } \\
\text { - The wave can travel longer } \\
\text { distances than direct transmission } \\
\text { (Senalik et al. 2014). }\end{array}$ & $\begin{array}{l}\text { - A slight inclination may give } \\
\text { high resolution but the dead } \\
\text { zone may be significant. } \\
\text { - An experienced operator is } \\
\text { needed. }\end{array}$ \\
\hline
\end{tabular}




\begin{tabular}{|c|c|c|c|}
\hline & $\begin{array}{l}\text { normal pulse direction } \\
\text { using wedges. }\end{array}$ & $\begin{array}{l}\text { The assembly can be a cheaper } \\
\text { alternative to generate P-waves, S- } \\
\text { waves, or R-waves. }\end{array}$ & \\
\hline $\begin{array}{l}\text { Ultrasonic } \\
\text { Sequential } \\
\text { Array } \\
\text { Method }\end{array}$ & $\begin{array}{l}\text { Wave signals } \\
\text { measured from a } \\
\text { patterned arrangement } \\
\text { of various elements } \\
\text { within the transducers } \\
\text { (linear/curved/annular) } \\
\text { that sequentially } \\
\text { produce rectangular, } \\
\text { trapezoidal, or cone- } \\
\text { shaped beam. }\end{array}$ & $\begin{array}{l}\text { - A single setup can take various } \\
\text { measurements. } \\
\text { - Higher lateral resolution is possible } \\
\text { with a higher number of elements. } \\
\text { - Produce 3D real-time videos of the } \\
\text { inner condition of the test member } \\
\text { using tomographic techniques } \\
\text { (Chapagain et al. 2018). } \\
\text { - High speed (1000 mm/sec) } \\
\text { (Chapagain et al. 2018). }\end{array}$ & $\begin{array}{l}\text { - Expensive than conventional } \\
\text { transducers. }\end{array}$ \\
\hline $\begin{array}{l}\text { Phased Array } \\
\text { Method }\end{array}$ & $\begin{array}{l}\text { Multiple } \\
\text { independently } \\
\text { controlled transmitting } \\
\text { and receiving channels } \\
\text { are arranged in linear, } \\
\text { matrix, circular, or } \\
\text { sector pattern. These } \\
\text { send and receive } \\
\text { desired beam signals } \\
\text { using sequential } \\
\text { electronic delay, } \\
\text { which are summed and } \\
\text { digitized to generate } \\
\text { an A-scan signal } \\
\text { (Maes 2018, Bolotina } \\
\text { et al. 2019). }\end{array}$ & $\begin{array}{l}\text { - Tomographic imaging enabling real- } \\
\text { time analysis of discontinuities } \\
\text { (Bolotina et. al 2019). } \\
\text { - High speed (up to } 50 \mathrm{~mm} / \mathrm{sec} \text { in a } \\
\text { welded joint) (Bolotina et. al 2019). } \\
\text { - Accurate defect detection, } \\
\text { localization, and classification } \\
\text { through software control of beam } \\
\text { characteristics (beam steering and } \\
\text { focusing) (Maes 2018). } \\
\text { - Focusing algorithms such as Total } \\
\text { Focusing Method (TFM) and } \\
\text { Sectorial Focusing Technique (SFT) } \\
\text { can be used for live interpretation } \\
\text { with idealized focusing (Maes } \\
\text { 2018). } \\
\text { - Flexible and reliable inspection } \\
\text { using different transducers patterns } \\
\text { from a single setup. } \\
\text { - Inspection of geometrically complex } \\
\text { members. } \\
\text { Easy and direct interpretation of } \\
\text { images. }\end{array}$ & $\begin{array}{l}\text { - Not possible to recover A-scan } \\
\text { of individual signal (Maes } \\
\text { 2018). } \\
\text { - Lower lateral resolution with } \\
\text { beam steering, but can be } \\
\text { improved with beam focusing } \\
\text { (Maes 2018). } \\
\text { - Expensive equipment. }\end{array}$ \\
\hline
\end{tabular}

UT waves and the velocity in concrete is sensitive to and is affected significantly by temperature, moisture, cement type, aggregate type, shape and size (Niederleithinger 2018), watercement ratio and concrete age (Lawson et al. 2011); distance between transducers, positioning and contact of the transducers with respect to the test member, path length (Ndagi et al 2019, Gupta and Jaiswal 2019); and steel reinforcement (Bungey et al. 2006, Fodil et al. 2019). In the case of 
wood, the velocity is affected by factors such as species, specific gravity, the direction of the grain, moisture content, mechanical properties (Sharma and Shukla 2012, Dackermann et al. 2014).

UT technique is useful for determining the material properties (such as dynamic modulus of elasticity, compressive strength); accessing deterioration; detecting, localizing, and characterizing surface as well as subsurface defects in new or existing materials and structural members. It has been successfully applied to measure the concrete pavement thickness with an error of $5 \mathrm{~mm}$ (Salles et al. 2017); detect delamination, cracks and debonding of asphalt overlay in a concrete bridge deck as part of its rehabilitation using ultrasonic surface waves (Li et al. 2016); assess fire-damaged concrete building in site and in lab (Aseem et al. 2019); check the healing of the member crack after grouting (Kaur et al. 2018), locate ducts and reinforcement in concrete structures with an accuracy of $\pm 1 \mathrm{~cm}$ (Vonk and Taffe 2018); detect voids in the metallic ducts of a post-tensioned bridge beam (Forde 2013); measure the concrete strength (Bogas et al. 2013, AlNu'man et al. 2015), test compressive strength of concrete with sulphate corrosion (Genovés et al. 2017, Stawiski and Kania 2019), check the frost resistance of concrete subjected to freeze/thaw cycle (Molero et al. 2012), real-time monitoring of the corrosion and damage degree of steel in concrete (Peng 2017); crack detection in steel and aluminum members (Halabe et al. 1999, 2001, 2013b; Franklin and Halabe 2014) and establish relationship between static and dynamic modulus of elasticity in wood (Hassan et al. 2013, Halabe et al. 1997). Similarly, in timber, it has been applied to locate the pith in a tree or structural elements (Perlin et al. 2018); locate knots, checks, decay, cracks and compute dynamic modulus of elasticity (Dackermann et al. 2014); and to locate the biological corrosion in a historical roof truss using semi-direct and indirect UT method (Skowronski and Stawiski 2019).

The most recent research in UT has been in the image generation to characterize defects in isotropic (Nguyen et al. 2017, Haach and Ramirez 2016) and anisotropic materials (Agrawal et al. 2020), the automation of the instruments (Schickert 2012, Chapagain et al. 2018), and nonlinear method for assessing microstructures (Zamen and Niri 2020, Sohn et al. 2019, Kim et al. 2018). 


\subsection{REVIEW OF APPLICATIONS OF ULTRASONIC TECHNIQUES}

\subsubsection{ASSESSMENT OF CONCRETE STRUCTURES USING THE MIRA AND EYECON ULTRASONIC SHEAR WAVE DEVICES AND THE SAFT-C IMAGE RECONSTRUCTION TECHNIQUE (Haza et al. 2013)}

Introduction

This paper described the basic features of commercial ultrasonic instruments: Mira and Eyecon. These instruments produce 2D and 3D tomographic images of the reflected waves to estimate the real-time state of concrete, masonry, stone, and other structures. These systems utilize an array of low frequency, drypoint contact shear wave transducers, and SAFT algorithms to reconstruct images of the reflected waves. Several case studies involving the application of these instruments on different kinds of structures and materials are presented in the paper.

\section{$\underline{\text { Equipment }}$}

\section{Mira Ultrasonic Shear Wave System}

$1^{\text {st }}$ and $2^{\text {nd }}$ generation MIRA systems are fabricated with 40 and 48 shear wave transducers in an array of 10 and 12 rows respectively, as shown in Figure 3.3a. The transducers are equipped with spring-loaded DPC piezoelectric sensors with the center frequency of $50 \mathrm{kHz}$. Since the transducers are built with a ceramic tip, scanning rough and uneven surfaces pose no effect on the data collection. $1^{\text {st }}$ generation MIRA system needs an additional laptop for processing and further

analysis whereas $2^{\text {nd }}$ generation has a single console unit comprising sensors and processing software along with display screens. The data collected is processed using the SAFT C signal processing algorithm and displayed in 2D B-scan instantaneously (3 seconds after collection). The 3D images are generated by combining the signals from all the transmitting and receiving transducers in the array and using proprietary software.

\section{Eyecon Ultrasonic Shear Wave System}

It consists of a handheld control unit connected to an array of 24 shear wave transducers in 4 rows as shown in Figure 3.3b. Transducers in each row are connected electronically causing each row to behave as a single transmitter and a single receiver, requiring access to only one side of the 
test member. The transducers have the same characteristics as Mira with the center frequency of $55 \mathrm{kHz}$.

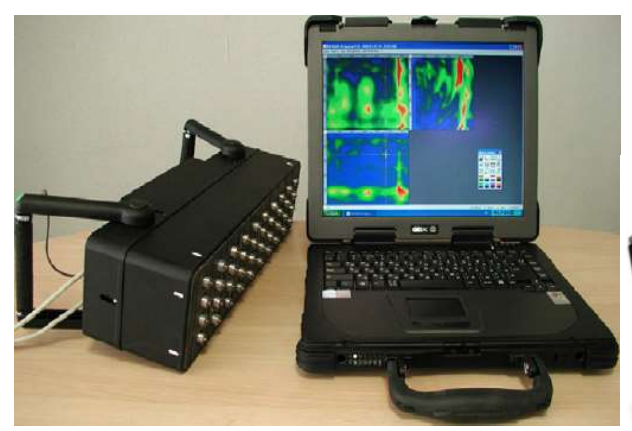

(a)

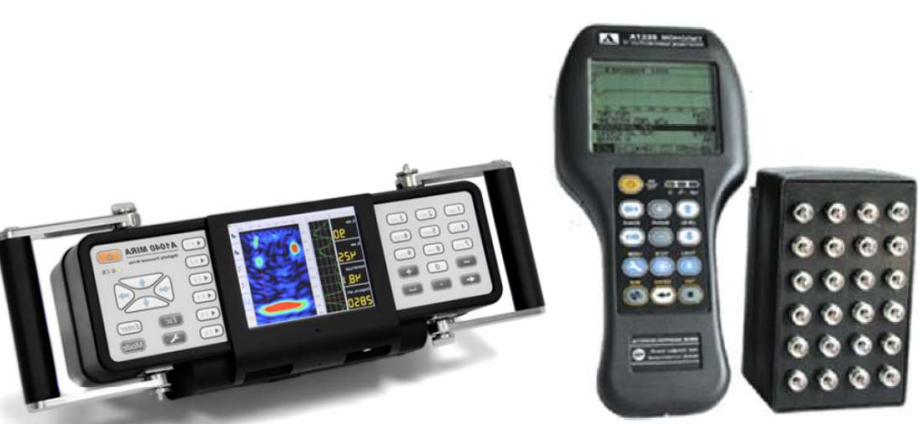

(b)

(c)

Figure 3.3: (a) MIRA equipment ( $\left(1^{\text {st }}\right.$ Generation); (b) MIRA equipment ( $2^{\text {nd }}$ Generation); (c) Eyecon System (Haza et al. 2013).

\section{Case Studies}

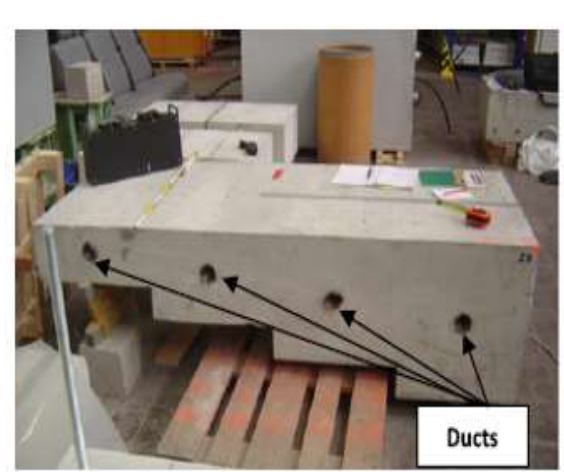

(a)

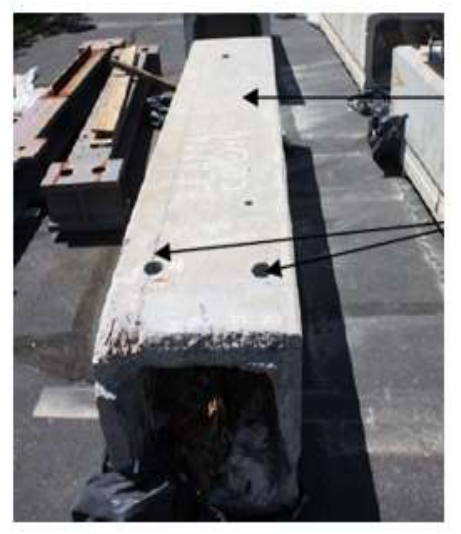

(b)

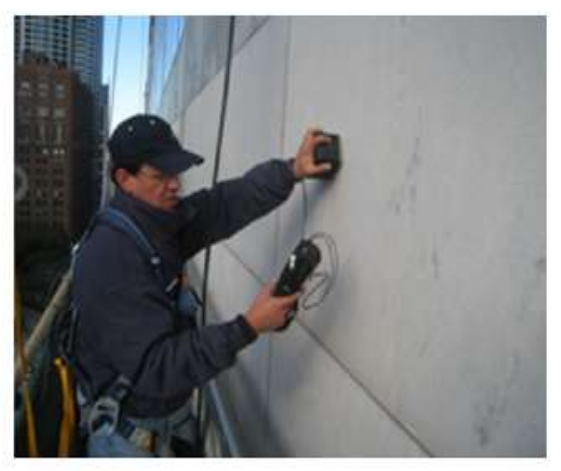

(c)

Figure 3.4: (a) Four-step concrete plate specimen with empty ducts; (b) Prestressed, precast box beam; (c) Eyecon test in progress on marble panel (Haza et al. 2013).

\section{a) Stepped Concrete Plate}

Both Mira and Eyecon systems were used to test two concrete step-plates: a three-step solid plate and a four-step plate containing empty metal ducts as shown in Figure 3.4a. Each plate had the thickness of the first, second, third, and fourth step as $250 \mathrm{~mm}, 350 \mathrm{~mm}, 450 \mathrm{~mm}$ and $550 \mathrm{~mm}$ respectively. The readings were taken along the flat surface at an interval of $50 \mathrm{~mm}$. Figure 3.5 clearly shows the reflections from the empty ducts as well as the backwall of the four-plate 
concrete plate specimen in the form of D-scan obtained using Mira (limiting the depth up to 450 $\mathrm{mm})$.

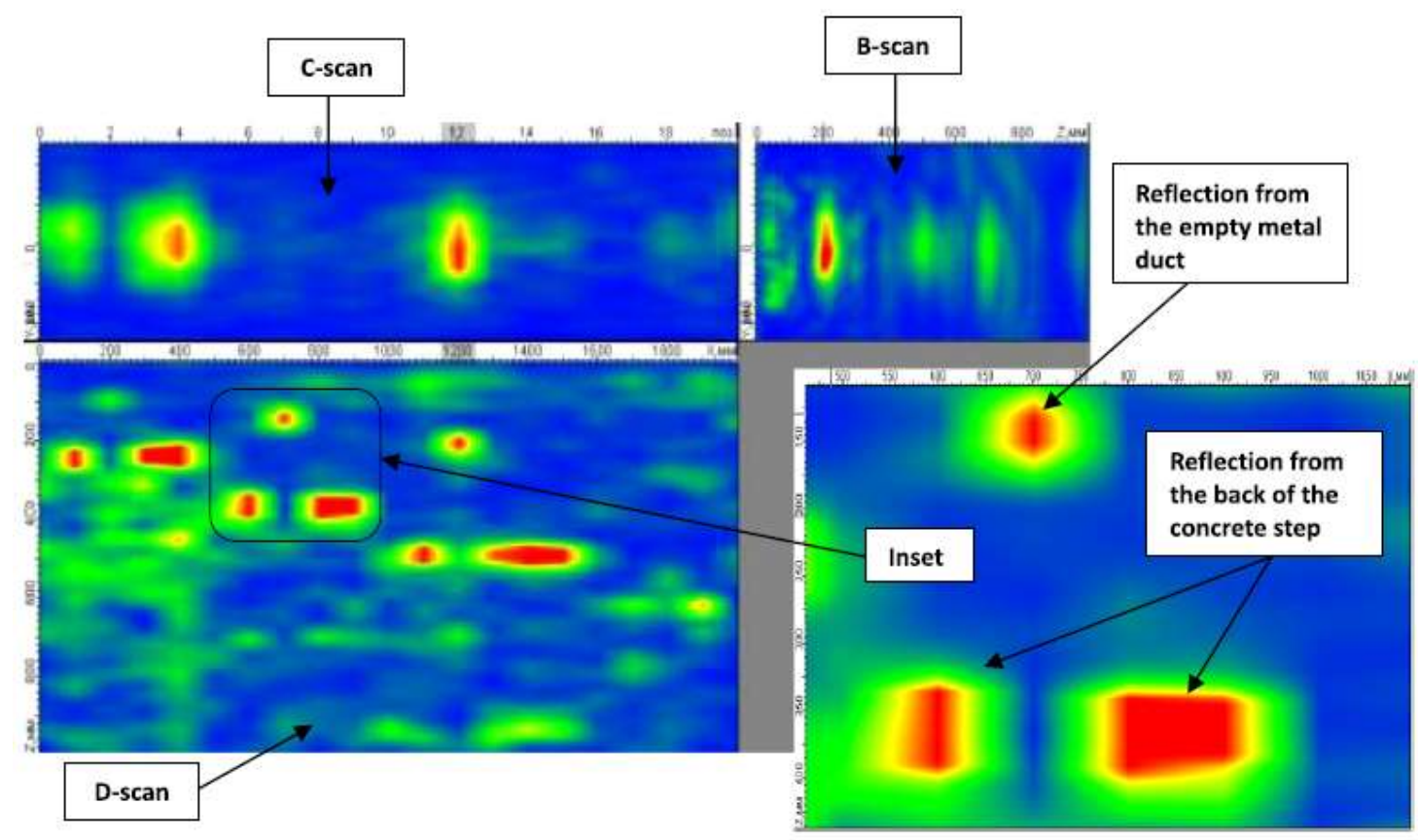

Figure 3.5: Mira results (B, C, and D scans) for the four-step concrete plate (Haza et al. 2013).

\section{b) Foundation Concrete Mat (laboratory)}

The systems were compared by testing a reinforced concrete foundation mat sample. The sample was built with top and bottom layers of reinforcement and two thicknesses of $800 \mathrm{~mm}$ and $1250 \mathrm{~mm}$. Readings were collected on the top surface at an interval of $100 \mathrm{~mm}$. The reflections from the backwall of the mat were observed clearly including a slight reflection from the vertical edge on both sides in the D-scans for both samples as shown in Figure 3.6.

\section{c) Prestressed, precast box-beams (Field)}

Figure $3.4 \mathrm{~b}$ shows one of the three prestressed and precast box-beams removed from the local old bridges following their distress due to the corrosion of prestressing strands. The $1^{\text {st }}$ generation Mira system was used to detect concrete deterioration (delamination, cracks, and spalls) after the corrosion of the strands. The readings were taken along the full length of the soffit at every $100 \mathrm{~mm}$ spacing. Figure 3.7 shows the 3D isosurface (surface representing points of constant values) view, reconstructed from the SAFT C analysis of the data, of one of the beam soffit 
surfaces with potential locations of concrete deterioration as denoted by red bright spots. The results for most areas were found consistent with those from Ground Penetrating Radar (GPR), Impact-Echo (IE) techniques, laser scanning, and Eyecon equipment. Eyecon was also used to observe a visible shear crack in the web of one of the beams and the A-scan obtained showed a promising result.

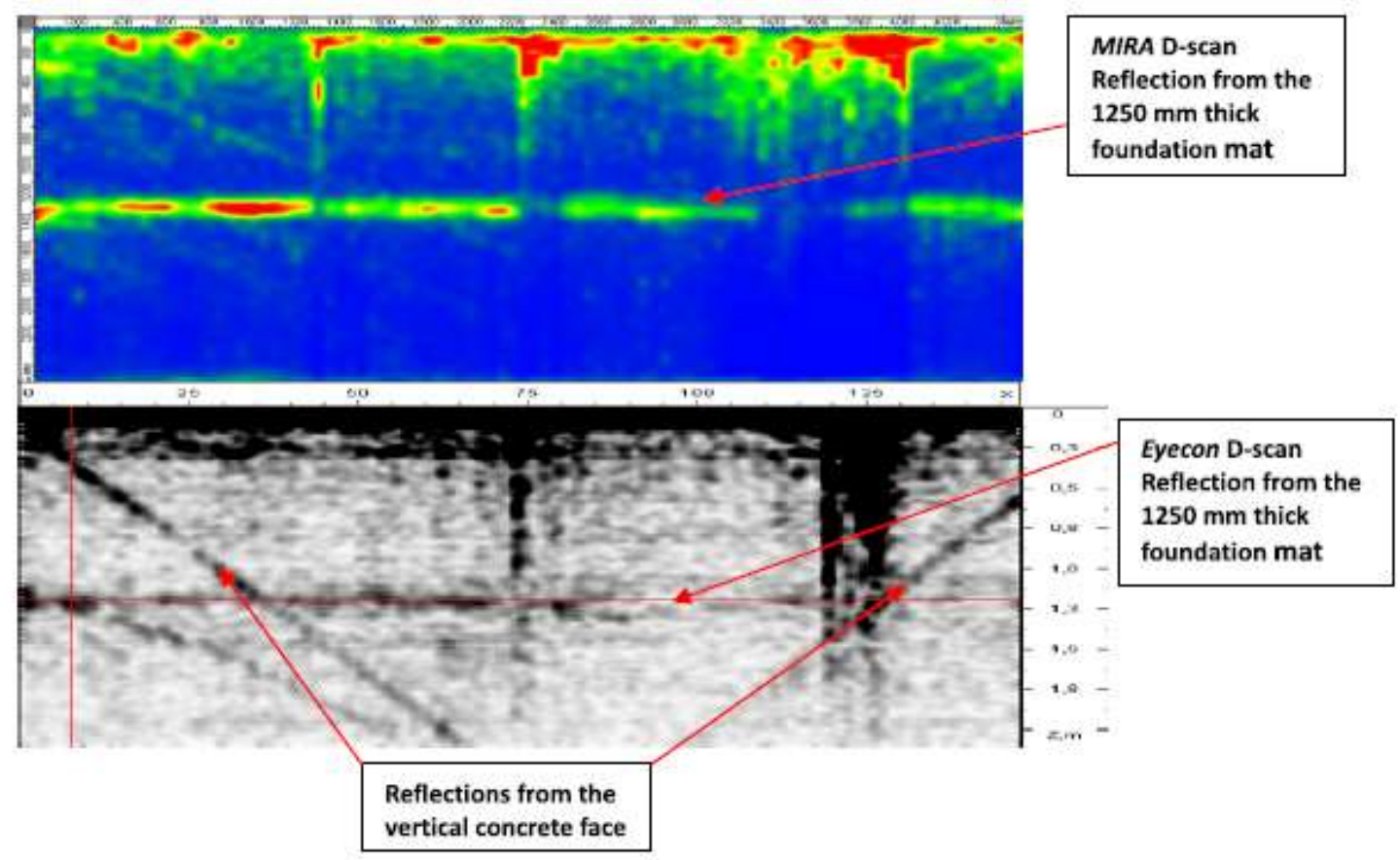

Figure 3.6: Mira (top) vs. Eyecon (bottom) results for $1.25 \mathrm{~m}$ deep concrete foundation mat (Haza et al. 2013).

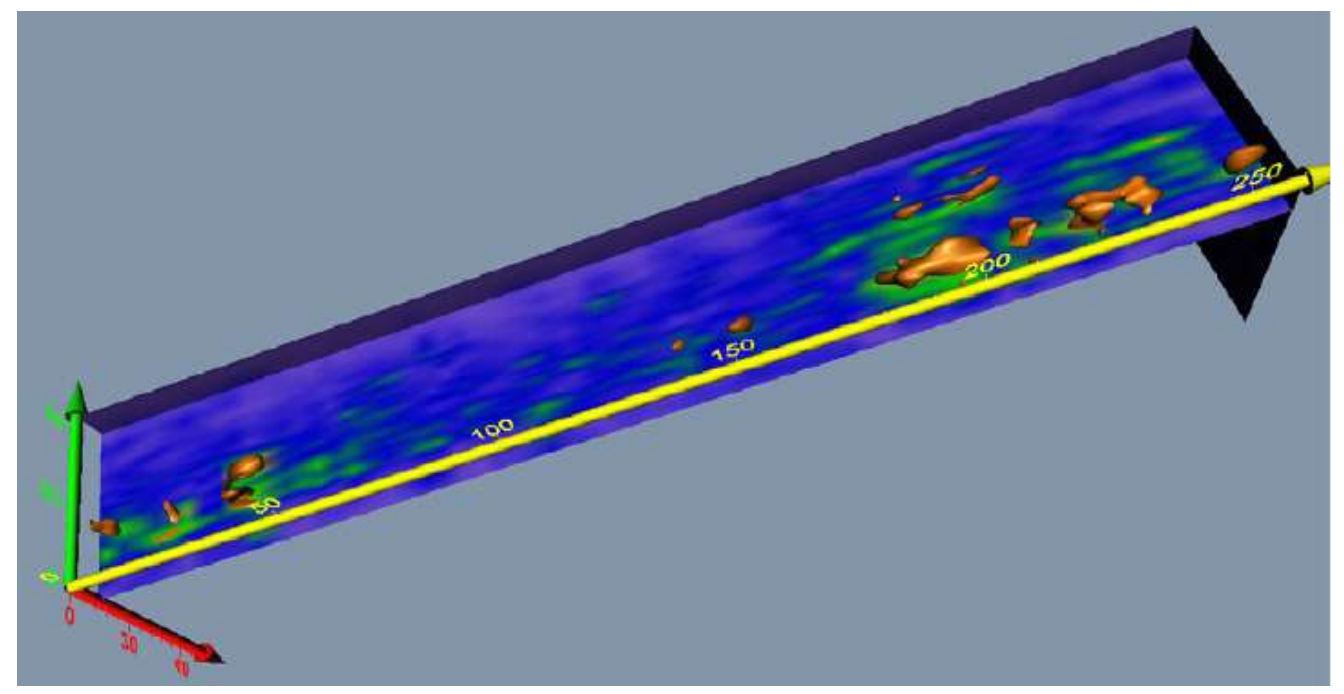

Figure 3.7: 3D isosurface view of Mira test results (Haza et al. 2013). 


\section{d) Stone Façade Testing (Field)}

A $127 \mathrm{~mm}$ thick stone marble façade of a building in Chicago, presented in Figure 3.4c, was assessed using the instruments to detect potential internal delamination due to weathering of the stone or overloading. In Figure 3.8a, full reflection from the delamination can be observed; whereas in Figure 3.8b, multiple reflections and reverberations from the backwall of the panel can be observed from Mira results. Similarly, Eyecon A-scans (Figure 3.9) estimated the depth of delamination $(34.8 \mathrm{~mm})$ and the thickness of the panel $(125.7 \mathrm{~mm})$, almost consistently.

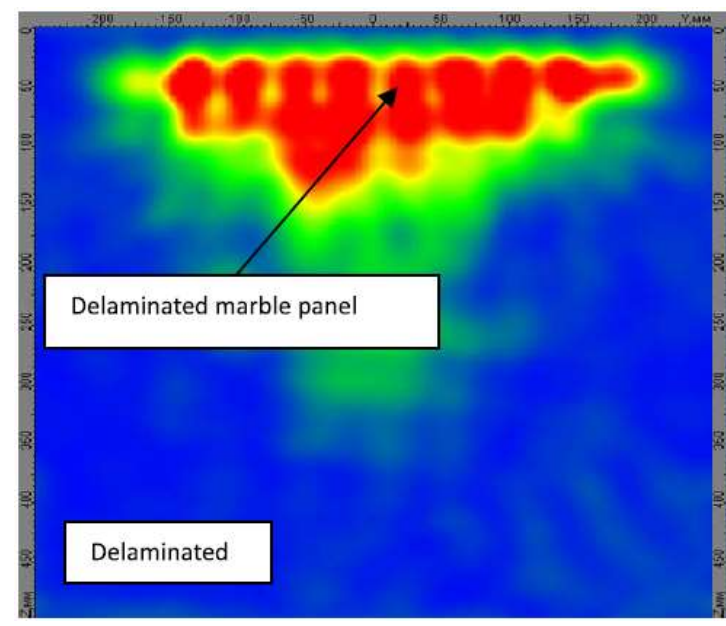

(a)

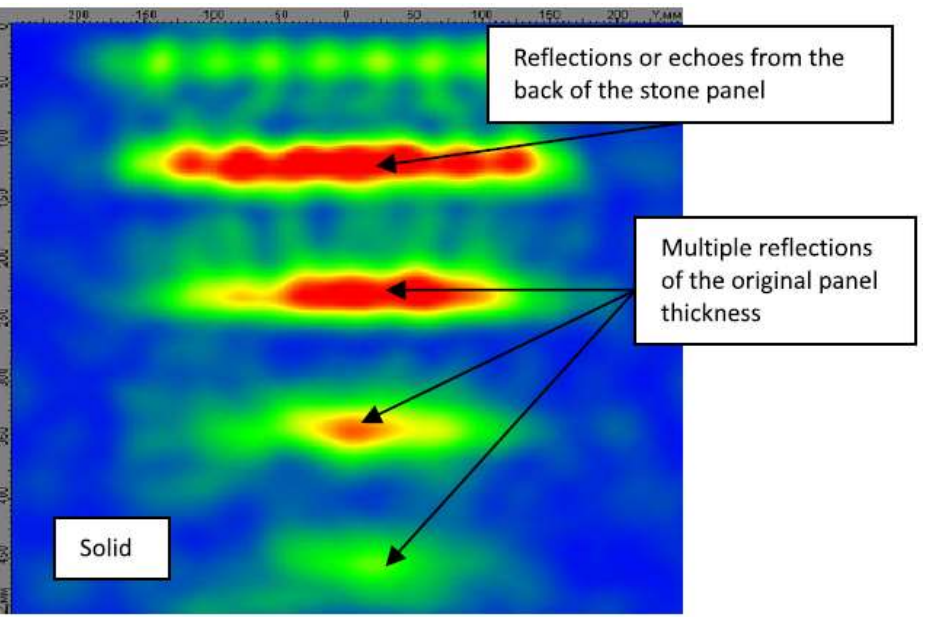

(b)

Figure 3.8: Mira results showing (a) delaminated area; (b) solid area (Haza et al. 2013).
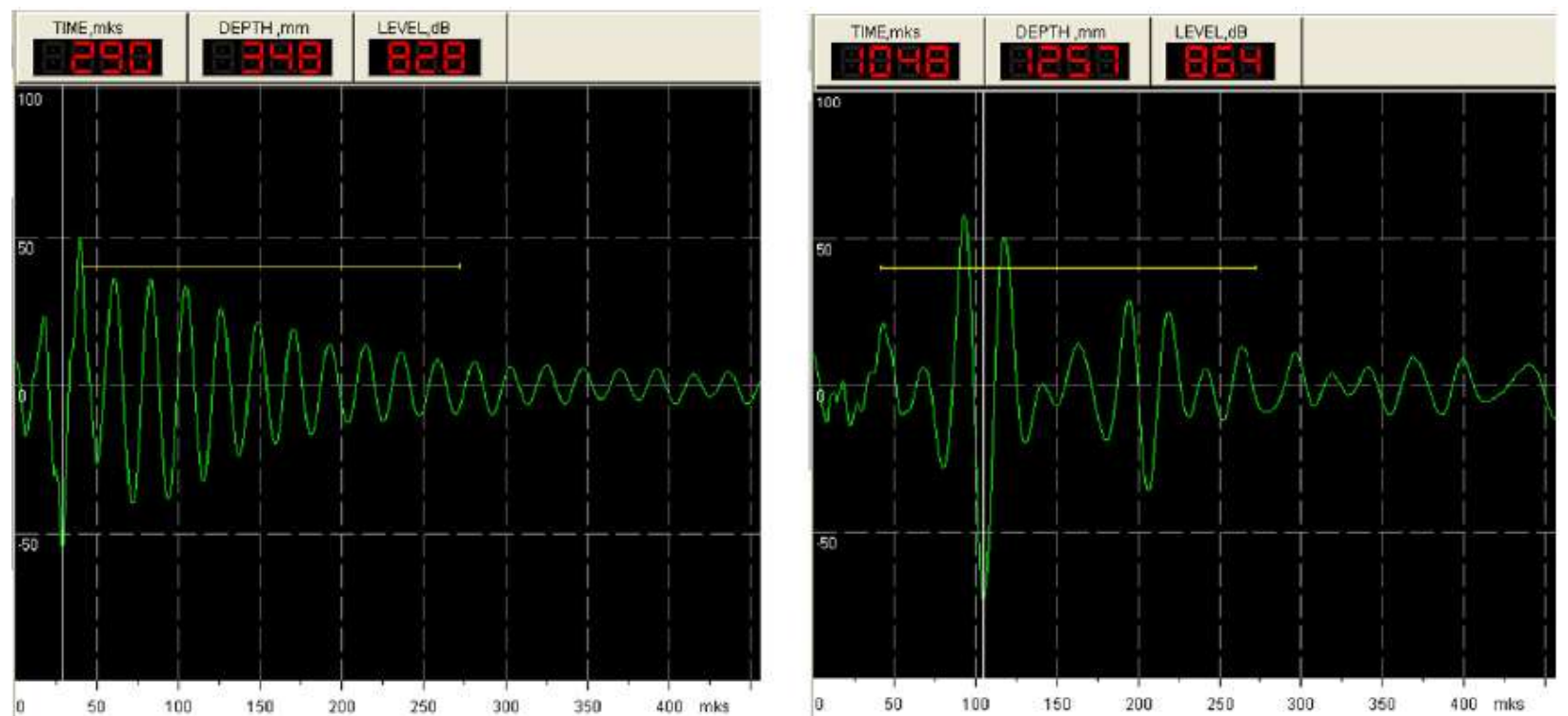

Figure 3.9: Eyecon A-scan showing delaminated depth (left); full panel thickness (right) (Haza et al. 2013). 


\section{e) Concrete Shear Wall (Field)}

After the removal of formwork, aggregate segregation, poor concrete consolidation, and voids were observed in the shear walls of a nine-story high condominium building. Tests were conducted using both Mira and Eyecon in discrete locations where voids were observed and reflections from the voided area were easily detected as shown in Figure 3.10. Both instruments suggested a voided area in the approximate depth of $84.3 \mathrm{~mm}$.
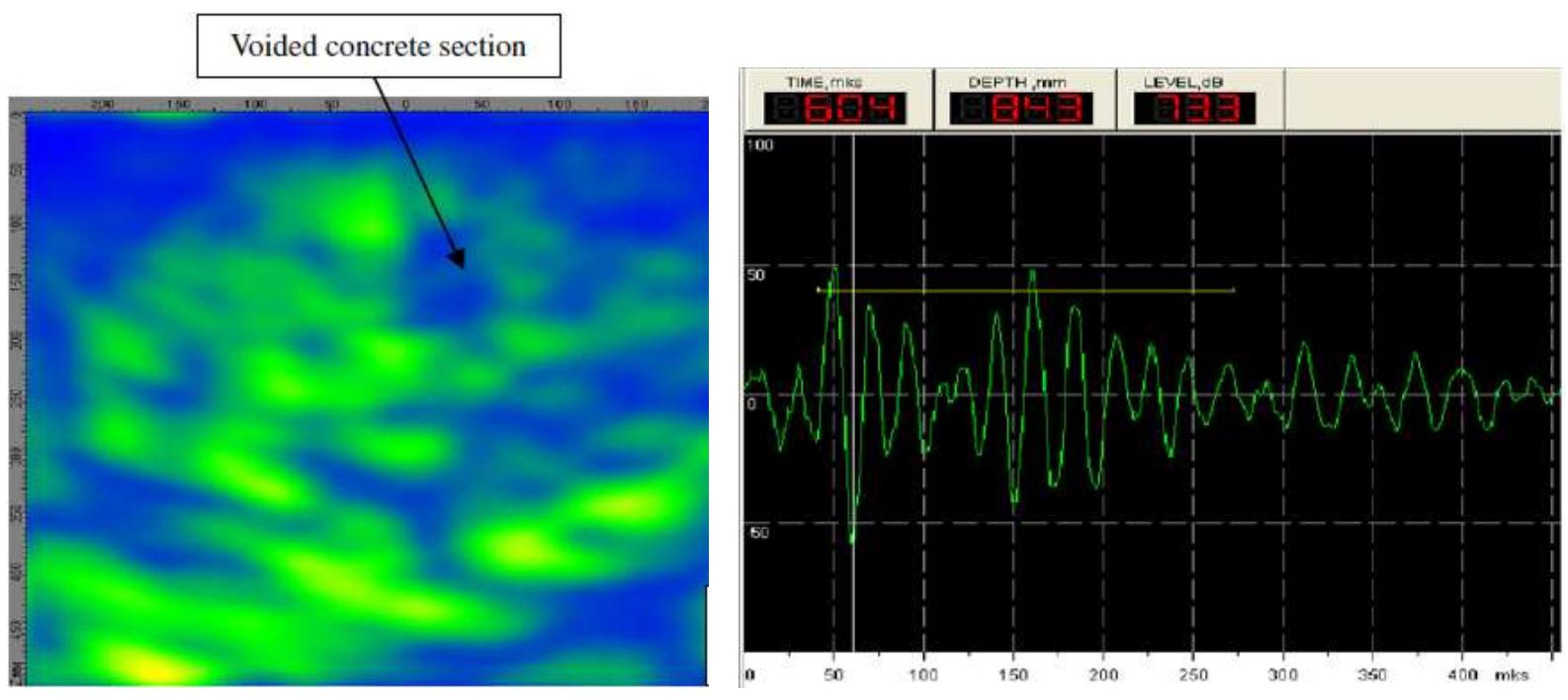

Figure 3.10: Mira delaminated area image (left); Eyecon A-scan showing delaminated depth (right) (Haza et al. 2013).

\section{Conclusion}

Technological advancements have enhanced the capability of techniques to inspect various types of structures with easily interpretable 2D and 3D digital images. Mira and Eyecon exhibited versatile and promising features to locate internal flaws of the test member such as delamination, cracks, voids, honeycombed concrete, and measure the thickness of the material. Case studies showed that the instruments have a minimum penetrable depth of $1.25 \mathrm{~m}$ and the sensitivity of $34.8 \mathrm{~mm}$. Compared to traditional ultrasonic testing methods, these particular instruments using ultrasonic shear waves were found to have the advantages of dry coupling and the sensor design that is unaffected by the surface textures and imperfections requiring very little surface preparation, portability, single-person operation, and fast ( 3 seconds after data collection) and accurate results. 


\subsubsection{DAMAGE DETECTION OF ASPHALT CONCRETE USING PIEZO-ULTRASONIC WAVE TECHNOLOGY (Pan et al. 2019)}

\section{$\underline{\text { Introduction }}$}

Asphalt concrete is widely used in roads and pavements because it delivers seamlessness with highly comfortable driving, ease in repair, and lower noise. Exposure to harsh environmental conditions and traffic loads may lead to rutting, raveling, and cracking causing premature failure. In this aspect, maintenance and repair of pavements by identifying the defects due to environmental and loading conditions in time is very important. This paper presented a laboratory investigation on the feasibility of ultrasonic wave technology for damage detection in asphalt concrete. Relationships between the ultrasonic velocity and various environmental conditions as well as damage progress were established.

\section{$\underline{\text { Experimental Tests }}$}

For laboratory tests, 24 asphalt concrete sample cylinders (diameter and height of 101.6 $\mathrm{mm}$ and $63.5 \mathrm{~mm}$ respectively) were prepared based on Marshall's design, with the gradation of AC-13. The ultrasonic wave velocity test was conducted using a TICO tester with a frequency of $30 \mathrm{kHz}$. Firstly, samples with different voidage were prepared based on different compaction temperature and ultrasonic velocities were measured for each one at the temperature of $15^{\circ} \mathrm{C}$. Voidage was calculated using an X-ray 3D microscope analysis on the scanned images of the samples. Secondly, keeping the voidage at $4.5 \%$, the ultrasonic wave velocities of samples were tested for wet and dry conditions, and 2 cycles of freeze-thaw. Thirdly, the tests were repeated in samples that were defected in two ways: drilling $5 \mathrm{~mm}$ diameter through-hole and grooving with different widths and $15 \mathrm{~mm}$ depths as shown in Figure 3.2 and 3.3. And the ultrasonic wave velocities of pretreated samples were tested again. Furthermore, the relationship between velocity and the damage progress was evaluated based on the three-point bending test.

\section{$\underline{\text { Results }}$}

The ultrasonic velocity decreased with the increase in voidage as shown in Figure 3.11a, as a result of higher dispersion and longer travel time for the P-wave to go around the voids. The ultrasonic velocities attained for voidage of $4.5 \%$ in different environmental conditions were presented in Figure $3.11 \mathrm{~b}$. In saturated water, the measured velocity of the ultrasonic wave 
increased because the voids were filled with water through which the wave travels much faster than air. In dry conditions, the temperature $\left(50^{\circ} \mathrm{C}\right)$ is higher than the softening point of bitumen. This makes the wave travel faster than in air but slower than in water because of viscous resistance. After two freeze-thaw cycles, the voidage increased and the ultrasonic velocity decreased gradually.

For the drilled sample, the transmitter was placed at P0 and receivers at all the other points as shown in Figure 3.12. The ultrasonic wave velocities were found to be equal in symmetric receivers. However, in the case of $\mathrm{P} 3$, the wave had to travel around the discontinuity, taking longer travel time and decreasing the ultrasonic velocity compared to P2. The velocities in different environmental conditions showed a similar trend as shown by samples without the defects. Similarly, for the grooved samples, Figure 3.13 shows that the ultrasonic wave velocity decreases with an increase in the groove width. In the case of the one with two grooves, the wave was highly attenuated after passing through the air in the two grooves causing a higher decrease in the velocity. The velocity only slightly changed when the wave travel direction was parallel to the crack direction. This established that there are some correlations between the ultrasonic velocity and, the crack length, position, and orientation.

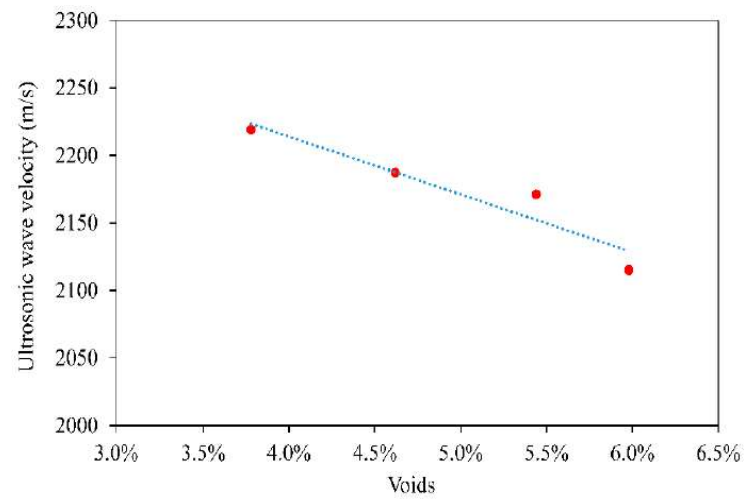

(a)

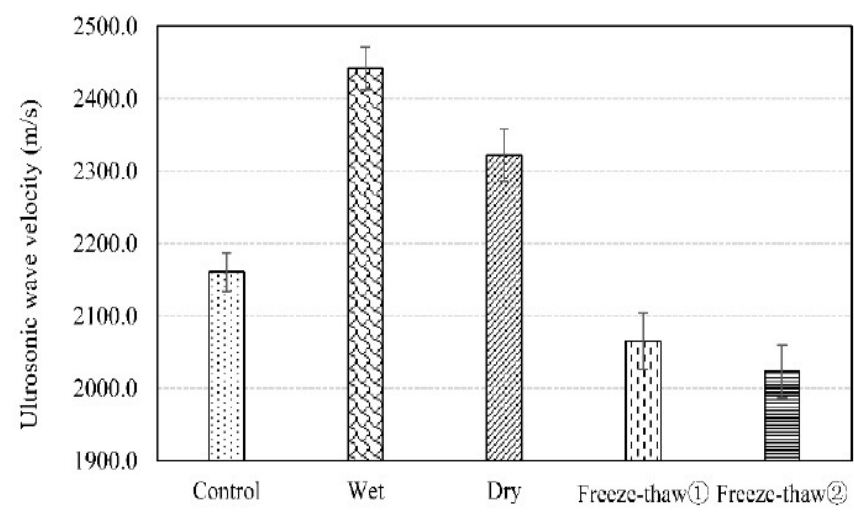

(b)

Figure 3.11: Comparison of ultrasonic velocities of Marshall specimens with different (a) voidage; (b) environmental conditions (Pan et al. 2019). 


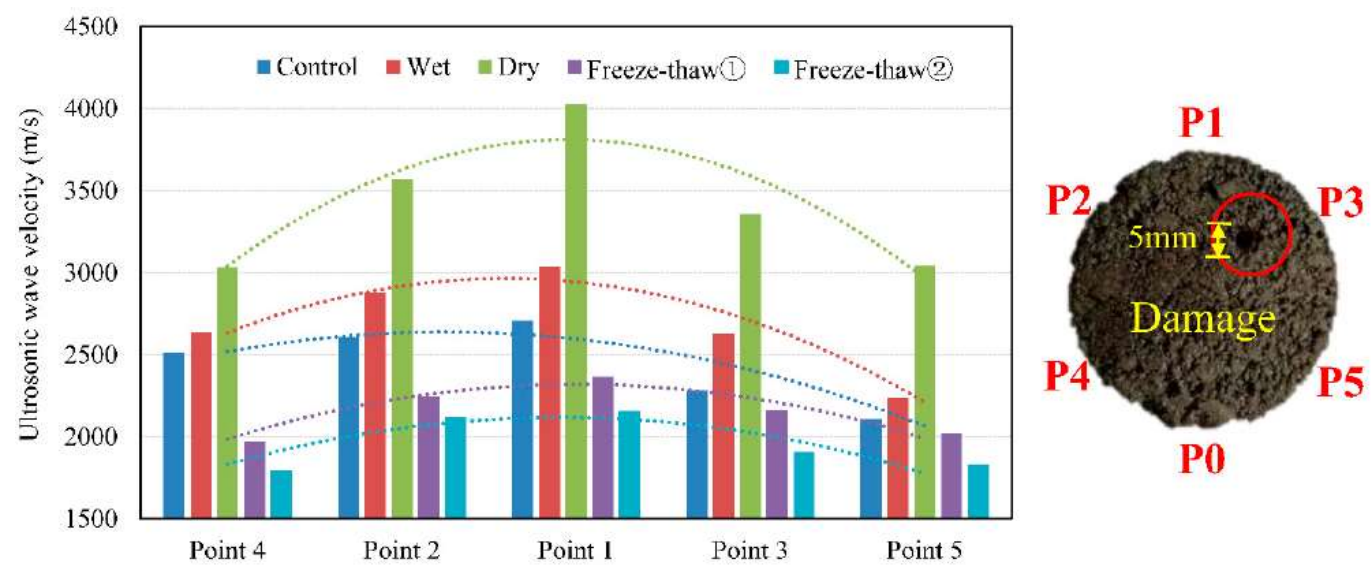

Figure 3.12: Ultrasonic velocity in a defected sample with different environmental conditions (Pan et al. 2019).
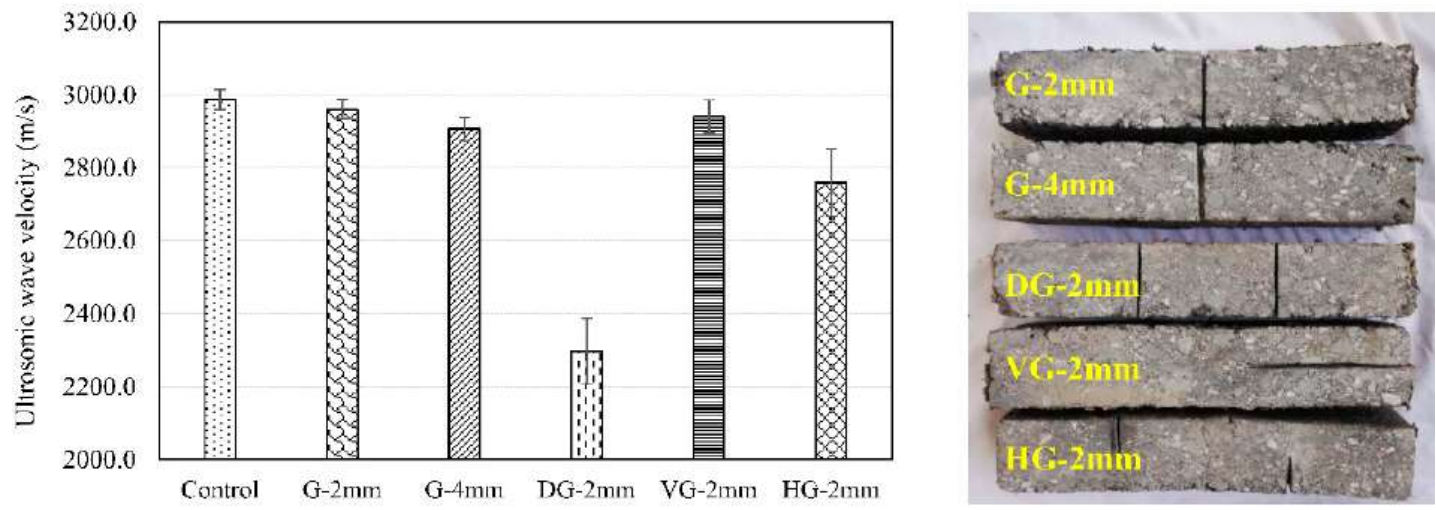

Figure 3.13: Ultrasonic velocity in five types of grooves in the samples (Pan et al. 2019).

A sample was tested under the three-point testing machine to evaluate the ultrasonic velocity relationship with load until failure as shown in Figure 3.14. During loading stage 1, the application of stress initiated the closing of the voids inside, causing ultrasonic velocity to increase initially. Owing to the micro-cracks formation in stage 2, it slowly decreased until it reached a balanced stage 3 (the growth rate of micro-cracks being close to the compaction rate of voids). At last, the velocity of the ultrasonic wave decreased rapidly (damage stage 4), when the cracks grew to the critical stage of penetration. Hence, ultrasonic velocity was deduced to be correlated to the damage progress in asphalt concrete. Thus, comparing the ultrasonic velocities measured, condition and prevalent damages in asphalt concrete can be determined. 


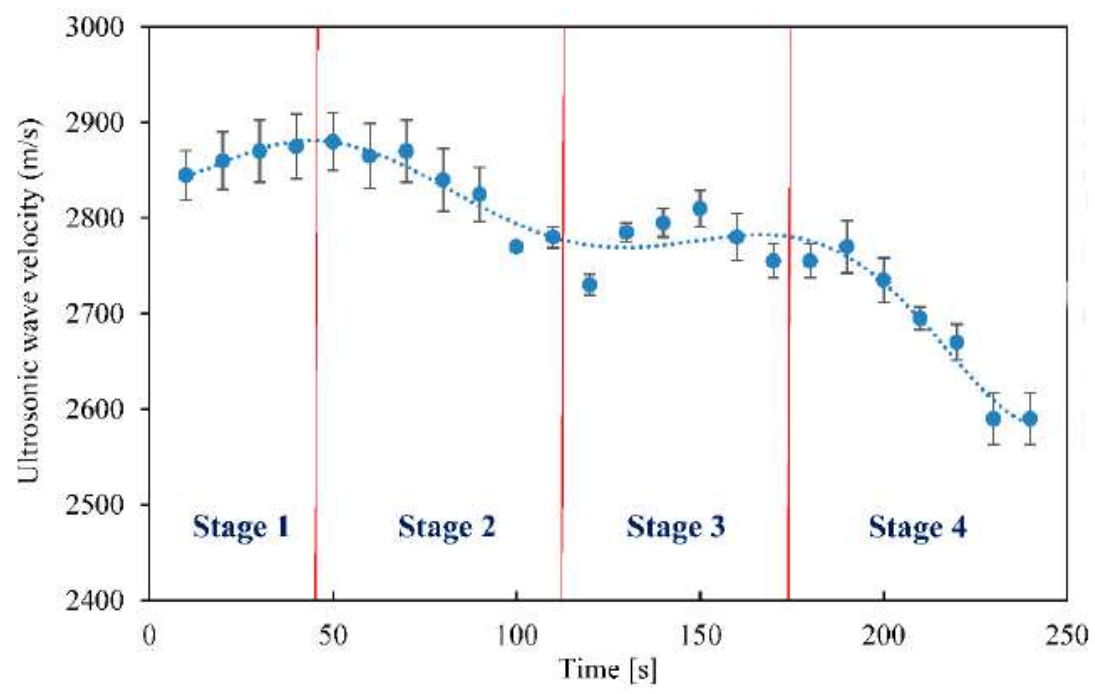

Figure 3.14: Ultrasonic velocity change trend during the entire process of damage (Pan et al. 2019).

\section{$\underline{\text { Conclusion }}$}

The test results indicated that the ultrasonic wave technique is promising for determining conditions and damages in asphalt concrete in various environmental conditions.

\subsubsection{IN SITU ASSESSMENT OF STRUCTURAL TIMBER USING STRESS-WAVE MEASUREMENTS (Dackermann et al. 2014)}

\section{$\underline{\text { Introduction }}$}

Timber is an anisotropic and inhomogeneous material comprising of tubular cells arranged in rings. Similar to concrete, the detection of defects in timber depends on their size, type, and level. For instance, early-stage decay is difficult to detect and brown rots decay fungi are easier to detect than white rots. This study discusses the recommendations given in previous studies for in situ assessment of structural timber members using ultrasonic methods such as time-of-flight, ultrasonic tomography, and ultrasonic echo methods.

\section{$\underline{\text { Determination and adjustment of stress wave velocity in Timber }}$}

The P-wave and S-wave velocities for sound timber generally range from $3500 \mathrm{~m} / \mathrm{s}$ to 5000 $\mathrm{m} / \mathrm{s}$ and $1000 \mathrm{~m} / \mathrm{s}$ to $1500 \mathrm{~m} / \mathrm{s}$ respectively. The S-wave has a lower value because it has to pass through several interfaces at the cell wall. The following are the factors that affect the stress wave 
propagation in timber and should be integrated into the determination of ultrasonic velocity for an accurate assessment.

\section{a) Annual Growth Rings}

The relative angle between the sensor placement and grain orientation influences the stress wave velocity and pattern. The velocity of S-wave is slowest for the sensor orientation of $45^{\circ}$ to the annual growth rings, fastest in radial $\left(30 \%\right.$ more than $\left.45^{\circ}\right)$ direction and in between in tangential direction.

b) Wood Species

The sound wave is known to travel faster in hardwood than softwood.

c) Moisture Content (MC) and Temperature

For $\mathrm{MC}>30 \%$, wave velocity stays stable; while for $\mathrm{MC}<30 \%$, wave velocity increases with decreasing $\mathrm{MC}$. Also, in the range of $0-40^{\circ} \mathrm{C}$, on average, an increase in $1{ }^{\circ} \mathrm{C}$ temperature causes the velocity to decrease by about $3 \mathrm{~m} / \mathrm{s}$. Hence, the velocities should be adjusted for $\mathrm{MC}$ and temperature using factors in Table 3.2.

d) Preservative Treatment

Treatment of timber with oil-borne preservatives decreases wave velocities by about $40 \%$ than untreated wood. Waterborne salt-treated timber velocities are unaffected.

Table 3.2: Adjustment factors for MC and temperature (Dackermann et al. 2014).

\begin{tabular}{lllll}
\hline MC $(\%)$ & \multicolumn{4}{l}{ Adjustment factors } \\
\cline { 2 - 5 } & $-18^{\circ} \mathrm{C}$ & $3^{\circ} \mathrm{C}$ & $27^{\circ} \mathrm{C}$ & $49{ }^{\circ} \mathrm{C}$ \\
\hline 1.8 & 0.94 & 0.95 & 0.97 & 0.98 \\
3.9 & 0.95 & 0.96 & 0.98 & 0.99 \\
7.2 & 0.93 & 0.98 & 1.00 & 1.01 \\
12.8 & 0.97 & 0.99 & 1.00 & 1.01 \\
16.5 & 0.99 & 1.01 & 1.03 & 1.05 \\
23.7 & 1.05 & 1.07 & 1.09 & 1.14 \\
27.2 & 1.07 & 1.1 & 1.12 & 1.17 \\
\hline
\end{tabular}




\section{Computation of decay}

The stress wave velocities for sound samples of various species are compiled and easily available. These reference velocities are compared with the measured velocities from sonic/ultrasonic methods and relative velocity decrease is used to determine the percentage of decay in the test member using Table 3.3. If the percentage difference in the measured stress wave velocity and the reference velocity is more than $10 \%$, the section should be assumed to be decayed.

Table 3.3: Percentage decayed area corresponding to the relative velocity decrease (Dackermann et al. 2014).

\begin{tabular}{ll}
\hline $\begin{array}{l}\text { Relative velocity } \\
\text { decrease in } \%\end{array}$ & $\begin{array}{l}\text { Decayed area } \\
\text { ratio in \% }\end{array}$ \\
\hline $0-10$ & No decay \\
$10-20$ & 10 \\
$20-30$ & 20 \\
$30-40$ & 30 \\
$40-50$ & 40 \\
$\geq 50$ & $\geq 50$ \\
\hline
\end{tabular}

\section{Computation of Dynamic Modulus of Elasticity (MOE $\left.{ }_{d}\right)$}

Stress wave velocity (V) can also be useful to predict the $\mathrm{MOE}_{\mathrm{d}}$ of timber with the equation: $\mathrm{MOE}_{\mathrm{d}}$ $=\mathrm{V}^{2} \rho$, where $\rho$ is the mass density of the test member.

\section{Experimental Tests}

In this paper, defects were detected in timber using three methods as discussed below. Sonic stress wave test was found promising for the assessment of defect having a depth greater than $89 \mathrm{~mm}$ while ultrasonic tests for smaller defects.

\section{Time-of -flight sonic method}

This method was applied in the longitudinal and transverse directions in locations 1,2,3,4 and 5 of the beam shown in Figure 3.15a. The sonic stress wave method included an impact of frequency less than $10 \mathrm{kHz}$, induced using a hammer. With the known distances between the impact and receiving transducers and computed time of travel, velocities were determined. The velocities were adjusted as mentioned above and the relative decrease in the stress wave velocities were computed as in Figure 3.15b, to determine the internal condition of the member. It was 
construed that no damage existed in location 3; whereas for locations 4 and 5, the decrease of relative velocities by approximately $30 \%$ depicted that about $20-30 \%$ of the cross-sectional area was decayed.

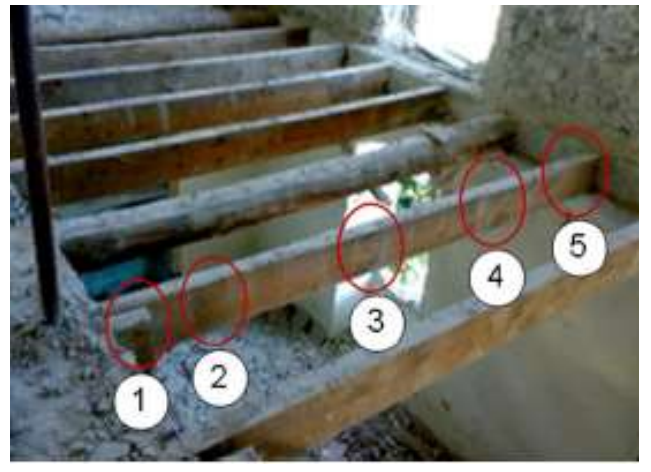

(a)

\begin{tabular}{llll}
\hline Location & \multicolumn{3}{l}{ Relative decrease in stress wave velocity $(\%)$} \\
\cline { 2 - 4 } & $\begin{array}{l}\mathrm{A}-\mathrm{B} \\
\left(\approx 75^{\circ} \text { to grain) }\right.\end{array}$ & $\begin{array}{l}\text { C-D } \\
\text { (radial) }\end{array}$ & $\begin{array}{l}\text { E-F } \\
\text { (longitudina) }\end{array}$ \\
\hline 1 & 22.0 & 19.5 & 20.9 \\
2 & 22.7 & 19.1 & \\
3 & 4.7 & -4.2 & -2.0 \\
4 & 30.5 & 29.0 & 26.6 \\
5 & 31.1 & 26.5 & \\
\hline
\end{tabular}

(b)

Figure 3.15: (a) Timber test member in site; (b) relative velocity decrease in test locations (Dackermann et al. 2014).

\section{Time-of-flight acoustic tomography}

In acoustic tomography, the computed apparent velocity distribution is used as the basis for cross-sectional imaging (greyscale or color contrast). This method is used in structural timber elements to detect heterogeneities (knots and checks) and damages (decay and cracks). Chains of electronically connected piezo sensors were used in the base of a timber post as shown in Figure 3.16a. A hammer was used to strike a sensor or nail to induce stress-wave throughout the chain. Figure $3.16 \mathrm{~b}$ displays the $2 \mathrm{D}$ tomogram of the test member with different colors indicating apparent velocities, which can be used to reconstruct the internal condition of the post crosssection. The red lines represent areas where the wave went around an anomalous part while green lines indicate the sound section. In the case of rectangular sections (annual rings oriented diagonally) or circular sections (pith is centered), TOF readings for tomography can be taken keeping sensors on the opposite sides. In sections with unknown annual ring orientation, TOF readings should be taken only from opposite sides. Many softwares are available to reconstruct the images with attributes to choose anisotropic material, certain limits on the size and shape of the specimen, number of measurements, and minimum spatial resolution. Image analysis techniques, like segmentation of histograms, in these softwares, can be used to better interpret tomograms. For instance, Figure 3.17 portrays the areas with different features corresponding to the provided 
threshold using a color contrast. However, this technique can only provide global qualitative information about the internal condition of the test member. To identify the local defect and deterioration quantitatively, different frequencies of the signal in acoustic tomography or other complementary techniques like resistance drilling or electrical impedance could be applied.

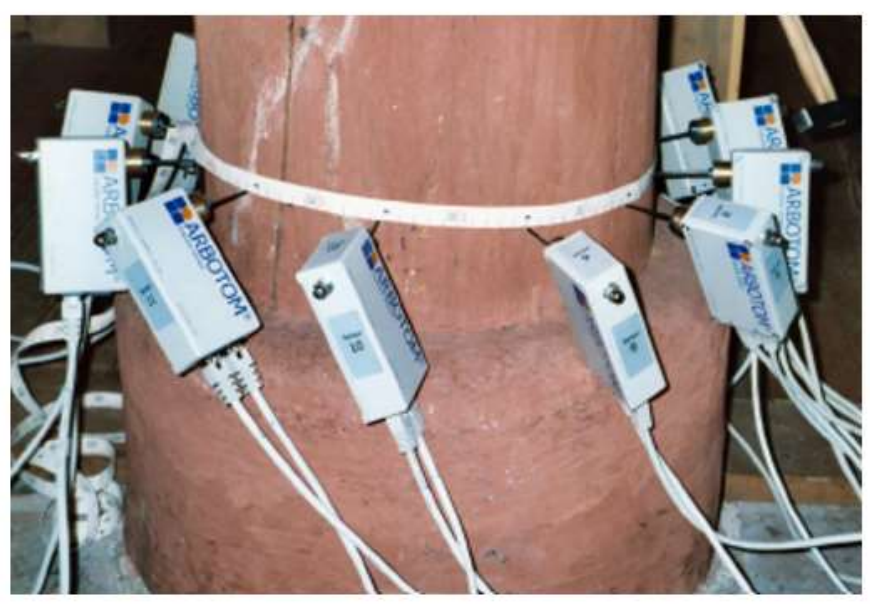

(a)

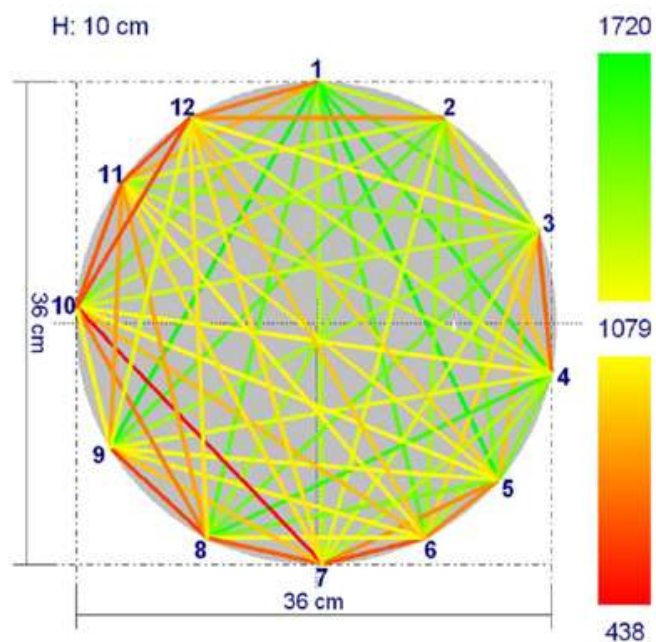

(b)

Figure 3.16: (a) Sensor setup in the timber post; (b) 2D-tomogram of the timber post (Dackermann et al. 2014).

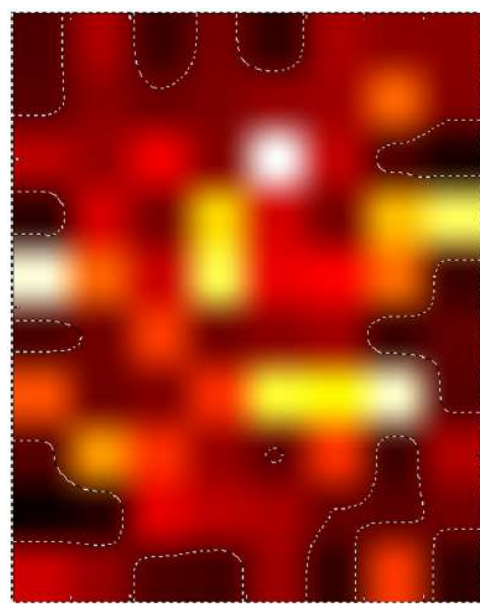

(a)

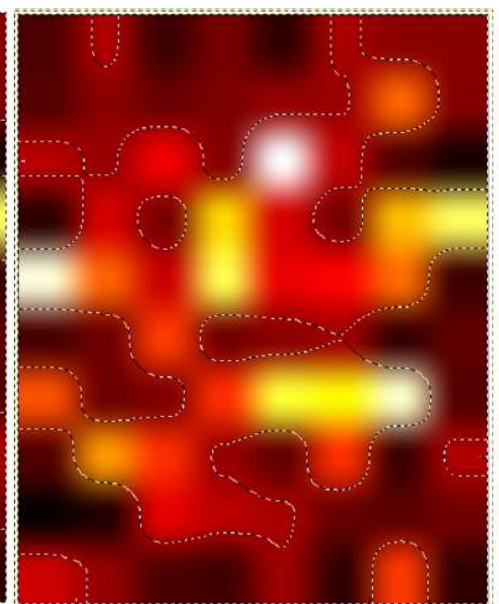

(b)

Figure 3.17: (a) Tomographic image segmentation of area with a velocity less than $600 \mathrm{~m} / \mathrm{s}$; (b) less than $900 \mathrm{~m} / \mathrm{s}$ (Dackermann et al. 2014). 


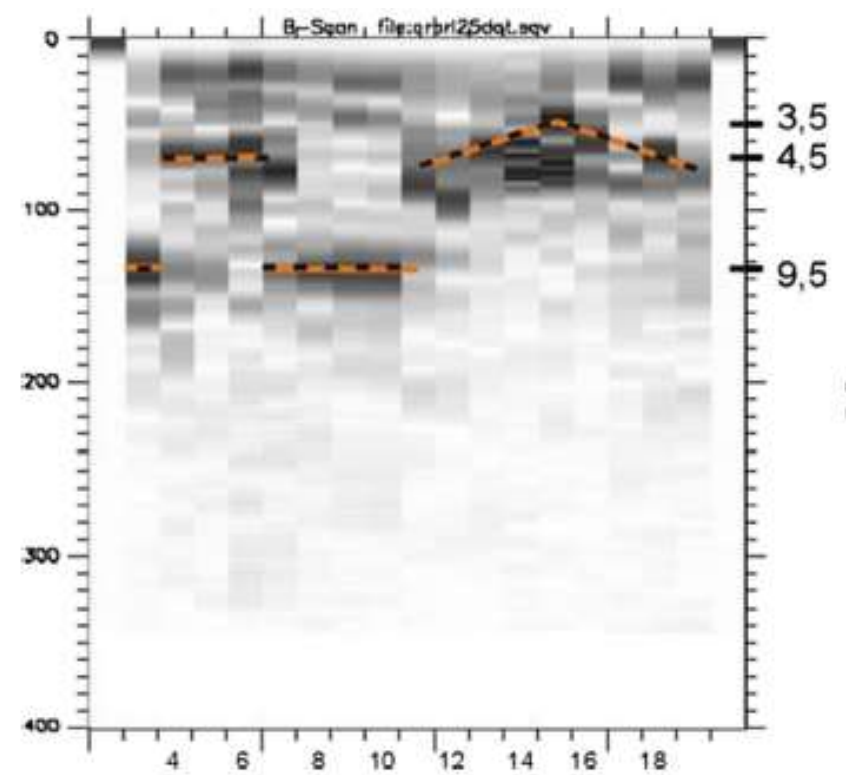

(a)

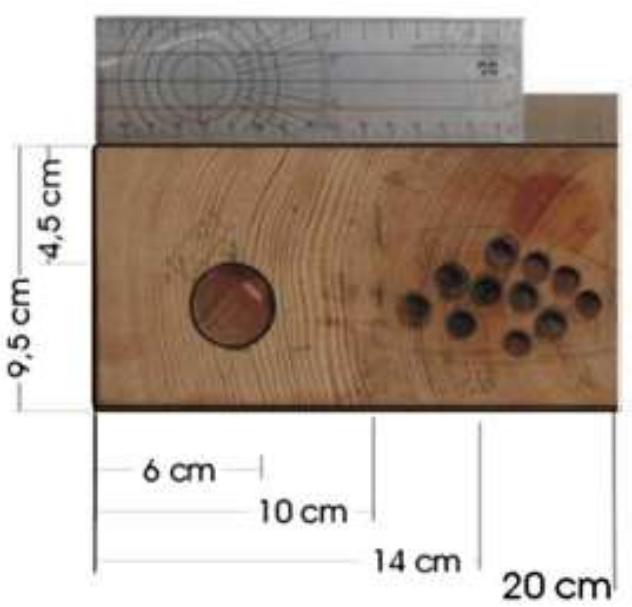

(b)

Figure 3.18: (a) B-scan of the sample obtained from the ultrasonic echo method (units in mm); (b) Timber sample with defects (Dackermann et al. 2014).

\section{Ultrasonic Echo}

This method can be applied to assess the internal condition of timber structural elements. Because of the radial and tangential anisotropy, low $(50-200 \mathrm{kHz})$ frequency shear wave transducers are considered best for the assessment of timber. Using such transducers is very efficient as there is no need for a coupling. For the test, a shear wave array transducer was used that comprised 24 sensors (12 transmitters and 12 receivers), each activated with a frequency of $55 \mathrm{kHz}$. For this frequency, in a pine sample, the wavelength in the direction perpendicular to the grain is approximately $25 \mathrm{~mm}$. Hence, defects of size greater than $12 \mathrm{~mm}$ could only be detected using the system. The results were obtained as A and B-scans. Figure 3.18 presents the B-scan of the sample, where we can observe the reflectors accurately, back-wall at $9.5 \mathrm{~cm}$, and the defected area around $3.5 \mathrm{~cm}$.

\section{Conclusion}

Stress wave methods were deduced to be reliable to assess the soundness of structural timbers. It was established that incorporating adjustment factors (annual ring orientation, MC, etc.) in the measured data was necessary for an accurate assessment. Acoustic TOF tomography was 
found to be useful to investigate large portions of a structure qualitatively with less resolution. It could be used to detect cracks and delamination in glulam beams, estimate MOE, assess structures showing overloading signs, etc. After a qualitative assessment, complementary techniques could be applied for further examination in a specific area. The ultrasonic echo method was shown to detect and locate the defects more or less accurately.

\subsubsection{A NOVEL METHODOLOGY FOR CONDITION ASSESSMENT OF WOOD POLES USING ULTRASONIC TESTING (Tallavo et al. 2012)}

\section{Introduction}

This study presents an approach of condition assessment of wood poles using the ultrasonic technique. Unlike the simple methods, this method was found to be very useful to detect the early stages of decay in the electrical distribution poles to verify their condition to remain in-service. In addition to the wave velocity measurements, this paper discusses the integration of transmission factors and elastic moduli in the assessment of orthotropic materials considering the uncertainties in the elastic (effect of MC and temperature on elastic modulus) and mechanical properties. Unlike the use of adjustment factors for better results, discussed in Dackermann et al. (2014), this technique accounts for the influencing factors without having to adjust the velocity measured. The integrated parameters give the statistical quantities called dissimilarity indices (DIs) that can be used to represent the condition of the test members.

\section{$\underline{\text { Experimental Tests }}$}

A sound pole and two pole specimens of red pine, new (31.6 diameter) and aged in-service (25.8 diameter), were used in the ultrasonic tests. Two $50 \mathrm{kHz}$ transducers, two aluminum coupling cones, vacuum grease, waveform generator-amplifier-acquisition system, UT-Pole device, and analysis software were used in the experiments. Figure 3.19 presents the transducers setup in the pole, where the transmitters were placed at points A, B, C, and D; with the receivers at angles of $\pm 90^{\circ}, \pm 135^{\circ}$, and $180^{\circ}$ for each transmitter. Hence, an array of 5 receiving transducers were arranged for each transmitter position and 14 independent ray paths were defined for each test to measure wave velocity. The parameters measured for the assessment were the wave velocity, transmission factor (reciprocal of the attenuation), and elastic moduli in radial as well as tangential directions. Wave velocity and elastic moduli were obtained from the travel time of compression 
wave, and the transmission factors $\left(\mathrm{A}_{\mathrm{f}}\right)$ from full waveform analysis using frequency response function (FRF). Dissimilarity Index (DI) represented the number of standard deviations by which the measured parameters differed from the expected values for the sound pole. For instance, for

wave velocity, $D I=\frac{V_{p}-\mu_{V_{p}}}{\sigma V_{p}}$, where $V_{p}, \mu_{V p}$, and $\sigma_{V p}$ represent the measured wave velocity, and expected value and standard deviation of the sound pole wave velocity respectively. Overall dissimilarity indices (ODIs) were computed integrating wave velocity and transmission factor in an equation. The test members were assessed using criteria for decayed area: ODIs less than -2 and the ratio of radial and tangential elastic moduli $\left(\mathrm{E}_{\mathrm{r}} / \mathrm{E}_{\mathrm{t}}\right)$ less than 2 (obtained through various research for red pine). Numerical simulations using the finite element method and simplified model of plane wave propagation in an infinite orthotropic material using MATLAB were calibrated with the experimental results.

\section{$\underline{\text { Results and discussion }}$}

The variation in mean wave velocity for various receiver locations in both specimens was found to be nonlinear (as expected) as wood is not homogeneous, the cross-section is not perfectly circular and the pith does not coincide with the center of the section. Figure 3.20a and 3.21a depict the wave velocity and transmission factor for the new pole that is within the mean values plus/minus one standard deviation obtained from the sound pole. The average $\mathrm{E}_{\mathrm{r}} / \mathrm{E}_{\mathrm{t}}$ was $15 \%$ smaller than in sound pole and ODIs were found between 1.4 and -0.38 . These values indicated that the specimen was also sound. For aged pole, there were no visible cracks but the measured mean velocities and transmission factors were outside the safer range for all the receiver points as shown in Figure 3.20b and 3.21b. Wave velocities for receivers at $\pm 135^{\circ}$ and $180^{\circ}$ were $51 \%$ less than the sound specimen. Similarly, the transmission factor, the average elastic moduli in the radial, and tangential directions were found to be smaller than the sound pole by $96 \%, 80 \%$, and $43 \%$ respectively. Figure 3.22 (left) conveyed that 10 out of 14 raypaths had ODIs below -2 , minimum reaching -3.8 for raypath \#9. These values suggested that the pole was in a substandard condition in the regions shown in Figure 3.22 (top, right). These results were verified by cutting the pole section. The observed deterioration pattern (two decay areas $10 \%$ and $20 \%$ of the total cross-sectional area) was consistent with the estimated condition (Figure 3.22 (bottom, right)) 
using overall dissimilarity indices. The resolution could be further increased by increasing the number of raypaths.

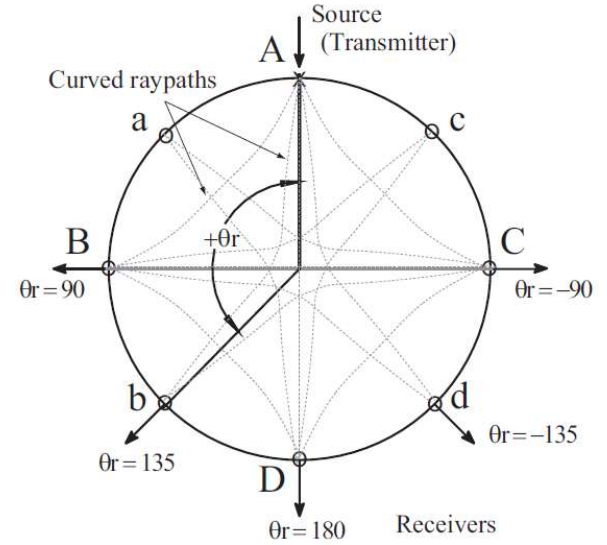

(a)

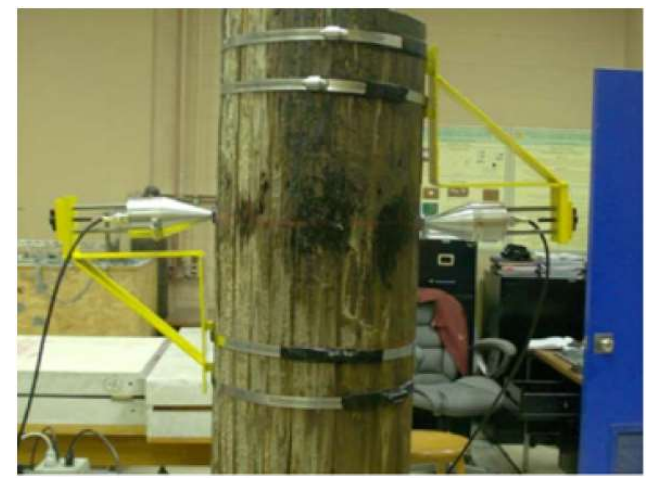

(b)

Figure 3.19: (a) Ultrasonic transducer setup with raypaths; (b) test setup in aged specimen (Tallavo et al. 2012).

\section{Conclusion}

The condition assessment of cylindrical and orthotropic pole specimens represented by dissimilarity indices, basing on various parameters obtained from the ultrasonic technique, was verified to be accurate and would be effective to be used in other structural members in buildings and bridges. Early stages of decay were also detected with accuracy which would not be possible by a simple ultrasonic wave velocity method.

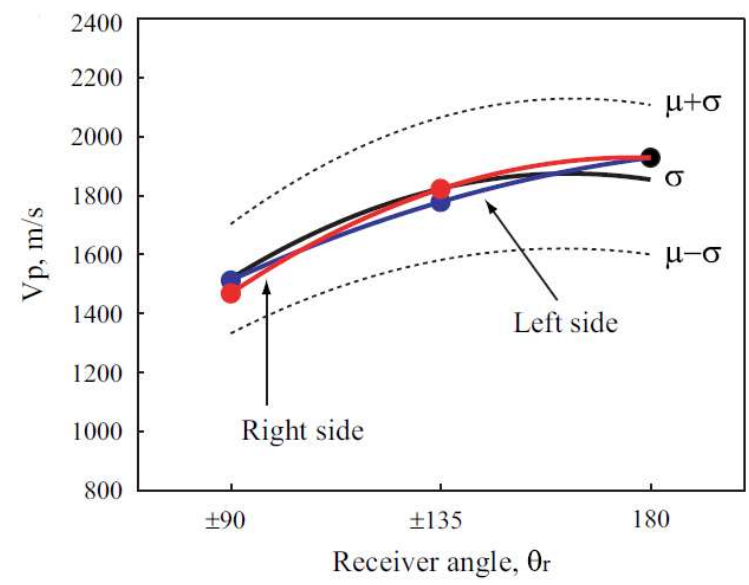

(a)

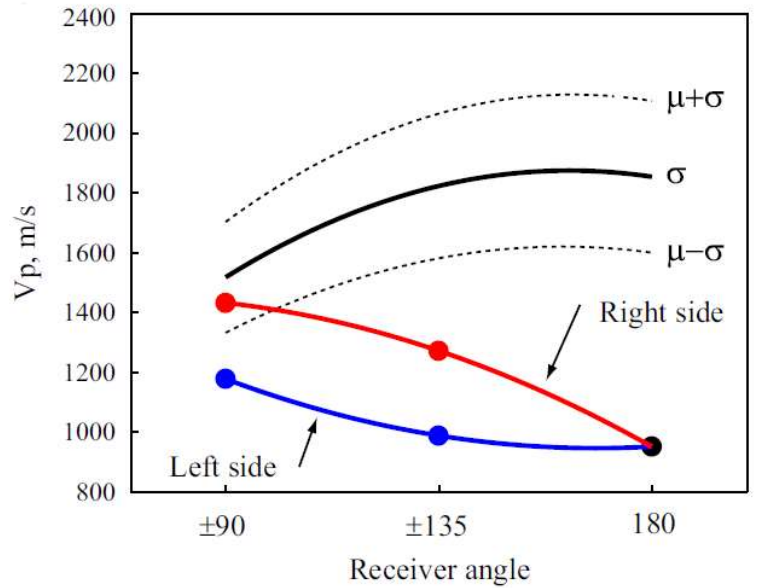

(b)

Figure 3.20: (a) Measured wave velocity for different receiver positions in new pole; (b) aged pole (Tallavo et al. 2012). 


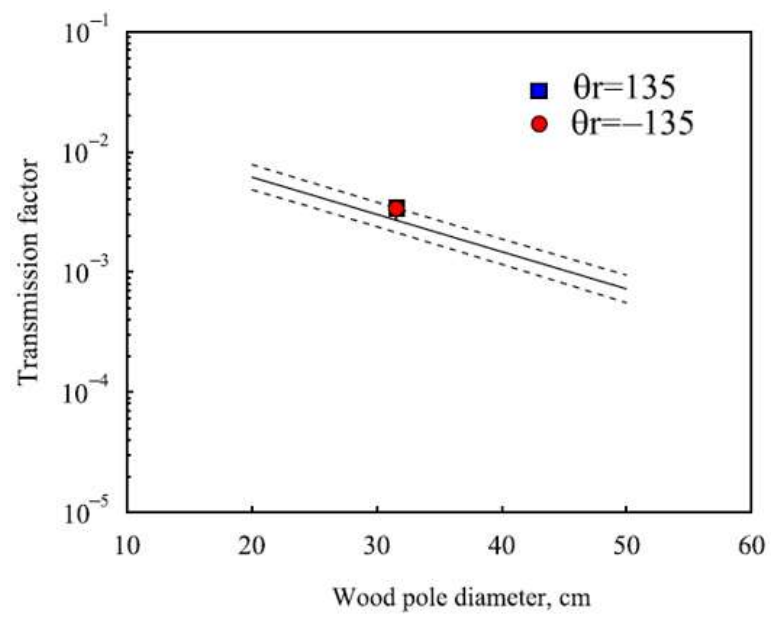

(a)

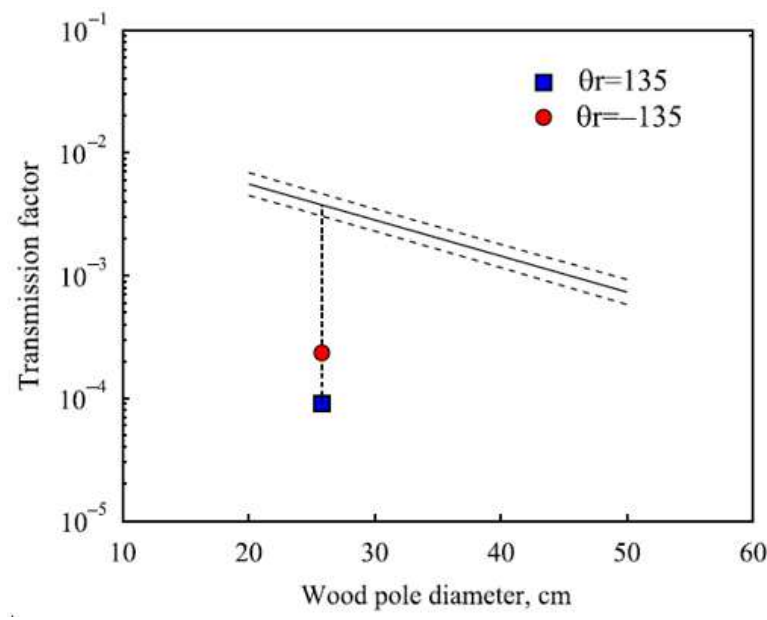

(b)

Figure 3.21: (a) Transmission factors for receiver located at $135^{\circ}$ in new pole; (b) aged pole (right) (Tallavo et al. 2012).
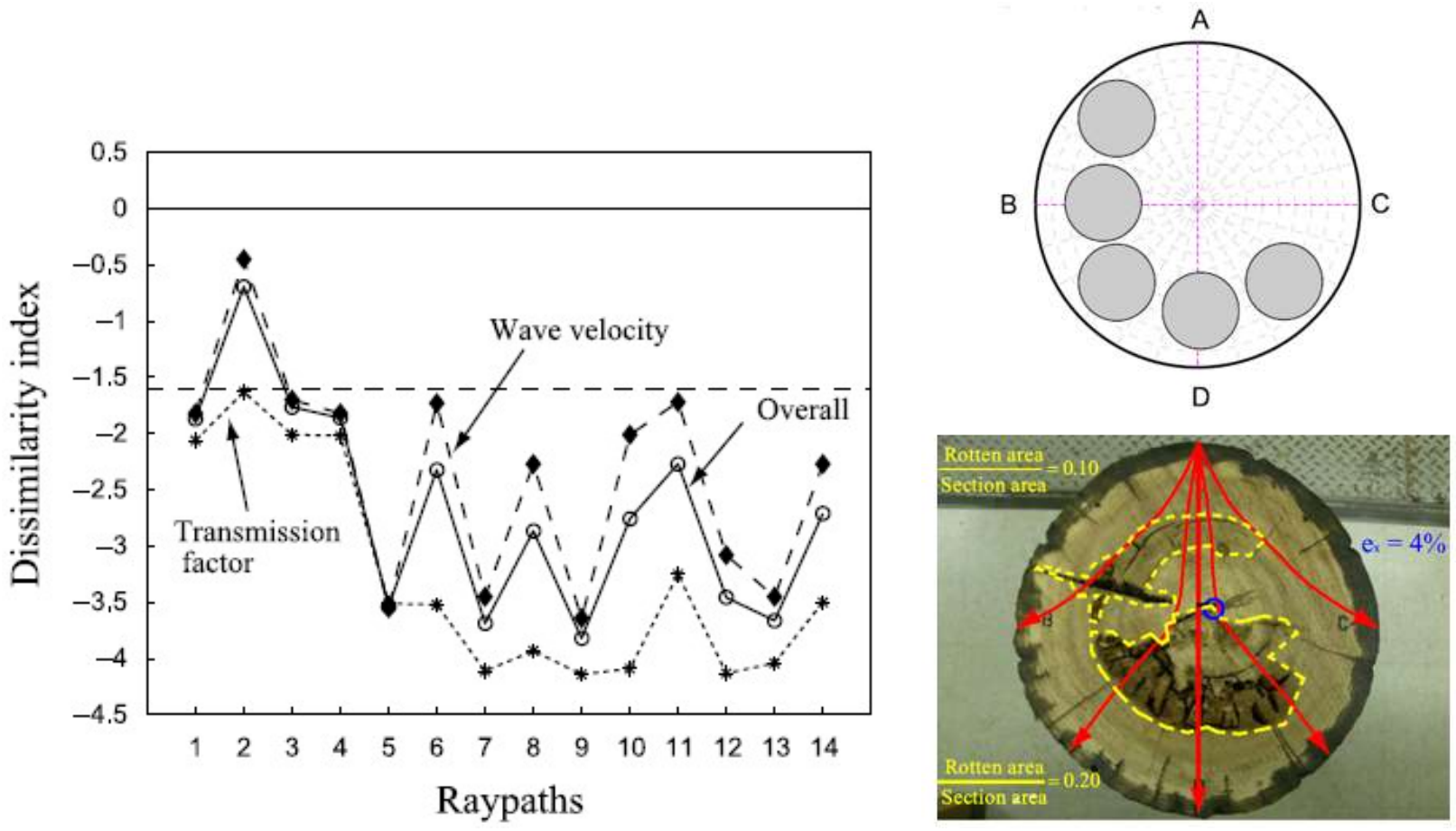

Figure 3.22: Dissimilarity indices in 14 raypaths (left); estimated condition of the aged pole using DIs (top, right); actual condition of the aged pole (bottom, right) (Tallavo et al. 2012). 


\subsubsection{CORROSION DETECTION OF REINFORCEMENT OF BUILDING MATERIALS WITH PIEZOELECTRIC SENSORS (Peng 2017)}

\section{Introduction}

With the extensive use of steel in the construction industry, corrosion detection of the steel rebars is becoming increasingly important for the health monitoring and repair of reinforced concrete structures. Corrosion causes a decrease in the steel rebar cross-section, thus reducing its capacity and bonding with concrete. Additionally, expansion in the volume of corrosion products leads to the formation of cracks in the surrounding concrete. Hence, it is crucial to detect corrosion of rebars in time and take appropriate measures for structural safety and durability. This study investigated qualitative as well as quantitative corrosion detection on construction materials using piezoelectric sensors.

\section{Experimental Tests}

The designed ultrasonic system was composed of piezoelectric transmitting and receiving sensors. 30 days old reinforced concrete sample blocks were used in the experiment with G-85 steel. The blocks were immersed in $\mathrm{NaCl}$ solution, with exposed steel rebar at the end, to initiate the corrosion and the transmitting as well as receiving sensors were pasted at both ends of the block. The ultrasonic transmitting sensor was connected to a waveform generator generating pulses with a frequency of $100 \mathrm{kHz}$. After the corroding process started, the ultrasonic velocity was collected every hour until the formation of a crack. A similar process was carried out in another sample block for more comprehensive monitoring of the corrosion of the rebar. The data was also taken before applying any load and in different damage degree under the maximum load (50 $\mathrm{N} / \mathrm{mm}^{2}$ ) with step-by-step load application. The changing trend in the received signal parameters during the damage process was used to analyze the quantitative relationship between the ultrasonic signal and the damage of the reinforced concrete.

\section{$\underline{\text { Results and Discussions }}$}

The number of the ultrasonic signals was found to increase gradually with the increase in corrosion time as shown in Figure 3.23a. After 9 hours, the signal number started increasing fast as the rust product reaching a certain amount started forming cracks in the concrete. It was thus clear that ultrasonic signals could be used to determine damage degree. Using the ultrasonic 
velocities, an equation was derived to calculate the quantitative damage degree (D) $=1-\frac{\rho_{0}}{\rho} \frac{v_{0}^{2}}{v_{1}^{2}}$. Here, $\rho_{0}, \rho, v_{0}$, and $v_{1}$ represent densities of steel rebar and longitudinal wave velocities under damaged and intact conditions respectively. Additionally, the frequency of the received ultrasonic signal in the sample block was found to be different under different damage degrees from loads. Figure $3.23 \mathrm{~b}$ shows that the resonant frequency was $100 \mathrm{kHz}$ under zero load; whereas it reduced by half under the maximum load of $50 \mathrm{~N} / \mathrm{mm}^{2}$, which caused crack formation. Furthermore, a correlation was established between the rate of increase in the amplitude of ultrasonic signals and mass loss of steel bars represented by Figure 3.24. The increase in mass loss of steel bars corresponded to an increase in the growth rate of ultrasonic amplitude. After reaching the mass loss of about $1.5 \mathrm{gm}$, the amplitude ceased to increase and was more or less constant. This stage indicated the complete separation of steel with concrete. Hence, it was deduced that it was possible to determine the degree and stage of corrosion of the steel materials using ultrasonic signals (number, resonant frequency, and growth rate of amplitude).

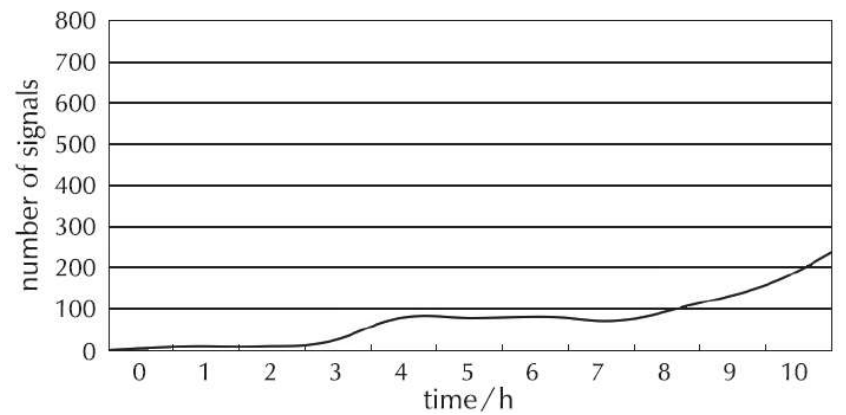

(a)

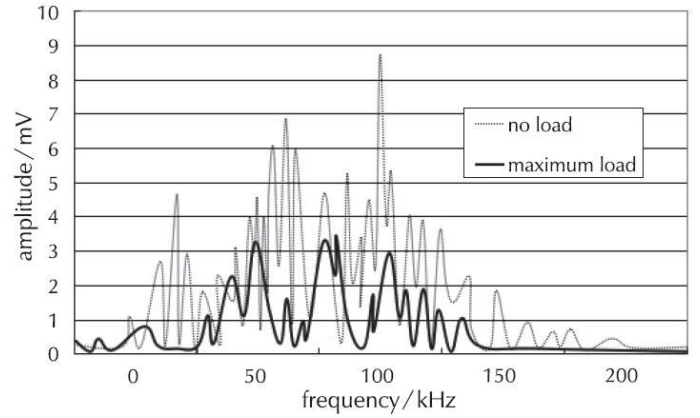

(b)

Figure 3.23: (a) Time of corrosion vs. the number of ultrasonic signals; (b) Received ultrasonic signals under different loadings (Peng 2017).

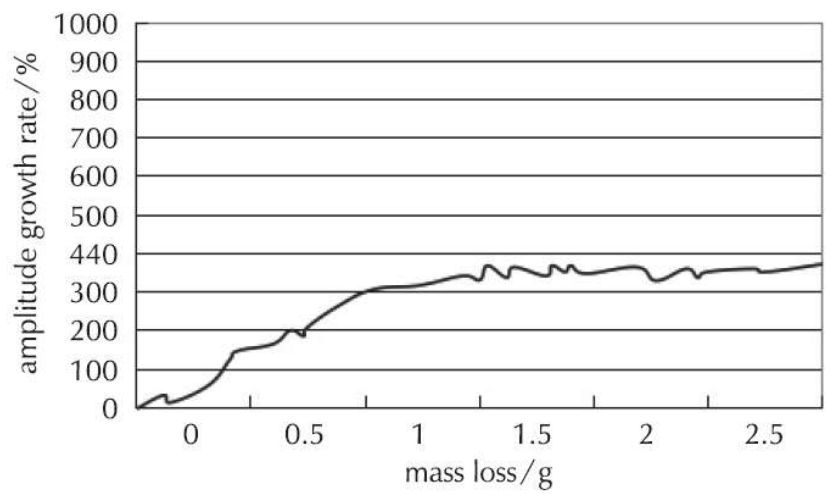

Figure 3.24: Mass loss of steel vs. the amplitude growth rate of ultrasonic signals (Peng 2017). 


\section{Conclusion}

This study concluded that piezoelectric sensors enable real-time monitoring of the corrosion and damage degree of steel materials to provide an effective basis for the evaluation of structural safety and durability.

\subsubsection{THE LAUS : FIRST APPLICATIONS OF A NEW SYSTEM FOR ULTRASONIC IMAGING OF VERY CONCRETE STRUCTURES. (Niederleithinger and Wiggenhauser 2018)}

\section{Introduction}

BAM and the University of Kassel (Germany) together developed The Large Aperture Ultrasonic System (LAUS) to overcome the lack of penetration of commercial instruments for the inspection and imaging of massive structures. This paper discussed three different LAUS employed case studies: foundation slab, bridge girder, and retaining wall.

\section{Experimental Tests and Results}

The LAUS was designed to inspect very thick concrete structures using the ultrasonic pulse-echo technique. It consisted of 12 separate array units each comprising of an ultrasonic module, an electronic module, and a suction pod. Each unit could serve as a transmitter or a receiver. Each ultrasonic module was built with 32 dry point contact shear wave transducers that could use frequencies between 25 and $150 \mathrm{kHz}$. The electronic module was used to generate ultrasonic impulse and convert analog data to digital and vice-versa. An external computer with WiFi was used to switch the modules and the time lag between units was kept less than $1 \mu \mathrm{s}$. A 3D printed suction pod and vacuum case were used to attach the transducer arrays to the test surface. A total of 132 transmitter-receiver combinations were possible for this model. The data obtained were reconstructed as B-scan or C-scan using a simplified version of SAFT (derived from MIRA Linear Array device). The orientations of LAUS modules were flexible to be changed with larger distances in between. However, this would need remodeling of the system with precise position measurement and SAFT technique modification. 


\section{Foundation Slab}

The penetration depth check of the system was performed on part of a $5 \mathrm{~m}$ thick heavily reinforced foundation slab (Figure 3.25b), located at the BAM test site. Figure 3.25c clearly shows the reflection of the heavy reinforcement with the partly layered zone (at the top) and the bottom of the slab (at $5 \mathrm{~m}$ ). Additionally, multiple reflections at $10 \mathrm{~m}$ were also observed, giving a possibility of higher penetration capability for the instrument.
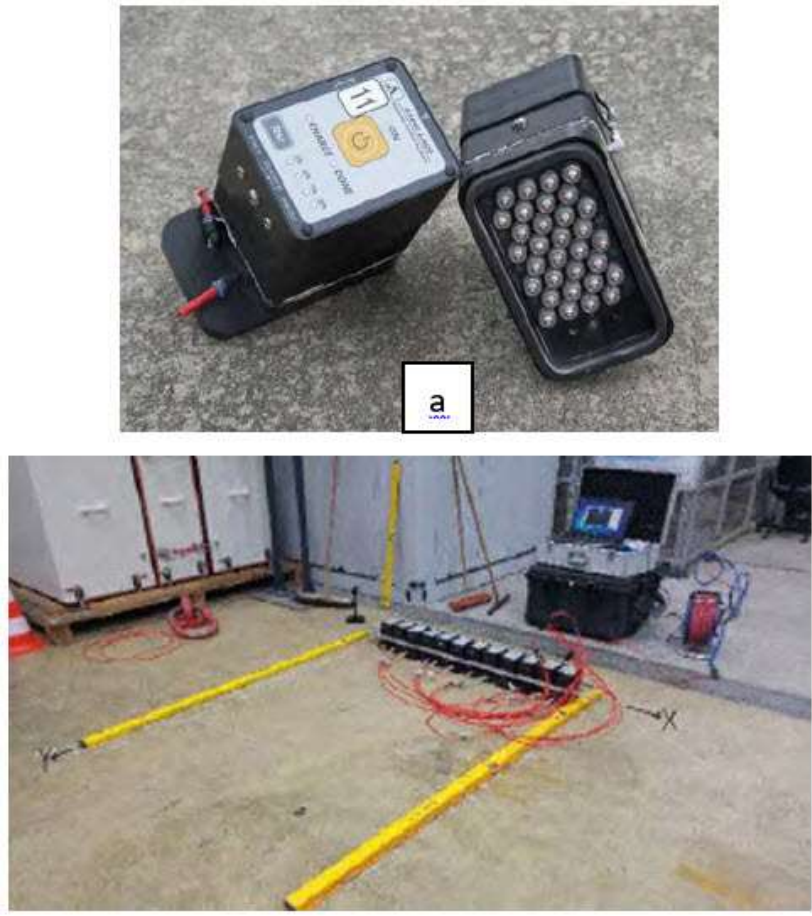

(b)

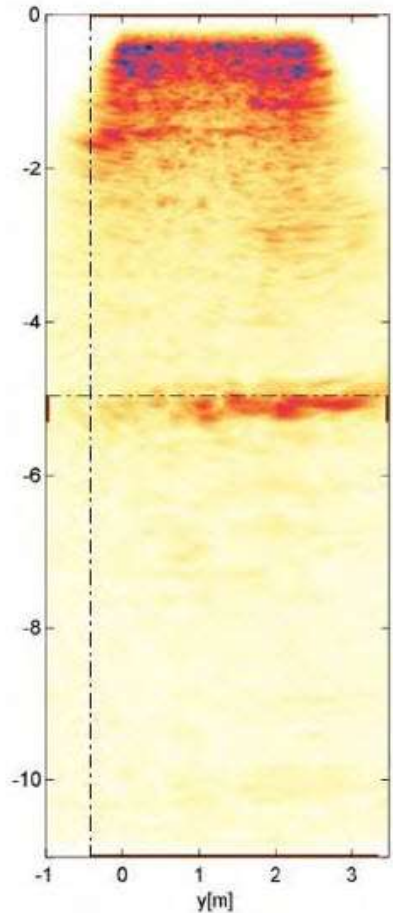

(c)

Figure 3.25: (a) The LAUS unit; (b) Foundation slab under test with LAUS data acquisition; (c) SAFTreconstructed B-scan of the slab (Niederleithinger and Wiggenhauser 2018).

\section{Bridge Girder}

The LAUS was used to inspect a massive post-tensioned girder supporting a 4-lane bridge. There were some concerns about the concrete quality and imperfections of the girders (caused due to a heavy rainstorm during concreting) that became visible after removing the formwork. Figure 3.26a shows the B-scan obtained using the LAUS with clear reflections from the tendon ducts at the depth of $1.8 \mathrm{~m}$ as well as from the back wall at $2 \mathrm{~m}$. The back wall reflections were weaker at the edges due to less measurement coverage. Similarly, horizontal C-scans were analyzed at the 
level of the top of the tendon ducts (1.8 m depth) as shown in Figure 3.26b. The tendons were shown clearly with some limited anomalous areas of blurred reflections. Those areas coincided with the concreting level at the point and time of the heavy rainstorm. The areas were confirmed to be honeycombed by drilling holes.

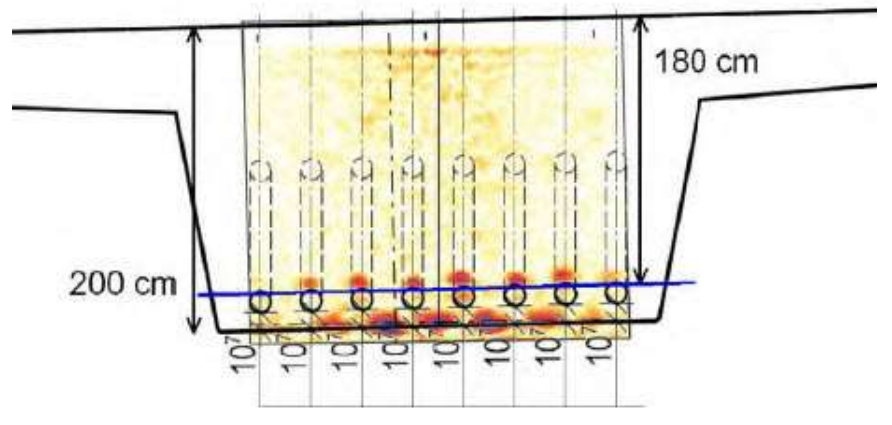

(a)

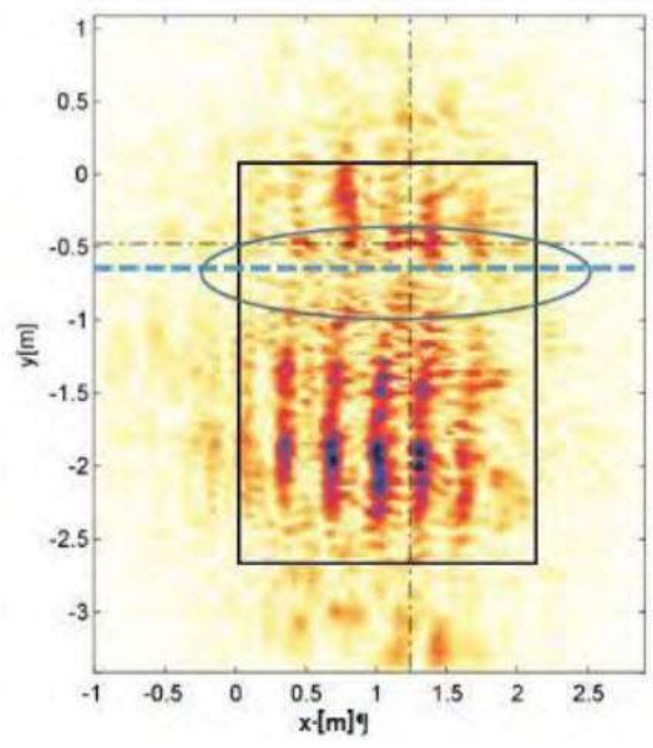

(b)

Figure 3.26: (a) SAFT-reconstructed B-scan of the girder at $1.8 \mathrm{~m}$ depth; (b) C-scan of the girder at $1.8 \mathrm{~m}$ depth: rectangle - measurement area, hatched line - the level of concrete at the start of rainstorm and ellipse - anomalous area (Niederleithinger and Wiggenhauser 2018).

\section{Retaining Wall}

A large retaining wall in a former coal mine plant (Figure 3.27a) was checked for thickness. Figure $3.27 \mathrm{~b}$ showed the back-wall reflection at about $60 \mathrm{~cm}$ and multiple reflections. The thickness of the wall was therefore found to be about $60 \mathrm{~cm}$ with a slightly thin section at the top. The information for deeper sections could not be obtained as the wall was debonded from the material behind it.

\section{Underground waste deposit sealing plugs}

The LAUS was used for quality assurance of sealing unreinforced plugs in underground waste deposits (nuclear and other types). The penetration depth was found to be up to $7 \mathrm{~m}$. 


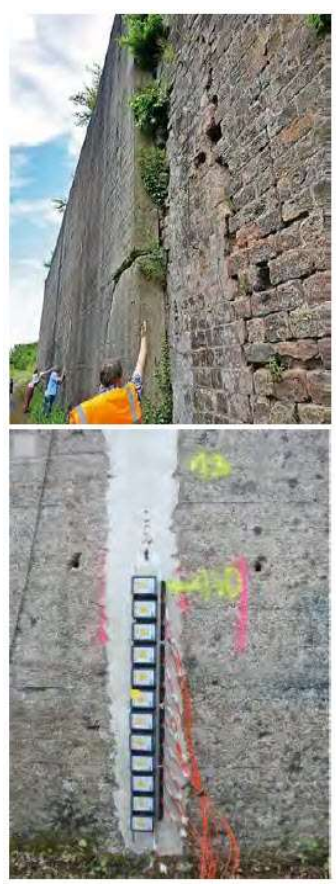

(a)

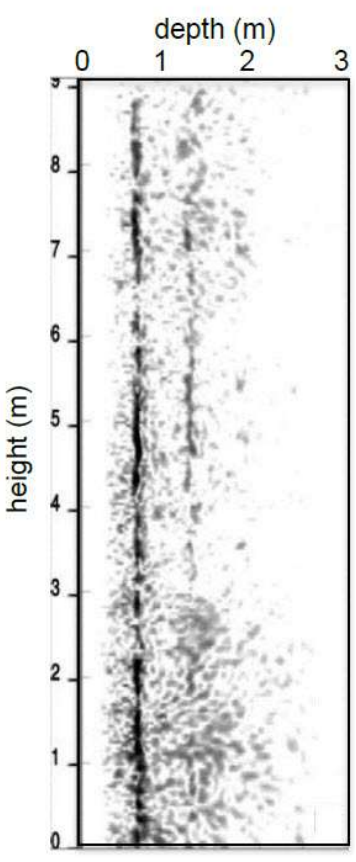

(b)

Figure 3.27: (a) The LAUS system data acquisition in the retaining wall in former coal mine plant; (b) Saftreconstructed B-scan of the retaining wall (Niederleithinger and Wiggenhauser 2018).

\section{Conclusion}

It can be deduced that LAUS could be used to map inner conditions of reinforced concrete structures of up to $5 \mathrm{~m}$ thickness with the possibility of even deeper inspection and unreinforced concrete of up to $7 \mathrm{~m}$.

\subsubsection{IN SITU NONLINEAR ULTRASONIC TECHNIQUE FOR MONITORING MICROCRACKING IN CONCRETE SUBJECTED TO CREEP AND CYCLIC LOADING (Kim et al. 2018)}

\section{$\underline{\text { Introduction }}$}

This study demonstrated the potential of in situ nonlinear ultrasonic (NLU) measurements for the monitoring of mechanical load-induced microscale damage initiation and progression in concrete structures in service. This was otherwise complicated due to difficulties in measurement setup in specimens under loading conditions. Early-stage microscale damages in concrete structural members, due to factors like alkali-silica reaction, shrinkage, and thermal damages, had 
been previously detected utilizing acoustic nonlinearity parameter $(\beta)$. It had been proved to be more sensitive to nano to microscale damages in various materials than other linear parameters (velocity, attenuation) of ultrasonic techniques. In this experiment, $\beta$ and strain were measured to quantitatively assess the early-age damages in concrete specimens subjected to creep or cyclic loadings in a controlled environment. Nonlinear behavior in concrete was observed using the second harmonic generation (SHG). First, the practicality of using the SHG technique to measure $\beta$ in concrete cylinders was checked, and it was then used to track early-stage damage progression due to creep and cyclic loadings.

\section{$\underline{\text { Experimental tests }}$}

From the stress-strain curve under axial compression loading, the ultimate strength of the concrete cylindrical specimen was found to be approximately $33 \mathrm{MPa}$ and that beyond $18 \mathrm{MPa}$ (or $1 \times 10^{-3}$ strain), nonlinear behavior started that initiated microcracks formation. Then, the SHG setup was prepared that utilized nonlinear Rayleigh surface waves to measure $\beta$ for the specimens under the uniaxial load simultaneously as shown in Figure 3.28. A tone-burst signal of 10 cycles at $57 \mathrm{kHz}$ was generated, which was amplified by $50 \mathrm{~dB}$ and served to the $50 \mathrm{kHz}$ transmitting transducer (Ultran GRD 50). A Teflon wedge at an angle of $36.3^{\circ}$ (Rayleigh wave critical angle for the interface), having the same bottom surface curvature as the specimen, was used to attach the transmitter to the concrete surface using vacuum grease. The receiving $100 \mathrm{kHz}$ air-coupled transducer (Ultran GRD 100), placed at an angle of $8^{\circ}$, would move along the propagation path to detect nonlinear Rayleigh surface waves leaked into the air, that was transmitted to an oscilloscope. The wave was detected frequently in 7 points (interval of $0.5 \mathrm{~cm}$ ) along the path and a steady part of the time domain signal was processed with FFT. The fundamental $\left(\mathrm{A}_{1}\right)$ and second harmonic $\left(\mathrm{A}_{2}=2 \times \mathrm{A}_{1}\right)$ amplitudes were observed in the frequency spectrum. $\beta$ was calculated by taking the

slope of the $A_{2} / A_{1}^{2}$ vs. $x$ plot: $\beta=\left(A_{2}\right) /\left(A_{1}^{2} x\right)$, where $x$ is the propagation distance. $R^{2}$ for the plot was $99 \%$ confirming the method's effectiveness for measuring $\beta$ of concrete cylinders. Then, the same setup was used to determine $\beta$ and monitor damages due to creep and cyclic loading on specimens at the relative humidity and temperature of $20 \%$ and $24^{\circ} \mathrm{C}$ respectively. The specimens were subjected to 25 days of creep with a constant load of $22 \mathrm{MPa}(68 \%$ of $33 \mathrm{MPa}$, corresponding to $1 \times 10^{-3}$ strain). $\beta$ and strain were measured frequently until 603 hours. Also, 11 cycles of loadings of $26 \mathrm{MPa}(77 \%$ of $33 \mathrm{MPa})$ were applied on the specimens at the time interval of 15 
minutes with the measurement of $\beta$ depending only on the material degradation due to load and not on the effects of elastic recovery. $\beta$ and strain were measured each time after unloading.

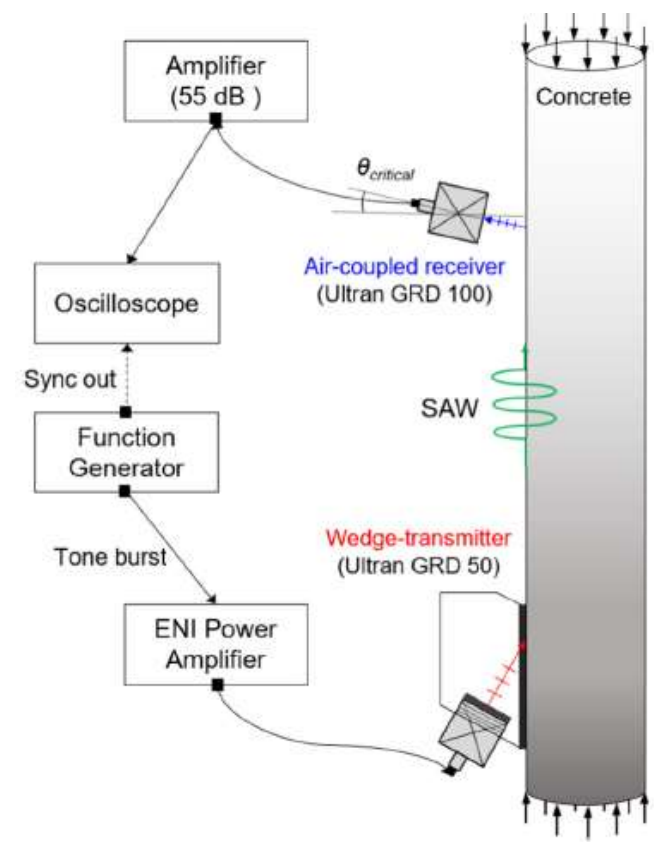

a)

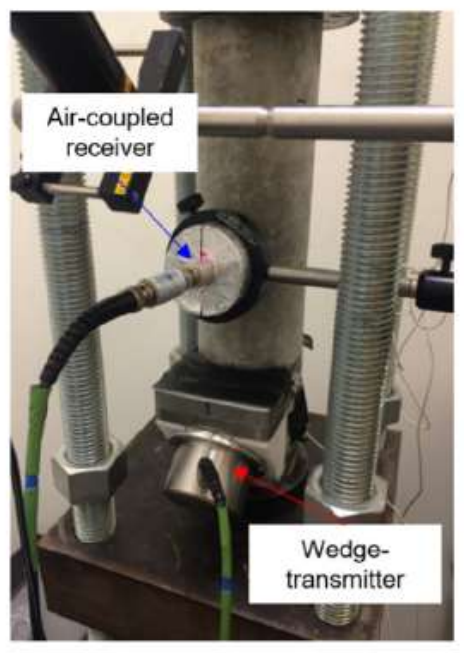

(b)

Figure 3.28: (a) Schematic diagram of SHG setup for concrete cylinders; (b) SHG setup (Kim et al. 2018).

\section{$\underline{\text { Results and discussions }}$}

Figure 3.29 shows the time domain of signal and computation of $\beta$ in the specimens under creep. The plots of strain and $\beta$ vs. time after loading were compared in Figure 3.30a. Considering time from $20 \mathrm{~h}$ to $60 \mathrm{~h}, \beta$ increases exponentially while strain remains constant under $22 \mathrm{MPa}$ load. This property is due to the formation of cracks in the longitudinal direction, consistency of strain in the longitudinal direction while the microcracks grow in transverse direction and potential of $\beta$ to detect continuous microcrack growth in this transition time. $\mathrm{R}^{2}$ for the linear fit of $\beta$ was higher than $97 \%$ for different sets. By the end of 603 hours, the percentage change in $\beta$ was 14 times more than that of uniaxial strain. Hence, $\beta$ was found more sensitive compared to uniaxial strain and could be directly linked to changes in microstructure associated with the accumulated microscale damages like microcracks and plasticity. Similar was the case for cyclic loading, where $\mathrm{R}^{2}$ for the linear fit of $\beta$ was higher than $98 \%$ for different sets. Figure $3.30 \mathrm{~b}$ presents the increase of $\beta$ by $182 \%$ over 11 cycles that corresponded to the buildup of microscale deformation. Changes in $\beta$ for both the parameters were found to be of the same order. Thus, the high sensitivity of $\beta$ was 
used to deduce that microscale cracks and plasticity associated with early-stage creep and cyclic damages could be monitored precisely by measuring $\beta$. This NLU setup was suitable for detecting damage evolution up to approximately $43 \mathrm{~mm}$ below the test surface.

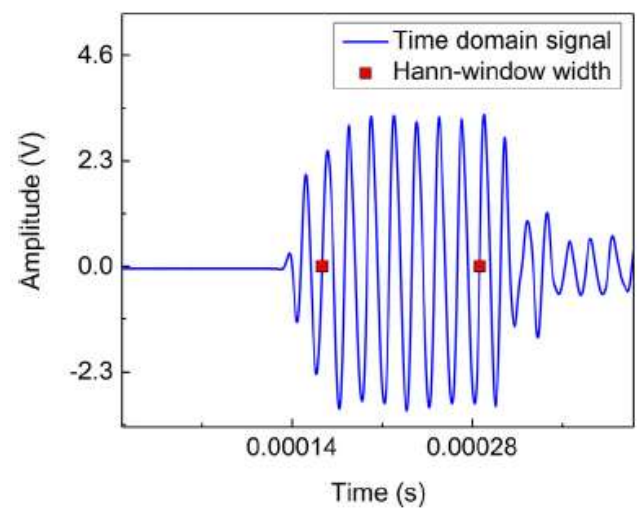

a)

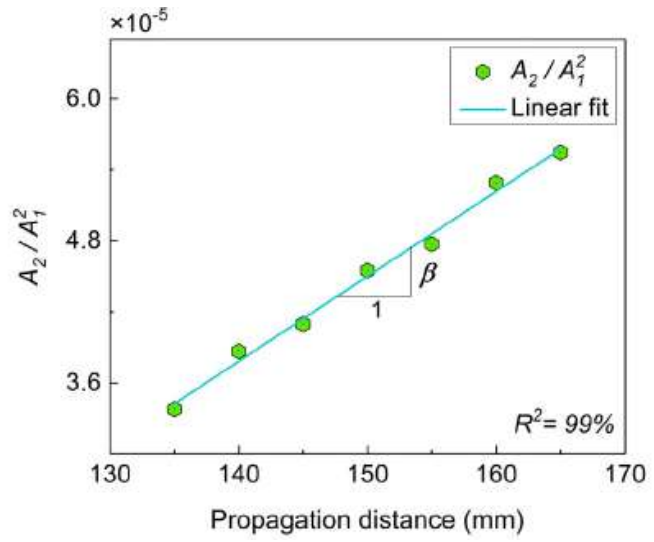

(b)

Figure 3.29: SHG measurement results under creep: (a) Time domain signal for concrete specimens; (b) $\beta$ as a slope of the plot (Kim et al. 2018).

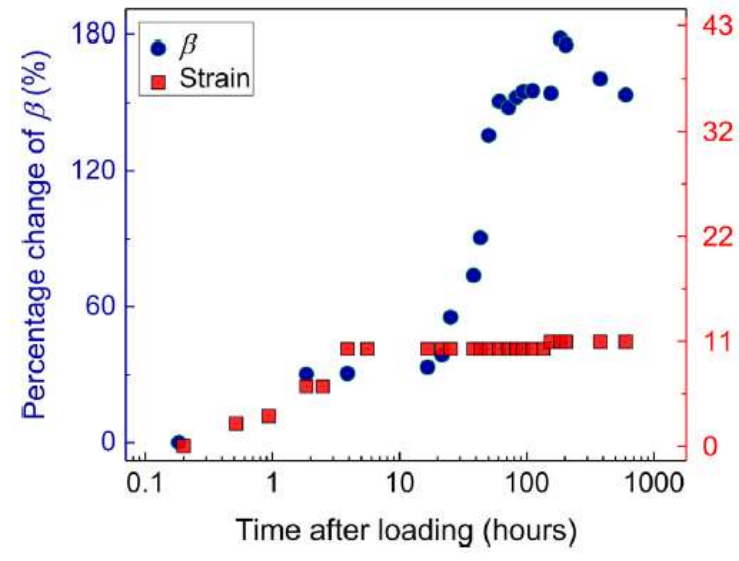

a)

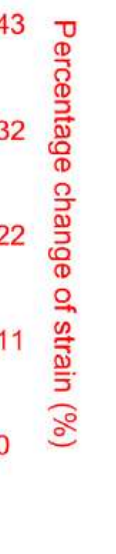

Figure 3.30: (a) Strain vs. $\beta$ curve with time after loading under creep load of $22 \mathrm{MPa}$; (b) change in $\beta$ with cycles of $26 \mathrm{MPa}$ loading (Kim et al. 2018).

\section{Conclusion}

This study inferred that the in situ nonlinear ultrasonic (NLU) procedure is highly effective for understanding the changes in the microstructure of test members under creep and cyclic loadings, which is relevant to real-time monitoring of damages due to such loads in the components of concrete structures in the field. Additional investigation incorporating actual field tests in 
ambient conditions and further details about the technique such as penetration depth limit and resolution can be valuable.

\subsubsection{IMAGING WOOD DEFECTS USING AIR COUPLED FERROELECTRET ULTRASONIC TRANSDUCERS IN REFLECTION MODE (Vossing et al. 2020)}

\section{$\underline{\text { Introduction }}$}

The increasing use of Engineered Wood Products in the construction industry has led to the increasing necessity of their examination for defects. Air-coupled ultrasound (ACU) is a fully automated high-speed technique that can be used to detect defects in wood panels without the need for physical contact with the surface. This feature is very useful for timber products as the coupling agents may contaminate or perforate the sample, causing a significant reduction in their performance. Transmission on the structures and materials up to $200 \mathrm{~mm}$ have been possible with contemporary air-coupled transducers. This paper discusses the suitability of transducers made with charged cellular polypropylene (PP) (also called ferroelectret or piezoelectret) with high signal to noise ratio for better performance of ACU in timber structures. ACU results were compared between transmission and reflection techniques using the three most common samples.

\section{$\underline{\text { Experimental Tests }}$}

Three samples of multiplex, laminated veneer lumber (LVL), and medium-density fiberboard (MDF), with details provided in Table 3.4, were investigated in reflection mode. Some artificial defects such as drillings, millings, and wrong adhesives simulating delamination were inserted into the samples. Tests were conducted in sound samples as well to compare the measurements. The PP transducer used was like a thin foam with a thickness of approximately 70 $\mu \mathrm{m}$, a density of $330 \mathrm{~kg} / \mathrm{m}^{3}$, and a lower acoustic impedance closer to that of air. So, their receivers can pick up signals to three times stronger than piezoceramic transducers. A center frequency of $90 \mathrm{kHz}$, a focal distance of $50 \mathrm{~mm}$, and an aperture diameter of $27 \mathrm{~mm}$ were applied for the measurements along a grid of $1.5 \mathrm{~mm}$. Scanning devices like FlatScan1000 and USPC 4000 AirTech were used. Figure 3.31a shows the through transmission setup using the PP transducers, which was proved efficient to detect delamination, joints, knots, and degradation of wood by fungi and insects in previous studies. In reflection mode, the scan was performed over the test surface 
by moving together with the transmitter and receiver, separated by a roller foam barrier as shown in Figure $3.31 \mathrm{~b}$ and an incidence angle of $1^{\circ}$ (as the perpendicular orientation was found most effective in previous studies).

Table 3.4: Details of wood panel samples (Vossing et al. 2020).

\begin{tabular}{lll}
\hline Multiplex, birch (betula) & LVL, beech (fagus) & MDF \\
\hline Density: $670 \mathrm{~kg} / \mathrm{m}^{3}$ & Density: $700 \mathrm{~kg} / \mathrm{m}^{3}$ & Density: $740 \mathrm{~kg} / \mathrm{m}^{3}$ \\
$1000 \times 500 \times 24 \mathrm{~mm}^{3}$ & $380 \times 250 \times 40 \mathrm{~mm}^{3}$ & $600 \times 450 \times 40 \mathrm{~mm}^{3}$ \\
18 crosswise bonded veneers glued with PVA D3 & 12 layers of veneer glued with a PU-glue & Mixed fibers \\
4 defects: missing adhesive on the bottom $\left(100 \times 100 \mathrm{~mm}^{2}\right), 2$ millings in the & 4 defects: 4 lateral drillings in the & 9 defects at three levels $(10,20,30 \mathrm{~mm}): 3$ \\
middle $\left(10 \mathrm{~mm}\right.$ diameter, $5 \mathrm{~mm}$ depth, and $\left.50 \times 50 \times 12 \mathrm{~mm}^{3}\right)$, and 1 & middle of the panel (10 mm diameter, & $\times 3$ delamination $\left(100 \times 50 \mathrm{~mm}^{2}\right)$, spaced \\
milling on the top $\left(100 \times 100 \times 1 \mathrm{~mm}^{3}\right)$ & $160 \mathrm{~mm}$ depth) & out evenly \\
\hline
\end{tabular}

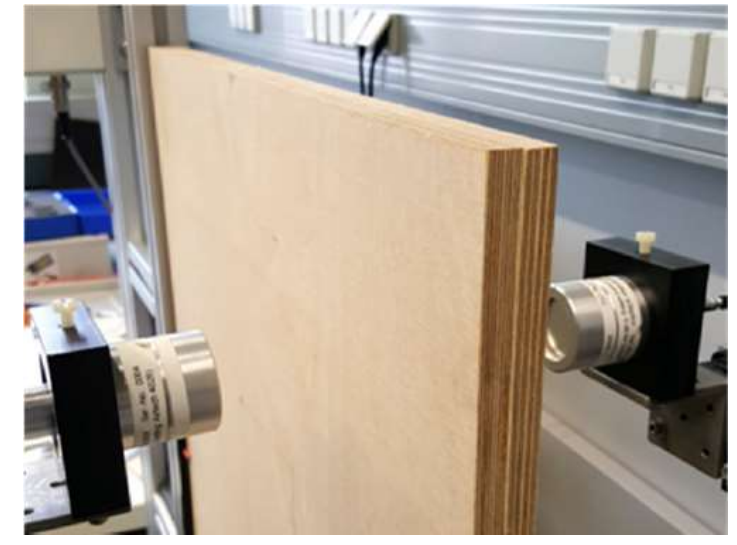

(a)

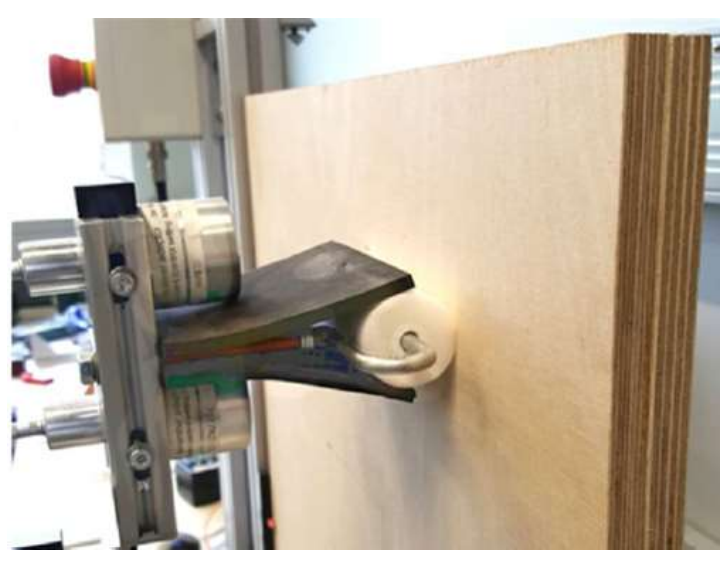

(b)

Figure 3.31: (a) Through transmission; (b) reflection techniques setup (Vossing et al. 2020).

\section{$\underline{\text { Results and Discussion }}$}

The TOF and signal amplitude received for individual points were combined to create Cscans and D-scans. The reflection mode C-scan results in Figure 3.32b shows that some defects like millings (center at coordinates $\{160,670\}$ and $\{210,450\}$ ) were clearly observed whereas delamination (use of the wrong adhesive) was not completely detectable. This may have caused because just a small portion of the energy is transmitted into the sample, which is further attenuated inside the anisotropic material with several boundaries and twice the travel path, eventually disappearing in the noise during reflection. The time of flight (TOF) of the signal in reflection mode could be used to determine the depth of defects without the scans. On the other hand, Figure 3.32c depicts clear and accurate reflections from all the defects in through transmission. The 
difference between the sound and defected wood signal strength in transmission was found to be $25 \mathrm{~dB}$ higher than in reflection mode. Attenuation in the transmission was found more than reflection mode as the travel length is reduced by reflection from the defect without crossing a boundary. Similarly, the LVL sample was investigated to determine the natural as well as artificial defects accurately. A sliding seal and a roller seal results were also compared resulting in less accurate D-scan for slide seal due to higher noise generation and poor acoustic shielding compared to roller seal. Additionally, MDF sample delaminations were observed clearly whose exact position could be inferred using sound velocity or sample thickness. Hence, it was possible to take high-resolution measurements at the rate of 75 points per second (200 times faster than the conventional point-contact transducers) and at a lower cost, using ACU transducers. However, compared to $200 \mathrm{~mm}$ using through transmission, the reflection mode test is capable to investigate structures and materials of maximum thickness of $40 \mathrm{~mm}$.
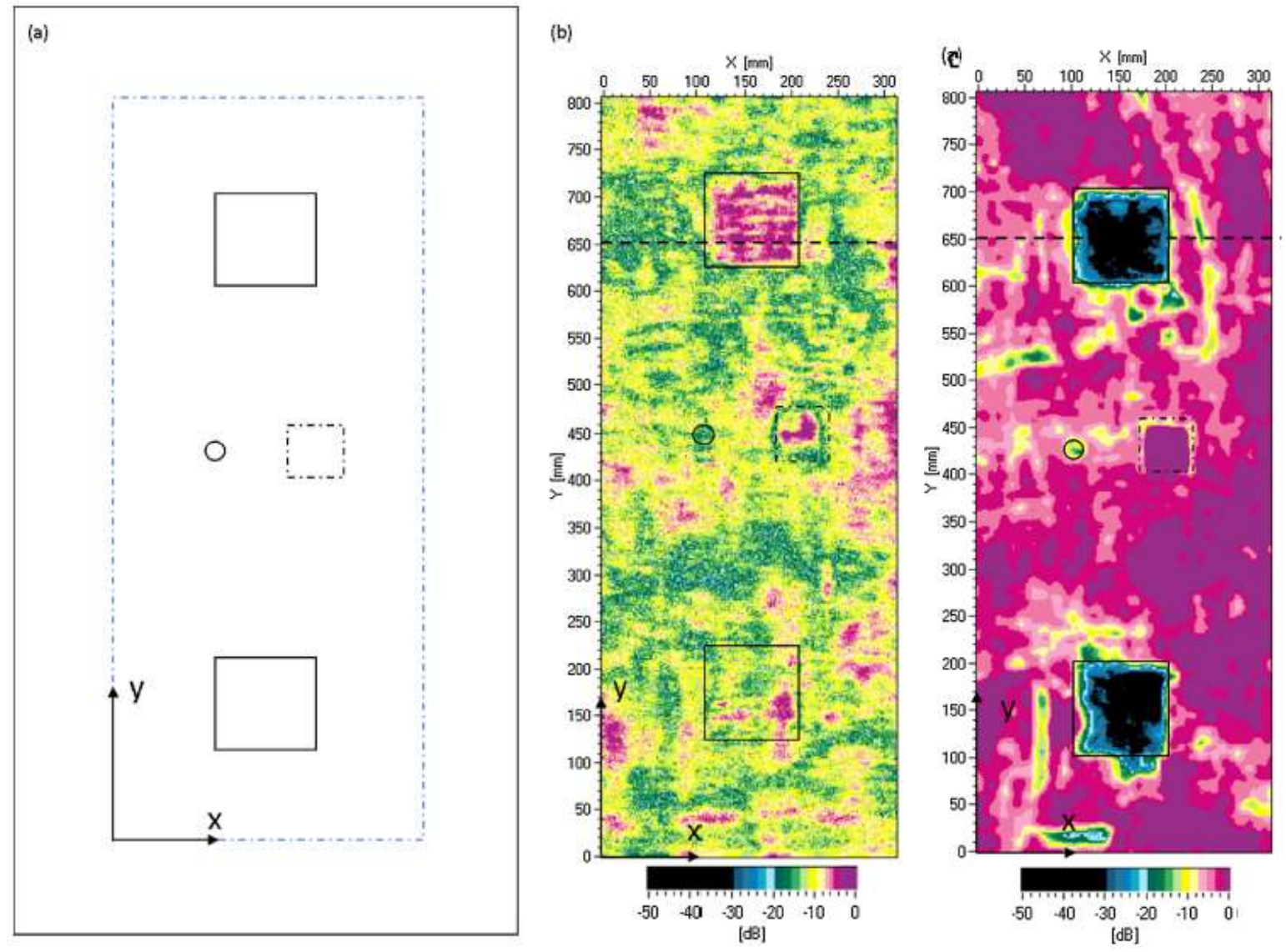

Figure 3.32: (a) Multiplex sample with top three millings and bottom delamination; (b) C-scan of the sample in reflection mode; (c) C-scan of the sample in transmission mode (Vossing et al. 2020). 


\section{Conclusion}

Detection and localization of defects like millings, cavities, and drillings were proved to be accurate in wood panels using ACU with cellular PP transducers and an acoustic barrier. The method has a significant advantage considering the automated operation and scan speed equal to $11.25 \mathrm{~cm} / \mathrm{sec}$. Through transmission technique was deduced to be suitable for the reliable investigation of wood members with thickness up to $200 \mathrm{~mm}$. Similarly, one-sided reflection technique was able to investigate a wood panel up to $40 \mathrm{~mm}$ thickness but at the expense of measurement accuracy. Future research should focus on enhanced use of this technique in thicker samples with higher accuracy.

\subsubsection{IN SITU INSPECTION OF CONCRETE STRUCTURES USING A ROLLING ULTRASOUND SCANNER (Chapagain et al. 2018)}

\section{$\underline{\text { Introduction }}$}

This paper introduced and validated a prototype of an ultrasonic rolling scanning system (COBRI) for the inspection of concrete structures using a Piezoelectric Polyvinylidene Fluoride (PVDF) array transducer. The system was developed by ELOP AS with the frequency range of $50-250 \mathrm{kHz}$. The ultrasonic roller was equipped with an array of multi-layered transducers made by stacking and folding sequences of PVDF films using an adhesive. This configuration improved the electrical impedance match between the transducer and front-end electronics that helped to achieve higher sensitivity and a lower resonance frequency, which is more suitable for heterogeneous material such as concrete.

\section{Experimental Tests}

The scanner had two separate rolling wheels equipped with a Tx (transmitter) and an Rx (Receiver) unit. The separate assembly avoids the need to switch Tx and Rx electrically and can produce continuous scans. Both units were $70 \mathrm{~mm}$ in diameter, separated axially by $85 \mathrm{~mm}$, and comprised of 8 transducers in each unit, as shown in Figure 3.33a. The segmented elastomer rings outside the roller wheels provided dry coupling to the test surface. The scanner was rolled manually along the test surfaces of different concrete structures. The Tx transducers were excited by a pulse with the frequency of $150 \mathrm{kHz}$ and the acoustic reflections were picked up by Rx transducers. The 
signal was then digitized and processed further in software. The system was kept in a track by a rotational encoder. At each roller position, 64 A-scan data were generated by 8 transmitters and 8 receivers. These data were used to generate $\mathrm{B}, \mathrm{C}$, and D scan images. The images were further reconstructed using SAFT, improving the signal to noise ratio (SNR).

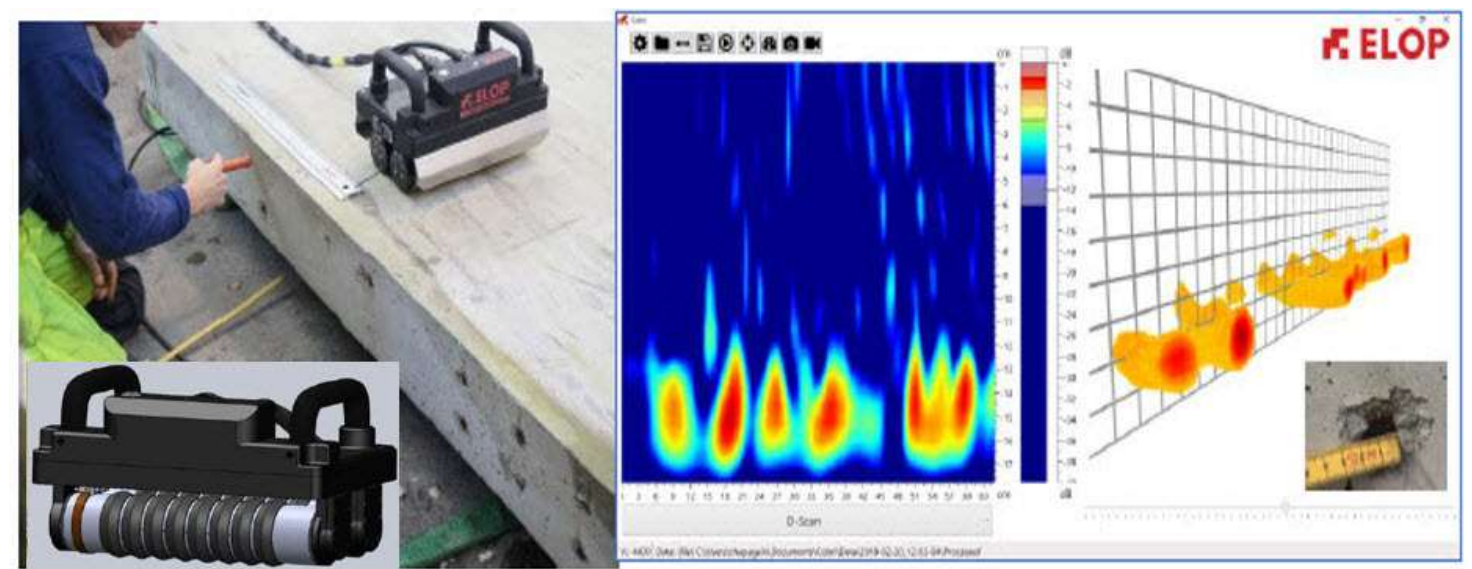

(a)

(b)

Figure 3.33: (a) Concrete test sample with rolling scanner prototype; (b) D-scan and 3D image of the concrete sample (Chapagain et al. 2018).

\section{$\underline{\text { Results and Discussions }}$}

One of the test structures was a $20 \mathrm{~cm}$ thick and $65 \mathrm{~cm}$ long concrete sample with rebars at the depth of about $13 \mathrm{~cm}$ from the scanned surface. Figure $3.33 \mathrm{~b}$ presents the user interface of the scanning system with the D-scan (cross-section image) and the 3D view of the sample. The rebars were detected clearly along the direction perpendicular to the rolling track at the expected depth. The results were also verified using a cover meter. Other samples with air tubes and artificial delamination were also scanned using the system and the resulting images were accurate. Keeping the scan interval at $0.1 \mathrm{~cm}$, a large concrete area was scanned with the inspection speed of $10 \mathrm{~cm} / \mathrm{s}$. In situ data representation through 3D real-time video with high resolution and easy interpretation was an important feature of the system. Since the frequency is adjustable, this system would be highly beneficial for the inspection of concrete mixed with aggregates of variable sizes.

\section{Conclusion}

The portable and user-friendly rolling ultrasonic scanning system enabled the inspection of a large concrete area within a relatively short time and the generation of reliable, easy to 
interpret, and high-resolution 3D real-time video of internal state. The wide range of frequency allowed scanning with options of required penetration depth, resolution, and types of concrete. (DuBose 2020) presents an updated model with features: wireless unit, handheld, inspection speed of 10 to $100 \mathrm{~cm} / \mathrm{sec}$ (10 times faster than the current state of the art instruments), penetration depth from $15 \mathrm{~cm}$ to $50 \mathrm{~cm}$, and a resolution of $1 \mathrm{~cm}$. Further study and experiments were recommended prompting towards modifying the transducer design to increase the resonance frequency of the system for its application in different types of metals and composite materials. Moreover, the instrument can be further improved with arrangements, such as a pulley, to scan non-horizontal surfaces for more efficiency and the broader area of inspection.

\subsection{CONCLUSION}

UT has been established as a reliable, efficient, fast, economical, safe, and easy to perform nondestructive technique to assess various materials and structural members. With some remarkable technological advancements, comprehensive specification of the technique includes portability, penetration depth up to $7 \mathrm{~m}$ in concrete structures; real-time monitoring of corrosion and damage degree of steel in reinforced concrete as well as formation and progress of damages including micro-cracks; early-stage defect detection in anisotropic materials such as timber, 3D video of the inner condition of the test member with resolution as high as $1 \mathrm{~cm}$, data collection speed as high as $100 \mathrm{~cm} / \mathrm{sec}$; on-site data acquisition and result speed as fast as 3 seconds, larger data file size, and so on. Hence, these specifications could be significant in the early detection of defects in civil infrastructure saving billions of dollars. However, there still exist many areas for improvement. On one side, limitations in penetration depths with better instrument setup, resolution, and condition assessment in vertical surfaces of large structures in the field could be enhanced. On the other side, limitations due to gaps in validation, standardization, and certification could be acknowledged and worked upon. 


\section{INFRARED THERMOGRAPHY AND DIGITAL TAP TESTING}

\subsection{INTRODUCTION}

\subsubsection{INFRARED THERMOGRAPHY}

Infrared Thermography (IRT) is a non-invasive technique that measures the intensity of thermal radiation emitted by an object and converts it into thermal images showing the distribution of surface temperature that can be linked with the subsurface conditions (Bauer et al. 2018). The first infrared (IR) sensitive camera was developed in 1929 (Lisowska et al. 2011). The camera was commercialized in the late 1960s and it wasn't until late 1970s when the FLIR systems developed the first radiometric thermal imagers (Kylili et al. 2014). The use of IRT then expanded to assess the airport pavements, bridge decks, sewer systems, and roof leakages by the 1980s (Halabe et al. 1995). IRT has since advanced as a means of structural health monitoring technique with considerable enhancements in its performance and reduction in cost.

IRT is based on the fundamental principle that subsurface defects, such as delamination and voids in an object will have a different heat conduction rate than the defect-free area because of differences in thermal properties. This creates non-uniformity in the heat flow between the two areas, inducing temperature gradient throughout the thickness and differences in the surface temperatures. Therefore, by measuring surface temperatures under such conditions, the presence and location of any subsurface defects can be determined (Kylili et al. 2014). Air-filled defects can be detected easily owing to the low conductivity of air causing it to act like a thermal insulator inducing higher temperature difference. Water, on the other hand, has conductivity only slightly lower than that of concrete resulting in low thermal differences. Hence, water-filled defects may be harder to detect (Halabe et al. 1995).

Every object whose surface temperature is more than absolute zero $(0 \mathrm{~K})$ radiates electromagnetic radiation (Omar and Nehdi 2019). In the electromagnetic spectrum, the infrared band ranges from $0.8 \mu \mathrm{m}$ to $1000 \mu \mathrm{m}$ (Usamentiaga et al. 2014). Radiation in this band is invisible to human eyes or photographic camera but can be detected by IR cameras made of special material 
(Germanium) in ambient temperature $\left(30^{\circ} \mathrm{C}\right)$ (Kylili et al. 2014). The band is further divided into near infrared (NIR, 0.8 to $1.7 \mu \mathrm{m}$ ), short-wavelength infrared (SWIR, 1 to $2.5 \mu \mathrm{m}$ ), midwavelength infrared (MWIR, 2 to $5 \mu \mathrm{m}$ ), and long-wavelength infrared (LWIR, 8 to $14 \mu \mathrm{m}$ ). Among the regions, MWIR and LWIR are mostly used in IR devices. The MWIR devices are generally used for high-temperatures whereas the LWIR devices are used for ambient temperatures $\left(30^{\circ} \mathrm{C}\right)$. Figure 4.1 depicts the scheme for IRT, where the radiation is measured by the IR camera with built-in sensors that are converted into electronic signals and displayed as images in the different color range corresponding to different temperature scale (Usamentiaga et al. 2014). Generally, the brighter color indicates a higher temperature while the darker color indicates a lower temperature.

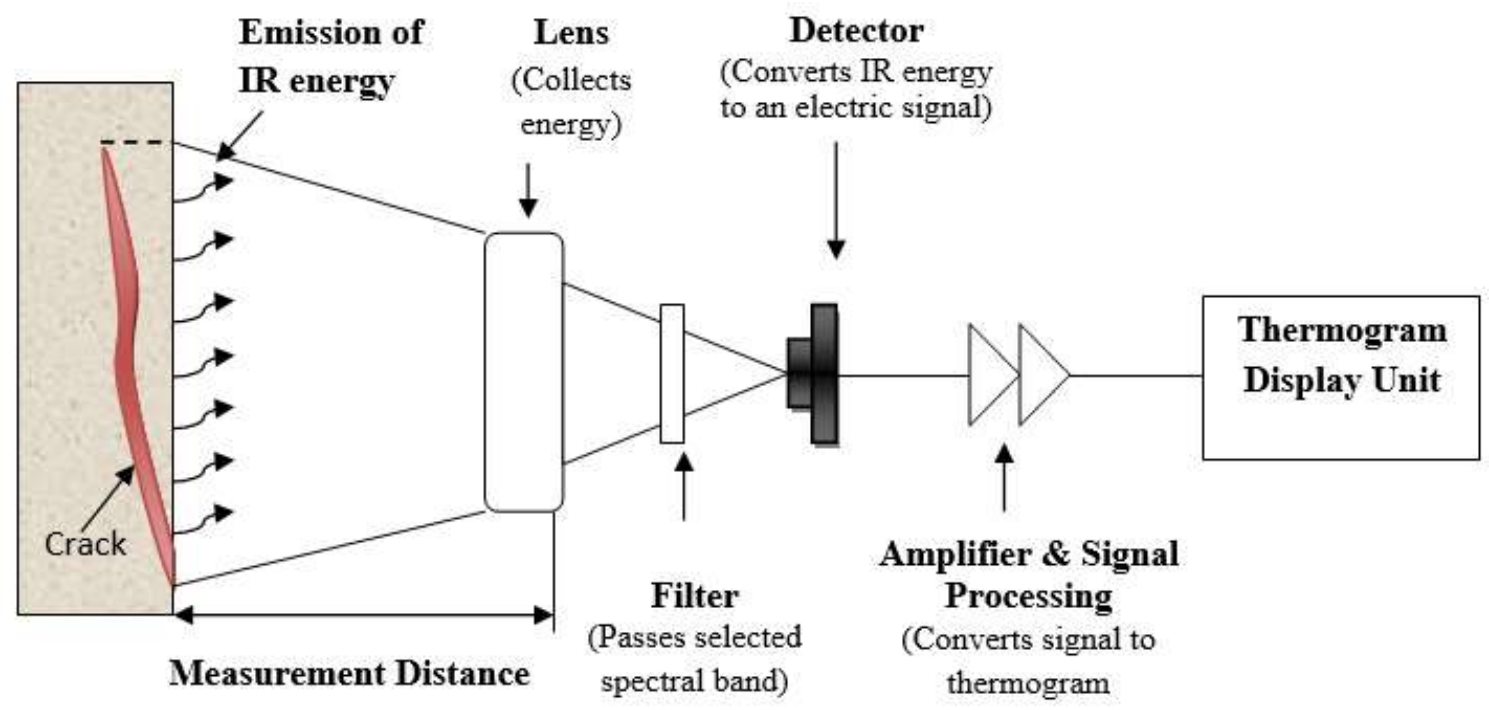

Figure 4.1: Schematic diagram of Infrared Thermography (Jo et al. 2013).

The infrared radiation from an object is directly proportional to its temperature and this relationship is reflected in IRT using an IR camera. In addition to the target object itself, the camera receives radiation from other sources that influence the energy: emission from the surrounding that is reflected by the test surface (depends on the emissivity of the object), and the emission from the atmosphere. Hence, to compute the accurate temperature, these added radiations must be eliminated from the conversion. Depending on the transmittance of the atmosphere, the emitted and reflected radiation might be attenuated. Therefore, the total radiation received by the IR camera $\left(\mathrm{W}_{\text {tot }}\right)$ and the temperature of the object $\left(\mathrm{T}_{\mathrm{obj}}\right)$ can be expressed as: 


$$
\begin{aligned}
& \mathrm{W}_{\mathrm{tot}}=\varepsilon_{\mathrm{obj}} \cdot \tau_{\mathrm{atm}} \cdot \sigma \cdot\left(\mathrm{T}_{\mathrm{obj}}\right)^{4}+\left(1-\varepsilon_{\mathrm{obj}}\right) \cdot \tau_{\mathrm{atm}} \cdot \sigma \cdot\left(\mathrm{T}_{\mathrm{refl}}\right)^{4}+\left(1-\tau_{\mathrm{atm}}\right) \cdot \sigma \cdot\left(\mathrm{T}_{\mathrm{atm}}\right)^{4} \\
& \mathrm{~T}_{\mathrm{obj}}=\sqrt[4]{\frac{W_{\text {tot }}-\left(1-\varepsilon_{\mathrm{obj}}\right) \cdot \tau_{\mathrm{atm}} \cdot \sigma \cdot\left(\mathrm{T}_{\mathrm{refl}}\right)^{4}-\left(1-\tau_{\mathrm{atm}}\right) \cdot \sigma \cdot\left(\mathrm{T}_{\mathrm{atm}}\right)^{4}}{\varepsilon_{\mathrm{obj}} \cdot \tau_{\mathrm{atm}} \cdot \sigma}} \quad \text { (Equation 4.1) }
\end{aligned}
$$

where, $\varepsilon_{\text {obj }}=$ Emissivity of the test object; $\sigma=$ Stefan-Boltzmann constant; $\tau_{\text {atm }}=$ Transmittance of the atmosphere; $\mathrm{T}_{\text {refl }}=$ Reflected temperature; and $\mathrm{T}_{\mathrm{atm}}=$ Atmospheric temperature (Usamentiaga et al. 2014).

The reflected temperature and the emissivity of the test object need to be calibrated in IR camera before the test. These parameters can be determined following procedures described in ISO 18434-1:2008. The reflected temperature can be determined using either direct or reflector method. The latter is more common as it is easy to use and gives better results. Similarly, the emissivity can be measured using two methods: contact method and reference emissivity material method. The latter is more common as it utilizes the available IR camera and doesn't need any external measuring devices. Emissivity has been found to be dependent on the measurement angle as well (Mac et al. 2020). Alternately, the emissivity values for certain materials have been listed in some literature (FLIR Tech Note 2020).

Several methods have been developed to perform IRT in passive and active ways, namely passive thermography and active thermography. Passive thermography uses the natural heat source, i.e. solar radiation, to produce thermograms. This method is applicable when the target is not in thermal equilibrium with the environment and has a sufficient temperature gradient naturally. Active thermography, on the other hand, uses external heating sources such as optical radiation (lamps, heaters, heat guns, thermal blankets, and laser), eddy currents and microwaves, and mechanical ultrasonic waves (Wang et al. 2018). It can be further classified according to the way heat is introduced some of which are explained hereafter: Pulsed Thermography (PT), StepHeating Thermography (SHT), Long Pulse Thermography (LPT), Lock-in Thermography (LT), Frequency Modulated Thermography (FMT), and Vibrothermography among others.

PT (or Flash Thermography) introduces heat in an object with a short duration flashes $(0.1$ $\mathrm{ms}$ to $50 \mathrm{~ms}$ ) depending on the thermal properties of the test material (Wang et al. 2018). Sources such as a flash lamp or pulsed laser can be used for the stimulation and thermal gradient in cooling 
can be monitored for accurate defect detection and estimation of their depths (Poelman and Vesely 2014). Detection of defects in this technique in higher depths may not be possible due to the application of short pulses thus making it suitable for thin layers and near surface defects. A PT with 5 seconds long pulse was able to detect defects of size $0.8 \mathrm{~mm}$ (Mac et al. 2020). Additionally, the need for expensive high-energy flash-light sources is another drawback of this technique (Wang et al. 2018). SHT applies a low-intensity step-pulse heat source, such as halogen lamps, for a long period (5-10 seconds) (Poelman et al. 2020). The signals are recorded during the application of step-pulse. The longer stimulation is useful for the detection of defects located at higher depths (Ciampa et al. 2018). The technique is highly sensitive to defects in low conductivity materials such as FRPs (Wang et al. 2018). A defect size of $20 \mathrm{~mm}$ could be detected using SHT in concrete strengthened with CFRP (Mac et al. 2020). LPT employs a long thermal stimulation pulse in the test object. The stimulation is the same as SHT but the signals are recorded during the cooling process. The intensity of thermal excitation was found to be higher in LPT than PT (Wang et al. 2018).

LT (or Amplitude Modulated Thermography) employs a periodic single frequency sinusoidal signal (with modulated amplitude) stimulation of the test object using affordable sources such as halogen lamps. The technique however needs longer measurement time with such sources (Svantner and Vesely 2014). Hence, these sources might need powerful amplifiers for the stimulation (Wang et al. 2018). FMT stimulates a test object with thermal waves generated by a low-intensity signal with modulated frequency. This technique can be useful in detecting defects at variable depths (Ciampa et al 2018). Vibrothermography (ultrasound-stimulated IR thermography) is a technique where heat is generated in an object in response to vibration. The vibration is triggered through a high power, low-frequency ultrasound generating frictional energy in the defects that induces heat. This method has been found to be reliable for the detection of cracks but not for other types of flaws (Foreman 2017 and Kylili et al. 2014).

Along with the advances in stimulation approaches, numerous post-processing algorithms have also been developed to reduce the noise in the data acquired and enhance the accuracy of defect detection and characterization. Contemporary algorithms such as Multi-Scale Gapped Smoothing Algorithm, Differential Absolute Contrast, Pulsed phase thermography, 
Thermographic Signal Reconstruction, Principal component thermography, etc. are discussed in detail in some literature (Poelman et al. 2020, Garrido et al. 2020, Ciampa et al. 2018).

While performing IRT, recorded signals may be influenced by several factors. Some of the factors to be considered are listed below.

- The emissivity of the target should be correctly calibrated. Even a small change in emissivity, especially in targets made of low emissivity materials such as steel or aluminum, can cause a significant change in the temperature measured (Usamentiaga et al. 2014). Simple measures such as covering the surfaces with high emissivity black paint can resolve this problem (Kylili et al. 2014).

- ASTM D4788-03 lists the condition requirements for using passive IRT for detecting delaminations in the bridge decks including the most appropriate time and environmental conditions for the scanning:

- The rise of $11.1^{\circ} \mathrm{C}$ in ambient temperature, during the winter season, after $4 \mathrm{~h}$ of the sun on the concrete deck or $6 \mathrm{~h}$ of the sun for asphalt overlay decks with wind speed less than $24 \mathrm{~km} / \mathrm{h}$ allows accurate data collection for the detection of subsurface delamination.

- The wind speed should not exceed $50 \mathrm{~km} / \mathrm{hr}$ (30 mph).

- The scanning speed should not be greater than $16 \mathrm{~km} / \mathrm{hr}$. However, even the speed of 48 $\mathrm{km} / \mathrm{hr}$ provided the same results as stationary scans using an IR camera with cooled detectors (Hiasa et al. 2016). Moreover, a cooled camera working in MWIR, with higher integration time, is capable of scanning the test surface with the speed as high as $50 \mathrm{miles} / \mathrm{hr}$ (Guarino et al. 2018).

- The thermal contrast between a sound and a delaminated area should be at least $0.5^{\circ} \mathrm{C}$. Nonetheless, this criterion was reasoned to be on the conservative side with the thermal contrast ranging from $1^{\circ} \mathrm{C}$ to $2.5^{\circ} \mathrm{C}$ between sound areas in concrete (Omar et al. 2018).

- It is critical to follow the ideal time for passive thermography to retrieve accurate images. For passive IRT in buildings, a minimum temperature gradient of $10^{\circ} \mathrm{C}$ is required between interior and exterior temperatures. Additionally, a temperature gradient of at least $2^{\circ} \mathrm{C}$ is required between the test surface and the environment (Nardi et al. 2014). The gradient can easily be achieved during the daytime in summer and night time in winter. 
- Thermograms in asphalt overlaid decks are difficult to interpret. The asphalt layer might reduce the thermal contrast between the delamination and the mass above it. Hence, debonds may be mistaken for delaminations in the images. Roddis and Maser (1990) suggested that the difference might be spotted by the shape of the defect in thermograms: delaminated areas will appear circular and uniform, whereas debonded areas will be represented by large, noncircular, and non-uniform spots (Omar and Nehdi 2019).

- Some shadowed areas might give an impression of defect due to the uneven absorption of solar radiation. Tsai et al. (2019) proposed an approach to quantify the shadow effect on building facades and to produce thermograms removing the shadow effect.

- The location and angle of the IR camera should be strategically decided to avoid possible errors from the background or solar reflections. The closer the camera, the better is the resolution. The camera placed at right angles to the test surface provides more details and better results (Kylili et al. 2014).

Various IR cameras available today come with sophisticated but convenient features. FLIR Systems has developed state of the art IR camera models with improved specifications, few of which are listed below:

- Resolution: $1280 \times 1024$

- Accuracy: $\pm 1{ }^{\circ} \mathrm{C}$ or $\pm 1 \%$ of reading for limited temperature range

- Thermal Sensitivity: $<0.018^{\circ} \mathrm{C}(<18 \mathrm{mK}$ NETD $)$

- Temperature Range: $-40^{\circ} \mathrm{C}$ to $3,000^{\circ} \mathrm{C}$

- Frames per second: $1004 \mathrm{~Hz}$ at a full window, and $4,175 \mathrm{~Hz}$ at a minimum window

- Minimum integration time: $480 \mathrm{~ns}$

- Communication Interfaces: USB Micro-B, Wi-Fi, Bluetooth, HDMI

- Storage: 16 GB RAM and support SD card up to $4 \mathrm{~TB}$

- $180^{\circ}$ rotating lens platform, touchscreen feature.

- Highly affordable IR cameras.

IRT can be used as a tool for the condition monitoring of civil infrastructures. Different applications can take advantage of this technique such as detection of near surface voids, honeycombing, cracks, delamination, roof leak, loss of insulation, molds, and moisture, and 
thermal bridges to spot energy loss to list a few. There has been various research on the possible detectable size of defects in concrete structures using IRT. Delaminations up to a depth of $7 \mathrm{~cm}$ was observed in concrete in laboratory conditions (Huh et al. 2018). It was found that using a thermal or phase contrast post-processing method, it is possible to detect defects with size greater than or equal to the concrete cover. Ultimately, it was demonstrated that using phase contrast method, delaminations up to a depth of $12.5 \mathrm{~cm}$ can be observed (Cotic et al. 2015). Furthermore, delaminations as thin as $2 \mathrm{~mm}$ were detected below the 2-3 $\mathrm{cm}$ thick plaster (Cotic et al. 2014).

\subsubsection{DIGITAL TAP TESTING}

Tap Testing is a simple but effective impact-based NDT technique that gives localized results from local excitation. This technique has been in use for a long time in the aerospace industry for the testing of composite materials. Over the years, this technique has evolved from a hearing based coin tap testing to an instrumented testing capable of producing c-scans with quantitative detection of sub-surface discontinuities (delamination, debonds, and voids) in thin composite laminates, sandwich structures, and bonded joints (Hsu et al. 2009, Georgeson et al. 1996).

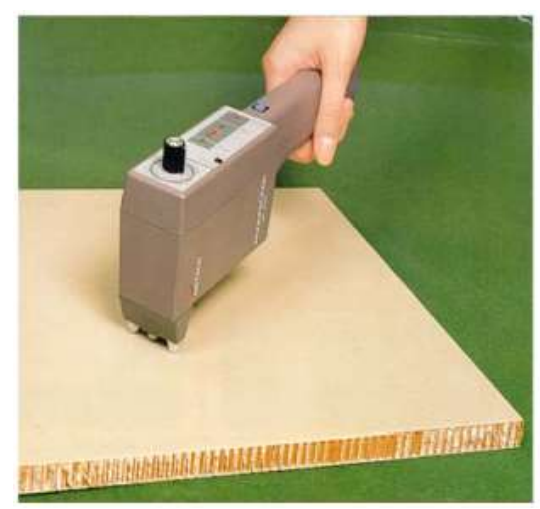

(a)

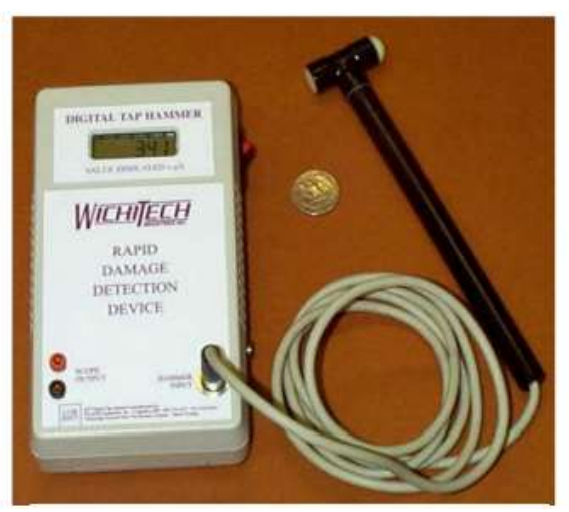

(b)

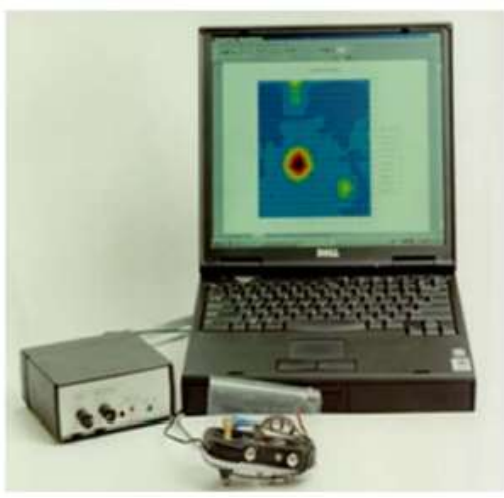

(c)

Figure 4.2: DTT devices: a) Woodpecker; b) RD3; c) CATT (Poveromo 2015).

Coin Tap Testing involved the tapping of a coin or a hammer on the surface of the test member whose condition was assumed depending on the type of sound it made. Solid high pitch sound would suggest that the member is in a good condition whereas a dull sound suggested a bad condition. Although simple and cost-effective, this method could only provide qualitative data and 
was entirely dependent on the operator's hearing ability and was influenced by the background noises. To eliminate these drawbacks, the technique was reformed into instrumented devices (Hsu et al. 2009). Three major commercial devices to perform digital tap testing (DTT), developed thereafter, were automated Woodpecker developed by Mitsui Industries (Mitsuhashi et al. 1991), Rapid Damage Detection Device $\left(\mathrm{RD}^{3}\right)$ by WichiTech Industries (Georgeson et al. 1996), and Computer Aided Tap Tester (CATT) by Iowa State University (Hsu et al. 2001), as shown in Figure 4.2 (Poveromo 2015).

The technique involves tapping the test surface with an impact hammer or tapper, for which the contact time (impact duration) is measured. The contact time can be measured by mounting an accelerometer or force transducer into the tapping mass. The force-time pulse received by the accelerometer after each tap is converted into a voltage pulse. The width at half-amplitude, in other words, the contact time, is measured by a logic circuit in $\mu$ s and displayed in the numerical form (Georgeson et al. 1996). In this case, the half amplitude width is taken because the force-time curve is not defined at the bottom for the full amplitude width due to inherent noise. The presence of defects will decrease the local stiffness of a structure and produce a wider force-time pulse or shows a longer contact time. The test surface is analyzed by comparing the contact time or determining the deviation of the force-time pulse width from the nominal width obtained from a reference undamaged surface. Hence, a sound or rigid area will give lower reading whereas a damaged area will give a higher reading.

The contact time correlates to the mechanical impedance and stiffness of the test member. Under a constant tapping mass $(\mathrm{m})$, the contact time $(\tau)$ of the tap depends on the local stiffness (k) of the surface as:

$$
\left.\tau=\pi(\mathrm{m} / \mathrm{k})^{1 / 2} \quad \text { (Equation } 4.3\right)
$$

Various literature has shown that the contact time is insensitive to the tapping velocity or force. Figure 4.3 shows the force-time history of increasing levels of taps (with a constant tapping mass of $10 \mathrm{~g}$ ) in a good and a damaged region on a composite honeycomb sandwich panel. It can be noticed that the contact time is almost constant for all levels of forces in both areas. This eliminates the need for mechanized tapper and proves that different operators can tap using the device and still produce similar results. This observation has been verified with experiments resulting in a 
variation of less than 5\%. Furthermore, the stiffness determined from tap testing results (using Equation 4.3) and static load test on the same location were compared. Figure 4.4 shows a good agreement in the linear regression curve, proving that the instrumented tap testing technique is capable of quantitative condition assessment of structures (Hsu et al. 2009).

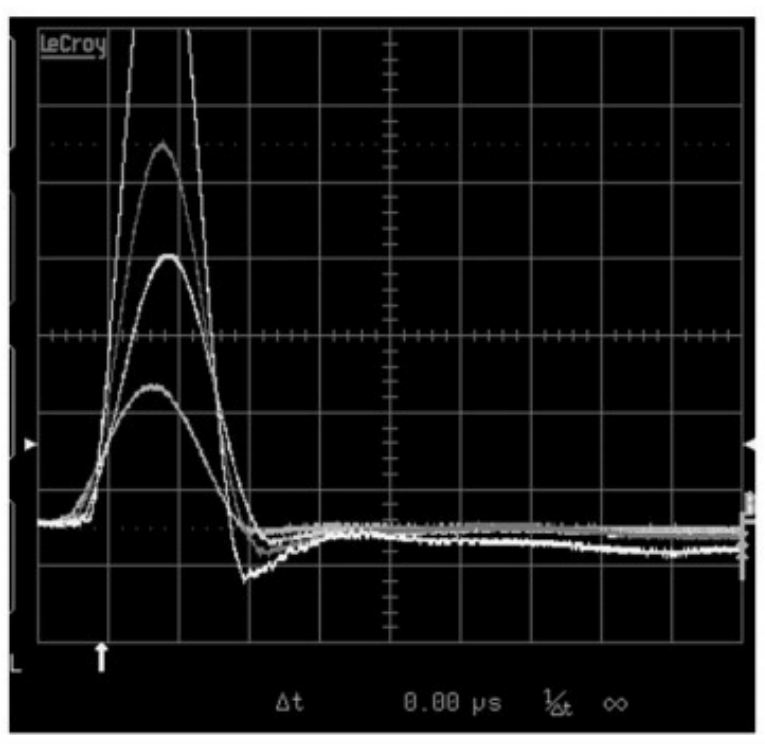

(a)

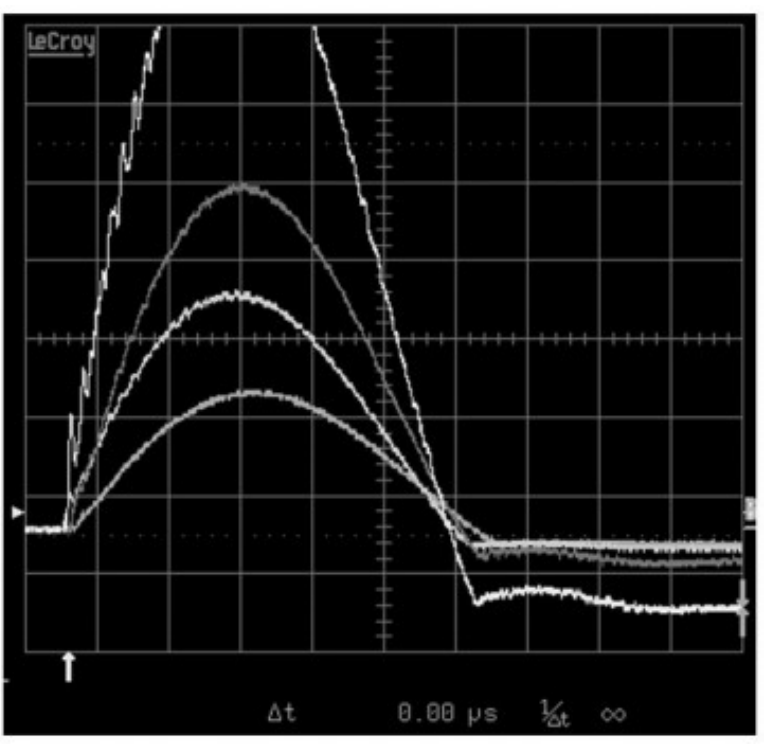

(b)

Figure 4.3: Different levels of force vs. time curves for (a) good area; (b) bad area (Hsu et al. 2009).

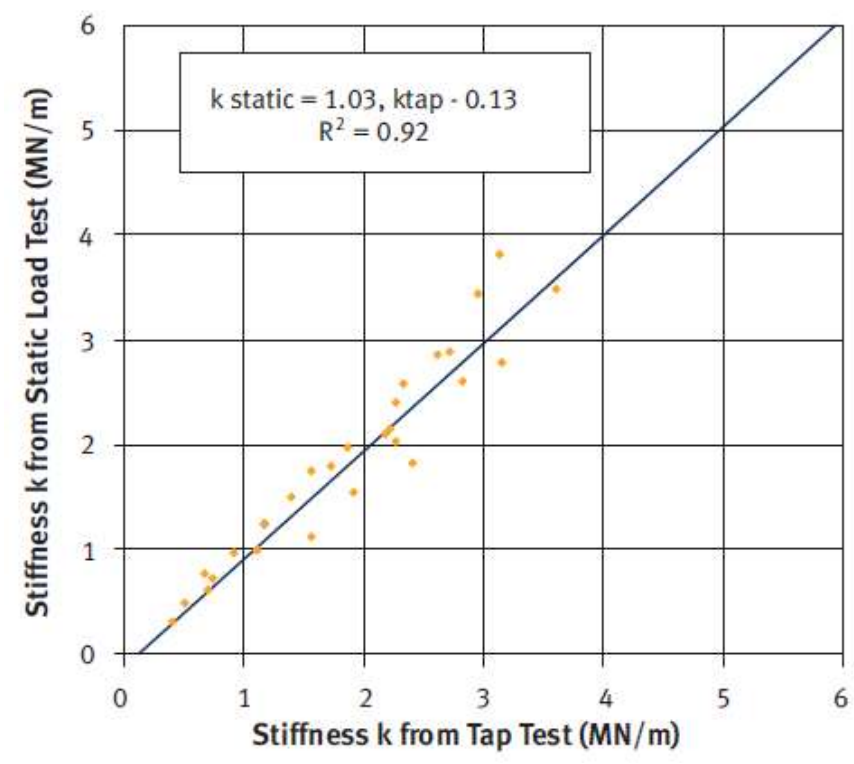

Figure 4.4: Linear regression curve for stiffness computed from the Static Load Test vs. the Tap Test (Hsu et al. 2009). 
Woodpecker is a handheld, battery-operated tap test device with the ability to measure the stiffness and produce quantitative results. It comprises of a solenoid-driven hammer integrated with an accelerometer to measure and display the contact time (Hsu et al. 2009). The device was designed with an LED light system that alerts about the condition of the test member. A reference reading is taken from a defect-free area, and the readings from the test surface are depicted with different colored lights. Green, yellow and red lights signify that the contact time is in good, adjustable, and bad condition ranges respectively (Poveromo 2015). The latest model of Woodpecker WP-632AM, in addition to the time display, can be equipped with an additional X/Y plotter capable to produce a color tile map of the test area (Gryzagoridis and Findeis 2013).

$\mathrm{RD}^{3}$ consists of a lightweight hammer mounted with an accelerometer; the hammer is attached to the hand-held control module through a cable. After each new tap, the display resets and a new value is shown. According to the user manual of this device, an area is considered defective if the number displayed is at least $10 \%$ higher than the reading from a sound reference area without any defects. The device allows 16 hours of continuous operation with rechargeable Nicad batteries. The maximum detectable depth by the instrument was found to be $6 \mathrm{~mm}$ (Georgeson et al. 1996). The device was deduced to be designed typically for thin composites with thickness ranging from 5-10 mm and is not appropriate for thick composite or concrete members (Halabe et al. 2020).

Tap testing, being a local inspection technique, full coverage of large area would be extremely slow and tedious. Hence, automated and mechanized systems were integrated into CATT to make it more proactive. The system provides quantitative, image-based results for the test area. It involves laying up a transparent grid on the test surface, inserting the grid information on the system software, and tapping the area within each grid. The system also has an alternative semi-automatic magnetic cart for faster data collection. After the collection of data from laid-out grids, CATT displays the c-scans corresponding to the collective local stiffness that is computed using the contact time in Equation 4.1. These scans show the percent reduction in stiffness due to the presence of damages (Hsu et al. 2009).

Fiber reinforced polymers (FRP) composites are being increasingly used in the construction and rehabilitation of civil infrastructures. Some of their benefits include high strength 
to weight ratio, high resistance to corrosion, durability, and low maintenance cost. When it comes to rehabilitation, the addition of newer material should aid in the strength or serviceability of the existing structure. This can be assured by applying tap testing techniques in the field. The major advantages of this technique are portability, low cost, and easily-to-handle features. It has been extensively used to detect subsurface debonds and voids between FRP wraps and underlying structural members (Halabe et al. 2020, Wheeler 2018, Halabe et al. 2014).

ACI 440.2R-17 imposes a tolerance for debond size in FRP wraps around concrete elements: "Small delaminations less than 2 in. $^{2}\left(1300 \mathrm{~mm}^{2}\right)$ each are permissible as long as the delaminated area is less than 5 percent of the total laminate area and there are no more than 10 such delaminations per $10 \mathrm{ft}^{2}\left(1 \mathrm{~m}^{2}\right)$." However, experimental observations in FRP wrapped concrete cylindrical specimens in Halabe et al. (2013a) did not concur with that criterion. A 5\% debond area corresponded to a reduction of 20 to $30 \%$ confined compressive strength of the specimens. It was recommended that the amount of debond tolerance should be changed to less than 1.5 to $2 \%$ that resulted in an approximately $10 \%$ reduction in confined compressive strength. Debonds as small as $0.06 \mathrm{in}^{2}$ (0.25 in. $\mathrm{x} 0.25 \mathrm{in}$.) were easily detected in FRP wrap around concrete elements using WichiTech $\mathrm{RD}^{3}$ (Halabe et al. 2014).

\subsection{REVIEW OF APPLICATIONS OF INFRARED THERMOGRAPHY AND DIGITAL TAP TESTING}

\subsubsection{IR THERMOGRAPHY IN MOISTURE AND EARTHQUAKE DAMAGE DETECTION PERFORMED IN THE ZICA MONASTERY, SERBIA (Ristic and Polic- Radovanovic 2013)}

\section{Introduction}

A thermographic survey was conducted on Zica Monastery located in Serbia that was constructed in the 13th century. The components of the buildings were built using different materials such as bricks, stones, wood, and metals. Assessment using IRT was designated after several cracks were observed on St. Savior and St. Sava churches in the complex of the monastery, following an earthquake of magnitude 5.3 on $3 \mathrm{rd}$ November 2010 . The tests were conducted in December 2010, before which preliminary post-seismic assessments performed had ensured no 
endangerment to the stability of the buildings. However, considering the constant propagating nature of cracks, the non-contact technique was considered the best fit to achieve a seismic retrofit strategy whilst abiding by the heritage conservation principles. The study focused on the investigations of possible cracks and moisture infiltration in the buildings using IRT.

\section{$\underline{\text { Experimental Tests }}$}

IRT was conducted on three buildings: St. Savior church, St. Savior tower, and St. Sava church. Thermograms were recorded using Therma CAM T-335 developed by FLIR Systems. The outside temperature during the test was $10^{\circ} \mathrm{C}$ while the inside temperature for St. Savior church with the floor heating system was $14^{\circ} \mathrm{C}$, and that for St. Savior tower without heating was $6^{\circ} \mathrm{C}$. This study presented the investigation results from the monastery complex entrance, St. Savior Church indoor walls, eastern and northern façade, and St. Savior Tower indoor walls.

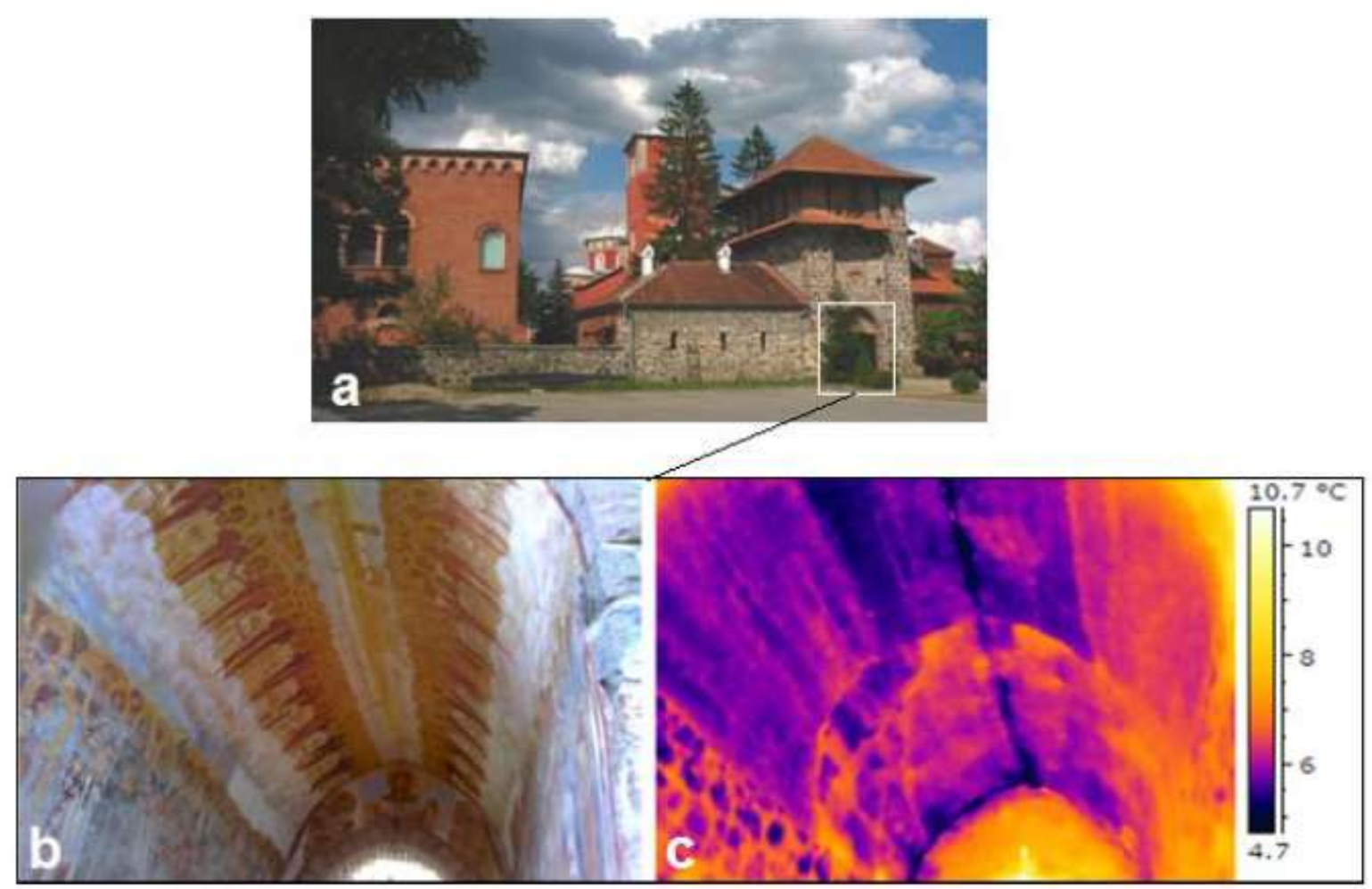

Figure 4.5: (a) Monastery complex entrance; (b) the entrance ceiling; (c) thermogram corresponding to the entrance (Ristic and Polic-Radovanovic 2013). 


\section{$\underline{\text { Results and Discussion }}$}

Figure 4.5 represents the monastery complex entrance with the recorded thermogram. Several cracks and moisture presence were identified as dark spots, some of which were visually inaccessible. One major flaw was detected in the middle of the ceiling with entrapped moisture. The images were partly influenced by frescoes that appeared as the areas reflecting different temperatures with moisture presence. Generally, the damp area temperature can be lower or higher compared to the dry area basing on the microclimatic conditions during the recording. It might be lower due to the surface evaporation or higher due to the lower thermal conductivity of water compared to other building materials. Similarly, the extent of moisture damage was also observed in a wall in St. Savior church. Since moisture damage can be easily detected through visual inspection, a field test may be considered unnecessary. However, in some cases, the condition can be noticed only after serious damage to the structure. IRT can, therefore, produce a moisture map of the target area that is not possible with a visual inspection.

Figure 4.6 presents a thermogram of a wall of St. Savoir Tower. Since the inside temperature for this building was $4^{\circ} \mathrm{C}$ lower than the outside temperature, the defects such as cracks appeared warmer with brighter light. The dark areas representing lower temperatures on the top of the wall and the tower dome were identified as moisture damage. The cracks were partially noticeable with a visual inspection, however, IRT was capable to provide a precise delineation of the location, length, and width of the cracks.
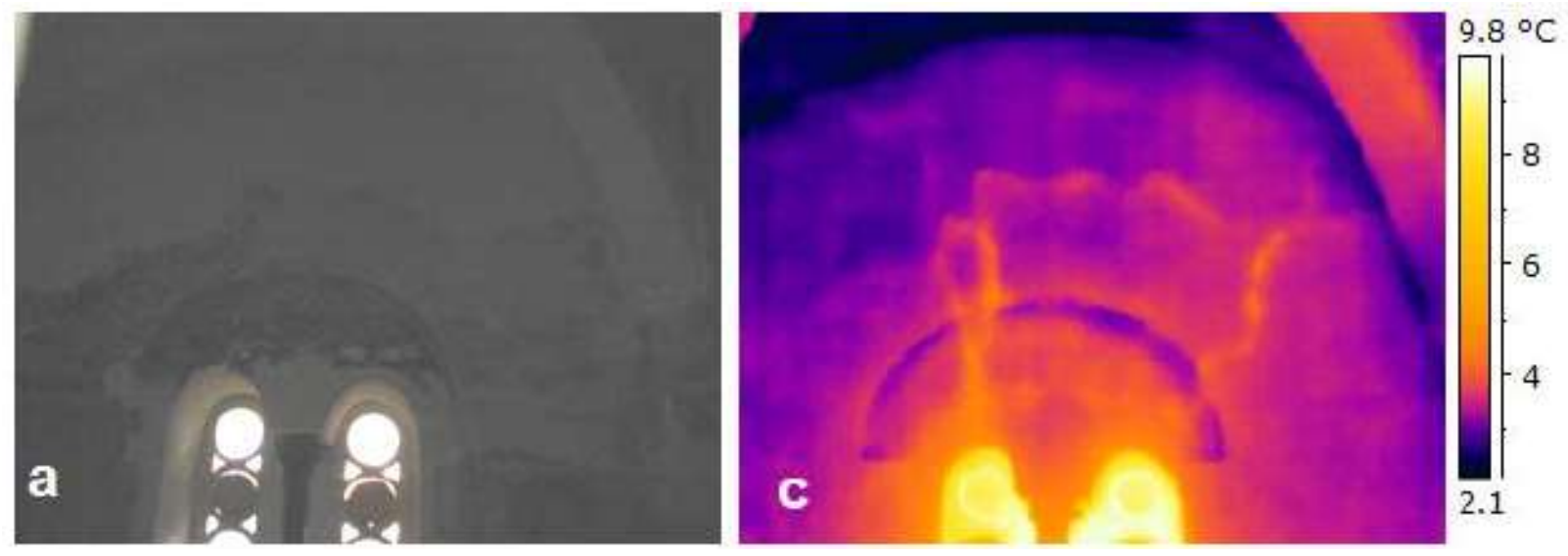

Figure 4.6: (a) St. Savior Tower wall with corresponding thermogram (Ristic and Polic-Radovanovic 2013). 
A lightly visible damp area on the bottom part of the eastern façade of St. Savior Church was also investigated using IRT as shown in Figure 4.7. Moisture infiltration from the ground was detected up to a height of $1.5 \mathrm{~m}$. Similarly, the northern façade of the church was discovered to be infiltrated with moisture up to a height of $2 \mathrm{~m}$.
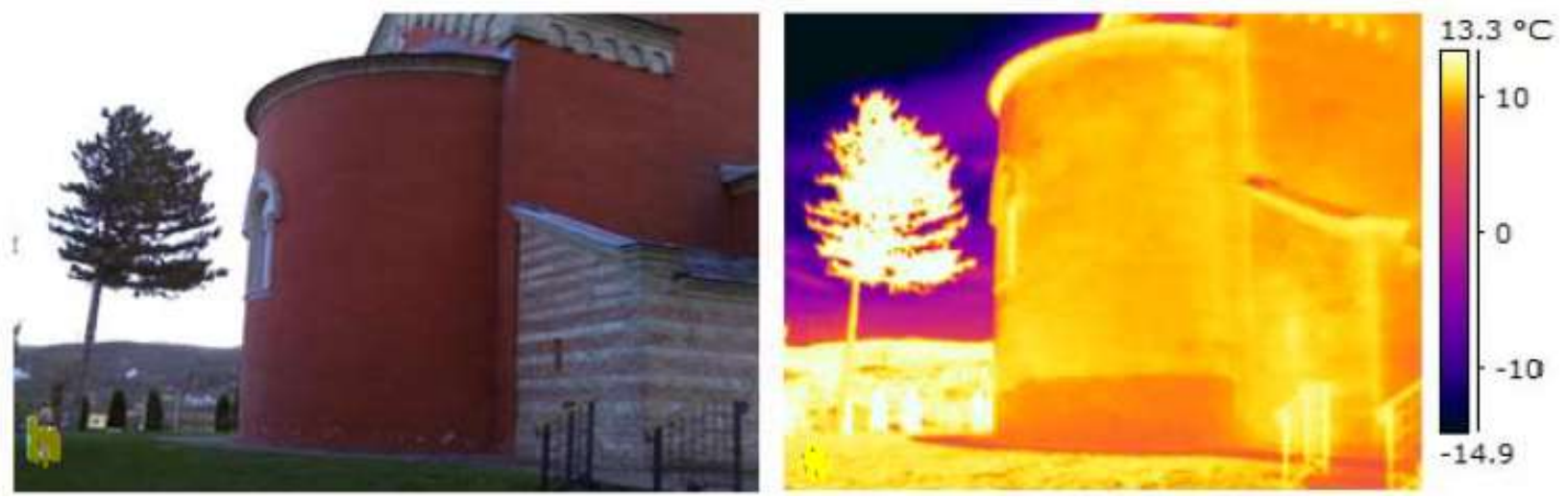

Figure 4.7: Eastern façade with corresponding thermogram (Ristic and Polic-Radovanovic 2013).

\section{Conclusion}

Non-contact IRT was able to detect the short and long term damages due to earthquake such as the presence of cracks, and moisture infiltration through the cracks in the historically important masonry buildings. The technique was found reliable for onsite moisture damage detection and moisture mapping. Although the exact properties of cracks could not be obtained, qualitative definitions of defects such as position, length, and width of cracks were attained by using the technique. Moreover, IRT was able to demonstrate promising results from the assessment of large surfaces in a short time. Therefore, cognition of damages, using IRT, provided a ground for making the final decision regarding the retrofit option for the monastery buildings.

\subsubsection{EVALUATING THE DAMAGE DEGREE OF CRACKING IN FACADES USING INFRARED THERMOGRAPHY (Bauer et al. 2018)}

\section{$\underline{\text { Introduction }}$}

IRT has been increasingly used to locate and map defects in the building façade. Formation of cracks is one of the major defects in the building facades that compromises its integrity and can be the source of other defects such as detachment and efflorescence. Measuring their degree or 
severity is therefore very important in the maintenance or rehabilitation process. Crack width and damage width are two different things. Crack width indicates the opening of the crack, whereas the damage width represents the extended damage initiated by the crack. Crack width can be easily identified visually, however, it is not so simple to determine subsurface damage width. Since facades are made up of different elements, their responses to heat flux are different that keeps changing throughout the day because of variations in environmental conditions. This causes variations in thermograms frequently. Hence, monitoring the dynamic behavior of the temperatures over time may be useful to understand and classify the damages. This study aimed to identify the width and depth of the façade damage by measuring the changing behavior of the temperatures with time using quantitative passive IRT and hygrothermal simulation.

\section{$\underline{\text { Experimental Tests }}$}

Quantitative passive IRT was applied to the ceramic tile covered masonry façade of a building in Brazil. The façade was oriented towards the east and consisted of significant cracks in three regions as shown in Figure 4.8a. Before the field tests, a hygrothermal simulation of 60 days was run for the building façade in WUFI Pro 5.3 software to estimate the temperature profile for the three days ( 72 hours) field test with IRT. Various parameters were given as input such as façade layers, material properties, orientation of the façade that affects the solar incidence, location, etc. IRT was conducted using FLIR T-420 with the temperature range of -20 to $120^{\circ} \mathrm{C}$, the spectral range of 7.5-13 $\mu \mathrm{m}$, the pixel resolution of $320 \times 240$, and telescopic lens with an instantaneous field of view (IFOV) of $0.82 \mathrm{mrad}$. A BOSCH laser was used to measure the distance and environmental conditions (relative humidity and air temperature) were measured by an EXTECH M0297. The emissivity and apparent reflected temperature were measured in the field and entered in the camera. Figure $4.8 \mathrm{~b}$ shows that the IR camera was placed at a distance of $33 \mathrm{~m}$ from the façade with an angle of incidence of $35^{\circ}$ and it was programmed to collect data every 5 minutes. From the simultaneous thermograms produced, the temperatures in the cracked area $\left(T_{d}\right)$ and sound area $\left(\mathrm{T}_{\mathrm{nd}}\right)$ were measured for all three regions of inspection. The severity of cracks in terms of depth was determined using the thermographic contrast (Delta- $T=T_{d}-T_{n d}$ ). Previous studies proved that the crack depths are directly related and proportional to Delta-T values. For the computation of crack width ( $\mathrm{L}_{\text {crack}}$ ), a temperature line perpendicular to the identified crack was drawn in the thermogram, which was exported to Excel with the temperature values for each pixel 
in the line. Figure 4.11a depicts the profile obtained from the thermogram. $\mathrm{L}_{\text {crack }}$ was computed in mm using the profile and equation: $\mathrm{L}_{\text {crack }}=\mathrm{L}_{\mathrm{cr}} \times$ IFOV $\mathrm{x} \mathrm{L}$, where, $\mathrm{L}_{\mathrm{cr}}$ is the width obtained from the thermograms in pixels, and $\mathrm{L}$ is the distance between the thermographic camera and target in meter.

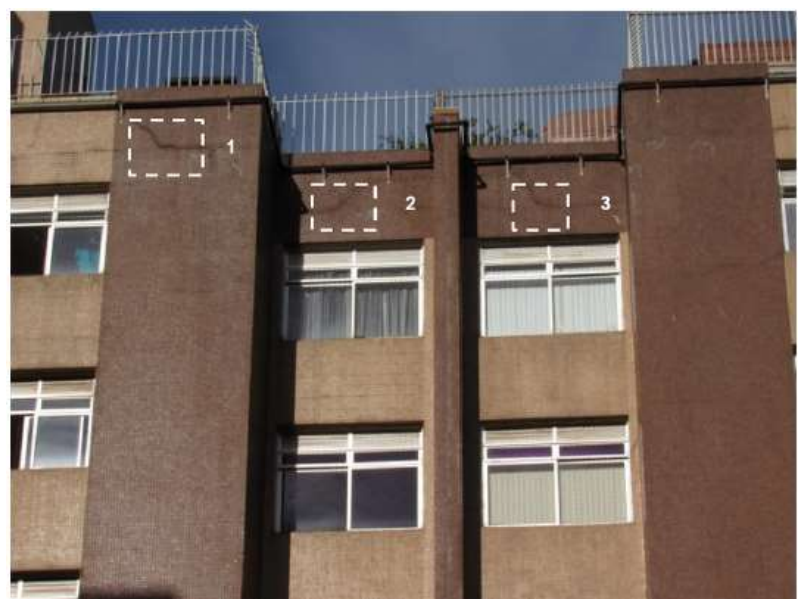

(a)

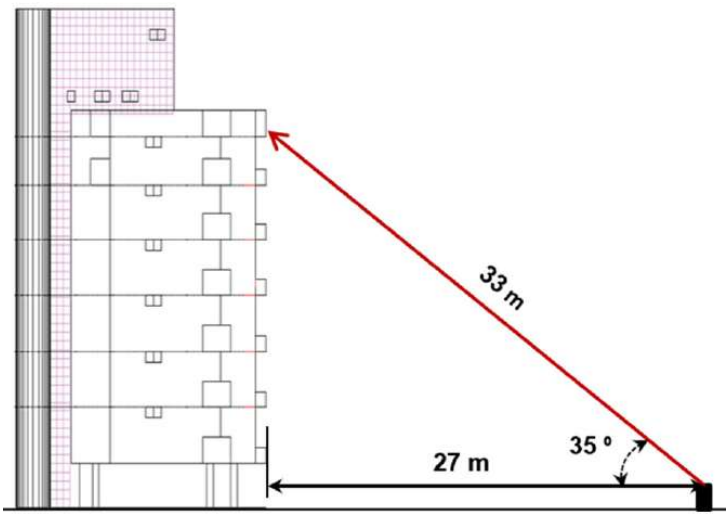

(b)

Figure 4.8: (a) IRT target building façade with visible cracks in regions 1, 2, and 3; (b) Data acquisition position of the IR camera (Bauer et al. 2018).

\section{$\underline{\text { Results and Discussion }}$}

The hygrothermal simulation produced a temperature profile of the façade layers, based on which three days (72 hours) for field testing were selected. Figure 4.9 depicts the temperature profile for the three days obtained from the software: $T_{\text {sup }}, T_{a m b}, G_{\text {rev }}$ represents the outer surface temperature of the façade, ambient temperature, and temperature gradient between interior and exterior of the façade ceramic layer respectively. It was found that the façade had a cyclic thermal behavior similar to the atmosphere. Initially negative (exterior temperature lower than that of interior), the temperature gradient would be highest $\left(3.9^{\circ} \mathrm{C}\right)$ at about 9:00 am. The temperature profile of region 1 between 7:30 and 10:40 am from IRT was found to be very similar to the software profile. It showed a heating process with a positive temperature gradient higher than the established required value $\left(0.6^{\circ} \mathrm{C}\right)$ to identify defects. Hence, this period was chosen for further analysis, during which the surface above the cracked region appeared as a hot spot. The temperatures of cracked and sound areas from the three hours were compared between each region. For all regions, it was found that the temperatures were close initially, then increasing difference 
was noticed with time, mostly after 40 minutes into the test. However, Figure 4.10 reveals that the crack was more prominent in the thermograms at 20 and 40 minutes of heating process and that it was difficult to locate cracks at 150 minutes possibly because of the higher and fluctuating temperature in the whole system. Hence, for the quantitative analysis, data up to 40 minutes were utilized. Comparing the temperature behavior profile over time (instead of an isolated thermogram) for all three sections showed that the heat flux disturbance for each region was different, suggesting different damage degree. The Delta-T plots over time for each region were presented as Figure 4.12. The environmental conditions and the heating process for the tests in all three cracks were the same that resulted in a similar patterned temperature profile. However, crack 1 showed higher temperature gradients (Delta-T values) than the others. This behavior was directly related to the cracks influencing the heat flux suggesting a higher damage extent. Hence, it was clear that crack 1 was the deepest one, and crack 2 had the least depth. The temperature values for the lines perpendicular to all three cracks over time were also plotted; Figure $4.11 \mathrm{~b}$ shows the one for crack 1. Each $L_{c r}$ was measured that represented the region where the heat flux was disturbed. The final results during the clear heating process until 40 minutes were shown in Table 4.1. The mean widths of damage due to cracks 1, 2, and 3 were determined as $60.89 \mathrm{~mm}, 57.5 \mathrm{~mm}$, and $54.12 \mathrm{~mm}$ respectively. The spurious values for crack 3 were because of high $\mathrm{L}_{\mathrm{cr}}$ resulted from low contrast between $T_{d}$ and $T_{n d}$. The width corresponded to the damage extent (maybe due to internal tile detachment) of the crack and not the physical width of the crack that was observed visually.

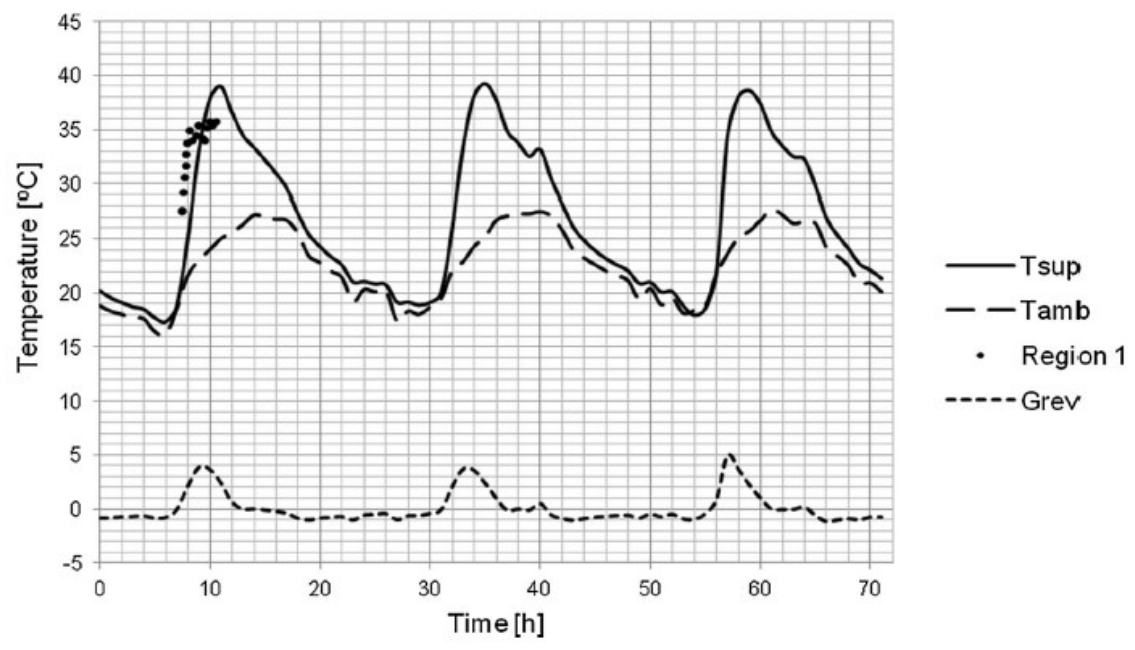

Figure 4.9: Temperature profile over time obtained from the hygrothermal simulation and comparison with IRT data in region 1 (Bauer et al. 2018). 

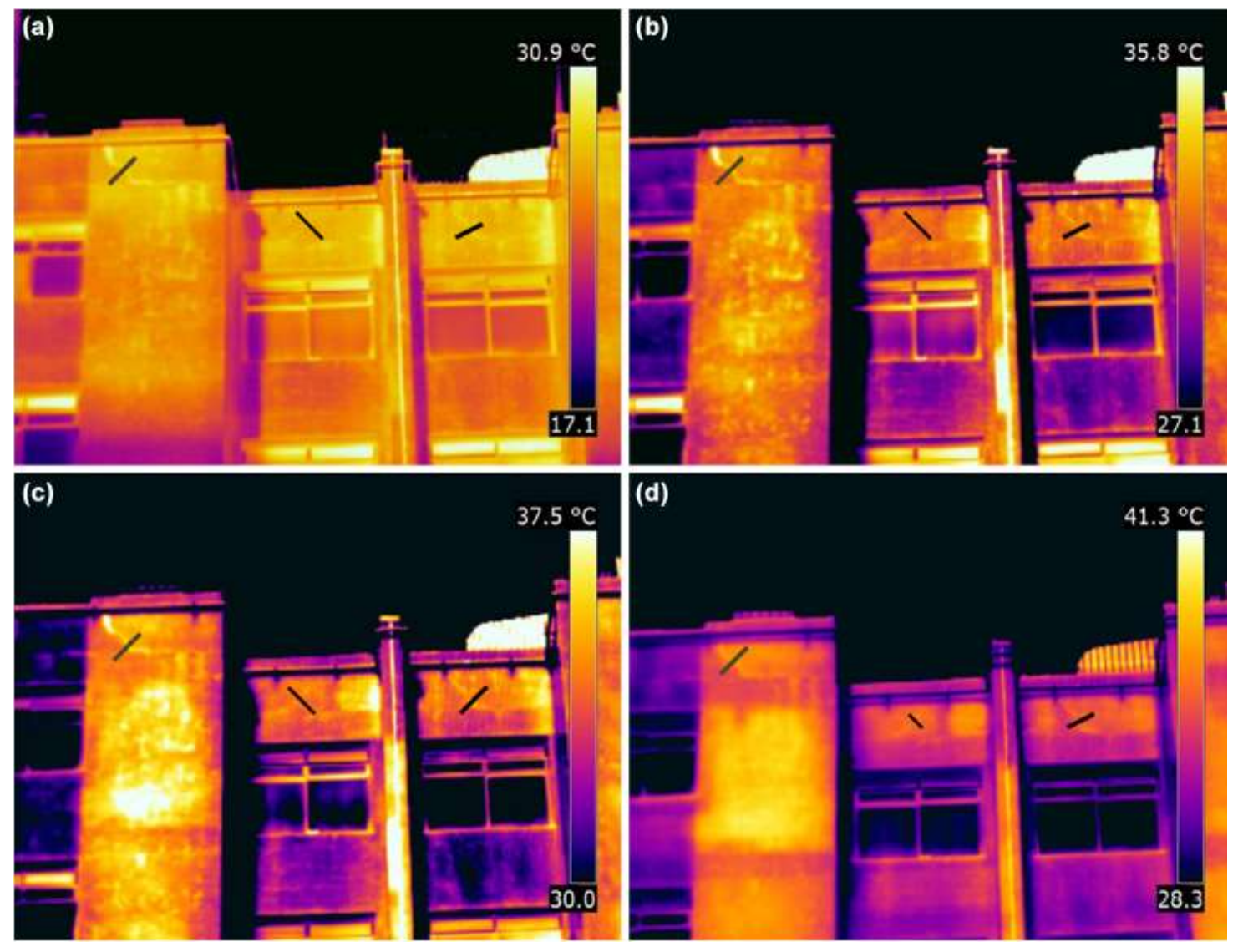

Figure 4.10: Thermograms showing different patterns at (a) 0; (b) 20; (c) 40; and (d) 150 minutes (Bauer et al. 2018).

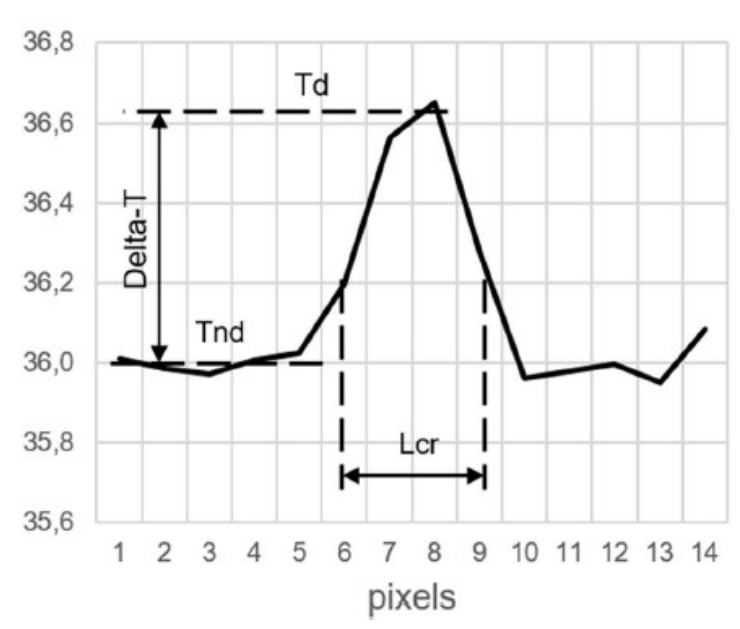

(a)

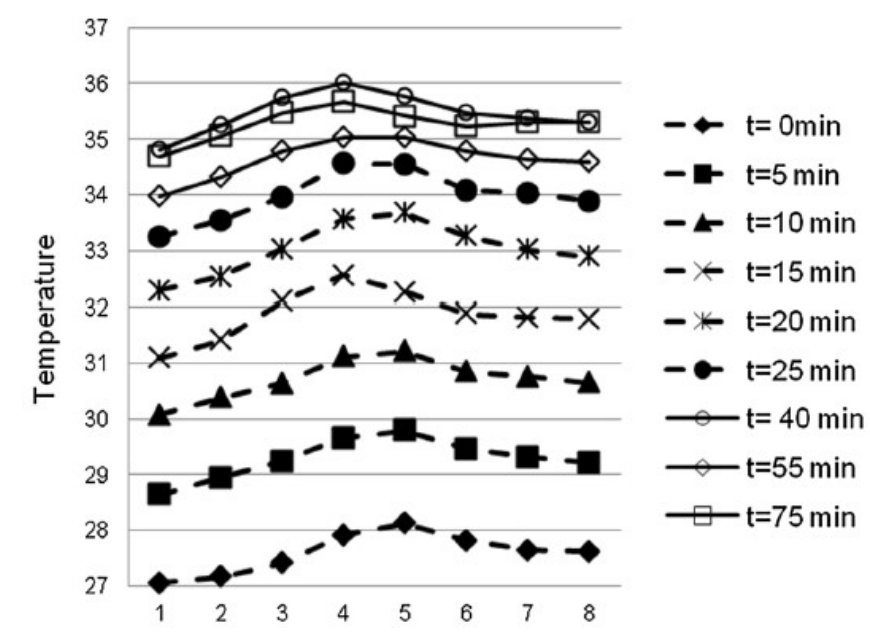

(b)

Figure 4.11: Temperature profiles of the pixels along the line perpendicular to the crack obtained (a) as an example; (b) from thermograms of crack 1 (Bauer et al. 2018). 


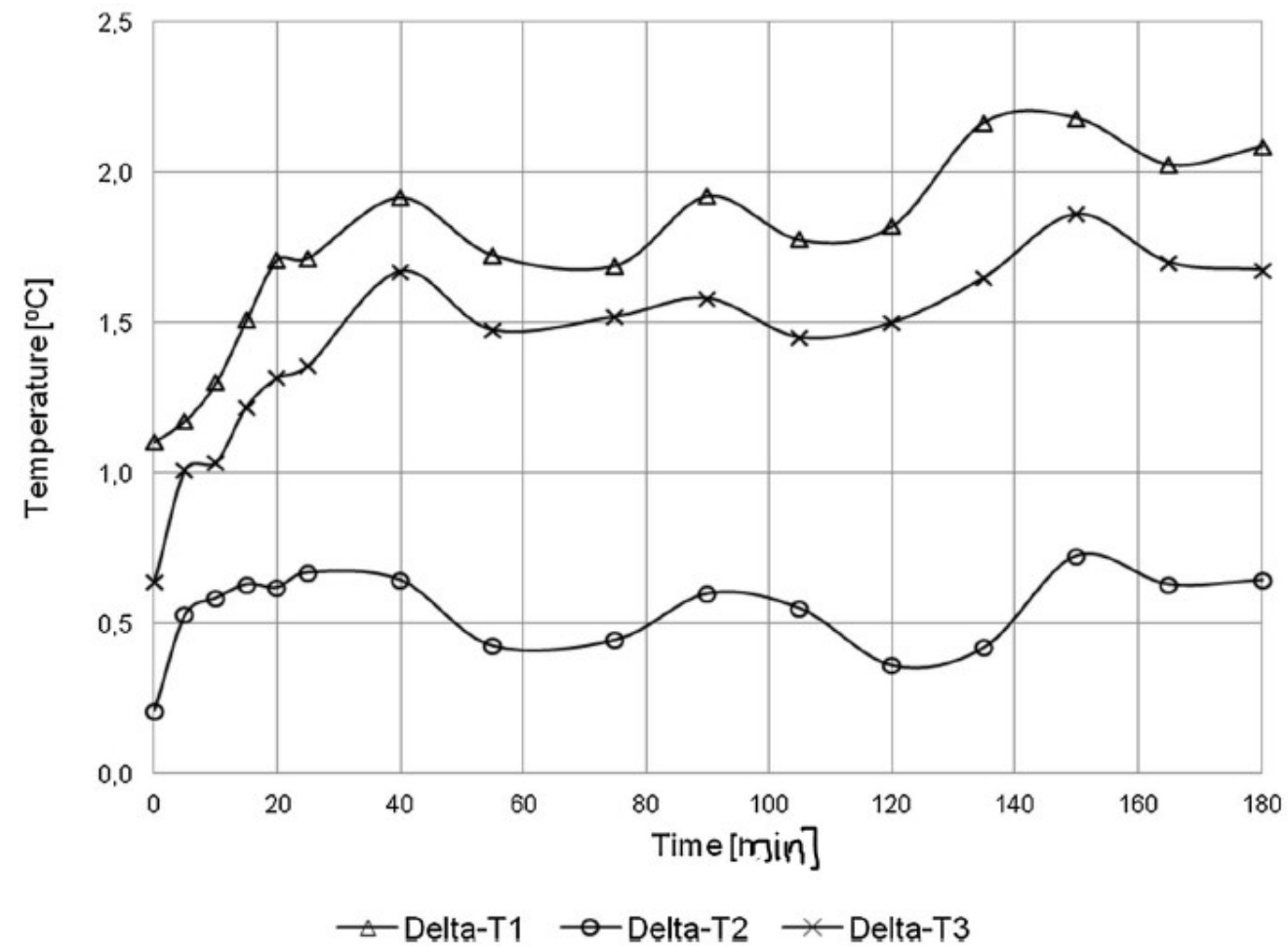

Figure 4.12: Delta-T plots for cracks 1, 2, and 3 (Bauer et al. 2018).

Table 4.1: Damage width of the crack (Bauer et al. 2018).

\begin{tabular}{lllllllll}
\hline Time $(\mathrm{min})$ & IFOV $(\mathrm{mrad})$ & Distance $(\mathrm{m})$ & $L_{\mathrm{cr}} 1$ (pixels) & $L_{\text {crack }} 1(\mathrm{~mm})$ & $L_{\mathrm{cr}} 2$ (pixels) & $L_{\text {crack }} 2(\mathrm{~mm})$ & $L_{\mathrm{cr}} 3($ pixels $)$ & $L_{\text {crack }} 3(\mathrm{~mm})$ \\
\hline 0 & 0.820 & 33 & 2 & 54.12 & 3 & 81.18 & 2 & 54.12 \\
5 & 0.820 & 33 & 2 & 54.12 & 2 & 54.12 & 6 & $-^{\mathrm{a}}$ \\
10 & 0.820 & 33 & 2 & 54.12 & 2 & 54.12 & 6 & $-^{\mathrm{a}}$ \\
15 & 0.820 & 33 & 3 & 81.18 & 2 & 54.12 & 9 & $-^{\mathrm{a}}$ \\
20 & 0.820 & 33 & 2 & 54.12 & 2 & 54.12 & 2 & 54.12 \\
25 & 0.820 & 33 & 2 & 54.12 & 2 & 54.12 & 9 & $-^{\mathrm{a}}$ \\
40 & 0.820 & 33 & 3 & 81.18 & 2 & 54.12 & 7 & $-{ }^{\mathrm{a}}$ \\
Mean & & & & 60.89 & & 57.50 & & 54.12 \\
\hline
\end{tabular}

anon-significant spurious values

\section{$\underline{\text { Conclusion }}$}

It was concluded that using hygrothermal simulation as a pre-analysis tool makes the thermographic field testing more efficient by limiting the period of inspection focusing on the purpose of the testing. This practice can eventually save time and cost for inspection. It was confirmed that the quantitative values of the subsurface damage degree could be determined by the passive thermographic investigation using only 40 minutes of data with appropriate conditions. 
Equipment having smaller IFOV would produce more accurate results. Hence, the method was proved to be very beneficial for the maintenance and rehabilitation of building facades.

\subsubsection{EVALUATING THE QUALITY OF REINFORCED CONCRETE ELECTRIC RAILWAY POLES BY THERMAL NONDESTRUCTIVE TESTING (Sannikov et al. 2018)}

\section{$\underline{\text { Introduction }}$}

The supporting poles for overhead electric lines are very important structures in the operation of an electric railway system. The service life of such reinforced concrete poles (much like other structural members for bridges such as beams, piers, and piles) is assumed to be about 50 years. However, defects such as corrosion can significantly reduce their strength and life span if not maintained properly. It is initiated with the separation of the reinforcing bars (rebars) with concrete and can eventually compromise the integrity of the members. Detection of corrosion, voids, rebar thinning and the contact quality between rebar and concrete in thick cylindrical structural members may be difficult. In this study, IRT was suggested to be used by heating the rebars with an external source to detect corrosion or debonds in such members. As the materials such as concrete, steel, corrosion products, and air have very different thermal properties, monitoring the temperature variation over time can be useful to detect the corrosion products and contact quality between concrete and rebars. This study investigated the relationship between the magnitude of temperature variation over time and the presence of such defects in prestressed concrete poles of the Transsiberian railway in Russia. The results were compared with those from ultrasonic testing, vibroacoustic testing, and mechanical destructive check.

\section{$\underline{\text { Experimental Tests }}$}

IRT was conducted on the bottom sections of 14 operating prestressed concrete poles with steel reinforcement. The practicality and the effectiveness of the test were first checked by a simulation run using the ThermoSource software for a similar assessment that generated synthetic thermograms. A concrete shell with reinforcement was modeled with three sectional characteristics: defect-free, reduction of rebar by $25 \%$, and same rebar with $1 \mathrm{~mm}$ air gaps in its contact surface with concrete. The rebars were placed $10 \mathrm{~mm}$ from the surface. Analyzing two thermograms taken at $60 \mathrm{~s}$ and $120 \mathrm{~s}$, the rebars and defects could be detected clearly, but it was 
found that the temperature variation $(\Delta \mathrm{T})$ was highest in defect-free section, medium in thin rebars and lowest in the air gaps (low by 3 times). Similarly, when the rebar depth was increased to 20 $\mathrm{mm}$, the values were found to decrease by $3^{\circ} \mathrm{C}$, and $\Delta \mathrm{T}$ rate was slower for all three types of sections. Hence, it was verified that this technique can be used for the condition assessment of reinforced concrete elements.

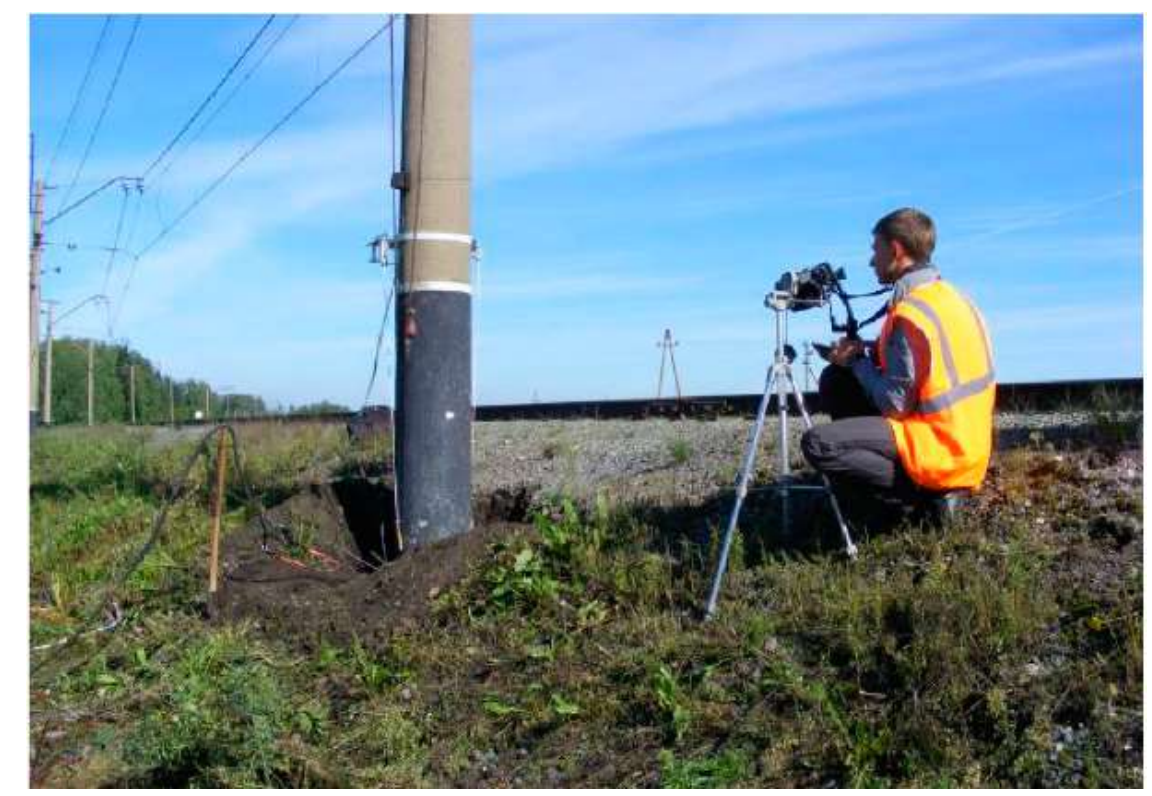

Figure 4.13: Test setup with a target length of $1 \mathrm{~m}$ marked by the aluminum strip (Sannikov et al. 2018).

Figure 4.13 shows the actual test setup on a dry sunny day with an ambient temperature of $25-30^{\circ} \mathrm{C}$. A contact-less heating process of rebars inside the concrete poles by using highfrequency inductors was employed in the field, optimizing power and electric pulses to ensure the surfaces are detectable by the FLIR P60 camera and damages to the rebars are avoided. The inductive heater was powered by a generator mounted on a truck and the inductive coil moved up and down at the velocity of $5-10 \mathrm{~mm} / \mathrm{s}$ by a special lifting mechanism. The efficiency of the testing was dependent on the uniform heating of the rebars. The optimum target area was several centimeters away from the heating area so that the target area temperature will not be influenced by powerful thermal radiation from the heating area. The tests were conducted on $1 \mathrm{~m}$ length of the poles divided into three sections: $0.5 \mathrm{~m}$ above the ground level, at the ground level, and $0.5 \mathrm{~m}$ below the ground level. The underground sections were made accessible by digging out the soil. Each pole was inductively heated for about $20 \mathrm{~s}$. As soon as the heating process started, sequences 
of thermograms were recorded and processed into maxigrams wherein each pixel reflected the maximum $\Delta \mathrm{T}$ recorded during the whole thermal process. The analysis was done based on the rate of $\Delta \mathrm{T}$ obtained from the maxigrams in the cooling stage and was dependent on the operators' interpretation.

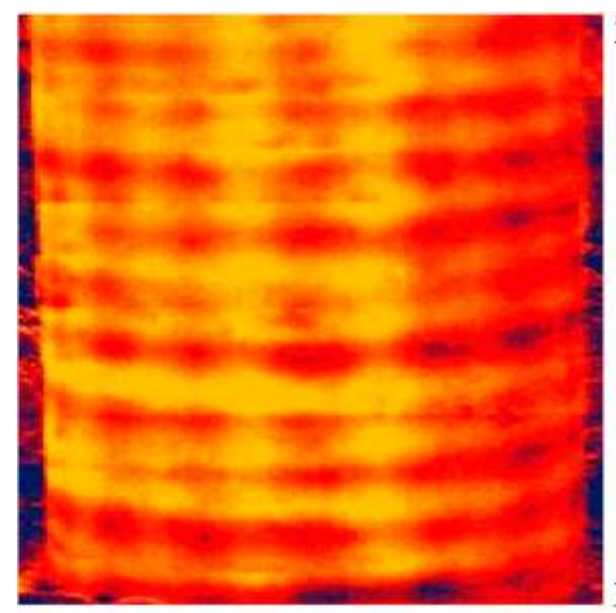

(a)
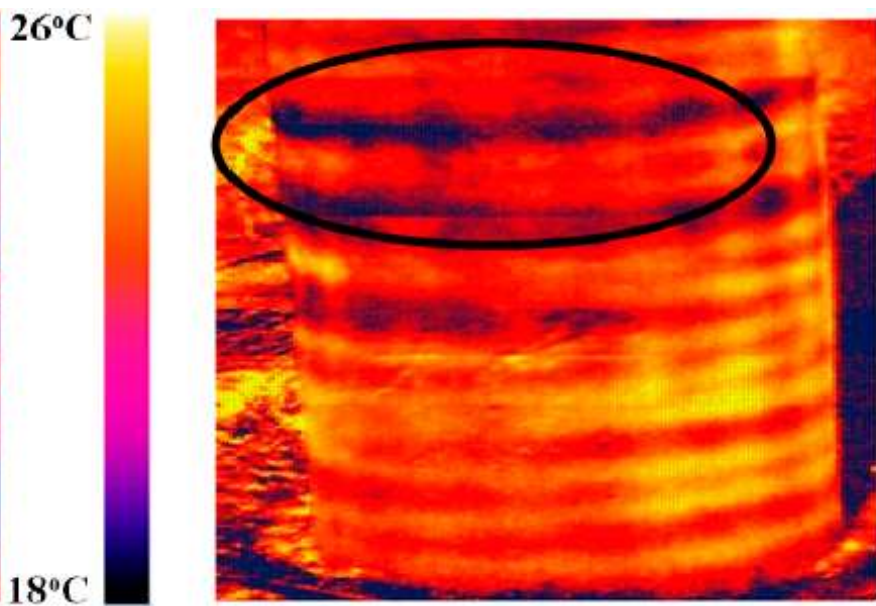

$26^{\circ} \mathrm{C}$

$18^{\circ} \mathrm{C}$

(b)

Figure 4.14: Maxigrams of the pole section above the ground level from (a) a defect-free area; (b) damaged area (Sannikov et al. 2018).

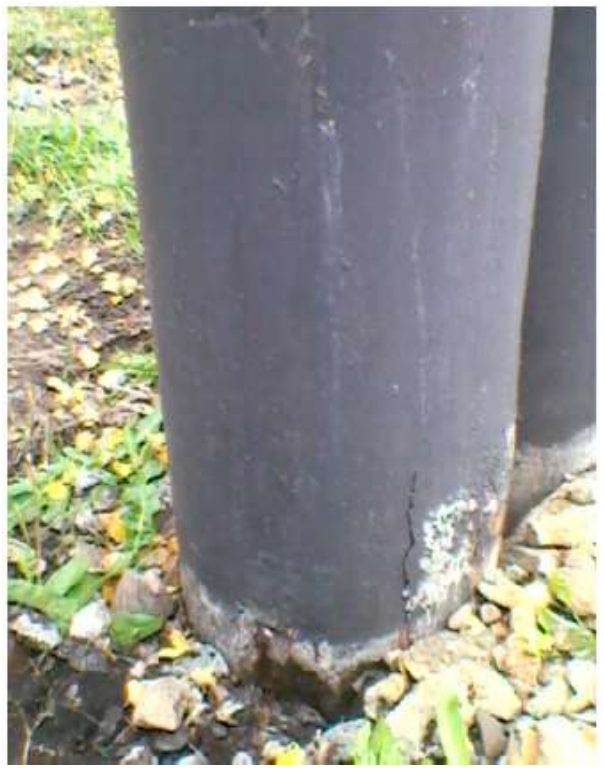

(a)

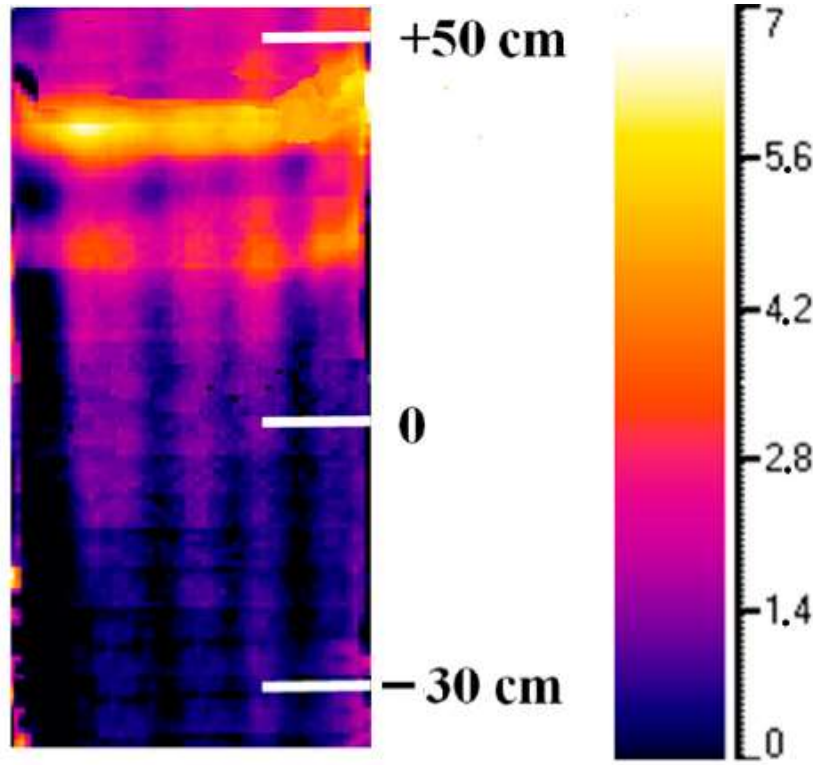

(b)

Figure 4.15: (a) Assessment of the pole section below the ground level; (b) Maxigram of the section (Sannikov et al. 2018). 


\section{$\underline{\text { Results and Discussion }}$}

Figure 4.14a represents the maxigrams of the sound section of a pole above the ground level. Regularly spaced longitudinal and shear reinforcement could be detected with the same $\Delta \mathrm{T}$ that ranged from $7-8^{\circ} \mathrm{C}$ between concrete and rebars without the sign of any defects. Figure $4.14 \mathrm{~b}$, on the other hand, shows a maxigram with a distinct area of decreased $\Delta \mathrm{T}\left(4-5^{\circ} \mathrm{C}\right)$ representing debonds between the concrete and rebars. The range was the same as that predicted from the simulation. The assumption was based on the fact that air acts as an insulator keeping the gaps cooler. All longitudinal and shear rebars were identified in the maxigram from the pole section above the ground. Similarly, the underground section of a pole, shown in Figure 4.15a, was assessed with the same setup. Figure $4.15 \mathrm{~b}$ presents the recorded maxigram for this section, where the circumferential rebars could not be detected. The $\Delta \mathrm{T}$ rate showed a significant decrease by $2-$ 4 times compared to that of the defect-free pole section, depicted in Figure 4.16. Moreover, the maximum $\Delta \mathrm{T}$ appeared after $170 \mathrm{~s}$ of the heating process. It was therefore assumed that the rebars had corroded forming corrosion products that act as an insulator and some hidden delamination were present between the concrete and the rebars. Cracks and traces of corrosion products were noticed during a visual inspection of the section. Results from ultrasonic and vibroacoustic tests on the poles were found to be similar to ones from IRT. Furthermore, the assumption and verdicts from IRT were confirmed during the replacement of both the above-mentioned poles

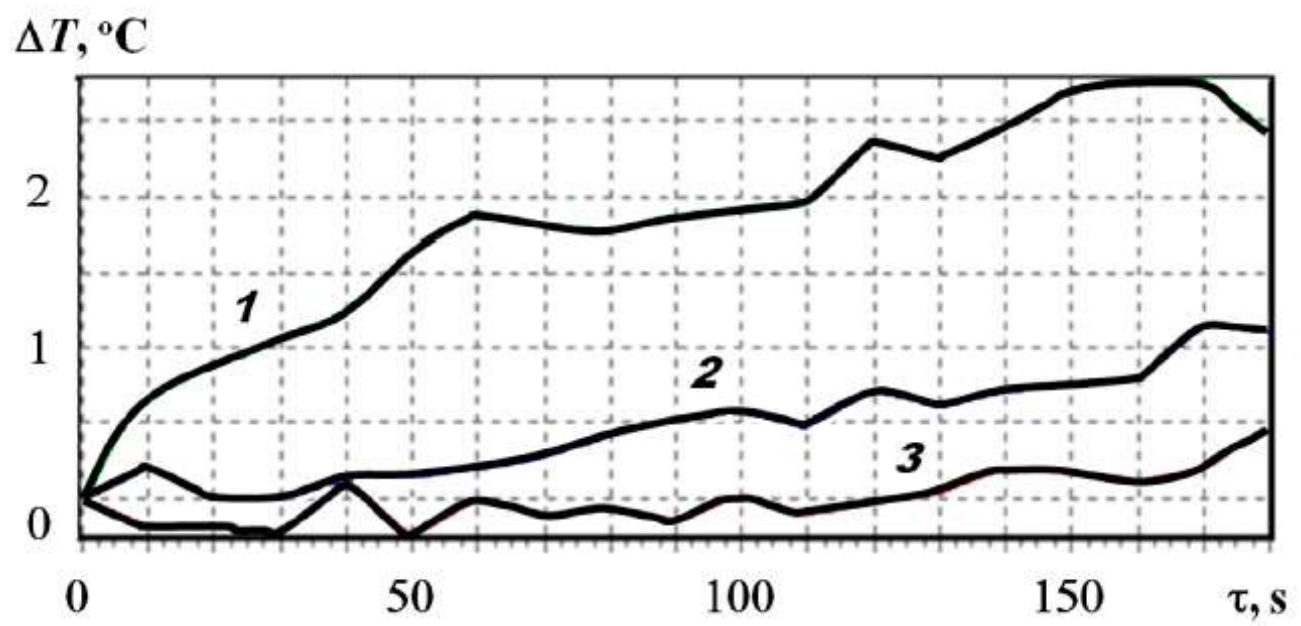

Figure 4.16: Maximum $\Delta \mathrm{T}$ rate for pole sections (1) $50 \mathrm{~cm}$ above the ground level; (2) at the ground level; (3) 30 $\mathrm{cm}$ below the ground level (Sannikov et al. 2018). 


\section{Conclusion}

IRT combined with inductive heating of test object was utilized to visualize the longitudinal as well as shear rebars in the cylindrical reinforced concrete poles with the possibility of detecting delamination due to corrosion of rebars and their quality. The technique was found to be safe and productive as the temperature difference of more than $15^{\circ} \mathrm{C}$ was not be noticed in such tests. Moreover, the technique has been recommended to predict the rebar dislocation and the residual strength of the member and to assess not only electric poles but various other critical reinforced concrete structural members.

\subsubsection{THERMOGRAPHY-BASED DETERIORATION DETECTION IN CONCRETE BRIDGE GIRDERS STRENGTHENED WITH CARBON FIBER-REINFORCED POLYMER (Mac et al. 2020)}

\section{$\underline{\text { Introduction }}$}

Application of carbon fiber-reinforced polymer (CFRP) wraps to strengthen important but vulnerable concrete structural members such as bridge girders have surged owing to their extraordinary capability to increase the capacity at significantly low cost. Delamination in such members can initiate either in the wraps or the core concrete. The delamination developed especially in the concrete cover area may result in spalls and may not be detected visually. Such defects should be detected and located as soon as possible to prevent any serious damage to the girders. There are several works of literature based on the condition assessment of the FRP wraps upon confining the concrete elements with compromised strength due to defects. This paper investigated the performance of step-heating thermography (SHT) for the quantification of delamination in the concrete core with CFRP wraps. Furthermore, an empirical equation for the determination of delamination depth was proposed. The temperature contrast in the thermograms obtained from concrete with CFRP (CSC) and concrete without CFRP (CWC) was also compared. Lastly, post-processing algorithms such as pulsed phase thermography (PPT) and thermal signal reconstruction (TSR) were compared with absolute contrast (ABC) on their command for enhancement applied to the data obtained from SHT for more accurate detection of delamination in CSC girders. 


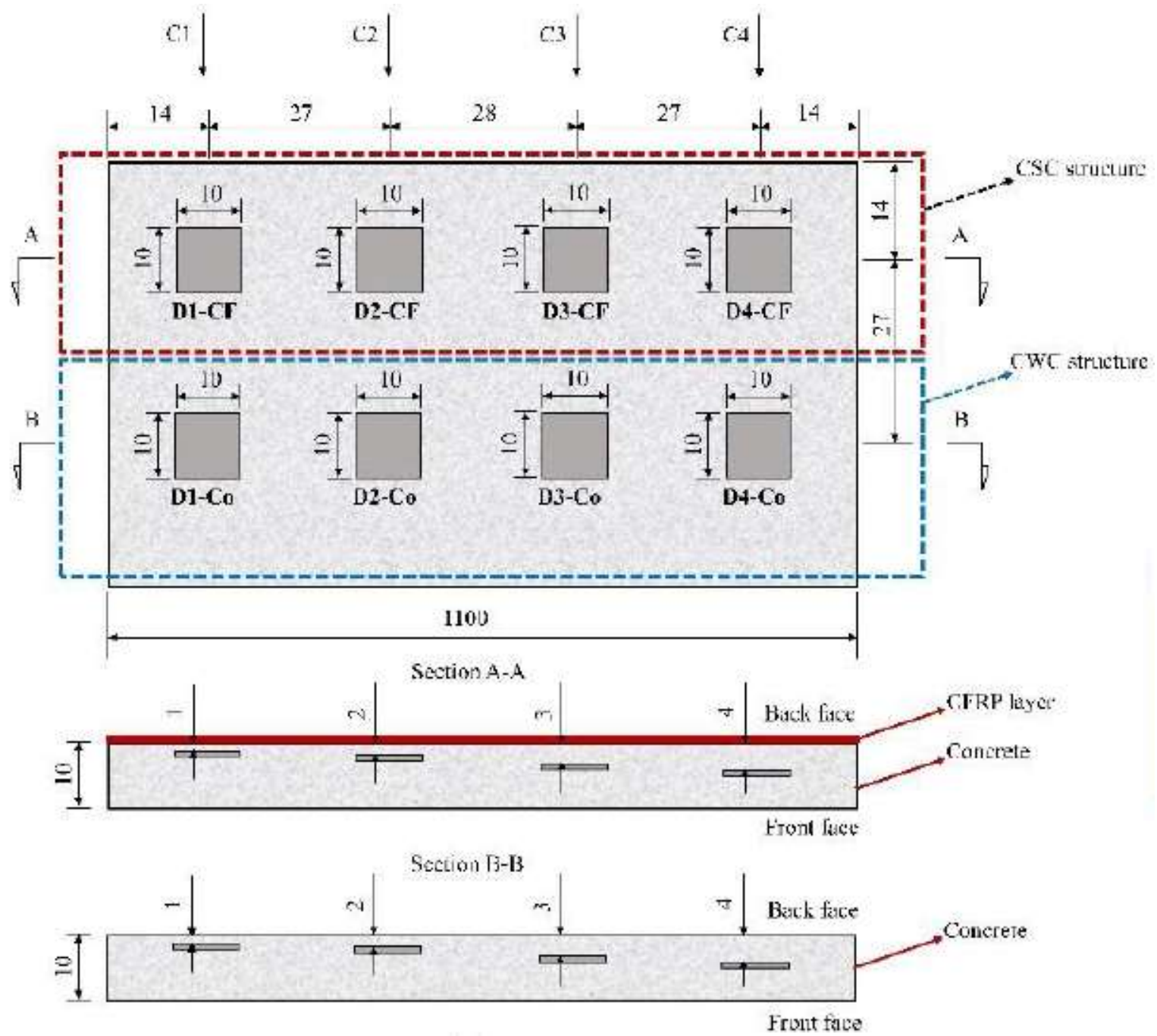

Figure 4.17: Concrete specimen with artificial delaminations arrangement with and without CFRP sheets installed (Mac et al. 2020).

\section{Experimental Tests}

A concrete specimen (simulating a bridge girder) with the compressive strength of $30 \mathrm{MPa}$ was cast with eight square delaminations $(10 \mathrm{~cm} \times 10 \mathrm{~cm} \times 1 \mathrm{~cm})$ at the depths of $1,2,3$, and $4 \mathrm{~cm}$ from the back face as shown in Figure 4.17. The red dashed portion of the specimen was covered with one layer of a $0.167 \mathrm{~mm}$ thick one-direction CFRP sheet (CSC girder) while the blue dashed portion was bare concrete (CWC girder). Epoxy was used as a glue and a coating on top for the attachment of the CFRP sheet. The artificial delaminations, simulating air, were made from polystyrene with thermal conductivity of $0.027 \mathrm{~W} / \mathrm{m}^{\circ} \mathrm{C}$ ( similar to that of air, $0.024 \mathrm{~W} / \mathrm{m}^{\circ} \mathrm{C}$ ). For 
the step heating thermography (SHT), four halogen lamps (500 W each) were used to heat the surface of the specimen from a distance of $1.2 \mathrm{~m}$. SHT was conducted for 36 cases with heating times of $3,5,10,15$, and 20 minutes on the back face; and 5, 10, 15, 20, 25, 30, and 40 minutes for the front face of the specimen with different delamination depths. Readings were taken from both front and back faces, with and without CFRP attached. FLIR SC660 camera working on the LWIR spectrum with a sensitivity of $0.03^{\circ} \mathrm{C}$ was used for recording the thermograms at a frequency of $0.5 \mathrm{~Hz}$. The emissivity for CFRP and concrete were taken as 0.97 and 0.95 respectively. The thermograms were mostly analyzed during the cooling process in the laboratory environmental condition. Nomenclature for each delamination was different: $\mathrm{Co}=$ concrete section without CFRP $(\mathrm{CWC}), \mathrm{CF}=$ concrete section with CFRP (CSC); BD1, BD2, BD3 and BD4 corresponding to the delaminations observed from the back face at the depths of 1, 2, 3, and $4 \mathrm{~cm}$ respectively; FD1, FD2, FD3 and FD4 corresponding the delaminations observed from the front face at the depths of $8,7,6$, and $5 \mathrm{~cm}$ respectively.

\section{$\underline{\text { Results and Discussion }}$}

\section{Detection of Delamination}

In this section, three aspects of delamination detection were discussed with respect to their depths: detectability, clarity, and heating time required. Delamination is detected in a thermogram if the temperature contrast is higher than the thermal sensitivity of the camera $\left(0.03^{\circ} \mathrm{C}\right)$ and if the signal to noise ratio (SNR) is higher than zero. Figure 4.18 displays the thermograms taken during the cooling process from the surfaces of the back and front face. Qualitatively, the delaminations up to the depth of $7 \mathrm{~cm}$ were detected, however, FD1-CF at the depth of $8 \mathrm{~cm}$ could not be detected. Furthermore, the delaminations in the back face with lower depths $(1,2,3$, and $4 \mathrm{~cm})$ were observed more clearly than the ones on the front face with higher depths, despite a longer heating time for the front face. Therefore, shallower delaminations were detected more clearly than the deeper ones. The reason for these observations was explained with the plot in Figure 4.19. With the readings taken every 2 seconds, it could be seen that after the cooling process starts, the maximum absolute contrast $(\Delta \mathrm{T})$ is higher for shallower delaminations than the deeper ones. Moreover, the delaminations in the CSC area with depths 1, 2, and $3 \mathrm{~cm}$ were detectable with the heating time under 5 minutes, while the one at $4 \mathrm{~cm}$ was only detectable after heating for 10 
minutes (after which $\Delta \mathrm{T}>0.03^{\circ} \mathrm{C}$ ). Also, the delaminations at 4,5 , and $6 \mathrm{~cm}$ were detected clearly with the heating time under 15 minutes, while the one at $8 \mathrm{~cm}$ could not be detected even after heating for 40 minutes, with a maximum $\Delta \mathrm{T}$ of $0.033^{\circ} \mathrm{C}$ but $\mathrm{SNR}$ of $-653 \mathrm{~dB}$. Hence, longer heating time is required for deeper delaminations.

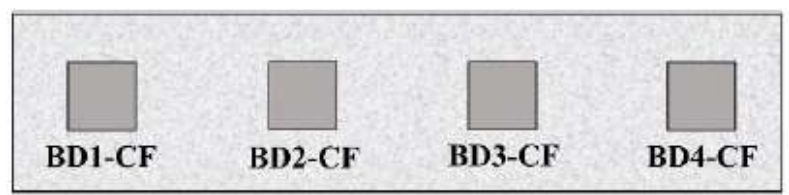

a)

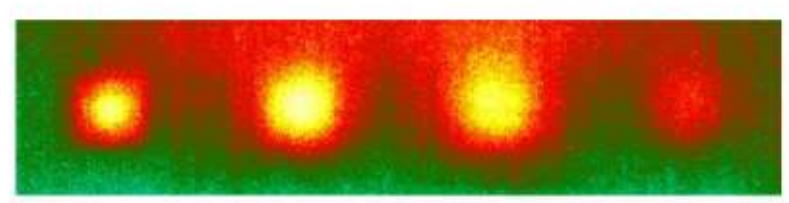

c)

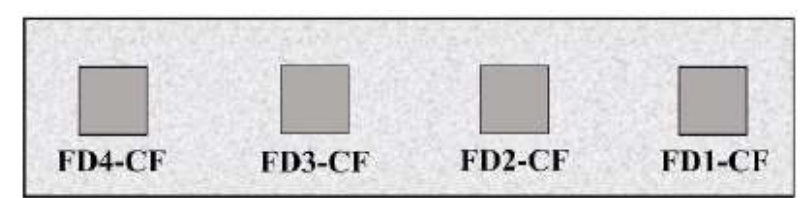

b)

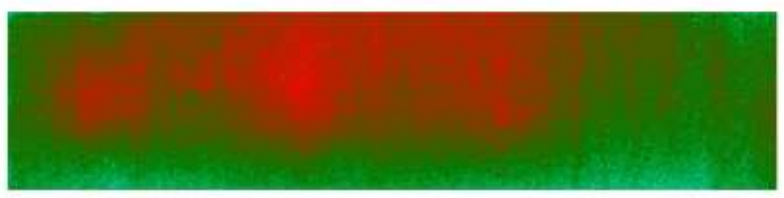

d)

Figure 4.18: $(\mathrm{a}, \mathrm{c})$ Delaminations from the back face with the corresponding thermogram after 15 min heating and 10 min cooling $(b, d)$ delaminations from the front face with the corresponding thermogram after 25 min heating and 40 min cooling (Mac et al. 2020).

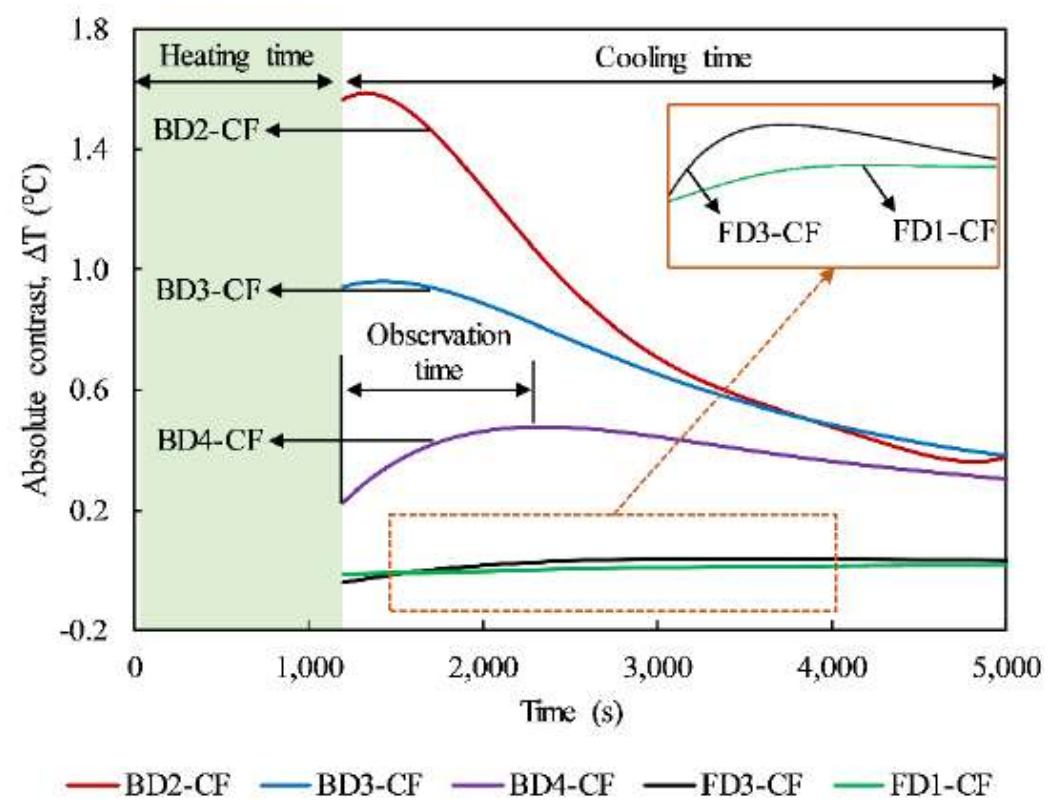

Figure 4.19: Absolute temperature contrast $(\Delta \mathrm{T})$ vs. time (Mac et al. 2020). 


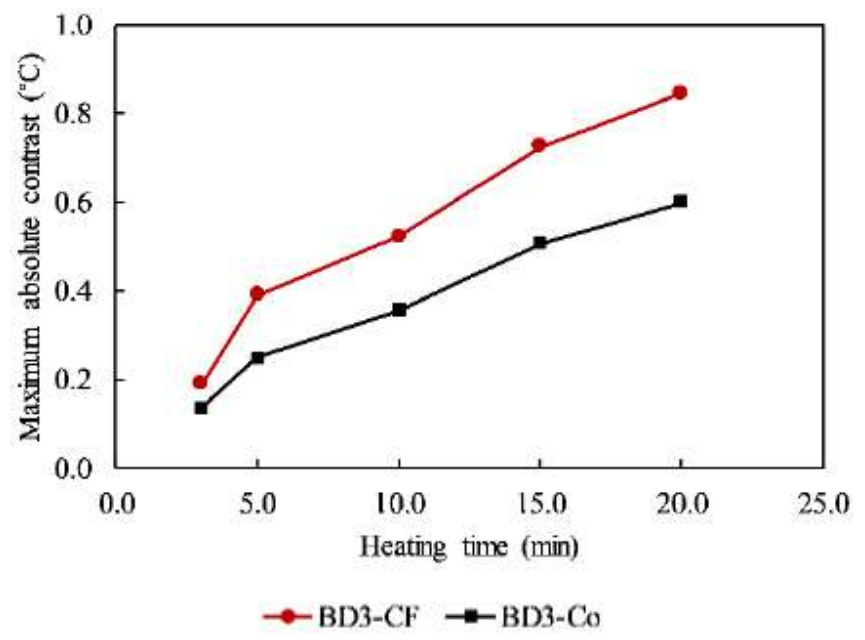

Figure 4.20: Maximum absolute contrasts for delaminations from the back face in CSC (BD3-CF) and CWC (BD3Co) area (Mac et al. 2020).

\section{Influence of CFRP on Delamination Detection}

Figure 4.20 shows that the maximum $\Delta \mathrm{T}$ for $\mathrm{BD} 3$ was $0.73^{\circ} \mathrm{C}$ (SNR of $8.66 \mathrm{~dB}$ ) in CSC area; whereas it was $0.51^{\circ} \mathrm{C}$ (SNR of $6.02 \mathrm{~dB}$ ) in $\mathrm{CWC}$ area for identical experimental conditions (15 min heating and 20 min cooling), which is well reflected in the thermograms presented in Figure 4.21. Similar results were observed in other delaminations as well. Hence, it was inferred that delaminations can be observed more distinctly in thermograms of CSC than CWC structures. This observation was justified with the fact that the CFRP surface with higher emissivity can absorb more energy than concrete. Furthermore, the difference in the maximum $\Delta \mathrm{T}$ between delaminations in CWC and CSC exhibited an increasing trend with increasing heating time.

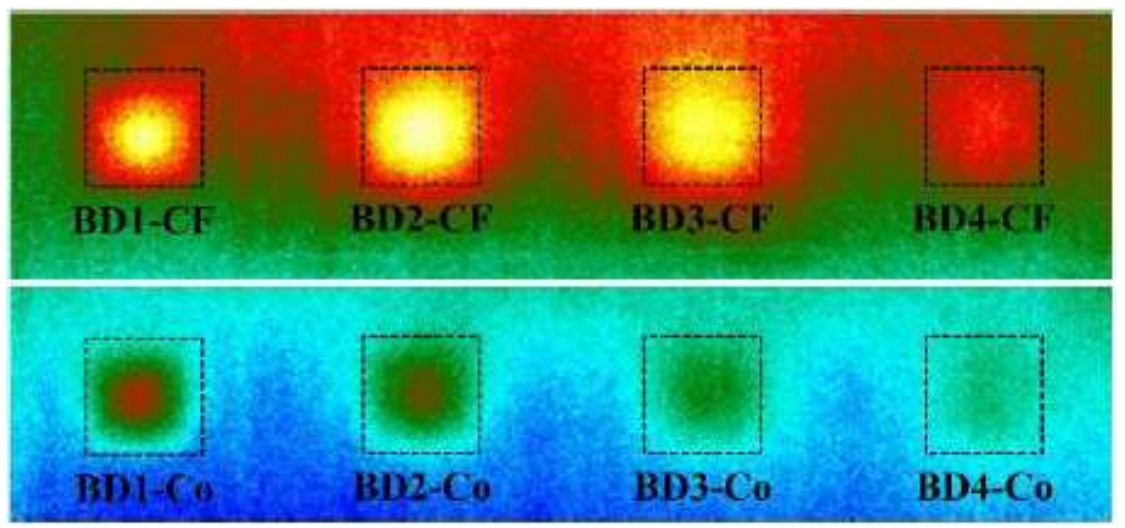

Figure 4.21: Thermograms for delaminations from the back face after 15 min heating and 20 min cooling in the CSC area (top); CWC area (bottom) (Mac et al. 2020). 


\section{Prediction of delamination depth}

A delamination depth equation was proposed for a concrete strengthened with CFRP wraps from IRT data: $Z^{2}=1.0153$ x OBT, where $1.0153 \mathrm{~cm}^{2} / \mathrm{min}$ was the empirical thermal diffusivity coefficient (between the established corresponding values of concrete $\left(0.53 \mathrm{~cm}^{2} / \mathrm{min}\right)$ and CFRP $\left.\left(3.7 \mathrm{~cm}^{2} / \mathrm{min}\right)\right)$ derived from the experimental conditions for CSC area, and OBT represented the observation time between the start of the cooling process and the peak of $\Delta \mathrm{T}$ curve (shown in Figure 4.22) for distinct delamination. The linear regression curve fitting $\left(\mathrm{R}^{2}=0.982\right)$ of the predicted depths in various heating times using the proposed equation was approximately a $2 \%$ offset from the actual line. Thus, the equation was found to be reliable to predict the delamination depths. The root mean square error (RMSE) for delaminations with depths of 1 to $4 \mathrm{~cm}$ for the heating time of 3,5 , and $10 \mathrm{~min}$ were $0.69,0.68$, and 0.42 respectively. Similarly, RMSE for delaminations with depths of 5 to $8 \mathrm{~cm}$ for the heating time of 25,30 , and $40 \mathrm{~min}$ were $0.63,0.64$, and 0.5 respectively. Therefore, the accuracy was found to increase with longer heating time.

\section{Enhancement of delamination depth using post-processing algorithms}

Certain post-processing algorithms can be applied to the recorded thermograms for accurate detection and identification of defects. Three such algorithms were investigated in this study: absolute contrast (ABC), thermal signal reconstruction (TSR), and pulsed phase thermography (PPT). Application of the simplest algorithm ABC was observed in the thermograms displayed in the previous sections. It was further used to inspect the efficiency of advanced PPT and TSR. Figure 4.22 displays the thermograms for delaminations taken from the back face using these algorithms. PPT, with a frequency of $0.38 \times 10^{-3} \mathrm{~Hz}$ used amplitude and phase data. TSR used logarithm data, and its first and second derivative with a cooling time of 13, 8, and $12 \mathrm{~min}$ respectively. The cooling time used for $\mathrm{ABC}$ was $12 \mathrm{~min}$. Compared to $\mathrm{ABC}$, PPT and TSR were able to reduce noisy data significantly for some delaminations (BD2-CF and BD3-CF) as shown in Figure 4.22. For the heating time of $5 \mathrm{~min}, \mathrm{SNR}$ in case of BD2-CF thermogram was only 4.98 $\mathrm{dB}$ using $\mathrm{ABC}$ compared to 9.74 and $9.49 \mathrm{~dB}$ using PPT and TSR respectively. However, with some delaminations, the SNRs using PPT and TSR were lower compared to ABC. It was noticed that PPT displayed better SNR when the heating time was small. Hence, it was recommended to use several image processing methods to compare and combine the results to eventually identify defects with higher accuracy. 


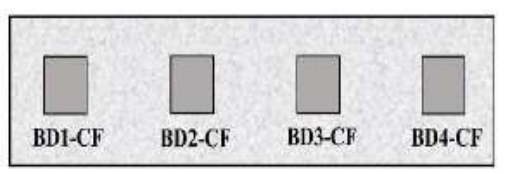

Location of delaminations

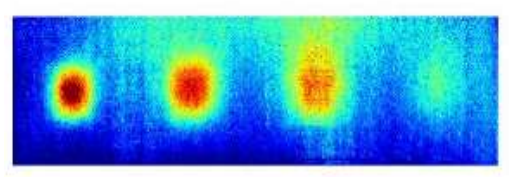

$\mathrm{ABC}$

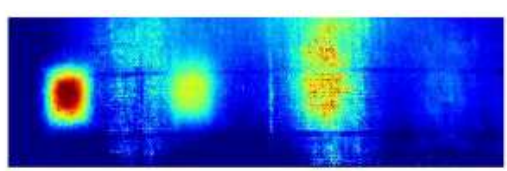

PPT: Amplitude image

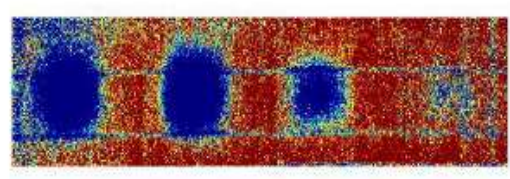

PPT: Phase image

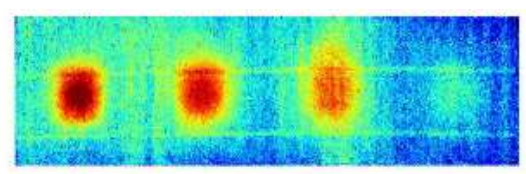

TSR: Logarithm image

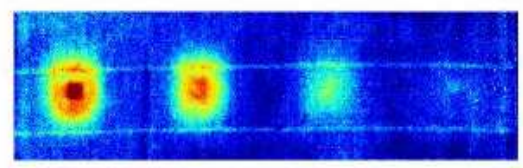

TSR: First derivative image

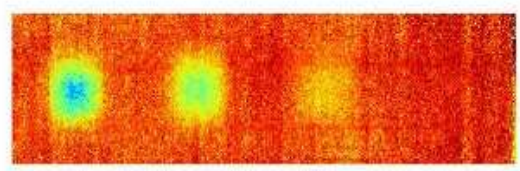

TSR: Second derivative image

Figure 4.22: Comparison of thermograms (10 min heating for delaminations from the back face) processed using different algorithms (Mac et al. 2020).

\section{Conclusion}

Detection possibility and enhancement features for delamination depth in a concrete member core strengthened by CFRP were investigated in the study. It was deduced that SHT can be used with the heating time of 40 minutes to accurately identify the delaminations up to a depth of $7 \mathrm{~cm}$ in CSC girders. Owing to the increased absolute contrast in the CSC area, delaminations in concrete members wrapped with CFRP was shown to be more distinct than those without it. Furthermore, the proposed equation to compute delamination depth for a CSC member was found to be highly accurate. The application of post-processing algorithms such as PPT and TSR and their combination was suggested to improve the detection of delamination than using an absolute contrast algorithm. Additionally, with the increased heating time, TSR was found to be more effective than PPT. Hence, the use of SHT, the proposed equation for depth computation, and the featured post-processing algorithms were recommended to be utilized in the actual field assessment of the cores of CSC girders. 


\subsubsection{INFRARED THERMOGRAPHY MODEL FOR AUTOMATED DETECTION OF DELAMINATION IN RC BRIDGE DECKS (Omar et al. 2018)}

\section{$\underline{\text { Introduction }}$}

The analysis of data obtained from IRT for the condition assessment of bridge decks is dependent on subjective interpretation of the thermograms by the operator. Delamination is recognized when the temperature value measured from the thermogram is higher than the predefined threshold value. Even though the measured data is accurate, this practice may still produce inconsistent results. To resolve this problem, a novel automated approach was proposed in this paper to detect and classify subsurface delamination accurately in concrete bridge decks under passive IRT testing. The obtained results were then compared with those from other NDT techniques.

\section{$\underline{\text { Experimental Tests }}$}

Passive IRT was performed on the decks of four full-scale in-service bridges. The IRT was conducted according to the guidelines in ASTM D4788-03 using IR cameras with specifications shown in Table 4.2. To quantitatively detect the size and location of the defect regardless of the temperature ranges obtained from various thermograms produced in various environmental conditions, an automated approach was developed following several steps: image enhancement, image registration, image segmentation, and k-means clustering, identification of some clusters, and condition mapping. Utilizing FLIR Tools + and ResearchIR software, the thermal images collected in the field were enhanced by filtering out the background noise automatically that increased the image resolution. The image contrast was also improved through histogram equalization that distributed the intensities on the histogram. This step was used to differentiate the subsurface delamination area from other conditions. Image registration involved creating a mosaic thermogram of the entire bridge deck by combining enhanced thermograms. Then, the mosaic image was analyzed using the k-means clustering technique which was used for segmenting the image and determine objective thresholds. Finally, the condition map was plotted using all the analyzed data outlining different categories of subsurface defects. 


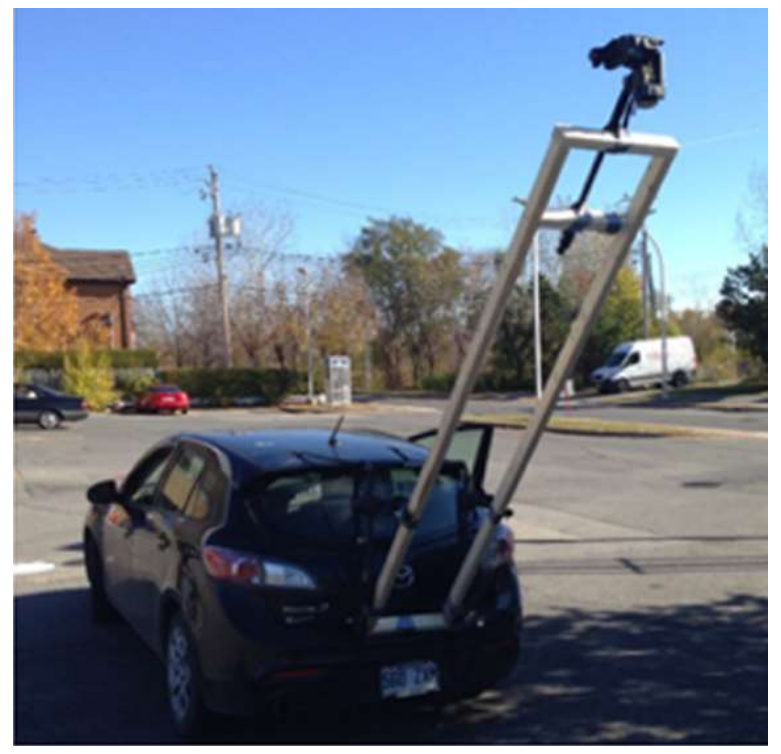

Figure 4.23: IR camera setup (Omar et al. 2018).

Table 4.2: IR camera specification used in the tests (Omar et al. 2018).

\begin{tabular}{|c|c|c|c|c|c|c|c|c|}
\hline \multirow[t]{2}{*}{ Thermal Camera } & \multicolumn{8}{|l|}{ Characteristics } \\
\hline & Spectral Range & Thermal Resolution & Frame Rate & $\begin{array}{l}\text { Thermal Sensitivity } \\
\text { at } 30^{\circ} \mathrm{C}\end{array}$ & Field of View & Temperature Range & Accuracy & Digital Camera \\
\hline FLIR 650Sc & $7.5-13 \mu \mathrm{m}$ & $640 \times 480$ & $60 \mathrm{~Hz}$ & $0.03^{\circ} \mathrm{C}$ & $25^{\circ} \times 19^{\circ} \mathrm{C}$ & $-40^{\circ}$ to $2000^{\circ} \mathrm{C}$ & $\pm 1^{\circ} \mathrm{C}$ & Built-in (5MP) \\
\hline FLIR A40(M) & $7.5-13 \mu \mathrm{m}$ & $320 \times 240$ & $30 \mathrm{~Hz}$ & $0.08^{\circ} \mathrm{C}$ & $24^{\circ} \times 18^{\circ} \mathrm{C}$ & $-40^{\circ}$ to $200^{\circ} \mathrm{C}$ & $\pm 2^{\circ} \mathrm{C}$ & $\mathrm{N} / \mathrm{A}$ \\
\hline
\end{tabular}

Table 4.3: Environmental conditions during the IRT tests in all four bridges (Omar et al. 2018).

\begin{tabular}{lllllll}
\hline Bridge & Survey Date & $\begin{array}{l}\text { Time of Data } \\
\text { Collection }\end{array}$ & $\begin{array}{l}\text { Ambient } \\
\text { Temperature }\left({ }^{\circ} \mathrm{C}\right)\end{array}$ & $\begin{array}{l}\text { Ambient Temperature } \\
\text { Variation }{ }^{\circ}\left({ }^{\circ} \mathrm{C}\right)\end{array}$ & $\begin{array}{l}\text { Wind Speed } \\
(\mathrm{km} / \mathrm{h})\end{array}$ & $\begin{array}{l}\text { Humidity } \\
(\%)\end{array}$ \\
\hline Montreal Surveyed Bridge & $23 / 10 / 2015$ & $9.00 \mathrm{PM}$ & 3 & 1 & 11.3 & 37 \\
& $27 / 10 / 2015$ & $1.00 \mathrm{PM}$ & 14 & 3 & 8.1 & 26 \\
Bridge (A) & $15 / 07 / 2010$ & $2.00 \mathrm{PM}$ & 29 & 2 & 12.9 & 38 \\
Bridge (B) & $31 / 05 / 2011$ & $1: 30 \mathrm{PM}$ & 27 & 2 & 16.1 & 51 \\
Bridge (C) & $02 / 07 / 2015$ & $12: 45 \mathrm{PM}$ & 24 & 1 & 9.7 & 43 \\
\hline
\end{tabular}

\section{Montreal Bridge}

Constructed over a roadway in 1969, the Montreal Bridge in Quebec, Canada was a singlespan reinforced concrete rigid frame bridge. The bridge was $44.8 \mathrm{~m}$ long and $9.1 \mathrm{~m}$ wide (two lanes of $4 \mathrm{~m}$ each) with the decks connected directly to the abutments without bearings. The testing was arranged by the Quebec Ministry of Transportation (MTQ) after a condition survey of the bridge illustrated the presence of several transverse, longitudinal and diagonal cracks, corrosion, and high content of chloride ion. Using FLIR T650sc camera mounted on a vehicle, IRT was 
conducted two times: October $23^{\text {rd }}, 2015$ at 9 pm (two hours after sunset) and October $27^{\text {th }}, 2015$ at $1 \mathrm{pm}$ (six hours after sunrise). To cover one entire lane in two runs, FOV of $2.13 \mathrm{~m} \times 1.62 \mathrm{~m}$ for each image, and mounting height of $2.6 \mathrm{~m}$ was decided for the IR camera facing straight down as shown in Figure 4.23. The camera comprised of an uncooled microbolometer detector with the specification given in Table 4.2. With the setup, the data were collected at an interval of $0.91 \mathrm{~m}$ over the entire deck length and at the speed of $16 \mathrm{~km} / \mathrm{hr}$, producing 392 thermograms. Before the tests, inputs such as emissivity of 0.95 for the concrete, ambient and reflected temperature, humidity, and the distance between the deck surface and the camera lens were entered into the camera software to calibrate the temperature measurements and to account for the attenuation of radiation by the atmosphere. The data was collected in approximately two hours both days. Figure 4.24 represents the condition map of the Montreal Bridge deck.

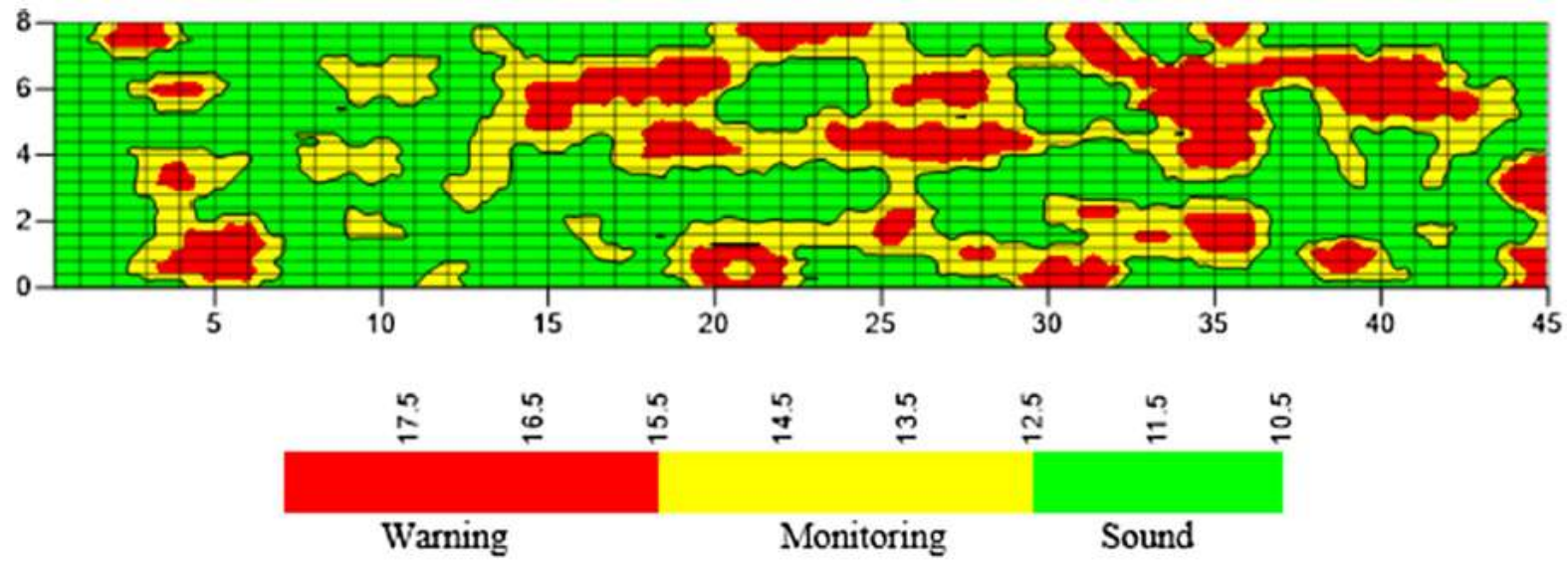

(a)
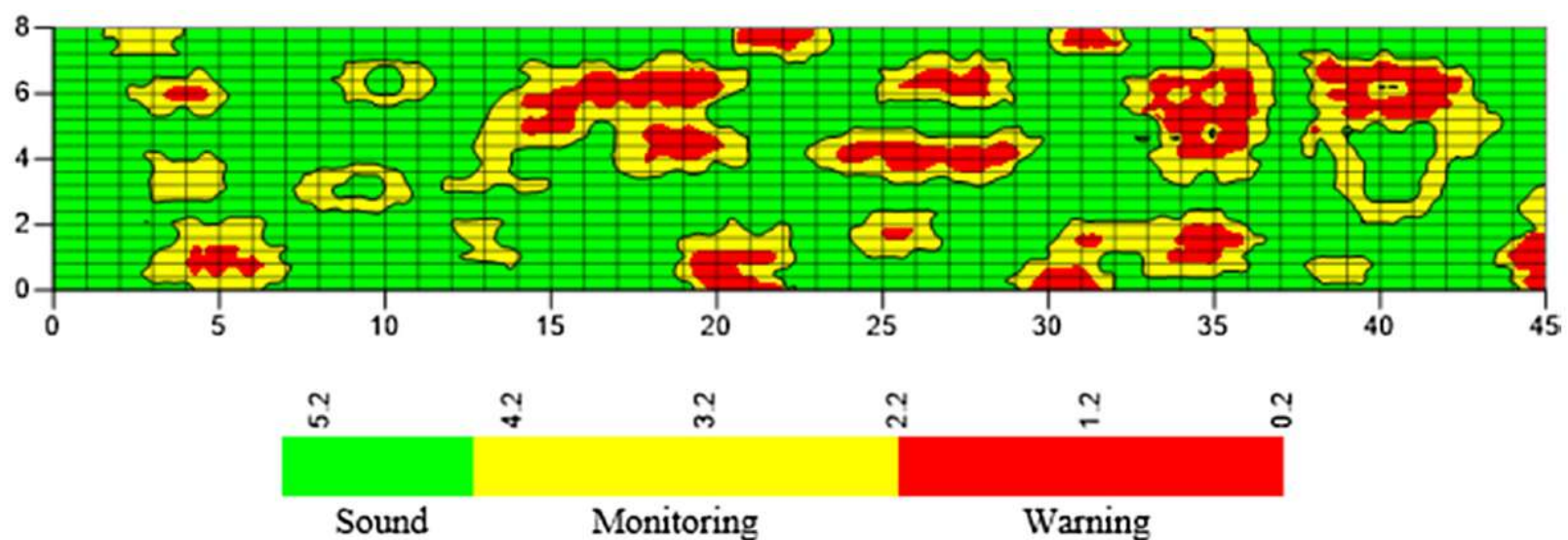

(b)

Figure 4.24: Condition maps of Montreal Bridge using thermograms collected during (a) day; (b) night (Dimensions in m) (Omar et al. 2018). 


\section{Bridge A}

Constructed in 1963, the seven-span continuous concrete box girder bridge comprised of a $367.5 \mathrm{~mm}$ RC slab deck. It was $296.9 \mathrm{~m}$ long and $10.7 \mathrm{~m}$ wide (two lanes $9 \mathrm{~m}$ wide). IR camera FLIR A41 (M) camera mounted on a vehicle at an angle of $45^{\circ}$ was used for the test to cover one lane in one run at a speed of $16 \mathrm{~km} / \mathrm{hr}$. A total of 1948 images were produced with readings taken at an interval of $0.305 \mathrm{~m}$ over the entire bridge. The environmental conditions were as shown in Table 4.3. With appropriate inputs, 3 condition categories were determined and the condition map of the bridge deck was plotted as shown in Figure 4.25a, outlining various categories of subsurface defects. Figure $4.25 \mathrm{~b}$ exhibits the condition map of the same deck determined by the Wisconsin DOT.

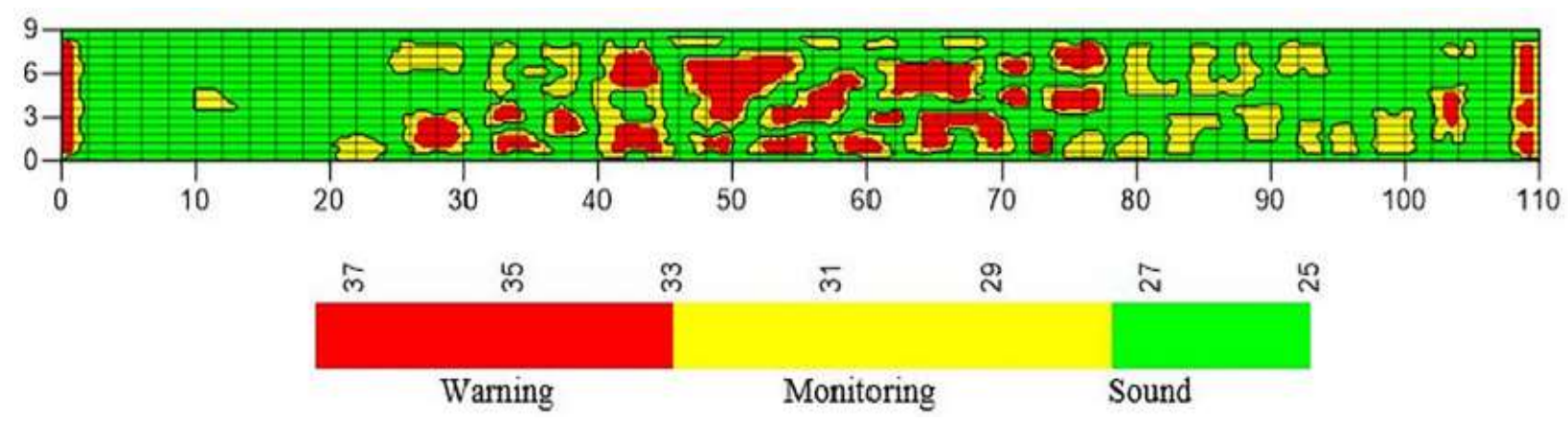

(a)

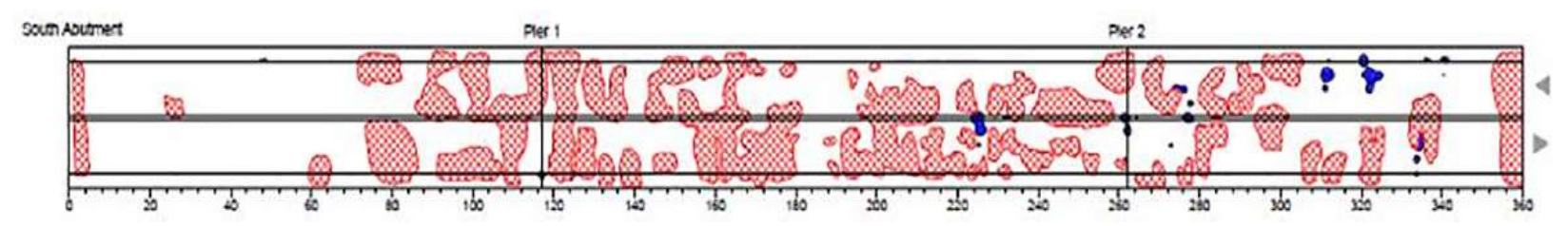

(b)

Figure 4.25: Condition maps of Bridge A determined using (a) novel automated system (dimensions in m); (b) IRT by Wisconsin DOT (dimensions in ft.) (Omar et al. 2018).

\section{Bridge B}

Constructed in 1965, the three-span continuous concrete box girder bridge comprised of a $350.2 \mathrm{~mm}$ RC slab deck. It was $26.3 \mathrm{~m}$ long and $9.15 \mathrm{~m}$ wide (two lanes $8.36 \mathrm{~m}$ wide). IR camera was setup similar to Bridge A. A total of 261 images were produced with readings taken at an 
interval of $0.305 \mathrm{~m}$ over the entire bridge. The environmental conditions were as shown in Table 4.2. Similar to Bridge A, the condition map of the bridge deck was also plotted and compared with that recorded by the Wisconsin DOT.

\section{Bridge C}

Constructed in 1967, the four-span continuous prestressed girder bridge comprised of a $362.9 \mathrm{~mm}$ RC slab deck. It was $94.5 \mathrm{~m}$ long and $12.8 \mathrm{~m}$ wide (two lanes $8.6 \mathrm{~m}$ wide). IR camera was setup similar to Bridge A and B. A total of 1240 images were produced with readings taken at an interval of $0.305 \mathrm{~m}$ over the entire bridge. The environmental conditions were as shown in Table 4.3. Similar to Bridges A and B, the condition map of the bridge deck was plotted outlining various categories of subsurface defects and was compared with that recorded by Wisconsin DOT.

\section{$\underline{\text { Results and Discussion }}$}

During the rehabilitation process, exact information about the location of delamination is very important. The condition maps produced were able to clearly show the areas with delamination categories based on severity. The threshold for the classification was generated automatically without the need for the operator's input thus reducing the chances of error. Results from Montreal Bridge, Bridges A, B, and $\mathrm{C}$ showed the temperature differentials of $8{ }^{\circ} \mathrm{C}, 12.5^{\circ} \mathrm{C}$, $11.9^{\circ} \mathrm{C}$, and $10.8^{\circ} \mathrm{C}$ respectively between the sound and unsound areas in the decks. The sound area showed the lowest and warning areas showed the highest temperature values. Since the tests in all the bridges were taken during daytime (between 1 and $2 \mathrm{pm}$ ), the surface above the defects resisted the transfer of heat into the defect. So, it was warmer than the defect-free area and appeared as a hot spot in the thermogram. In the case of Montreal Bridge, readings were also taken at night (two hours after the sunset), the area above defects lost heat faster than defect-free area, so it was colder and appeared as a cold spot. Figure 4.24b shows the temperature difference, in this case, was about $5.2^{\circ} \mathrm{C}$, with the sound area showing the highest and warning areas showing the lowest temperature values. It was noticed that some delaminated areas were not detected during the night which was reasoned because of concrete mass, thermal inertia, and conductivity affecting the transition rate. The results obtained from the proposed method were also compared with those from other NDTs such as Ground Penetrating Radar(GPR), IRT, and Sounding Hammer recorded by MTQ and Wisconsin DOT. The percentages of each delamination category were computed 
from the mosaic thermograms for all the bridges as shown in Table 4.4. The delaminated area of $42 \%, 39 \%, 37 \%$, and $28 \%$ from the proposed method as opposed to $38 \%, 41 \%, 40 \%$ and $23 \%$ from the MTQ, and DOT records were identified in the Montreal Bridge, Bridge A, B, and C respectively. The results were quite consistent for all techniques. The undetected defect in Bridge B over the piers was justified as a result of congested reinforcement in that area suggested from the structural drawings. GPR produced the condition map basing on the corrosion of the rebars in the Montreal Bridge and Bridge C. The maps identified less delaminated areas compared to IRT. Since delamination can occur with factors other than rebar corrosion such as freeze and thaw cycle, whose influence could not be mapped by GPR. Hence, the difference was justified. Hence, the given approach was able to located and size the delaminations with high accuracy. This was useful for the appropriate decision-making phase for the rehabilitation of the bridges.

Table 4.4: Comparison of results for four bridges obtained from different NDT (Omar et al. 2018).

\begin{tabular}{|c|c|c|c|c|c|}
\hline \multirow[t]{2}{*}{ Bridge Deck } & \multirow[t]{2}{*}{ NDT Survey Type } & \multirow[t]{2}{*}{ Survey Result| } & \multicolumn{3}{|c|}{ Concrete Condition } \\
\hline & & & Sound & Monitoring & Warning \\
\hline \multirow[t]{4}{*}{ Montreal Surveyed Bridge } & IRT & Nighttime & $64 \%$ & $15 \%$ & $21 \%$ \\
\hline & & Daytime & $58 \%$ & $17 \%$ & $25 \%$ \\
\hline & Hammer Sounding & MTQ Record & \multicolumn{3}{|c|}{ 38\% Total Delaminated Areas } \\
\hline & GPR & MTQ Record & $62 \%$ & $16 \%$ & $22 \%$ \\
\hline \multirow[t]{3}{*}{ Bridge (A) } & IRT & Present Study & $61 \%$ & $16 \%$ & $23 \%$ \\
\hline & & DOT Record & \multicolumn{3}{|c|}{ 41\% Total Delaminated Areas } \\
\hline & Hammer Sounding & DOT Record & \multicolumn{3}{|c|}{ 37\% Total Delaminated Areas } \\
\hline \multirow[t]{3}{*}{ Bridge (B) } & IRT & Present Study & $63 \%$ & $19 \%$ & $18 \%$ \\
\hline & & DOT Record & \multicolumn{3}{|c|}{ 40\% Total Delaminated Areas } \\
\hline & Hammer Sounding & DOT Record & \multicolumn{3}{|c|}{ 35\% Total Delaminated Areas } \\
\hline \multirow[t]{2}{*}{ Bridge (C) } & IRT & Present Study & $72 \%$ & $12 \%$ & $16 \%$ \\
\hline & GPR & DOT Record & \multicolumn{3}{|c|}{$23 \%$ Total Corroded Areas } \\
\hline
\end{tabular}

\section{Conclusion}

The study demonstrated the convenience of the well-established IRT to conduct a noncontact condition assessment of the bridge decks rapidly without the need for closure of the bridge lanes. The novel approach of IRT to quantify and categorize the subsurface defects in concrete bridge decks was established to be promising in providing more objective and automated analysis of the thermograms by producing easy to understand and accurate condition maps. The results on the bridges illustrated that the clustering technique could be used to classify the delamination based on severity. The approach was found to be applicable for different testing times and environmental conditions. Although the geometry and location of subsurface defects were identified accurately, there was no provision to determine their thickness or depth. The extension of the algorithms to 
account for a number of other variables and application of artificial intelligence approaches to make the process faster and fully automated would make this method optimum for the rehabilitation of concrete bridges.

\subsubsection{USING VARIOUS INFRARED TECHNIQUES FOR ASSESSING TIMBER STRUCTURES (Sandak and Sandak 2017)}

\section{$\underline{\text { Introduction }}$}

Condition assessment of timber structures, just like any other, includes evaluation of the mechanical strength of each member and the detection of defects affecting their intended performance. Methods for strength determination are well established and internationally standardized. However, the identification of possible failure section within any timber element is difficult due to its anisotropic and heterogeneous nature. Additionally, various damaging factors such as aging, weathering, insect attack may be clearly visible because of the changes in the surface appearance of the wood element. Some defects in the wood, however, may not be differentiated by visual inspection. IRT in this respect has been promising for reliable results. This study focused on the application of IRT, infrared spectroscopy, and hyperspectral techniques on timber structures. IRT was performed to detect, localize, and interpret the defects in a wooden beam and to locate failure cracks in a wooden block during a compression test.

\section{$\underline{\text { Experimental Tests }}$}

The IRT tests were conducted on two wood specimens. FLIR ONE (developed by FLIR Systems Inc.) integrating with a smartphone was used for the assessment of wood specimens as shown in Figure 4.26a. The temperature range for the equipment was $-20^{\circ} \mathrm{C}$ to $120^{\circ} \mathrm{C}$, along with the spatial resolution of $80 \times 60$, the frame rate of 8 frames $/ \mathrm{sec}$, and sensitivity of $0.05^{\circ} \mathrm{C}$. For the first experiment, as active IRT was performed on a wooden beam specimen which was heated using infrared emitting electric bulbs as shown in Figure 4.26c. A single operator was able to conduct the test given the simple configuration. Acrylic paint was applied on a portion of the specimen to hide defects and change the natural color of the wood. Similarly, in the second

experiment, a passive IRT was conducted on a wooden block $\left(20 \times 20 \times 50 \mathrm{~mm}^{3}\right)$ during a semistatic compression test along its fiber direction. The smartphone was set up in a tripod as shown 
in Figure 4.26b. The temperature difference in the specimen between the sound and cracked area was acquired through the applied stresses during the compression test that was performed for 15 seconds until the collapse of the specimen.

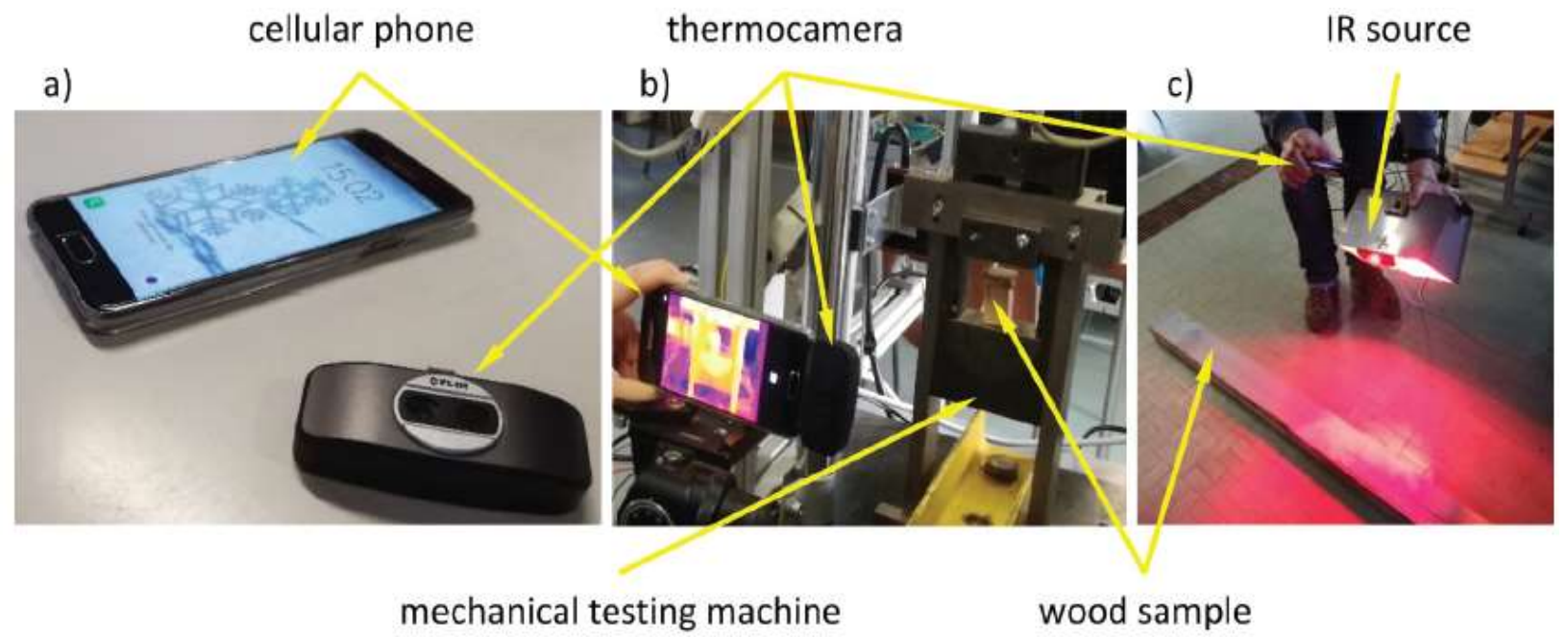

Figure 4.26: (a) FLIR ONE with the recording smartphone; (b) IRT setup for wooden block under compression testing machine; (c) IRT setup for wooden beam (Sandak and Sandak 2017).

\section{$\underline{\text { Results and Discussions }}$}

beam's surface coated with acrylic paint

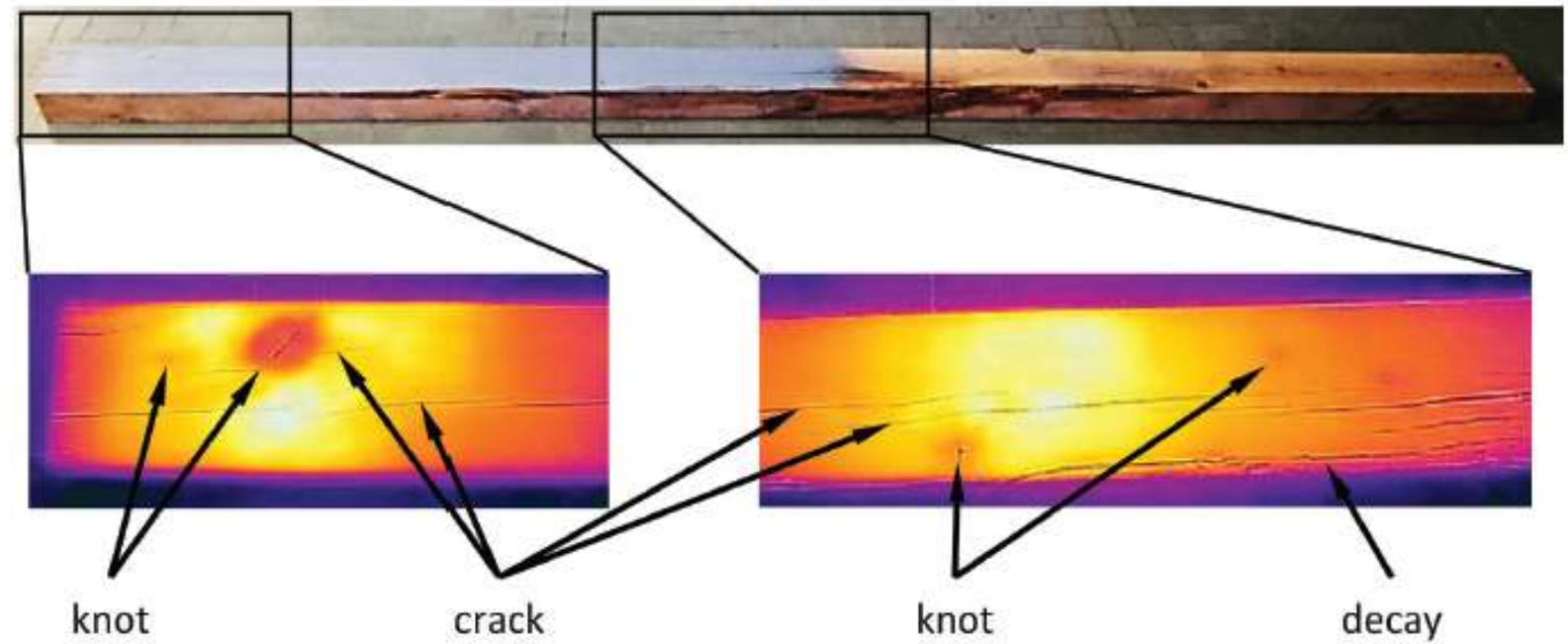

Figure 4.27: Wooden beam specimen with recorded thermograms from active IRT (Sandak and Sandak 2017). 


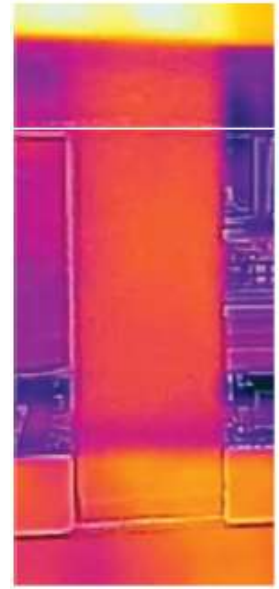

$0 \mathrm{~s}$

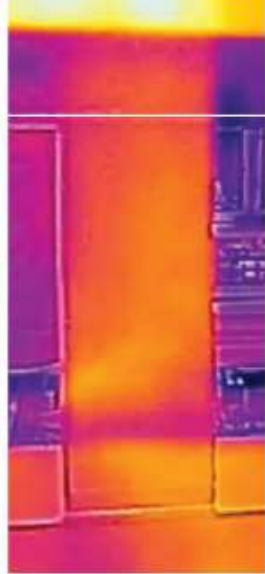

$5 \mathrm{~s}$

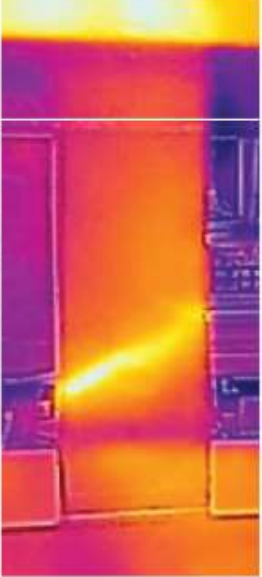

$7 \mathrm{~s}$

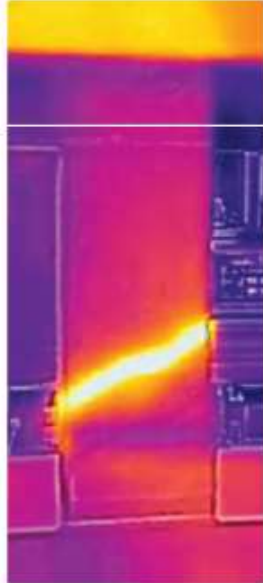

$9 \mathrm{~s}$

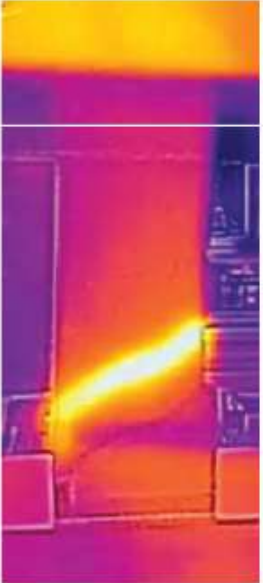

$11 \mathrm{~s}$

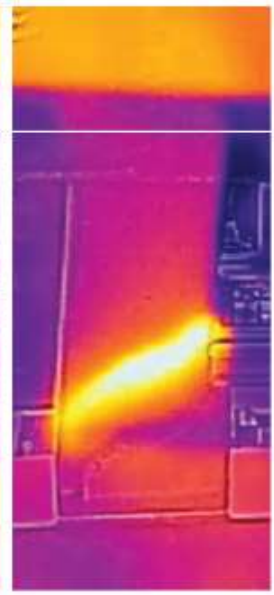

$13 \mathrm{~s}$

experiment progress time, $\mathrm{s}$

Figure 4.28: Wooden block specimen with recorded thermograms from passive IRT (Sandak and Sandak 2017).

Figure 4.27 displays the thermogram from the wooden beam with very noticeable defects. Some dark spots observed were identified and located as knots while a dark strip on the right bottom edge of the specimen could be identified as a biological decay (that was visible). Cracks that were not visible clearly with naked eyes were also observed prominently in the thermograms. Additionally, it was proved that IRT is independent of surface color as the defects were observed in both coated and bare wood. Sequential thermograms were produced for the wooden block presented in Figure 4.28. The images illustrate a clear detection of the collapsed fiber and the section of failure that initiated after seven seconds into the test. With the expansion of the crack, the surface temperature was also found to increase.

\section{Conclusion}

IRT was performed using an extremely convenient IR camera that can be integrated with a smartphone to record thermograms. Despite the low resolution of the equipment, defects such as knots, cracks, and decay in wood elements were detected fairly. For the qualitative condition assessment of timber structural elements, IRT remains considerably affordable, convenient, and fairly reliable. 


\subsubsection{TAP TESTING OF COMPOSITES BENCHMARKED WITH DIGITAL SHEAROGRAPHY (Gryzagoridis and Findeis 2013)}

\section{$\underline{\text { Introduction }}$}

This paper studied the application of tap testing in detecting subsurface defects in both monolithic and sandwich composite members. The results were compared with the ones obtained from optical laser-based digital shearography, which is considered highly effective in defect detection in composite materials. Tap testing was conducted using Woodpecker WP-632AM. This model, in addition to the numerical display of the contact times $(\mu \mathrm{s})$, can be equipped with an additional $\mathrm{X} / \mathrm{Y}$ plotter capable to produce a real-time color tile map of the test area into a pc or laptop. The colors can range through green, yellow, brown, purple, and red, depending on the differences between contact times from the test surfaces and the reference sound area. Green represents a reference area whereas red represents a defected area with a big difference in the contact times. Various degrees of defect can be determined from different colors on the map. The LED indicator can be used to determine reference sound area contact time.

\section{$\underline{\text { Experimental Tests }}$}

Tests were conducted on four specimens with defects as shown in Figure 4.29. Specimen\#1 was a $310 \times 40 \times 12 \mathrm{~mm}^{3}$ sandwich composite beam made of $1.5 \mathrm{~mm}$ fiberglass and $9 \mathrm{~mm}$ balsa core with a $30 \mathrm{~mm}$ long and $20 \mathrm{~mm}$ deep void near the middle of the beam between the skin and the core. Specimen\#2 comprised of two $210 \mathrm{~mm}^{2}$ perplex sheets with a thickness of $2 \mathrm{~mm}$ and 3 $\mathrm{mm}$ with two $25 \mathrm{~mm}$ and $15 \mathrm{~mm}$ Teflon sheets inserted between the perplex sheets with centers

$70 \mathrm{~mm}$ apart. Specimen\#3 was a $450 \times 150 \times 15 \mathrm{~mm}^{3}$ sandwich composite beam made of $3 \mathrm{~mm}$ fiberglass and $9 \mathrm{~mm}$ foam core with four flat bottom holes of $20 \mathrm{~mm}$ diameters at depths of 12 $\mathrm{mm}, 7 \mathrm{~mm}, 5 \mathrm{~mm}$, and $3 \mathrm{~mm}$ from the surface. Specimen\#4 was the same as specimen\#3 with four flat bottom holes of $25,20,15$, and $10 \mathrm{~mm}$ diameters at a depth of $5 \mathrm{~mm}$ from the surface.

\section{$\underline{\text { Results and Discussions }}$}

Figure $4.30 \mathrm{a}$ presents the tile map of specimen\#1, where the $30 \mathrm{~mm}$ void was clearly detected as the red spots. Similarly, the Teflon inserts were easily recognized in the map shown in Figure 4.30b. Even though specimen\#3 was made of foam core, which is considered vibration 
damping material, the $20 \mathrm{~mm}$ holes were clearly detected with red spots as shown in Figure 4.31a. In Figure $4.31 \mathrm{~b}$ corresponding to specimen\#4, however, all the defects were not identified. The method's ability to detect the defects, for a particularly vibration damping material, could be seen to be diminishing with decreasing defect diameter and was completely lost between $10 \mathrm{~mm}$ to 15 $\mathrm{mm}$ diameter holes.

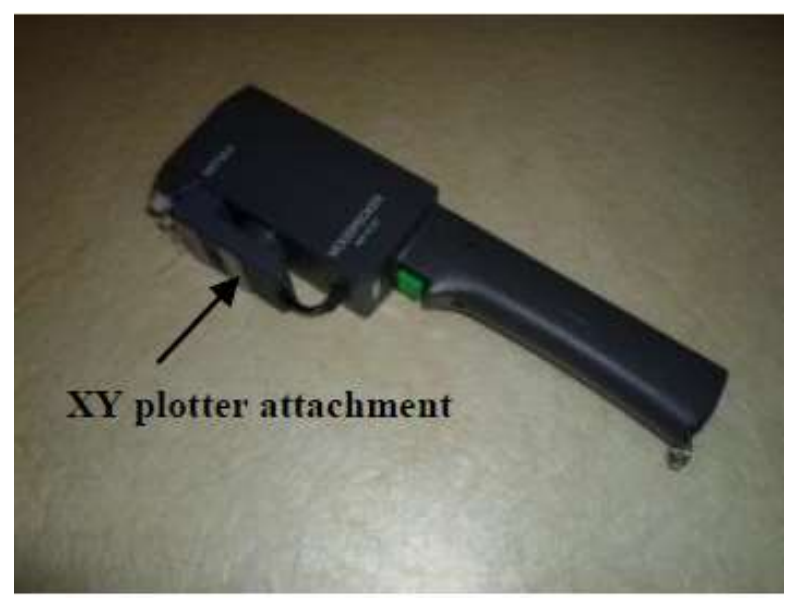

(a)

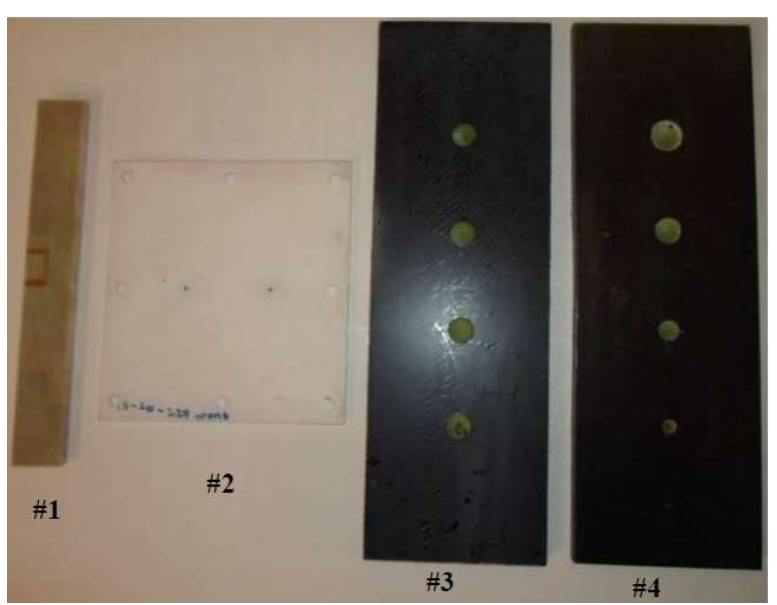

(b)

Figure 4.29: a) Woodpecker WP-632AM; b) Specimens used in the experiments (Gryzagoridis and Findeis 2013).

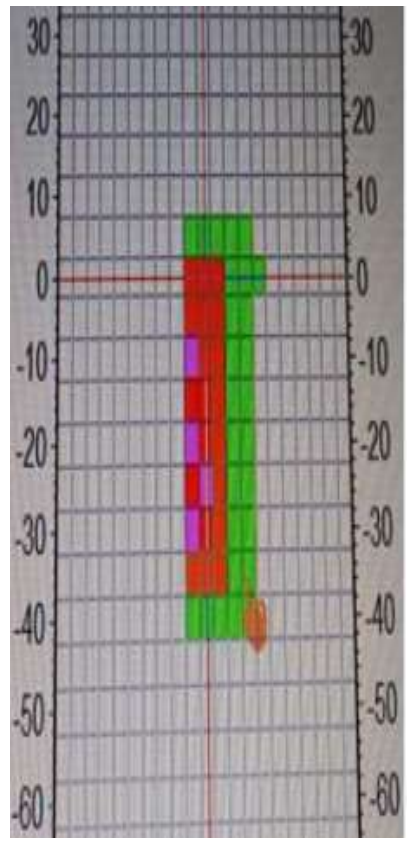

(a)

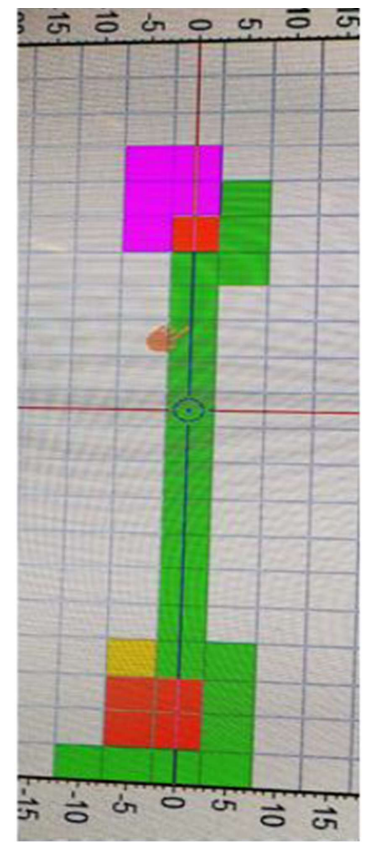

(b)

Figure 4.30: Woodpecker colour tile map for (a) Specimen\#1; (b) Specimen\#2 (Gryzagoridis and Findeis 2013). 


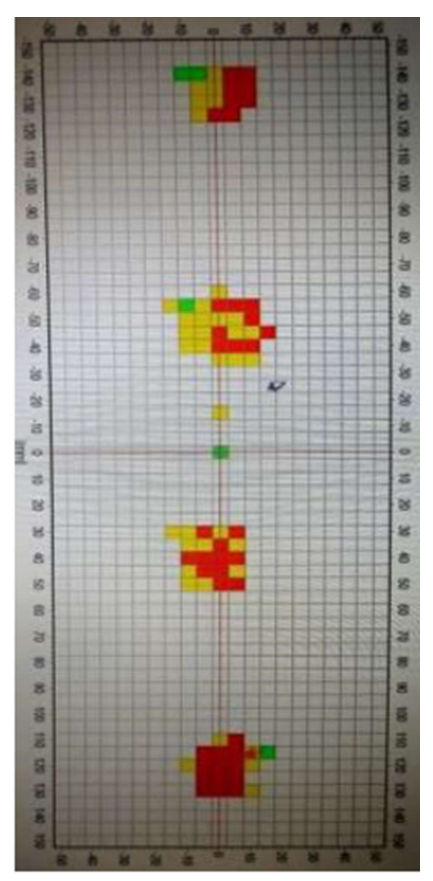

(a)

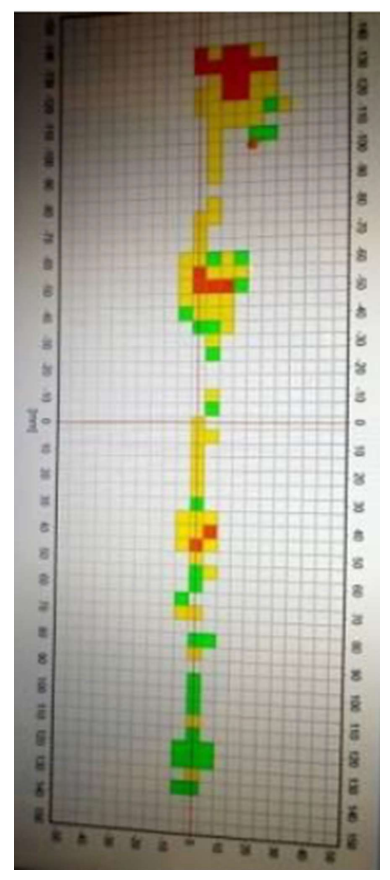

(b)

Figure 4.31: Woodpecker colour tile map for (a) Specimen\#3; (b) Specimen\#4 (Gryzagoridis and Findeis 2013).

\section{$\underline{\text { Conclusion }}$}

It was inferred that the Tap Testing technique was just as reliable as Shearography in detecting defects in monolithic and sandwich composite members. Woodpecker WP-632AM was found to be user-friendly, and cost-effective; needed less preparation and setup time; and was highly convenient to detect subsurface defects sized approximately from $10 \mathrm{~mm}$ readily in the pictorial as well as numerical format. For future work on the technique, it was recommended to establish the minimum detectable size of the defect and its performance on various types of composite materials.

\subsubsection{NONDESTRUCTIVE TESTING OF FRP COMPOSITE STRUCTURAL COMPONENTS AND FRP REHABILITATED BRIDGE USING DIGITAL TAP TESTING (Halabe et al. 2020)}

This study presented the use of $\mathrm{RD}^{3}$ to detect subsurface defects in the FRP wrapped concrete components in service. Additionally, the possibility of application of the device in various glass fiber reinforced polymer (GFRP) composite specimens was determined in the laboratory 
setup. The defects were recognized by comparing the numbers from test surfaces with a reference number from the sound area. The areas with numbers $10 \%$ higher than the reference number were considered defected. DTT was performed on carbon fiber reinforced polymer (CFRP) bonded box beams of the Whiteday Creek Bridge located in West Virginia. The beams were wrapped with CFRP to repair significant corrosion damage and needed detection of any debonds between the CFRP fabric laminate and the concrete surface for immediate repair. Although smaller sized debonds were also detected by DTT, only those ranging from 1.5 " x 0.75 " to 4 " x 3 ", following ACI 440.2R-17, were repaired or replaced. It was deduced that DTT can be very effective and convenient for rapid field testing of concrete members confined with FRP composite wraps at low cost. However, the method was unable to detect delamination in members over $5 \mathrm{~mm}$ thick and it was not capable of testing members with wearing surfaces. Hence, it was established that DTT's capability was limited to detecting defects only at shallow depth, such as delamination within thin FRP members, and debonds between the FRP wraps and the underlying structural components.

\subsection{CONCLUSION}

IRT and DTT have been well established as condition monitoring tools in the civil infrastructures. These techniques can detect near surface defects with high accuracy. IRT has been effective in the inspection of concrete, FRP wrapped concrete (e.g., Halabe et al. 2013c), and wood elements; whereas DTT has been promising in FRP, FRP wrapped concrete, fiberglass and balsa sandwich, and Perspex elements. However, both IRT and DTT were incapable to show detects in metals such as aluminum since it has high stiffness and high thermal diffusivity (Gryzagoridis and Findeis 2017). The major advantages of these techniques are portability, repeatability, economical, the need for access to only one side of the test member, no surface preparation requirements and easily-to-handle features. Moreover, IRT is a noncontact technique and hence can perform a remote inspection of large surfaces rapidly and reliably. This feature makes it safer during operation as well. Novel automated systems, although in the preliminary phase, have shown capabilities of result interpretation that can be independent of the operator's knowledge or experience. With modern advances in the post-processing methods and equipment capable of realtime measurement, IRT has become more practical, affordable, and faster. Nevertheless, significantly affordable models have comparatively low resolution. IRT is also highly influenced by environmental conditions and should be used in a controlled environment for accurate results. 
Additionally, with regards to the standardization of the technique, ASTM D4788-03 is the only international standard that can be used only for passive IRT in bridge deck inspection. Hence, more such standards should be developed for the employment of IRT and DTT that are efficient in terms of labor and equipment can significantly reduce the cost of maintenance and replacement of infrastructures. 


\section{NDT TECHNIQUES INTEGRATED WITH UNMANNED AERIAL SYSTEM}

\subsection{INTRODUCTION}

Unmanned aerial vehicle (UAV) or drone is an aerial device that can be flown and controlled remotely, without a pilot on board. Unmanned Aerial System (UAS) is a combination of UAV, a payload (load that can be carried), and a ground station to control the vehicle by an operator. These systems were first developed during World War I as a military weapon. Since then UAS has been employed in military applications (Dorafshan 2018). From its use only in the military, the system started gaining private market and slowly picked up as a commercial technological asset (Kim et al. 2015). In the last two decades, its application has expanded to other industries such as security, insurance, media, entertainment, etc. The global drone market is expected to rise from 4.4 billion USD in 2018 to 63.6 billion USD in 2025 with a compound annual growth rate of 55.9\% (Markets and Markets 2019). Silver et al. (2017) states that the most impacted industry has been infrastructure with the predicted value of business services and labor reaching 45.2 billion USD.

The major purpose of UAS application in the infrastructure industry has been the inspection of vulnerable structural member areas that are inaccessible to a human without risk. Inspection of structures using aerial visual media (photos and videos) from high-resolution cameras have shown promising results. Seo et al. (2018) presented the case studies of the application of UAS with a high-resolution camera in the inspection of a masonry building, two pedestrian timber bridges, and two in-service timber bridge (arch bridge and timber girder bridge) decks in South Dakota. The system was able to detect defects such as cracks, buckling damages, spalling, corrosion (quantification and level classification). The automated detection of cracks using high-resolution cameras and image processing and analysis software have also been used. For the extraction of features, edge detection technique using the Gaussian Blur equation to enhance the damaged area by highlighting with dense black color has been proved effective for cracks with considerable size (Eschmann et al. 2012 and Dorafshan and Thomas 2019). Kim et al. (2015) utilized a morphological approach to determine the width of the cracks. Ellenberg et al. (2016) concluded 
that it is possible to detect cracks with thickness as small as $0.75 \mathrm{~mm}$ with high-resolution cameras from a distance of $3 \mathrm{~m}$ from the test surface.

The application of UAS has recently advanced towards its integration with various NDT sensors and thermal cameras for inspection of in-service structures. Much research have been conducted for the determination of delaminations in bridge decks using UAS integrated with IRT (UAS-IRT). Brooks (2017) proved the feasibility of using UAS integrated with IRT (UAS-IRT) Additionally, Guarino et al. 2018 compared the results obtained from vehicle-based IRT and UASIRT. Similarly, other contact-based UAS has also been developed recently integrating ultrasonic testing (UT) and digital tap testing (DTT). Mattar and Kalai (2018) proposed UAS-UT for metals and Moreu et al. (2018) proposed UAS-DTT in concrete members, both of which will be discussed further in the chapter. Moreover, UAS-IRT based photogrammetry was found to be useful in the detection of damages resulting from extreme weather, moisture and seepage from the drainage network in Rupestrian cultural heritage site located in Georgia (Frodella et al. 2020).

UAVs are available in a wide range of operations. These can be categorized according to parameters: flight type, and weight. According to the flight type, UAV can be classified into three main categories: Fixed-wing, multicopters (quadcopters, hexacopters, and octocopters) and helicopters. Fixed-wing UAVs (such as Trimble UX-5 and Topson Sirius Pro) have the advantages of higher speed, higher payloads, and higher flight time. Multicopters and helicopters are capable of take-off and land vertically requiring small space. Helicopters have higher payload and longer flight time than multicopters. Multicopters, on the other hand, can maneuver more efficiently (Gillins et al. 2016). Kim et al. (2015) showed characteristics of UAVs based on their weight: model aircraft, small UAV, and large UAV. Model aircraft criteria vary in different countries with their weight typically ranging from 12 to $35 \mathrm{~kg}$. In general, small UAVs weigh $150 \mathrm{~kg}$ or less, and large UAVs weigh more than $150 \mathrm{~kg}$.

Dorafshan (2018) listed several ready-made UAS integrated with high-resolution and/or infrared cameras suitable for bridge inspection with details such as positioning system, size, maximum flight time, price ranging from $\$ 500$ to $\$ 50,000$, and particular applications in bridge inspections. Similarly, Duque et al. (2018) compared various features of available UAVs with price ranging from $\$ 700$ to $\$ 53,000$ and flight time ranging from 18 to 55 minutes. 
Each drone is required to be registered with the Federal Aviation Administration (FAA). Previously, the regulations for commercial UAVs operations were on the conservative side. In 2016, the FAA issued new regulations under which people only needed to pass an aeronautical knowledge test to be licensed to fly commercial UAVs. For inspection purposes of structures, FAA and DOT regulations should be followed appropriately. These include airspace class restriction: UAS to be operated in certain areas require air traffic control (ATC) authorizations depending on airspace classes A, B, C, D, E, and G. All classes except G need ATC approval. Most bridges fall under classes A through E and require ATC approval.

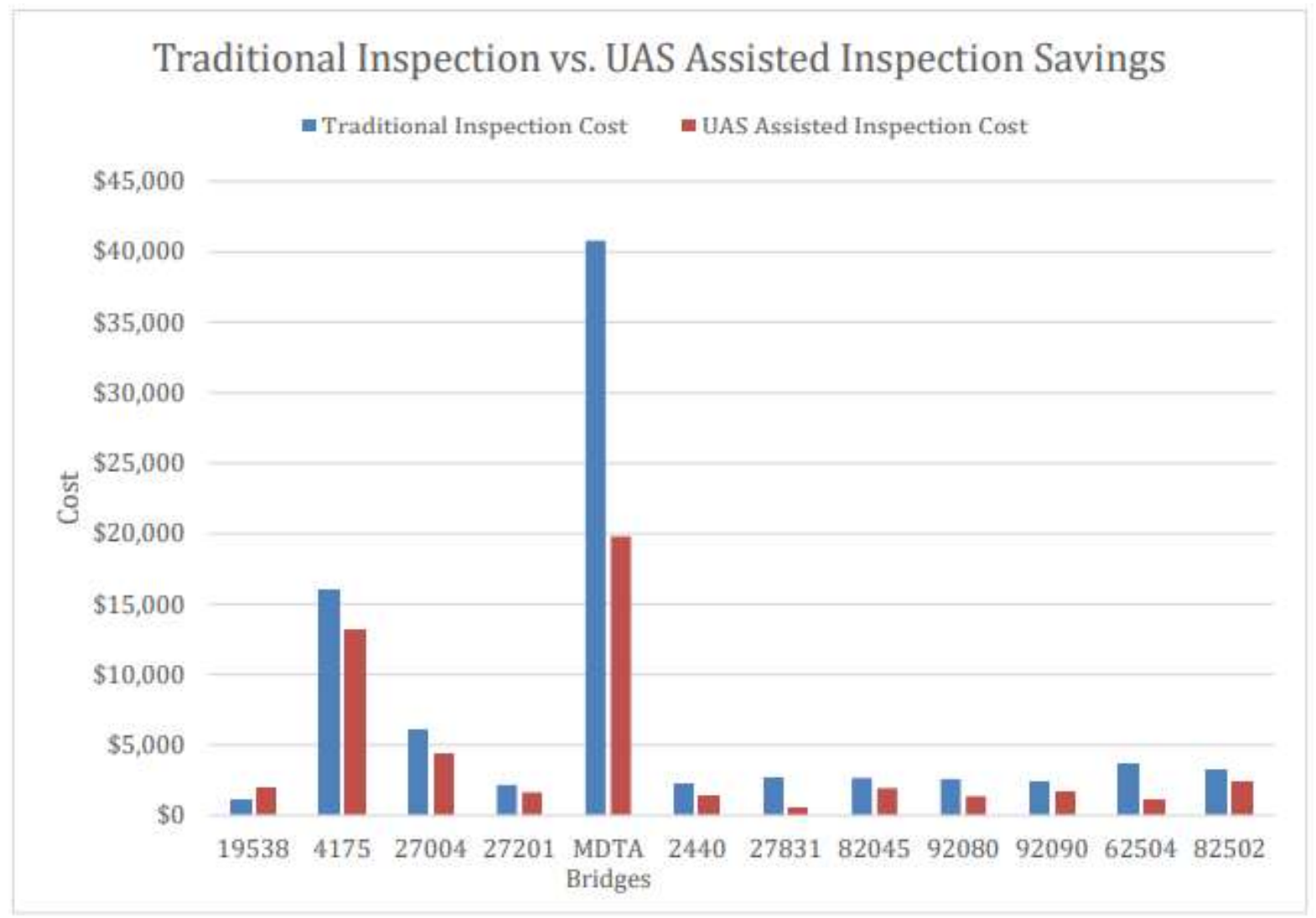

Figure 5.1: Traditional vs. UAS assisted inspection savings (Wells and Lovelace 2018).

\section{Benefits of UAS Assisted Inspections for Infrastructures}

- The technology provides a risk-free approach for the inspectors assessing structural members in hard-to-reach areas such as bridge soffit, confined spaces, etc.

- The application of UAS reduces the cost of inspection significantly compared to a manual assessment. This includes the elimination of salaries for labor and cost for the access and safety 
equipment required for the inspections. Figure 5.1 depicts the cost comparison between traditional inspection and UAS assisted inspection from the case studies of various bridges. It is clear that UAS assisted inspections are more cost-effective than manual inspections (Wells and Lovelace 2018).

- UAS facilitates the inspection of large structures with very high speed.

- The inspection process using UAS doesn't interrupt the operation of the structure being tested.

\section{Challenges and Selection Criteria for UAS integrated with NDT Equipment}

- Most of the UAS depend on GPS for navigation. In some instances when the GPS is blocked, there is a need for alternate navigation systems. Additional features such as SONAR sensors (Dorafshan et al. 2019) or ultrasonic sensors (Gillins et al. 2016) set a minimum distance that is maintained by the drone with the surrounding objects. Such systems would protect the device during the close-up inspections.

- UAS platforms should be stable for high-quality images. However, mechanical vibration and high-speed wind affect the performance of lightweight UAS especially. In a wind speed of 10 $\mathrm{m} / \mathrm{s}$, the minimum possible distance of the system from the test surface was increased by three times: $0.3 \mathrm{~m}$ (without wind) to $0.9 \mathrm{~m}$. This issue is aggravated in the inspection sites close to oceans, rivers, or canyons. Hence, heavy-weight UAS may be more effective in these areas (Dorafshan et al. 2019).

- Different types of obstructions in the inspection site may limit the use of UAS. These may be components of bridge such as cross-frames and bracings, debris, a bird's nest, or even markings from prior inspections. While some of these factors might not have been an issue for a human inspector, it is considerably challenging for UAS (Dorafshan et al. 2019). Collision-tolerant UAS might resolve some of the issues (Wells and Lovelace 2018).

- The flight times for available UAS range from 10 to 55 minutes. Typically, inspection under ideal conditions might not be affected by the range. However, some weather conditions such as high wind gust may require increasing maneuvers that may drain the battery quickly (Dorafshan et al. 2019). Therefore, self-heating or rechargeable batteries would be efficient in these cases. 
- The NDT equipment should be compatible with the payload of the UAS. Lightweight equipment with a high payload would be preferable in this regard.

- UAS should include good lighting equipment such as flashlights or head beams. This issue might be more apparent in the case of a high-resolution camera survey. Real-time tools for changing the camera aperture size during the operation would be a good feature to add (Gillins et al. 2016).

- The survey of structures such as bridge decks may be screened by traffic. It might be a problem in heavily trafficked bridges (Guarino et al. 2018). Hence, appropriate timing and weather condition is required for reliable results.

- For the inspections of large structures and at longer distances, long-range modules might be required for remote control (Duque et al. 2018).

\subsection{REVIEW OF APPLICATIONS OF NDT TECHNIQUES INTEGRATED WITH UNMANNED AERIAL SYSTEM}

\subsubsection{DEVELOPMENT OF CRACK DETECTION SYSTEM WITH UNMANNED AERIAL VEHICLES AND DIGITAL IMAGE PROCESSING (Kim et al. 2015)}

\section{Introduction}

The large size and complex geometry of infrastructure have made their inspection process very difficult and limited with some of their major structural components in hard-to-reach areas. This complication can be resolved through advancements in UAS integrated with digital image processing and analysis equipment. This study proposed a novel structural inspection system that integrated UAS with an image analysis technique for the detection and analysis of cracks in concrete structural members.

\section{$\underline{\text { Equipment Development }}$}

The device used in this study comprised a rotary-wing drone, a Gymbal, and an image acquisition unit. Among various rotary-wing drones, AiBotix X6 was chosen, given its low cost, stability (CFRP housing), and productivity in terms of flight time (30 minutes). Additionally, a digital image analysis software was developed with an aim to inspect test surfaces, identify cracks, and measure the crack widths. The involved algorithms were divided into two sections: crack 
detection and crack analysis. The automatic crack detection process was accomplished using the morphological technique. This technique involved segmentation of the image, feature extraction, and decision-making algorithms. In case the captured image quality is low, pre-processing would be performed before the rest of the steps. For the analysis of the detected crack images, a special algorithm was developed named Morphological Link for Crack (MorphLink-C). The algorithm distinguished pixels with cracked area from the image, grouped those pixels, selected the pixels, and further analyzed those to measure parameters of the crack and display the crack sizes in the units of $\mathrm{mm}$ in 12 steps.

\section{$\underline{\text { Experimental Tests and Results }}$}

Field tests, for the validation of the proposed device, were conducted on bridges in service, one of which is shown in Figure 5.2. Digital images were taken by the UAS from inaccessible areas. The images were then analyzed by the MorphLink-C algorithm in 12 steps as shown in Figure 5.3. The final three steps displayed the crack length, crack area, and crack width as shown in Figure 5.3. The crack widths, in different positions along the crack length, obtained from the software were compared with those measured under a microscope. The difference computed between the crack widths ranged from $0.01 \mathrm{~mm}$ to $0.08 \mathrm{~mm}$. Hence, the system was highly accurate in automatically determining the crack size.

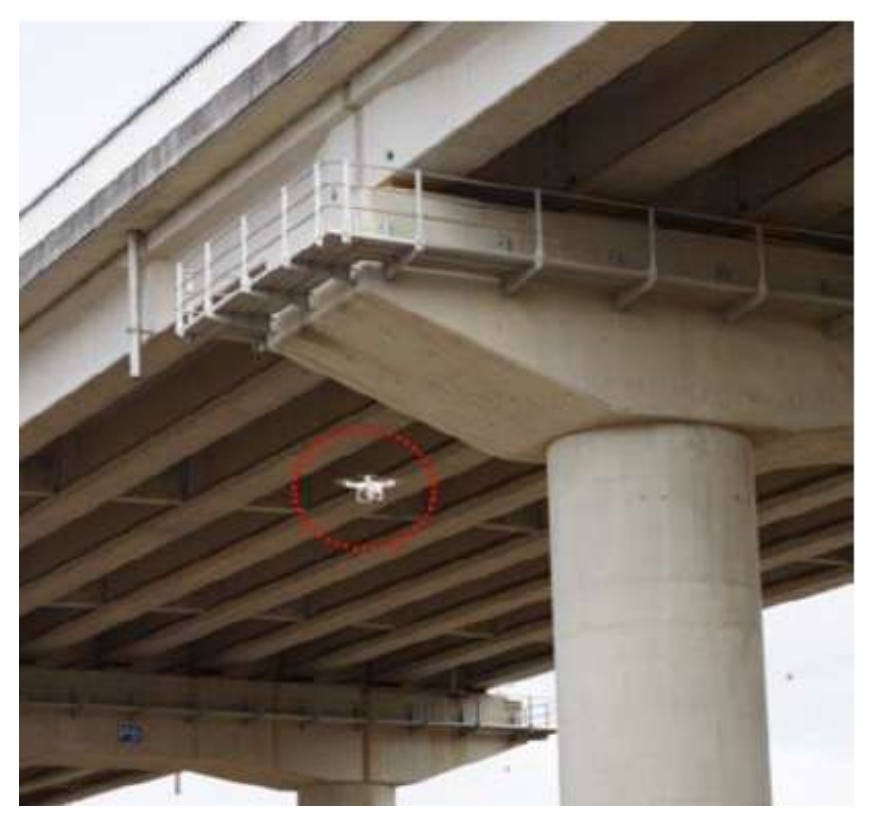

Figure 5.2: Field inspection site for the proposed device (Kim et al. 2015). 

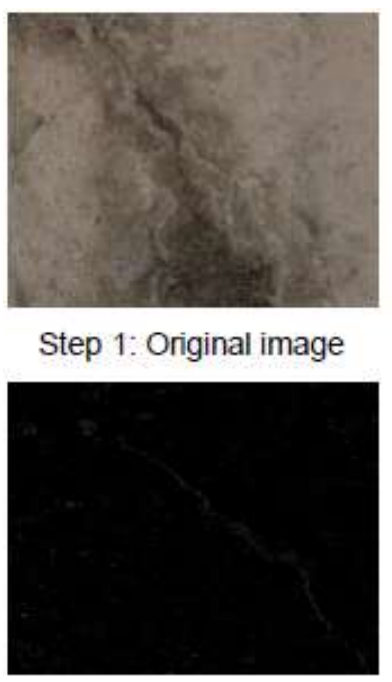

Step 5: Extracted cracks

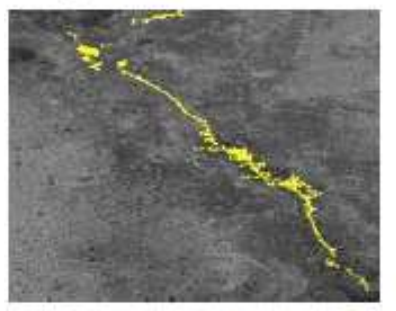

Step 9: Detected cracks
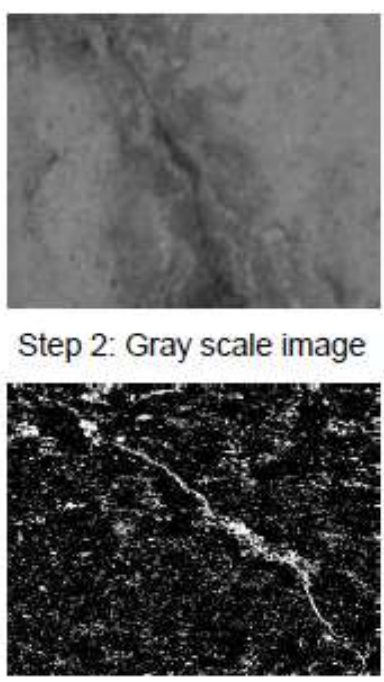

Step 6: Binary image

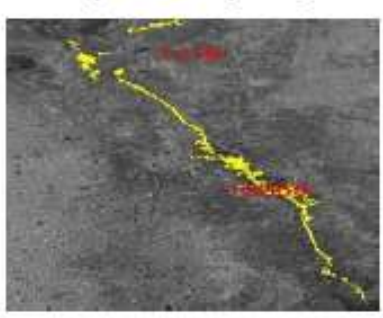

Step 10: crack area

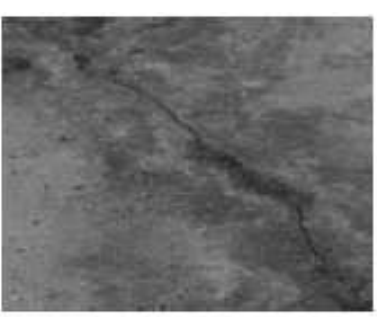

Step 3: Cut image

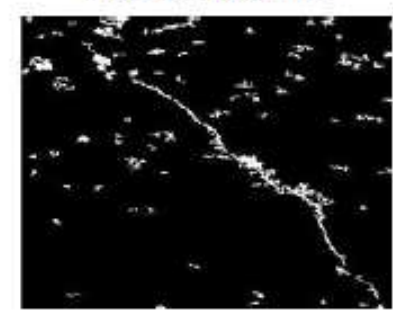

Step 7: Pre-denoise image

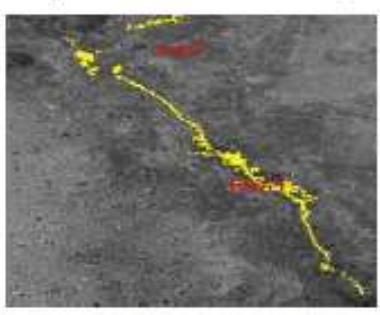

Step 11: crack length

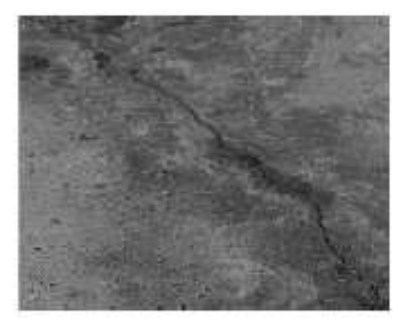

Step 4: Sharpen image

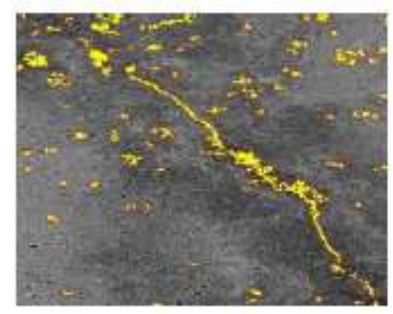

Step 8: Grouping cracks

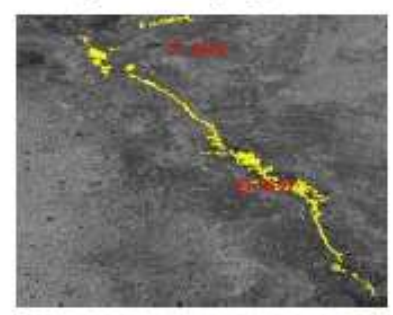

Step 12: crack width

Figure 5.3: Crack analysis and quantification steps (Kim et al. 2015).

\section{Conclusion}

The proposed technique was verified to automatically determine accurate crack widths in concrete elements. With this, the technique was deduced to be efficient in assessing cracks in concrete structural members without the need for direct human interaction. This results in lesser time, lower cost, and lower risk for the inspection process. Hence, the integration of UAV and proposed digital image analysis software can be very useful in the maintenance and rehabilitation of compromised structures. Future work was recommended on the software performance in terms of distinguishing the defects from fine details in the test surfaces. 


\subsubsection{THERMAL DETECTION OF SUBSURFACE DELAMINATIONS IN REINFORCED CONCRETE BRIDGE DECKS USING UNMANNED AERIAL VEHICLE}

(Omar and Nehdi 2019)

\section{$\underline{\text { Introduction }}$}

The increasing number of aging bridges have raised the necessity to develop a costeffective technology to rapidly assess the bridges without having to stop the traffic. Remote sensing has therefore become popular for field inspection of bridges. This paper examined the feasibility of using IRT combined with UAV to detect and quantify subsurface delaminations in the two concrete bridge decks on site. The results obtained were also compared with those from sounding hammer and half-cell potential (HCP) corrosion tests.

\section{$\underline{\text { Equipment }}$}

Figure 5.4 displays the equipment used in the test. A quadcopter drone - Inspire 1 Pro was used in the survey with specifications mentioned in the paper. It can be operable for 8-22 minutes and has a maximum flight speed of $18 \mathrm{~m} / \mathrm{s}$. The drone is integrated with GPS and can stay still in a position with $\pm 2.5 \mathrm{~m}$ horizontal and $\pm 0.5 \mathrm{~m}$ vertical accuracy. The drone was mounted with FLIR Vue Pro thermal camera (facing straight down) with a resolution of 640 x 512 and capable to rotate $360^{\circ}$. A tablet or a smartphone could be attached to the device to allow monitoring during the survey. The collected images could be processed using FLIR image processing software. Both systems were controlled using a smartphone with the DGI Go app and FLIR Vue Pro app.
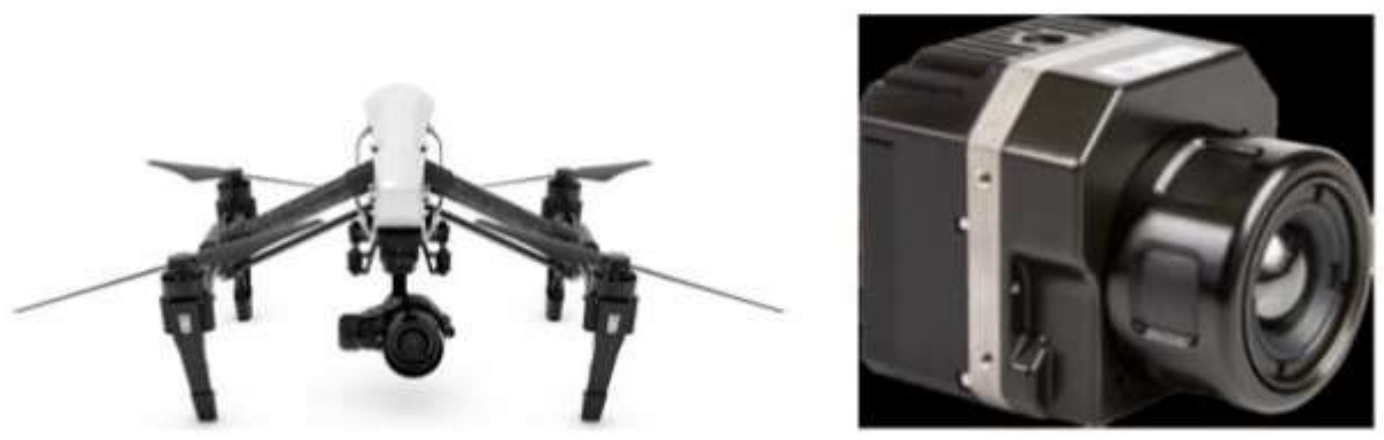

Figure 5.4: Inspire 1 Pro and FLIR Vue Pro thermal camera (Omar and Nehdi 2019). 


\section{$\underline{\text { Experimental Tests }}$}

The tests were conducted on two in-service reinforced concrete bridge decks situated over a creek in London, Ontario. The bridges (\#1 and \#2) were constructed in 1965 and both comprised of single spans of cast-in-place RC decks. Both the bridges were $15.24 \mathrm{~m}$ long, $12.18 \mathrm{~m}$ wide, and $0.91 \mathrm{~m}$ thick at the abutments and $0.48 \mathrm{~m}$ thick at the mid-span. The decks were overlaid with asphalt. Figure 5.5 presents the testing site of bridge \#2. The test was scheduled by the Ministry of Transportation Ontario (MTO) after defects were observed in a condition survey. The tests were conducted six hours after sunrise at $1 \mathrm{pm}$ with the ambient temperature of $26^{\circ} \mathrm{C}$, the relative humidity of $22 \%$, and the wind speed of $8 \mathrm{~km} / \mathrm{hr}$. The survey took approximately 20 minutes, with the actual flight time of only three minutes for each bridge. It was performed without any disruption to the traffic. The camera was able to capture both lanes at the same time from an altitude of $10 \mathrm{~m}$. The captured images had a spatial resolution of $2.5 \mathrm{~cm} .4$ thermal images were recorded for the entire bridge, overlapping each image by $50 \%$ at the spacing of $5 \mathrm{~m}$.
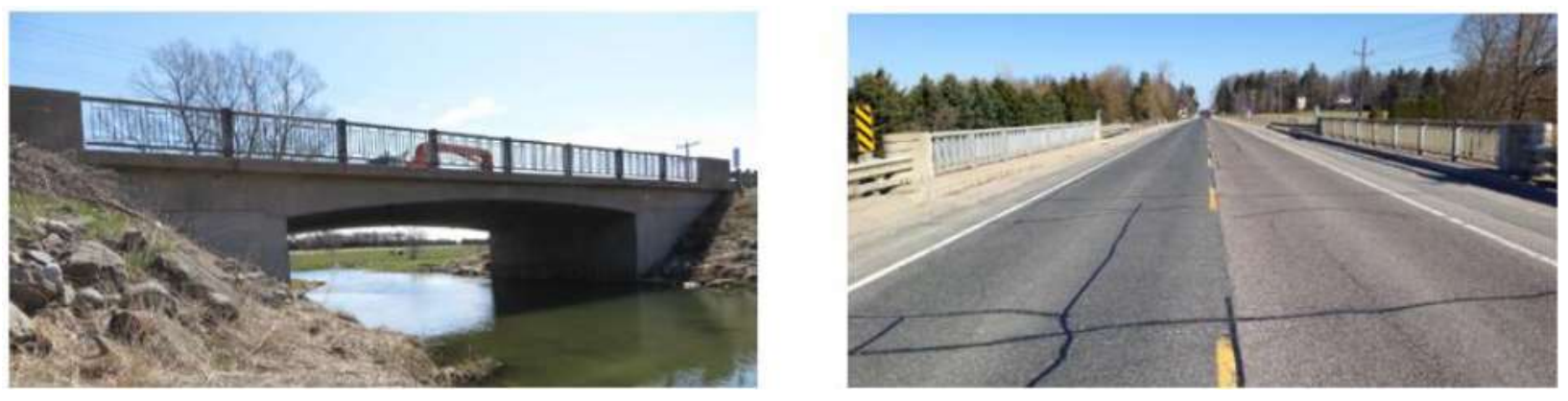

Figure 5.5: Bridge $\# 2$ testing site (Omar and Nehdi 2019).

\section{$\underline{\text { Results and Discussions }}$}

The recorded data were enhanced and processed into a final mosaicked thermal image with a pixel resolution of $128 \times 156$. The minimum thermal contrast was selected as $1^{\circ} \mathrm{C}$. The temperature contrast of each pixel was checked if it was higher than this threshold value to be recognized as a delaminated area. All the corresponding temperature values were grouped and a condition map outlining the geometry and location of subsurface delaminations was plotted using FLIR software. Figure 5.6 represents the condition maps of both bridges, where the pink and blue colors represented delaminated and sound areas respectively. Thus, by computing the total delaminated area from the map, a quantitative ground was provided for deciding on rehabilitation 
plans for the decks. The differences in the percentage of delaminated areas between the UAV-IRT system and the sounding hammer test for Bridge\#1 and Bridge\#2 were 1.6\% and 2.7\% respectively. Similarly, between the UAV-IRT and HCP, the differences were $9 \%$ and $7 \%$ for Bridge\#1 and Bridge\#2 respectively. Comparisons with both techniques showed high similarity in the location and shape of the defects obtained by the proposed system. Additionally, coring results indicated that the actual asphalt thickness was 50-60 $\mathrm{mm}$ and delaminations were present 45-50 $\mathrm{mm}$ below the concrete surface. The system did have some limitations in terms of the load capacity of the drone: interference by the wind affecting the image quality and the limited number of batteries reducing the flight time.
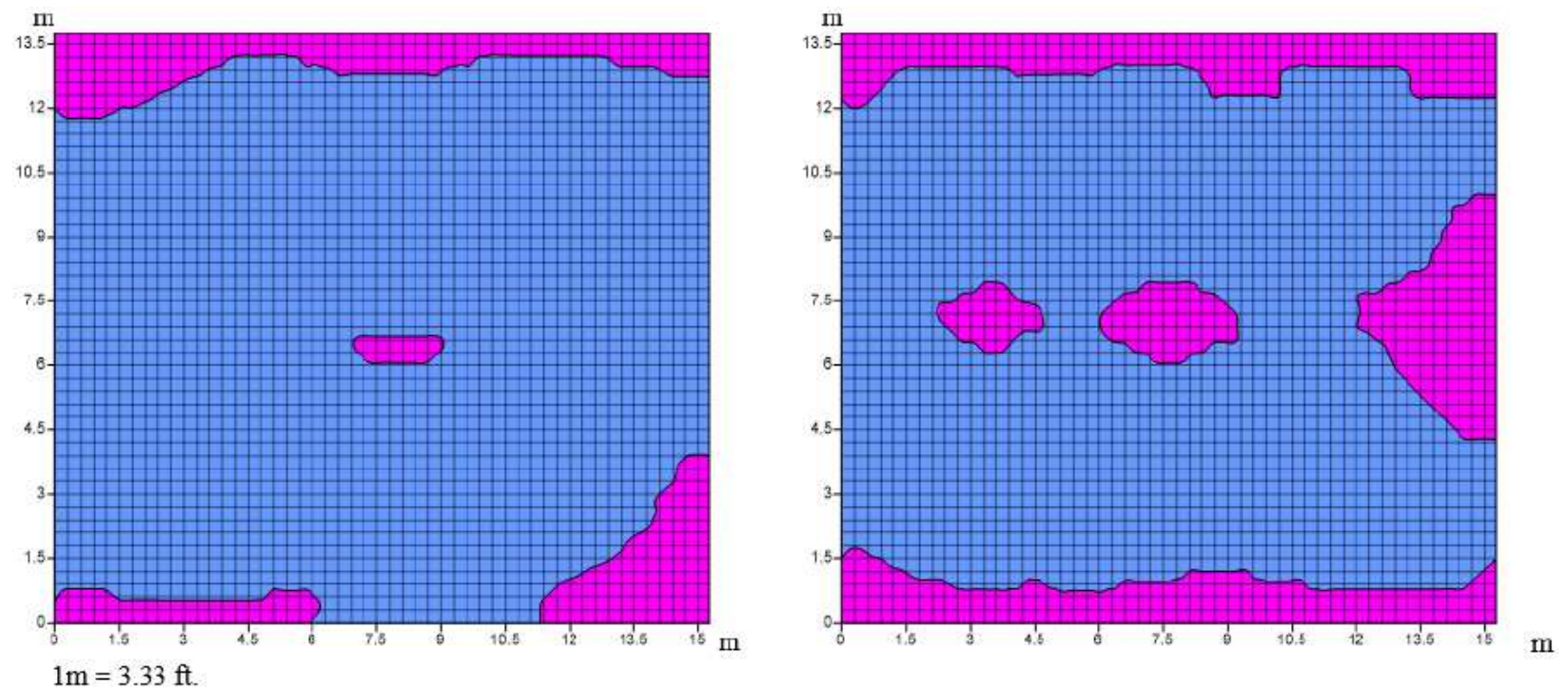

Figure 5.6: UAV-borne system condition map of (a) Bridge\#1; (b) Bridge \#2 (Omar and Nehdi 2019).

\section{$\underline{\text { Conclusion }}$}

The paper concluded that a considerable accurate condition map with details such as location and extent of delamination in the bridge deck could be obtained using the proposed UAVborne thermal system. The subsurface delaminations at the depth of around $1 \mathrm{~cm}$ were detected by the device. Information as such would be very beneficial in prioritizing the maintenance or rehabilitation process. The method was found to be more efficient and safer than the standard practice as the remote sensing could be very useful in assessing bridge elements that are not accessible easily, such as a bridge soffit. The inspection was rapid as the entire process took only 
20 minutes for each bridge. Moreover, the technology was cost-effective as there was no need for salary as well as the access and safety equipment cost for the inspector. It was recommended that the thermal camera should be compatible with the drone in terms of payload for better performance. Future work was recommended on the image processing algorithm for categorizing the delaminated areas basing on their severity.

\subsubsection{AERIAL VS. VEHICLE-BASED INFRARED THERMOGRAPHY FOR BRIDGE DECK DELAMINATION DETECTION (Guarino et al. 2018)}

\section{Introduction}

IRT conducted by mounting the IR camera on a vehicle has been an extremely convenient and effective approach for rapid inspection of bridge decks without interrupting the traffic. A cooled camera working in MWIR, with higher integration time, is capable of scanning the test surface with the speed as high as $50 \mathrm{miles} / \mathrm{hr}$. Nonetheless, aerial IRT provides greater coverage in a shorter period saving additional cost. One of the interesting features of using cameras integrated UAVs is the application of GPS coordinates to the images, making the analysis more efficient. This study presented a comparison between aerial IRT with UAVs and vehicle-mounted IRT on the on-site bridge deck inspection and condition mapping.

\section{$\underline{\text { Experimental Tests }}$}

Tests were conducted using both aerial IRT with fixed-wing UAVs and vehicle-based IRT in 4 different bridges in Southwest, Wisconsin. For the vehicle-based IRT, the FLIR A-655sc camera with a resolution of $640 \times 480$ was mounted on a vehicle. The scanning was done on a partly cloudy day with an ambient temperature of around $70^{\circ} \mathrm{F}$ and at the speed of 5-10 mph. The thermal images were collected in real-time allowing for spot check using sounding and impactecho techniques to confirm the reliability of the IRT performed. These checks were used to adjust the camera settings for some areas with indistinct results for more accurate mapping. The vehicle wheels were set up with an encoder working in sync with the data collected for accurate condition mapping. The fixed-wing aerial IRT was performed in all four bridge decks in the daytime and at night, i.e. in the heating and cooling cycle. The ambient temperature during the day was around $90^{\circ} \mathrm{F}$ and during the night was around $75^{\circ} \mathrm{F}$. A high-resolution MWIR camera was used to collect 
videos over the entire bridge decks from an altitude of $1000 \mathrm{ft}$. Images from separate frames were extracted to create a condition map.

\section{$\underline{\text { Results and Discussions }}$}

The condition maps of each bridge were compared between the aerial and vehicle-based IRT to recognize the reliability of aerial IRT using fixed-wing UAV. Figures 5.7 and 5.8 show the raw image and condition map from the two methods for Bridge\#4. It can be seen that the delamination patterns were very similar for both methods. Similar maps were obtained from all the inspected bridges. The percentage of delaminated areas determined using the maps from both methods were fairly close in all four bridges with a maximum difference of $8.9 \%$ for Bridge\#4. The higher difference resulted because the delaminations with lower thermal contrast were not defined well in aerial thermograms which lead to an over prediction of the delaminated areas. Therefore, although with less details, the aerial IRT was able to identify all the delaminations with locations perfectly matching with those obtained from vehicle-based IRT. Additionally, it was stated that aerial IRT possibly does not identify small delaminations with a size of smaller than 5 $\mathrm{ft}^{2}$. Aerial IRT had advantages to capture the entire deck in one run while the other method might need software to stitch the images obtained from several runs. Furthermore, it was found that the total cost for the survey using aerial IRT was $80 \%$ less than the vehicle-based IRT.

\section{$\underline{\text { Conclusion }}$}

Aerial IRT showed fairly reliable mapping of the delaminations in the concrete bridge decks under ideal environmental conditions without the need for lane closures. It was proven to be efficient in terms of time, cost, and effort. Nevertheless, the method compared to vehicle-based IRT did have some limitations: incomplete data resulting from heavy traffic that might screen the deck surface, and confirmation of the results using other methods such as sounding hammer would require separate time. Hence, aerial IRT could be utilized for rapid preliminary inspection of the bridge deck condition and prioritize the maintenance and rehabilitation of vulnerable bridges based on the severity level determined. 


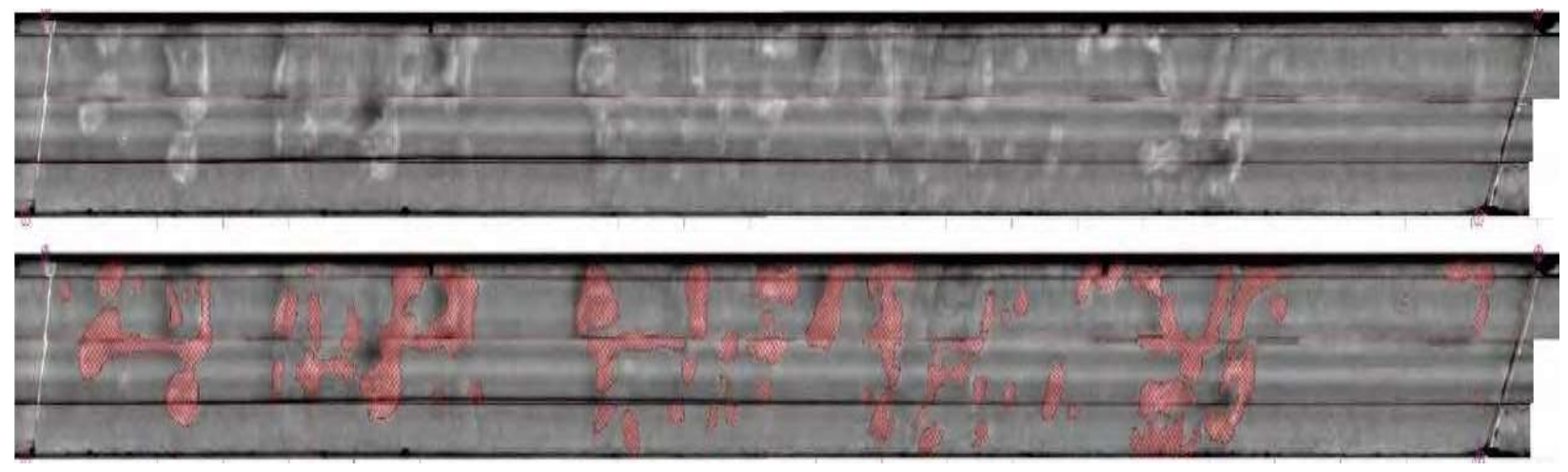

Figure 5.7: Bridge\#4 vehicle-based raw image (top); condition map (bottom) (Guarino et al. 2018).

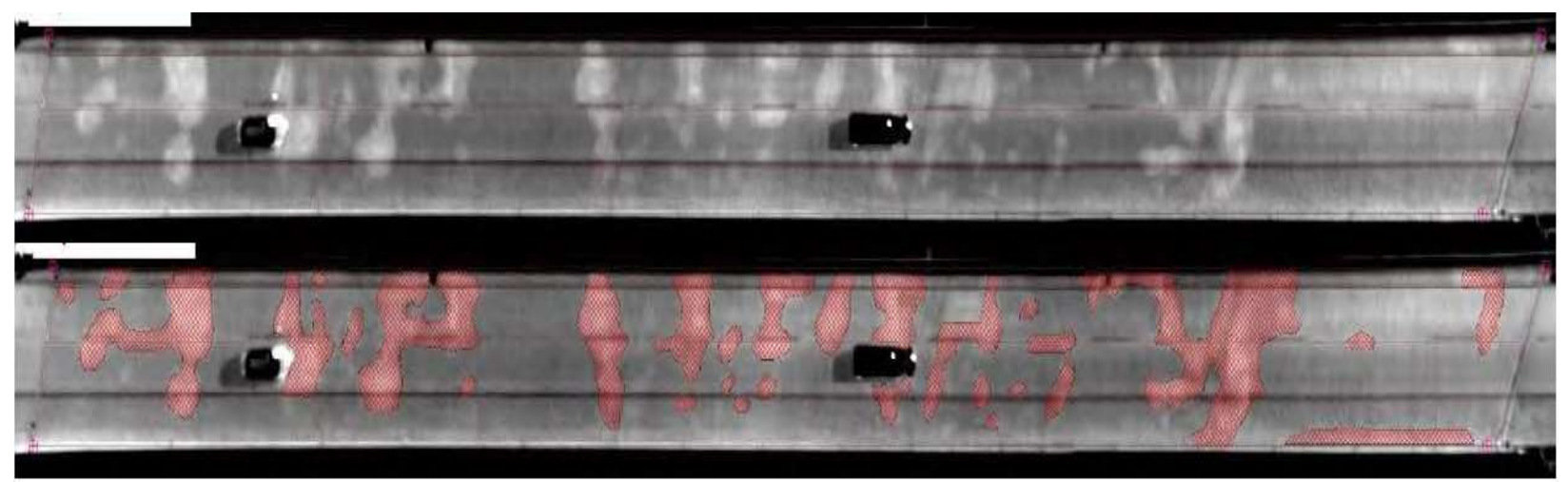

Figure 5.8: Bridge\#4 aerial raw image (top); condition map (bottom) (Guarino et al. 2018).

\subsubsection{REMOTE RAILROAD BRIDGE STRUCTURAL TAP TESTING USING AERIAL ROBOTS (Moreu et al. 2018)}

\section{Introduction}

Detection of deterioration in the structural members of railroad bridges has become necessary since the bridges are more vulnerable because of the increased car load capacity. With the increasing number of bridges in need of repair, the funding allocation is decreasing. Inspectors of railroad bridges are constantly looking for an efficient technique that can quantify the structural condition of the bridges to be able to prioritize and conduct the rehabilitation or replacement of the most critical bridges first. NDT techniques are being implemented, in this regard, to quantitatively assess the concrete members and evaluate the condition of the members. Modern techniques such as tap testing are costly, give qualitative results, and sometimes require man-lifts 
to access the target member. With an aim to enhance the features and convenience of a tap testing device while reducing the inspection cost, new technology was introduced. This paper proposed the use of a remotely operable tap testing device that would tap the target area, collect and analyze the impact sounds through a wireless sound system during the assessment of railroad bridges.

\section{$\underline{\text { Equipment Development }}$}

Applications of physical interaction of the UAVs with the target surface for inspection is in the preliminary phase, which is essential in tap testing. A new tap hammer was thus developed for the use in the experiment as shown in Figure 5.9. The system comprised of a closed-loop and planar four-bar linkage, namely crank-rocker. The crank was allowed to rotate $360^{\circ}$ whereas the rocker was restrained to angles between $0^{\circ}$ and $180^{\circ}$. The device was powered by a six volt DC meter. The tap hammer assembly with the drone would have the hammer orienting upside down to avoid contact with rotor blades of the drone. The hammer mass and length were fixed in a way such that its resonant frequency would approximately match the rotational speed of the motor. This would maintain synchronization between the motor and the beam supporting the hammer. The device would produce mechanical taps with similar energies and frequency. A digital recorder (TASCAMDR-44) and four external microphones (two on the drone body and two near the tap hammer) were used for the data acquisition. A single remote controller could be used to control the drone and actuate the hammer. Additionally, the microphones could be controlled using a smartphone that connects to the digital recorder. The collected data would be stored in an SD card for processing.

\section{Experimental Tests and Results}

The experiments in this study were conducted in three parts: manual operation of tap hammer, evaluation of automated tap hammer, and determination of the effect of noise on the microphones from the propulsion system of the drone. The first test involved the manual testing of two concrete specimens with the tap hammer. Figure 5.10 displays the sound and defected (with holes and corrosion) specimens used. The tests were conducted to check the performance of the tap hammer and the algorithm developed for inspection. For the second test, the tap hammer was mounted on the drone and the system was used to test five specimens. Among these, three were sound and defected concrete specimens with low compressive strengths and two were plywood 
specimens with one and two layers. These tests were used to examine the performance of the automated tap hammer with the increased complexity of analyzing the results from five specimens. Around 90 responses were collected from each specimen in one minute. The third test was conducted on the same five specimens used in the second one. For this test, the DJI Phantom multirotor drone was turned on and the effect of its presence on the interpretation of the acoustical responses was examined. Almost 150 responses were collected from each specimen. For the data collected in all the tests, principal component analysis (PCA) was utilized to generate clusters. These clusters were then classified using linear classifiers based on structural properties. Lastly, a confusion matrix was derived to accurately quantify the categorization performance. The classification of different sounds and structures under inspection was possible using this data processing method.

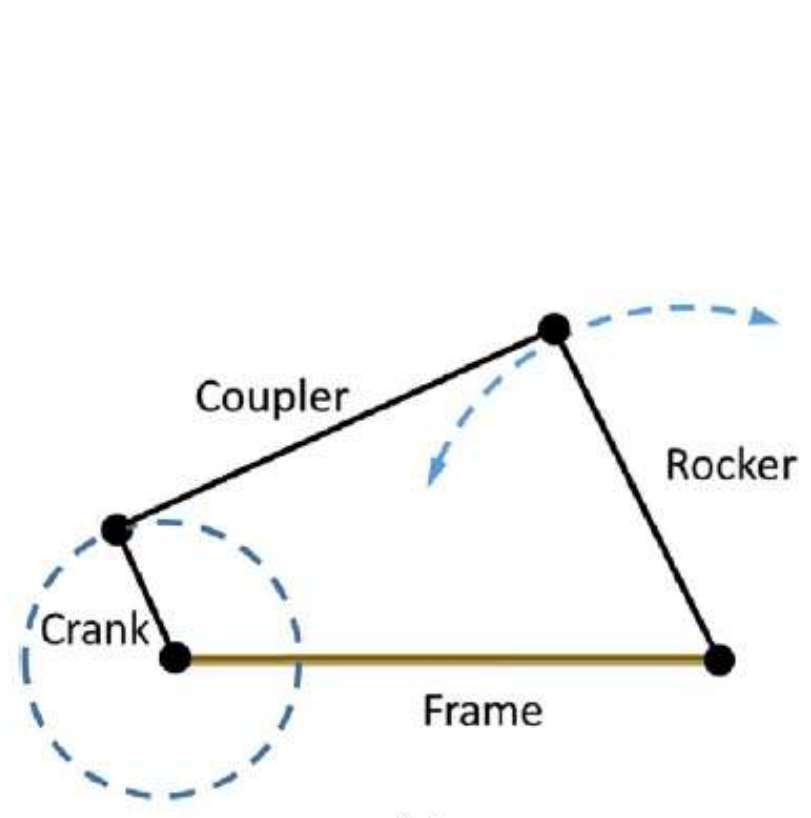

(a)

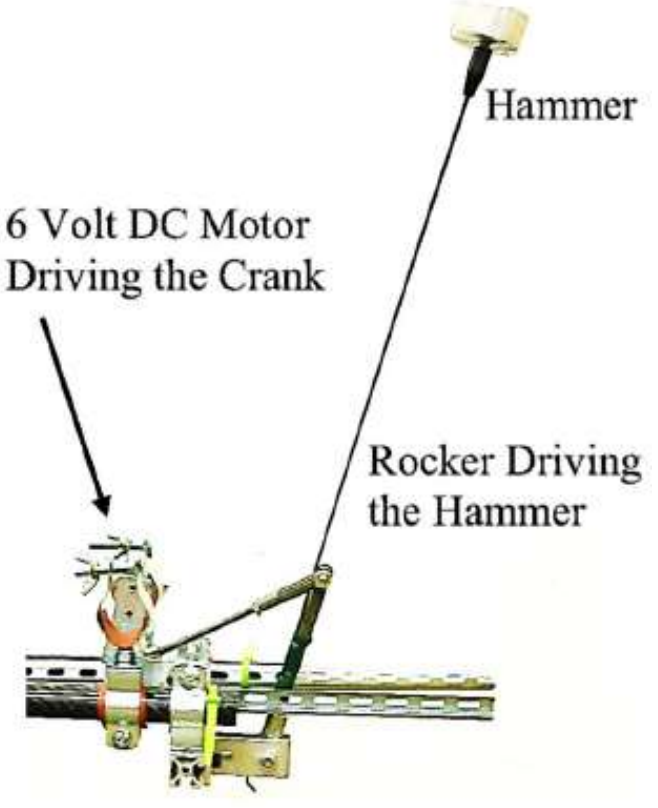

(b)

Figure 5.9: Tap hammer mechanism with a closed-loop and planar four-bar linkage (Moreu et al. 2018). 


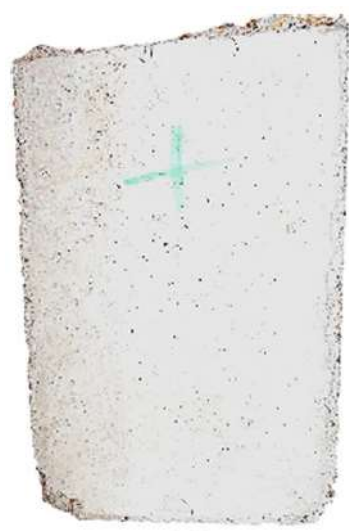

(a)

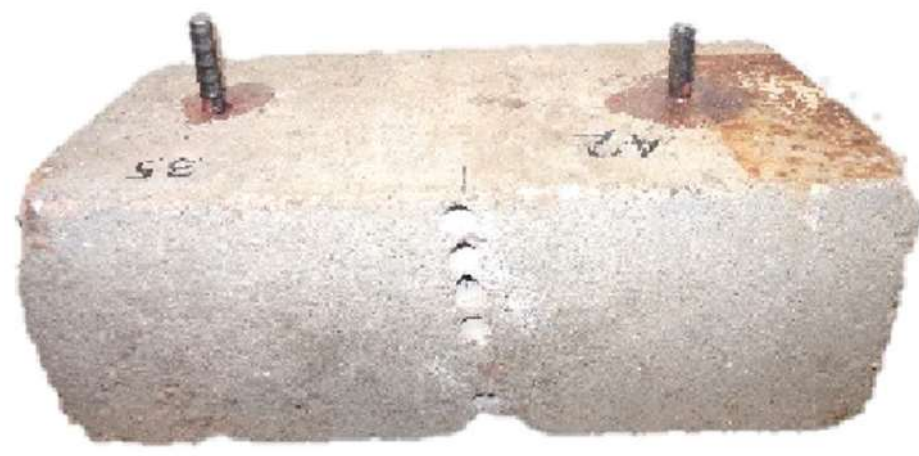

(b)

Figure 5.10: Concrete specimens (a) good; (b) bad (Moreu et al. 2018).

\section{Conclusion}

The proposed novel remote device was deduced to be effective in assessing the concrete structural members. The study also confirmed the feasibility of automated inspection of those elements capable of collecting a large amount of data. This would be very useful in a rapid and accurate inspection of the members. The large data sets can be processed using PCA and classified to identify different structural states. Additionally, the post-processing algorithms showed a good performance as those were able to distinguish the data from noise generated by the drone propulsion system. The major advantage of this device was the cost-effectiveness: the budget required for salaries and access equipment for the inspectors could be replaced by the cost of batteries. Further developments include the testing and field application of the remote-controlled automated device while deployed on the drone. The required parameters were established for the actual flight test in the next phase. The use of the developed device was not limited to drones. It could be mounted on a remote-controlled ground vehicle and could be applied not only on the railroad bridges but any concrete structure in need of assessment with low cost and high speed. 


\subsubsection{DEVELOPMENT OF A WALL-STICKING DRONE FOR NON-DESTRUCTIVE ULTRASONIC AND CORROSION TESTING (Mattar and Kalai 2018)}

\section{Introduction}

With the increase in the size of structures, inspection difficulties are also increasing. To resolve this problem, several wall-crawling robots have been developed. With the autonomous characteristics, these were able to perform inspections. However, these were not feasible to operate in the field because of some limitations. These were considered unsafe due to the possibilities of operation failure resulting from unpredictable strong wind or surface conditions. Drones integrated with high-resolution cameras, thermal and LIDAR cameras, etc. have been utilized for aerial inspections of different types of structures. Nonetheless, these devices give non-contact surveys. While the results from these devices are promising, a comprehensive assessment might need contact with the sensors for some materials such as metals. With an aim for a better solution, this paper proposed an aerial wall sticking robot for the inspection of any component of a structure. The robot comprised of electromagnetic units that would allow the robot to stick the sensors to the test surface to perform ultrasonic testing.

\section{Equipment Development}

A tri-copter was employed in the experiments as shown in Figure 5.11. The wall sticking mechanism consists of a combination of a thrust force and an electromagnetic force through which the sensor can stick to the vertical metal surface if the friction coefficient is greater than 1 . The drone was controlled using a remote controller and could maneuver in any direction. It had the characteristic of high control of rotation about the vertical axis and was robust against the highspeed wind. The system had variable modules to attach separate sensors that might be needed to conduct different kinds of techniques. In this experiment, a $2.25 \mathrm{MHz}$ thickness gauge acting as transmitter and receiver was used for ultrasonic testing. The device was also attached with two electromagnets that would allow the sticking of the sensors to the test surface (in addition to the thrust from the drone) for better results. This setDup reduces the effect of unpredictable high-speed wind in the data collection. In this manner, the sensor sticks to the test surface and will be able to continuously take the measurements, while the drone can pivot in different directions. The data 
collected were set up to be sent wirelessly into a laptop with the sensor software, which displays the data in real-time. The drone flight time was 15-20 minutes per battery pack.

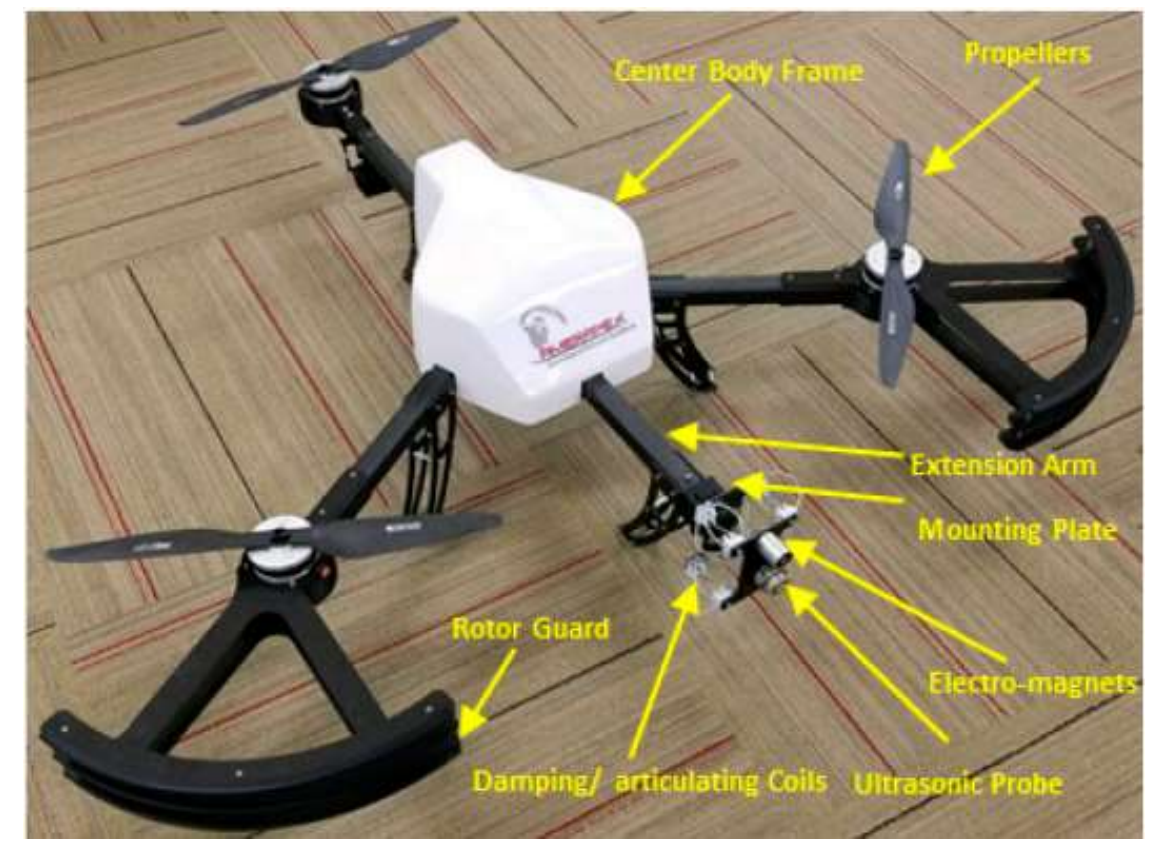

Figure 5.11: Tri-copter model used in the experiments (Mattar and Kalai 2018).

\section{$\underline{\text { Experimental tests and Results }}$}

Ultrasonic testing for the thickness determination at random points of an oil storage tank (nominal wall thickness of $5.08 \mathrm{~mm}$ ) were conducted in the field. This tank was vulnerable to corrosion and other environmental effects. The ultrasonic sensor was stuck to the tank wall surface by giving a command from the remote controller as shown in Figure 5.12. As soon as the sensor attached to the surface, ultrasonic waves were induced and the measured data (the wall thickness) was shown in real-time in the laptop at the ground-station. The result showed an accuracy of $\pm 0.127 \mathrm{~mm}$. 10 flight tests were performed with each test taking a maximum of 20 seconds between the takeoff and the real-time result display. The success rate of the wall sticking mechanism was $100 \%$ and $90 \%$ with and without the electromagnets respectively. The thicknesses of the wall were also determined using manual ultrasonic testing at the same points taken by the drone. Figure 5.13 depicts the plot comparing the results from both tests. The measured thickness ranged from 4.6 $\mathrm{mm}$ to $5.1 \mathrm{~mm}$. The thicknesses measured using the drone and manual testing matched 100\%. 


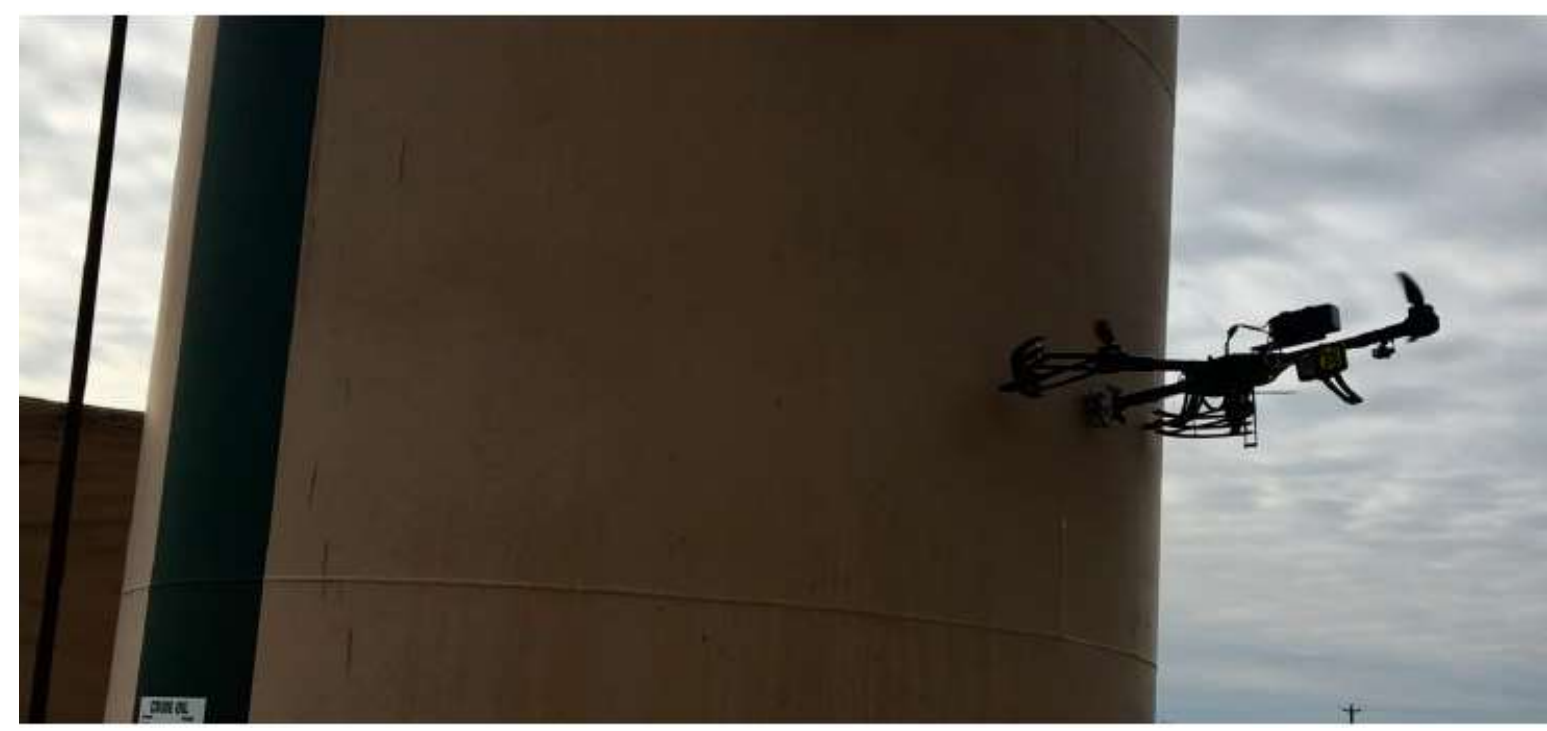

Figure 5.12: The proposed device taking measurements from the oil storage tank wall (Mattar and Kalai 2018).

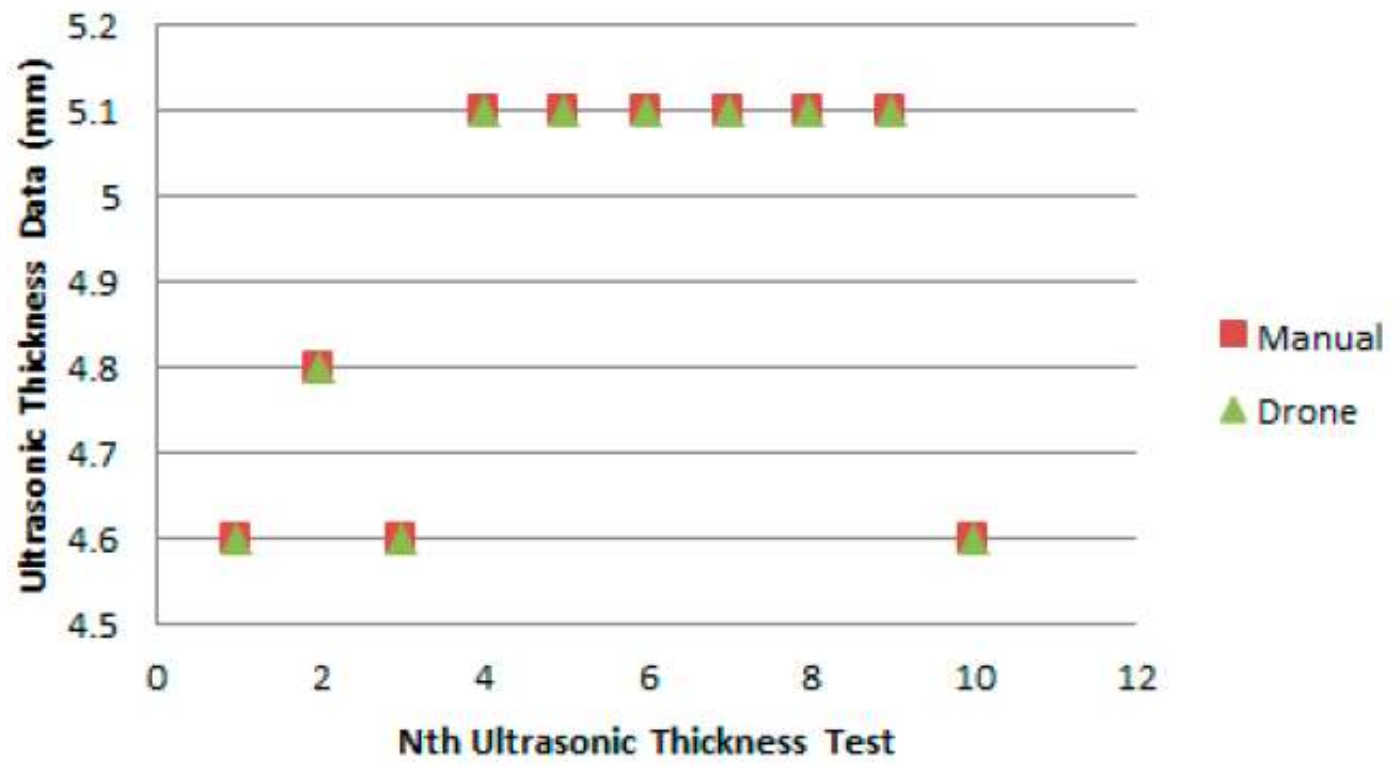

Figure 5.13: Comparison of thicknesses obtained from the drone and manual ultrasonic testing (Mattar and Kalai 2018).

\section{Conclusion}

The study confirmed the suitability of the proposed aerial wall sticking robot for the contact-based inspection (such as ultrasonic testing) of any structural components with a high success rate. The ability shown by this technology would be very beneficial for the assessment of materials such as metals. This technology was proved to be efficient for assessing components at 
higher altitudes or hard-to-reach areas. Additionally, measurement feasibility was ensured, simply using the thrust force from the drone, even for metal with coatings, concrete, composite or wooden surfaces that do not comply with electromagnetism.

\subsection{CONCLUSION}

UAS assisted inspections of infrastructures have shown promising results in terms of reduction of the cost, risk, and time. Apart from visual cameras, UAS integrated with NDT techniques has the capacity to provide more in-depth and accurate condition assessment of vulnerable structural members providing useful information for their maintenance and rehabilitation process. Although there might be some challenges with application of UAS in the field, these can be resolved by an appropriate selection of the system considering various factors. These factors include field conditions, weather conditions, type and location of test structure. Additionally, the experience and qualification of the UAS operator is also important for effective results. Hence, realizing the evident advantages, UAS assisted inspections should be considered by the responsible bodies to improve the field inspection programs. 


\section{CONCLUSIONS AND RECOMMENDATIONS}

\subsection{CONCLUSIONS}

This report presents a comprehensive review of different NDT techniques: Impact-Echo, Ultrasonic Testing, Infrared Thermography, Digital Tap Hammer, and their integration with Unmanned Aerial Vehicle. The following conclusions can be drawn from the literature reviews:

- The applications, advantages, and limitations of the NDT techniques discussed in the chapters present cost-effective solutions provided by the techniques towards maintenance and rehabilitation of vulnerable structures.

- Each technique has undergone some breakthroughs since those were first introduced. Replacement of heavy and bulky testing equipment by handheld and automated instruments have made the testing more practical, enhancements in sensors have increased the penetration depth with high accuracy, and the advances in data analysis and image processing methods with the features of real-time monitoring have made it extremely fast and easy to interpret the results. Hence, the techniques have reached a new ground that has enabled their use without the need for extensive knowledge or experience towards accurate assessments of structures.

- There are still limitations in some techniques regarding penetration depths, resolution, sensitivity, and data analysis that are being addressed by the constantly evolving field of NDT.

- Implementation of UT, IRT, and DTT analysis with Unmanned Aerial Systems has shown promising results in terms of reduction of the inspection cost, effort, and time. Some major challenges for testing large structures such as access to the underside of a bridge deck will be significantly minimized using UAS. Moreover, UAS mounted with high-resolution cameras can be used to record aerial photographs and videos for the inaccessible site surveys.

- Techniques featuring the equipment that is affordable, portable, and automated with userfriendly software will increase the use of NDT in the field.

- Lack of validation, standardization, and certification for some of the NDT techniques have limited their application in the field.

- The updated comprehensive literature reviews of various NDT techniques, much like this report, maybe more useful to understand their basic theories along with the current and future trends instead of referring to outdated documents for field applications. 


\subsection{RECOMMENDATIONS}

- Federal and state DOT should incorporate more NDT techniques, especially involving UAS (drone-based), into their field evaluations. This practice can save a lot of time, effort, and cost.

- Advanced data analysis software should be developed with the capacity to analyze large data sets. This would allow more enhancements in the automation of the techniques for more convenient field inspections.

- Referring to ample available literature, much like those reviewed in this report, standardized guides should be developed for the increased use of NDT techniques in the field evaluations. 


\section{REFERENCES}

1. ACI 117-10 (2010). "Standard Specifications for Tolerances for Concrete Construction and Materials." American Concrete Institution, Farmington Hills, MI, 20.

2. ACI 228.2R-13 (2013). "Report on Nondestructive Test Methods for Evaluation of Concrete in Structures." American Concrete Institute, Farmington Hills, MI, 20.

3. ACI 440.2R-17 (2017). "Guide for the Design and Construction of Externally Bonded FRP Systems for Strengthening Concrete Structures," American Concrete Institute, Farmington Hills, MI, pp: 20.

4. Al-Nu'man, B. S., Aziz, B. R., Abdulla, S. A, and Khaleel, S. E. (2015). "Compressive Strength Formula for Concrete using Ultrasonic Pulse Velocity." International Journal of Engineering Trends and Technology, Vol. 26, pp. 9-13.

5. Agrawal, V., Shelke, A., Ahluwalia, B. S., Melandso, F., Kundu, T., and Habib, A. (2020). "Damage Localization in Piezo-ceramic using Ultrasonic Waves Excited by Dual Point Contact Excitation and Detection Scheme." Ultrasonics, Article: 106113, doi: 10.1016/j.ultras.2020.106113.

6. American Society for Nondestructive Testing (ASNT) https://www.asnt.org/MajorSiteSections/Learn/Introduction_to_Nondestructive_Testing.asp $\underline{\text { x }}$ (Accessed: 26 January 2020)

7. Aseem, A., Baloch, W. L., Khushnood, R. A., and Mushtaq, A. (2019). "Structural Health Assessment of Fire Damaged Building using Non-Destructive Testing and Micro-Graphical Forensic Analysis: A Case Study." Case Studies in Construction Materials, Vol. 11, doi: 10.1016/j.cscm.2019.e00258.

8. ASTM C1383-15 (2015). "Standard Test Method for Measuring the P-Wave Speed and the Thickness of Concrete Plates Using the Impact-Echo Method." ASTM International, 100 Barr Harbor Drive, PO Box C700, West Conshohocken, PA 19428-2959, USA.

9. ASTM D5882-00 (2000). "Standard Test Method for Low Strain Integrity Testing of Piles." ASTM International, West Conshohocken, PA, USA.

10. ASTM D4788-03 (2013). "Standard Test Method for Detecting Delaminations in Bridge Decks using Infrared Thermography.” ASTM International, West Conshohocken, PA, USA. 
11. Baggens, O., and Ryden, N. (2014). "Systematic Errors in Impact-Echo Thickness Estimation due to Near Field Effects.” NDT\&E International, Vol. 69, pp: 16-27.

12. Bauer, E., Milhomem, P. M., and Aidar, L. A. G. (2018). "Evaluating the Damage Degree of Cracking in Facades using Infrared Thermography." Journal of Civil Structural Health Monitoring, Vol. 8, pp: 517-528.

13. Berubé, S. (2008). "Sample Size Effect of Ultrasonic Testing of Geomaterials-Numerical and Experimental Study.” Master's thesis, University of Waterloo, Ontario, Canada.

14. Bilgehan, M., and Turgut, P. (2010). "Artificial Neural Network Approach to Predict Compressive Strength of Concrete through Ultrasonic Pulse Velocity." Research in Nondestructive Evaluation, Vol. 21: pp:1-17.

15. Bogas, J.A., Gomes, M.G., and Gomes, A. (2013). "Compressive Strength Evaluation of Structural Lightweight Concrete by Non-Destructive Ultrasonic Pulse Velocity Method." Ultrasonics, Vol. 53, pp: 962-972.

16. Bolotina, I. O., Sednev, D. A., and Portenko, V. A. (2019). "Ultrasonic Testing Method for Quality Control of Mold Castings." IOP conference Series: Materials Science and Engineering, Vol. 511.

17. Brooks, C. N. (2017). "Unmanned Aerial Vehicle (UAV)-Based Assessment of Concrete Bridge Deck Delamination Using Thermal and Visible Camera Sensors: A Preliminary Analysis." Research in Nondestructive Evaluation, doi: 10.1080/09349847.2017.1304597.

18. Bucur, V. (1995/2006). "Acoustics of Wood" In Timell, T. E., and Wimmer, R. (eds.) Acoustics of Wood: $2^{\text {nd }}$ Edition, Springer Series of Wood Science, New York.

19. Bungey, J. H., Millard, S. G., and Grantham, M. G. (2006). “Testing of Concrete in Structures, $4^{\text {th }}$ Edition." Taylor and Fransis, 270 Madison Ave, New York, NY 10016, USA.

20. Carino, N. J. (2001). "The Impact-Echo Method: An Overview." Proceedings of the 2001 Structures Congress and Exposition, Washington, DC, USA, National Advances in Nondestructive Testing, 12th edition.

21. Carino, N. J. (2015). "Impact-Echo: The Fundamentals Principles of Impact-Echo Method." $B A M$, International Symposium, Non-Destructive Testing in Civil Engineering (NDT-CE), Sept. 15, Berlin, Germany. 
22. Chapagain, K. R., Bjerke, W., Melandsø, T., and Wagle, S. (2018). "In situ inspection of concrete structures using a rolling ultrasound scanner." Proceedings of the International Symposium Non-Destructive Testing in Civil Engineering (NDT-CE 2018), New Jersey, USA.

23. Chaudhary, M. (2013). "Effectiveness of Impact Echo Testing in Detecting Flaws in Prestressed Concrete Slabs." Construction and Building Materials, Vol. 47, pp: 753-759.

24. Cheng, C., and Sansalone, M. (1993b). "Effects on Impact-Echo Signals Caused by Steel Reinforcing Bars and Voids Around Bars." ACI Materials Journal, Vol. 90, No. 5.

25. Cheng, C., and Sansalone, M. (1995a). "Determining the minimum crack width that can be detected using the impact-echo method. I: Experimental study." Materials and Structures, Vol. 28, Period 2, pp: 74-82.

26. Cheng, C.-C., and Sansalone, M. (1995b). "Determining the minimum crack width that can be detected using the impact-echo method. II: Numerical fracture analysis." Materials and Structures, Vol. 28, Period 3, pp: 125-132.

27. Ciampa, F., Mahmoodi, P., Pinto, F., and Meo, M. (2018). "Recent Advances in Active Infrared Thermography for Non-Destructive Testing of Aerospace Components." Sensors, Vol. 18, doi: 10.3390/s18020609.

28. Cotic, P., Jaglicic, Z., and Bosiljkov, V. (2014). "Validation of Non-Destructive Characterization of the Structure and Seismic Damage Propagation of Plaster and Texture in Multileaf Stone Masonry Walls of Cultural-Artistic Value." Journal of Cultural Heritage, Vol. 15, pp: 490-498.

29. Cotic, P., Kolaric, D., Bosiljkov, V. B., Bosiljkov, V., and Jaglicic, Z. (2015). "Determination of the Applicability and Limits of Void and Delamination Detection in Concrete Structures using Infrared Thermography." NDT\&E International, Vol. 74, pp: 87-93.

30. Dackermann, U., Crews, K., Kasal, B., Li, J., Riggio, M., Rinn, F., and Tannert, T. (2014). "In situ assessment of structural timber using stress-wave measurements." Materials and Structures, Vol. 47, pp: 787-803, doi: 10.1617/s11527-013-0095-4.

31. De La Haza, A. O., Samokrutov, A. A., and Samokrutov, P. A. (2013). "Assessment of Concrete Structures using the Mira and Eyecon Ultrasonic Shear Wave Devices and the SAFT-C Image Reconstruction Technique." Construction and Building Materials, Vol. 38, doi: 10.1016/j.conbuildmat.2011.06.002. 
32. Deuse, M. (2017). "Non-destructive Diagnostics for Timber Structures in Historic Buildings: Investigation Methods and Testing Tools." Master's Thesis, University of Cantabria, Santander, Cantabria, Spain.

33. Dorafshan, S. (2018). "Bridge Inspection: Human Performance, Unmanned Aerial Systems and Automation." Journal of Civil Structural Health Monitoring, doi: 10.1007/s13349-0180285-4.

34. Dorafshan, S., and Thomas, R. (2019). "Benchmarking Image Processing Algorithms for Unmanned Aerial System-Assisted Crack Detection in Concrete Structures." Infrastructures, Vol. 4, doi: 10.3390/infrastructures4020019.

35. Dorafshan, S., Thomas, R. J., Coopmans, C., and Maguire, M. (2019). “A Practitioner's Guide to Small Unmanned Aerial Systems for Bridge Inspection." Infrastructures, Vol. 4, doi: 10.3390/infrastructures4040072.

36. DuBose, B. (2020). "New Ultrasonic Rolling Scanner for NDT of Concrete Structures." Materials Performance (Accessed: May $7, \quad$ 2020). http://www.materialsperformance.com/articles/material-selection-design/2018/07/newultrasonic-rolling-scanner-for-ndt-of-concrete-structures

37. Duque, L., Seo, J., and Wacker, J. (2018). "Synthesis of Unmanned Aerial Vehicle Applications for Infrastructures." Journal of Performance of Constructed Facilities, Vol. 32.

38. Economic Impact. (2017). Retrieved from ASCE https://www.infrastructurereportcard.org the-impact/economic-impact/

39. Ellenberg, A., Kontsos, A., Moon, F., and Bartoli, I. (2016). "Bridge Related Damage Quantification using Unmanned Aerial Vehicle Imagery." The Journal Structural Control and Health Monitoring, Vol. 23, pp: 1168-1179.

40. Eschmann, C., Kuo, C. M., Kuo, C. H., and Boller, C. (2012). "Unmanned Aircraft Systems for Remote Building Inspection and Monitoring." $6^{\text {th }}$ European Workshop on Structural Health Monitoring (EWSHM 2012), Dresden, Germany.

41. FAA (2016). "Summary of Small Unmanned Aircraft Rule (Part 107)." Federal Aviation Administration, Washington, DC 20591.

42. FLIR Tech Note (2020). "Radiometric Temperature Measurements: Surface characteristics and atmospheric compensation." (Assessed: May 23, 2020). https://www.flir.com/globalassets/guidebooks/suas-radiometric-tech-note-en.pdf 
43. Fodil, N., Chemrouk, M., and Ammar, A. (2019). "The Influence of Steel Reinforcement on Ultrasonic Pulse Velocity Measurements in Concrete of Different Strength Ranges." IOP Conference Series: Materials Science and Engineering, Vol. 603, doi: 10.1088/1757899X/603/2/022049.

44. Forde, M. C. (2013). "Differences in International Strategy for the NDT of Concrete." In O. Büyüköztürk (Ed.), Nondestructive Testing of Materials and Structures, RILEM Book series, Vol. 6, pp: 1217-1227.

45. Foreman, C. (2017). "Nondestructive Detection and Characterization of Damages in Honeycomb Composite Structures.” Master's Thesis, Iowa State University, Ames, Iowa.

46. Franklin, R., and Halabe, U. B. (2014). "Behavioral Study of Rayleigh, Lamb, and Critically Refracted Longitudinal Waves for Crack Detection in Painted and Rusted Steel Structural Components," European International Journal of Science and Technology (EIJST), Vol. 3, No. 7, pp: 252-270.

47. Frodella, W., Elashvili, M., Spizzichino, D., Gigli, G., Adikashvili, L., Vacheishvili, N., Kirkitadze, G., Nadaraia, A., Margottini, C., and Casagli, N. (2020). "Combining InfraRed Thermography and UAV Digital Photogrammetry for the Protection and Conservation of Rupestrian Cultural Heritage Sites in Georgia: A Methodological Application.” Remote Sensing, Vol. 12.

48. Gao, S., Wang, N., Wang, L., and Han, J. (2014). "Application of an Ultrasonic Wave Propagation Field in the Quantitative Identification of Cavity Detect of Log Disc." Computers and Electronics in Agriculture, Vol. 108, pp: 123-129.

49. Garrido, I., Laguela, S., Otero, R., and Arias, P. (2020). “Thermographic Methodologies Used in Infrastructure Inspection: A Review-Post-Processing Procedures.” Applied Energy, Vol. 266.

50. Genovés, V., Vargas, F., Gosálbez, J., Carrión, A., Borrachero, M.V., and Payá, J. (2017). "Ultrasonic and Impact Spectroscopy Monitoring on Internal Sulphate Attack of CementBased Materials." Materials and Design, Vol. 125, pp: 46-54.

51. Georgeson, G. E., Lea, S., and Hansen, J. (1996). "Electronic Tap Hammer for Composite Damage Assessment." Nondestructive Evaluation of Aging Aircraft, Airports, and Aerospace Hardware (SPIE), doi:10.1117/12.259107. 
52. Gillins, D. T., Parrish, C. E., and Gillins, M. N. (2016). "Cost-Effective Bridge Safety Inspections using Unmanned Aerial Vehicles (UAVs)." Project Report by PacTrans, Pacific Northwest Transportation Consortium University Transportation Center, and University of Washington More Hall, Seattle, Washington, Contract: DTRT12-G-UTC10.

53. Grabovski, S. L. W., Padaratz, I. J., and Pinto, R. C. A. (2011). "Use of Impact-Echo in Concrete Plates with Small Thicknesses and Different Kind of Cure." $5^{\text {th }}$ Pan American Conference for NDT, Oct 2-6, Cancun, Mexico.

54. Gryzagoridis, J., and Findeis, D. (2013). "Tap testing of composites benchmarked with Digital Shearography." Insight-Non-destructive Testing and Condition Monitoring, Vol. 56, pp: 3538.

55. Gryzagoridis, J., and Findeis, D. (2017). "Tap Testing vs. Thermography." e-Journal of Nondestructive Testing (NDT), Issn: 1435-4934, available at https://www.ndt.net/search/docs.php3?showForm $=$ off\&id=20626.

56. Guarino, E., Maser, K., and Carmichael, A. (2018). "Aerial vs. Vehicle-Based Infrared Thermography for Bridge Deck Delamination Detection." Proceedings of Structural Materials Technology for Highways and Bridges (SMT 2018), New Brunswick, New Jersey.

57. Gucunski, N., Yan M., Wang Z., Fang T. and Maher A. (2012). "Rapid Bridge Deck Condition Assessment using Three-Dimensional Visualization of Impact Echo Data." Journal of Infrastructure Systems, Vol 18, Issue 1, pp: 12-24.

58. Gupta, A. R., and Jaiswal, T. A. (2019). "NDT, Ultrasonic Pulse Velocity Test Assessment, Procedure and Limitation." International Journal for Research in Applied Science \& Engineering Technology, Vol. 7.

59. Guthrie, W. S., Larsen, J. L., Baxter, J. S., and Mazzeo, B. A. (2019). “Automated Air-Coupled Impact-Echo Testing of a Concrete Bridge Deck from a Continuously Moving Platform." Journal of Nondestructive Evaluation, Vol. 38.

60. Haach, V., and Ramirez, C. (2016). "Qualitative Assessment of Concrete by Ultrasound Tomography." Construction and Building Materials, Vol. 119, pp: 61-70.

61. Halabe, U. B., Bidigalu, G. M., GangaRao, H. V. S., and Ross, R. J. (1997). "Nondestructive Evaluation of Green Wood Using Stress Wave and Transverse Vibration Techniques," Materials Evaluation, Vol. 55, No. 9, pp: 1013-1018. 
62. Halabe, U. B., Dutta, S. S., \& GangaRao, H. V. (2013a). "Behavior of FRP Composite Wrapped Concrete Cylinders with Embedded Debonds." Structures Congress 2013, doi:10.1061/9780784412848.050.

63. Halabe, U. B., and Franklin, R. (1999). "Detection of Flaws in Structural Members Using Spectral Analysis of Ultrasonic Signals," Nondestructive Testing and Evaluation, Vol. 15, No. 3/4, pp: 215-236.

64. Halabe, U. B., and Franklin, R. (2001). "Fatigue Crack Detection in Metallic Members Using Ultrasonic Rayleigh Waves with Time and Frequency Analysis," Materials Evaluation (An Official Journal of the American Society for Nondestructive Testing), Vol. 59, No. 3, pp: 424431.

65. Halabe, U. B., and Franklin, R. (2013b). "Detection of Cracks in Long Painted or Rusted Steel Beams Using Ultrasonic Rayleigh Waves,” European International Journal of Science and Technology (EIJST), Vol. 2, No. 7, pp: 161-182.

66. Halabe, U. B., Joshi, R. M., and GangaRao, H. V. S. (2020). "Nondestructive Testing of FRP Composite Structural Components and FRP Rehabilitated Bridge using Digital Tap Testing." Journal of Multidisciplinary Engineering Science and Technology (JMEST), Vol. 7, Issue 1.

67. Halabe, U. B., Kotha, M., and GangaRao, H. V. S. (2014). "Condition Assessment of Reinforced Concrete and FRP Composite Structural Components using NDT Techniques.” Proceedings of Structural Materials Technology for Highways and Bridges (SMT 2014), Washington, DC, United States.

68. Halabe, U. B., Kotha, M., and GangaRao, H. V. S. (2013c). "Low Cost Infrared Thermography for Field Condition Assessment of FRP Composite Wrapped Concrete Members," Proceedings of the Texas Section - American Society of Civil Engineers, Fall 2013 Meeting, Dallas, Texas, September 11-14, pp: 1-12.

69. Halabe, U. B., Petro, S. H., and Hota, V. S. G. (1995). "Nondestructive Evaluation Methods for Highway Bridge Superstructures.” Report No. CFC 95-215 submitted to West Virginia Division of Highways (WVDOH) by Constructed Facilities Center, West Virginia University, Morgantown, WV, July, pp: 1-177.

70. Hassan, K. T. S., Horacek, P., and Tippner, J. (2013). "Evaluation of Stiffness and Strength of Scots Pine Wood Using Resonance Frequency and Ultrasonic Techniques.” BioResources, Vol. 8, pp: 1634-1645. 
71. Hiasa, S., Catbas, F. N., Matsumoto, M., and Mitani, K. (2016). "Monitoring Concrete Bridge Decks using Infrared Thermography with High Speed Vehicles." Structural Monitoring and Maintenance, Vol. 3, pp: 277-296.

72. Hsu, D. K., Barnard, D. J., Peters, J. J., and Hudelson, N. A. (2001). "Non-Destructive Inspections and the Display of Inspection Results." US Patent No. 6327921B1.

73. Hsu, D. K., Barnard, D. J., and Roach, D. P. (2009). "Tap Test: Evolution of an Old Technique.” Materials Evaluation-ASNT, Vol. 67, pp: 785-791.

74. Huh, J., Mac, V. H, Tran, Q. H., Lee, K, Lee, J., and Kang, C. (2018). "Detectability of Delamination in Concrete Structure using Active Infrared Thermography in Terms of Signalto-Noise Ratio." Applied Sciences, Vol. 8.

75. ISO 18434-1:2008 (2008). "Condition Monitoring and Diagnostics of MachinesThermography-Part 1: General Procedures." The International Organization of Standardization (ISO), pp: 1-32.

76. Jo, Y. H., Lee, C. H., and Yoo, J. H. (2013). "Study on Applicability of Passive Infrared Thermography Analysis for Blistering Detection of Stone Cultural Heritage." Journal of Conservation Science, Vol. 29, pp: 55-67, doi: 10.12654/JCS.2013.29.1.06.

77. Jwary, A. F. (2017). "Practical Considerations in Determining Timber Pile Depth using the Sonic Echo Method." Master's Thesis, The University of New Mexico Albuquerque, New Mexico.

78. Kasal, B., Lear, G., and Tannert, T. (2010). "In Situ Assessment of Structural Timber." RILEM State-of-the-Art Reports, Springer, Netherlands, pp: 5-24.

79. Kaur, N. P., Shah, J. K., Majhi, S., and Mukherjee, A. (2018). "Healing and Simultaneous Ultrasonic Monitoring of Cracks in Concrete." Materials Today Communications, doi: 10.1016/j.mtcomm.2018.10.022.

80. Khazanovich, L., and Hoegh, K. (2016). "Quantitative Ultrasonic Evaluation of Concrete Structures Using One-sided Access." Proceedings of AIP Conference 2016, doi: $10.1063 / 1.4940453$.

81. Kim, J. W., Kim, S. B., Park, J. C., and Nam, J. W. (2015). "Development of Crack Detection System with Unmanned Aerial Vehicles and Digital Image Processing." Proceedings of the 2015 World Congress on Advances in Structural Engineering and Mechanics (ASEM15), Incheon, Korea, August 25-29, 2015. 
82. Kim, G., Loreto, G., Kim, J. Y., Kurtis, K. E., Wall, J. J., and Jacobs, L. J. (2018). "In Situ Nonlinear Ultrasonic Technique for Monitoring Microcracking in Concrete Subjected to Creep and Cyclic Loading." Ultrasonics, Vol. 88, pp: 64-71, doi:10.1016/j.ultras.2018.03.006.

83. Kocab, D., Misak, P., Jindrova, B., Alexa, M., and Vymazal, T. (2019). "Analysis of the Influence of Transducer Frequency on the Ultrasonic Measurement of Concrete Homogeneity." Proceedings of Acta Polytechnica CTU 2019, Vol. 22, pp: 48-51.

84. Krzemień, K., and Hager, I. (2015). "Post-fire Assessment of Mechanical Properties of Concrete with the Use of the Impact-Echo Method." Construction and Building Material, Vol. 96, pp: 155-163.

85. Kylili, A., Fokaides, P. A., Christou, P., and Kalogirou, S. A. (2014). "Infrared Thermography (IRT) Applications for Building Diagnostics: A Review.” Applied Energy, Vol. 134, pp: 531549.

86. Lawson, I., Danso, K. A., Odoi, H. C., Adjei, C. A., Quashie, F. K., Mumuni, I. I., and Ibrahim I. S. (2011). "Non-Destructive Evaluation of Concrete using Ultrasonic Pulse Velocity." Research Journal of Applied Sciences, Engineering and Technology, Vol. 3, pp: 499-504.

87. Lee, Y. H., and Oh, T. (2016). "The Measurement of P-, S-, and R-Wave Velocities to Evaluate the Condition of Reinforced and Prestressed Concrete Slabs." Advances in Materials Science and Engineering, Vol. 2016, doi: 10.1155/2016/1548215.

88. Li, M., Anderson, N., Sneed, L., and Maerz, N. (2016). "Application of Ultrasonic Surface Wave Techniques for Concrete Bridge Dect Condition Assessment." Journal of Applied Geophysics, Vo. 126, pp: 148-157.

89. Lipa, L., Pasquel, E. N., Navarro, L. M., and Alamo, J. D. (2018). "Void Detection and Thickness Measurement in Concrete Elements." ACI Materials Journal, Vol. 115, doi: $10.14359 / 51702188$.

90. Lisowska-Lis, A., Mitkowski, S. A., Augustyn, J. (2011). "Infrared Technique and its Application in Science and Engineering in the Study Plans of Students in Electrical Engineering and Electronics." Proceedings of 2nd World Conference on Technology and Engineering Education, Ljubljana, Slovenia, 5-8 September, 2011. 
91. Liu, Y. L., Shi, J. J., Huang, J. Q., Wei, G. S., and Wu, Z. X. (2019). "Grouting Defect Detection of Lapped Bar Connections Based on Impact-Echo Method." Hindawi Shock and Vibration, Vol. 2019, Article ID 1934240.

92. Mac, V. H., Huh, J., Doan, N. S., Geunock, S., and Lee, B. Y. (2020). “Thermography-based Deterioration Detection in Concrete Bridge Girders Strengthened with Carbon FiberReinforced Polymer.” Sensors, Vol. 20, doi: 10.3390/s20113263.

93. Maes, G. (2018) Webinar: Advanced Focusing Techniques for Better UT Inspections [Webinar]. Available at: https://www.youtube.com/watch?v=VWz9YavSY5M\&t=1321s (Assessed: 12 February 2020).

94. Markets and Markets (2019). "Drone Service Market Application (Aerial Photography, Data Acquisition, Analytics), Industry (Infrastructure, Media \& Entertainment, Agriculture), Type (Drone Platform Service, Drone MRO, Drone Training, Solution, Region - Global Forecast to 2025." Markets and Markets, Report 4763830, pp: 1-175.

95. Mattar, R. A., and Kalai, R. (2018). "Development of a Wall-Sticking Drone for NonDestructive Ultrasonic and Corrosion Testing.” Drones, Vol. 2, doi: 10.3390/drones2010008.

96. Meyer, E., and Bock, E. (1939). "Hörschall- und Ultraschalluntersuchungen an Betonbalken mit Rissen.” Akustische Zeitschrift, Vol. 4, pp: 231-237 (In German).

97. Mitsuhashi, K., C. Jyomuta, F. Oka and H. Nishikawa. (1991). "Method and Apparatus for Impact-Type Inspection of Structures," US Patent No. 5,048,320.

98. Molero, M., Aparicio, S., Al-Assadi, G., Casati, M., Hernández, M., and Anaya, J. (2012). "Evaluation of Freeze-Thaw Damage in Concrete by Ultrasonic Imaging." NDT\&E International, Vol. 52, pp: 86-94.

99. Moreu, F., Ayorinde, E., Mason, J., Farrar, C., \& Mascarenas, D. (2018). "Remote Railroad Bridge Structural Tap Testing Using Aerial Robots." International Journal of Intelligent Robotics and Applications, Vol. 2, pp: 67-80.

100. Nardi, I., Sfarra, S., and Ambrosini, D. (2014). "Quantitative Thermography for the Estimation of the U-value: State of the Art and a Case Study." Journal of Physics: Conference Series, Vol. 547.

101. Ndagi, A., Umar, A. A., Hejazi, F., and Jaafar, M. S. (2019). "Non-destructive Assessment of Concrete Deterioration by Ultrasonic Pulse Velocity: A Review." Earth and Environmental Science, Vol. 357, doi:10.1088/1755-1315/357/1/012015. 
102. Nguyen, T. D., Tran, K. T., and Gucunski, N. (2017). "Detection of Bridge-Deck Delamination Using Full Ultrasonic Waveform Tomography." Journal of Infrastructure Systems, Vol 23, Issue 2.

103. Niederleithinger, E. (2018). "Ultrasonic Monitoring of Full-scale Load Experiments." Proceedings of Structural Materials Technology for Highways and Bridges (SMT 2018).

104. Niederleithinger, E. and, Wiggenhauser, H. (2018). "The LAUS : First Applications of a New System for Ultrasonic Imaging of Very Concrete Structures." Proceedings of Structural Materials Technology for Highways and Bridges (SMT 2018).

105. Olympus Industrial Resources (2020). “An Introduction to Angle Beam Assemblies.” White paper. Available at: https://www.olympus-ims.com/en/resources/white-papers/anintroduction-to-angle-beam-assemblies/ (Accessed: 13 April 2020).

106. Omar, T., and Nehdi, M. L. (2019). "Thermal Detection of Subsurface Delaminations in Reinforced Concrete Bridge Decks Using Unmanned Aerial Vehicle.” Durability of Concrete Structures Incorporating Conventional and Advanced Materials, Edition: ACI-SP 331, Publisher: American Concrete Institute, Project: Automated condition rating of concrete bridge decks.

107. Omar, T., Nehdi, M. L., and Zayed, T. (2018). "Infrared Thermography Model for Automated Detection of Delamination in RC Bridge Decks." Construction and Building Materials, Vol. 168, pp: 313-327.

108. Pan, W. H., Sun, X. D., Wu, L. M., Yang, K. K., and Tang, N. (2019). "Damage Detection of Asphalt Concrete using Piezo-Ultrasonic Wave Technology." Materials, Vol. 12, https://doi.org/10.3390/ma12030443.

109. Peng, J. (2017). "Corrosion detection of reinforcement of building materials with piezoelectric sensors.” Journal of Chemists and Chemical Engineers, Vol. 66, pp: 261-265, https://doi.org/10.15255/KUI.2017.010.

110. Perlin, L. P., Valle, A. D., and Pinto, R. C. D. A. (2018). "New Method to Locate the Pith Position in a Wood Cross-Section based on Ultrasonic Measurements." Construction and Building Materials, Vol. 169, pp: 733-739.

111. Pessiki, S.P., and Carino, N.J. (1988). "Setting Time and Strength of Concrete Using the Impact-echo Method." ACI Materials Journal, Vol. 85, No.5. 
112. Poelman, G., Hedayatrasa, S., Segers, J., Paepegem, W. V., and Kersemans, M. (2020). "Multi-Scale Gapped Smoothing Algorithm for Robust Baseline-free Damage Detection in Optical Infrared Thermography.” NDT\&E International, Vol. 112.

113. Poveromo, S. L. (2015). “Quantitative Percussion Diagnostics for Evaluating Bond Integrity between Composite Laminates.” PhD dissertation, University of California, Irvine, United States.

114. Pratt, D., and Sansalone, M. (1992). "Impact-Echo Signal Interpretation Using Artificial Intelligence." ACI Materials Journal, Vol. 89, No. 2.

115. Ristic, S., and Polic-Radovanovic, S. (2013). "IR Thermography in Moisture and Earthquake Damage Detection Performed in the Zica Monastery, Serbia.” International Journal of Conservation Science, Vol. 4, pp: 387-396.

116. Roblero, M. J. R. (2017). "Condition Assessment of Concrete Elements through Two Nondestructive Ultrasonic Techniques.” PhD dissertation, University of Waterloo, Ontario, Canada.

117. Rus, J., Kulla, D., Grager, J. C., and Grosse, C. U. (2019). “Air-Coupled Ultrasonic Inspection of Fiber-Reinforced Plates Using an Optical Microphone.” Proceedings of Annual Conference for acoustics DAGA 2019, Stadthalle Rostock, Sudring, Germany.

118. Sadler, J., and Maev, R. G. (2007). "Experimental and Theoretical Basis of Lamb Waves and Their Applications in Material Sciences." Canadian Journal of Physics, Vol. 85, pp: 707-731.

119. Salles, S., Balbo, J. T., and Khazanovich, L. (2017). "Non-destructive Ultrasonic Tomography for Concrete Pavement Evaluation: Signal Processing and Image Analysis of Crucial Parameters." Revista IBRACON de Estruturas e Materials, Vol. 10, doi: 10.1590/s198341952017000600004.

120. Sandak, J., and Sandak, A. (2017). "Using Various Infrared Techniques for Assessing Timber Structures." International Journal of Computational Methods and Experimental Measurements, Vol. 5, pp: 858-871.

121. Sangoju, B., Murthy, S. G. N., Parthasarathy, S., Wiggenhauser, H., Ravisankar, K., Iyer, N. R., Lakshmanan, N. (2009). "Reliability of the Impact-Echo Method on Thickness Measurement of Concrete Elements." Proceedings of the 7th International Symposium NonDestructive Testing in Civil Engineering, Nantes, France, CDROM. 
122. Sannikov, D. V., Kolevatov, A., S., Vavilov, V. P., and Kuimova, M. V. (2018). "Evaluating the Quality of Reinforced Concrete Electric Railway Poles by Thermal Nondestructive Testing.” Applied Sciences, Vol. 8, doi: 10.3390/app8020222.

123. Sansalone, M., and Carino, N.J. (1986) "Impact-echo: A Method for Flaw Detection in Concrete using Transient Stress Waves," Report No. NBSIR 86-3452, National Bureau of Standards, Washington, D.C./PB \#87-104444/AS, National Technical Information Service, Springfield, VA.

124. Sansalone, M., and Carino, N. J. (1990). "Finite Element Studies of the Impact-Echo Response of Layered Plates Containing Flaws." International Advances in Nondestructive Testing, $15^{\text {th }}$ Ed.W. McGonnagle, Gordon \& Breach Science Publishers, New York.

125. Sansalone, M. J., and Streett, W. B. (1997). "Impact-echo-Nondestructive evaluation for concrete and masonry.” Bullbirer Press, Ithaca, N.Y.

126. Schickert, M. (2012). “Automated Ultrasonic Scanning System for Three-dimensional SAFT Imaging of Concrete Elements using an Electronically Switched Transducer Array." Proceedings of IEEE International Ultrasonics Symposium, Dresden, Germany, pp: 40-43.

127. Schickert, M., and Krause, M. (2010). "Ultrasonic Techniques for Evaluation of Reinforced Concrete Structures." Non-Destructive Evaluation of Reinforced Concrete Structures: NonDestructive Testing Methods, Vol: 2, pp: 490-530, doi: 10.1533/9781845699604.2.490.

128. Schmerr, L. W., Sedov, A., and Li, X. (2016). "Ultrasonic Beam Models for Angle Beam Surface Wave Transducers." Research in Nondestructive Evaluation, Vol. 27, pp: 175-191.

129. Schubert, F., Wiggenhauser, H., and Lausch, R. (2004). "On the Accuracy of Thickness Measurements in Impact-Echo Testing of Finite Concrete Specimens - Numerical and Experimental Results.” Ultrasonics, Vol 42, Issue 1-9, pp: 897-901.

130. Schubert, F. and Kohler, B. (2008). "Ten Lectures on Impact-Echo." Journal of Nondestructive Evaluation, Vol. 27, No. 1-3, pp: 5-21.

131. Senalik, C. A., Schueneman, G., and Ross, R. J. (2014). "Ultrasonic-Based Nondestructive Evaluation Methods for Wood: A Primer and Historical Review.” General Technical Report FPL-GTR-235, U.S. Department of Agriculture, Forest Service, Forest Products Laboratory.

132. Seo, J., Wacker, J. P., and Duque, L. (2018). "Evaluating the Use of Drones for Timber Bridge Inspection." General Technical Report FPL-GTR-258, Forest Service, Forest Products Laboratory. 
133. Sharma, P. K., Kumar, R., and Sreenivas, P. (2011). "Non-Destructive Evaluation of Close Die Forged Main Body of Primary System Valves." Proceedings of the National Seminar \& Exhibition on Non-Destructive Evaluation NDE 2011, December 8-10, Chennai, India.

134. Sharma, S. K., and Shukla, S. R. (2012). "Properties Evaluation and Defects Detection in Timbers by Ultrasonic Non-Destructive Technique." Journal of the Indian Academy of Wood Science, Vol. 9, pp: 66-71, doi: 10.1007/s13196-012-0064-5.

135. Silver, B., Mazur, M., Wisniewski, A., and Babicz, A. (2017). "Welcome to the Era of DronePowered Solutions: A Valuable Source of New Revenue Streams for Telecoms Operators.” PWC Communications Review, July 2017.

136. Skowronski, W., and Stawiski, B. (2019). "Ultrasonic Evaluation Regarding the Effects of Biological Corrosion of Historical Roof Trusses." MATEC Web of Conferences, Vol. 284, Article No. 07006, doi: 10.1051/matecconf/2019284 ICSF 2019700607006.

137. Sohn, H., Liu, P., Lim, H.J., and Park, B. (2019). "Noncontact Nonlinear Ultrasonic Wave Modulation for Fatigue Crack and Delamination Detection.” In: Kundu T. (eds) Nonlinear Ultrasonic and Vibro-Acoustical Techniques for Nondestructive Evaluation, Springer, Cham, pp: 661-697.

138. Stawiski, B., and Kania, T. (2019). "Examining the distribution of strength across the thickness of reinforced concrete elements subject to sulphate corrosion using the ultrasonic method." Materials, Vol. 12, Issue 16, doi: 10.3390/ma12162519.

139. Subodh, P. S., Mathew, N., Murali, R., and Byju, C. (2015). "A Novel Method for Reverberation Cancellation in Single Ultrasonic Transducer based Measurement Systems.” Proceedings of NDE2015, Hyderabad, India.

140. Svantner, M, and Vesely, Z. (2014). “Active Thermography for Materials Non-Destructive Testing." Proceedings of the $23^{\text {rd }}$ Conference on Metallurgy and Materials, May 21-23, Brno, Czech Republic.

141. Tallavo, F., Cascante, G., and Pandey, M. D. (2012). "A novel methodology for condition assessment of wood poles using ultrasonic testing." NDT\&E International, Vol. 52, pp: 149156, doi:10.1016/j.ndteint.2012.08.002.

142. Teder, M., Pilt, K., Milijan, M., Lainurm, M., and Kruuda, R. (2011). "Overview of Some Nondestructive Methods for In Situ Assessment of Structural Timber.” Proceedings of 17th 
International Nondestructive Testing of Wood Symposium, Sopron, Hungary, Vol. 2, pp: $583-591$.

143. Tsai, P., Huang, Y., and Tai, J. (2019). "The Feasibility of Identifying Defects Illustrated on Building Facades by Applying Thermal Infrared Images with Shadow.” Proceedings 2019, Vol. 27.

144. Usamentiaga, R., Venegas, P., Guerediaga, J., Vega, L., Molleda, J., and Bulnes, F. G. (2014). "Infrared Thermography for Temperature Measurement and Non-Destructive Testing". Sensors, Vol. 14, pp: 12305-12348.

145. USNRC (2020). "Introduction to Ultrasonic Examination." Nondestructive Examination (NDE) Technology and Codes: Student Manual, Vol. 2, Chapter 8, Rev. 409.

146. Vonk, S., and Taffe, A. (2018). "Detection of Near-Surface Reinforcement in Concrete Components with Ultrasound." MATEC Web of Conferences, Vol. 199, doi:10.1051/matecconf/201819906007.

147. Vossing, K. J., Gaal, M., and Niederleithinger, E. (2020). “Imaging Wood Defects using Air Coupled Ferroelectret Ultrasonic Transducers in Reflection Mode." Construction and Building Materials, Vol. 241, doi:10.1016/j.conbuildmat.2020.118032.

148. Wang, Z., Tian, G. Y., Meo, M., and Ciampa, F. (2018). "Image Processing Based Quantitative Damage Evaluation in Composites with Long Pulse Thermography.” NDT\&E International, Vol. 99, pp: 93-104.

149. Wells, J., and Lovelace, B. (2018). "Improving the Quality of Bridge Inspections using Unmanned Aircraft Systems (UAS).” Report No. MN/RC 2018-26, Collins Engineers, Inc., St. Paul, Minnesota, USA.

150. Wheeler, A. S. (2018). "Nondestructive Evaluation of Concrete Bridge Columns Rehabilitated with Fiber Reinforced Polymers using Digital Tap Hammer and Infrared Thermography.” Master's Problem Report, West Virginia University, Morgantown, West Virginia, United States.

151. Wolf, J., Milmann, B., Helmerich, R., Kopp, C., Mielentz, F., Wiggenhauser, H., Kurz, J. H., Moryson, R. M., Samokrutov, A., Alekhin, S., Alver, N., and Sazak, H. O. (2014). "Embedded Ultrasound Sensors for Monitoring Concrete Structures.” Proceedings of Structural Materials Technology for Highways and Bridges (SMT 2014). 
152. Zamen, S., and Niri, E. D. (2020). "Fractal Analysis of Nonlinear Ultrasonic Waves in PhaseSpace Domain as a Quantitative Method for Damage Assessment of Concrete Structures." NDT\&E International, Vol. 111, doi: 10.1016/j.ndteint.2020.102235. 